DIW BERLIN

Discussion

Papers
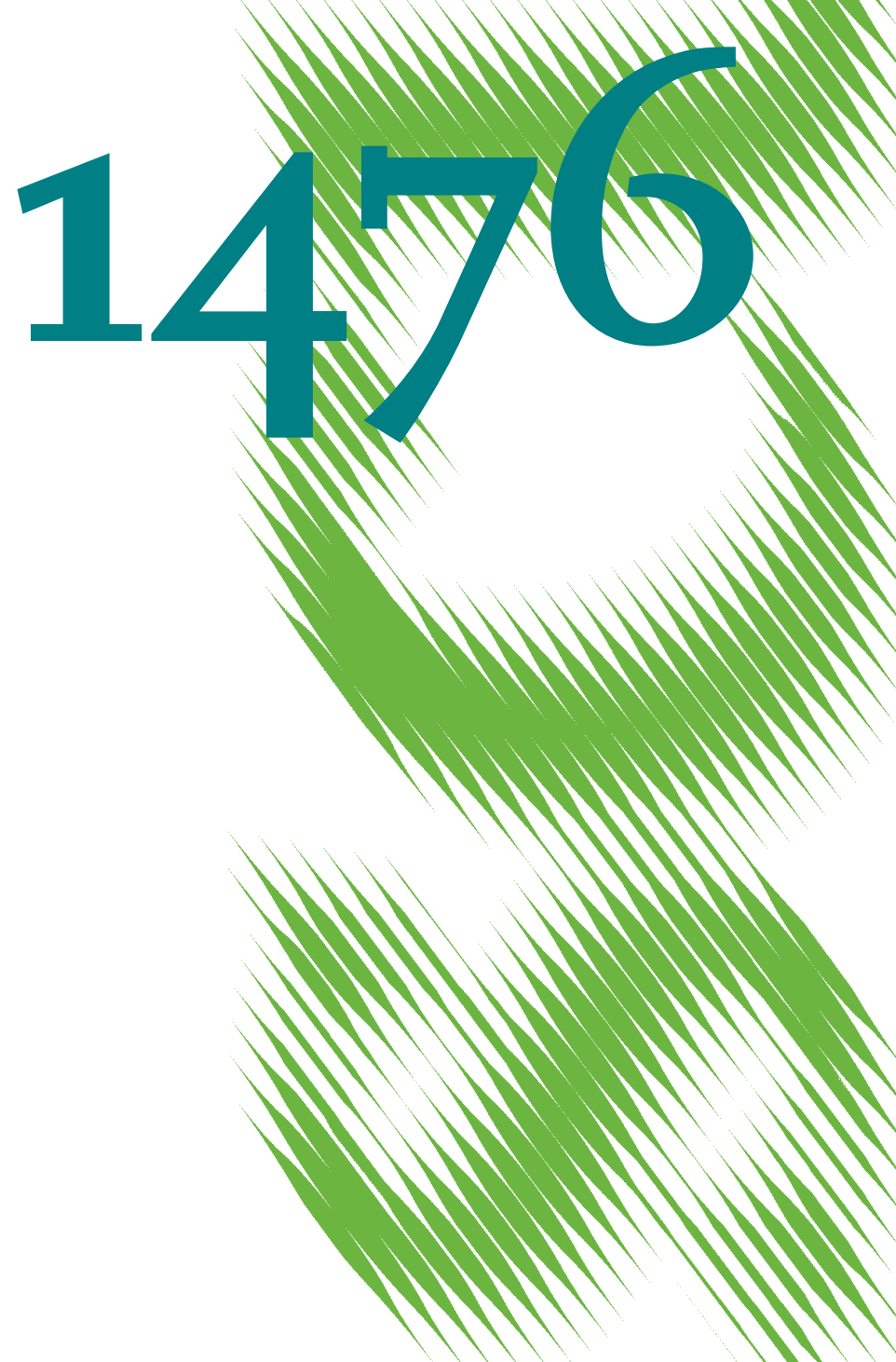

An Economic Assessment of Soil Carbon Sequestration with Biochar in Germany 
Opinions expressed in this paper are those of the author(s) and do not necessarily reflect views of the institute.

IMPRESSUM

(C) DIW Berlin, 2015

DIW Berlin

German Institute for Economic Research

Mohrenstr. 58

10117 Berlin

Tel. +49 (30) $89789-0$

Fax +49 (30) $89789-200$

http://www.diw.de

ISSN electronic edition 1619-4535

Papers can be downloaded free of charge from the DIW Berlin website:

http://www.diw.de/discussionpapers

Discussion Papers of DIW Berlin are indexed in RePEc and SSRN:

http://ideas.repec.org/s/diw/diwwpp.html

http://www.ssrn.com/link/DIW-Berlin-German-Inst-Econ-Res.html 


\title{
An Economic Assessment of Soil Carbon Sequestration with Biochar in Germany ${ }^{1}$
}

\author{
Isabel Teichmann ${ }^{2}$
}

April 2015

\begin{abstract}
Biochar is a carbon-rich solid obtained from the heating of biomass in the (near) absence of oxygen in a process called pyrolysis. Its soil incorporation is increasingly discussed as a means to sequester carbon in soils and, thus, to help mitigate climate change. When deployed in agricultural soils in Germany, it has been found by Teichmann (2014a, b) that slowpyrolysis biochar from a wide variety of feedstocks - together with the use of the pyrolysis by-products (liquids and gases) as renewable sources of energy - could lead to an annual mitigation of up to 10.2 million tonnes of carbon-dioxide equivalents by 2030 and of up to 10.6 million tonnes by 2050 . To analyze whether this technically feasible greenhouse-gas mitigation potential is also economically viable, we calculate the corresponding greenhousegas mitigation costs and construct so-called marginal abatement cost curves. Thereby, we find that about 3.1 million tonnes of carbon-dioxide equivalents could be abated in 2030 at costs below $€_{2012} 45$ per tonne of carbon dioxide and nearly 3.8 million tonnes in 2050 at costs below $€_{2012} 75$ per tonne of carbon dioxide.
\end{abstract}

JEL Classification: Q15; Q24; Q54

Keywords: Biochar, agriculture, Germany, climate change, soil carbon sequestration, mitigation costs, marginal abatement cost curves

\footnotetext{
1 I would like to thank Claudia Kemfert, Jakob Medick, Andreas Meyer-Aurich, Wolf-Peter Schill, and participants of the Second Mediterranean Biochar Symposium "Environmental Impact of Biochar and its Role in Green Remediation" (Palermo, 2014) and the Kiel Institute Summer School on Economic Policy on "Challenges of Climate Engineering" (Kiel, 2013), as well as seminar participants at DIW Berlin and participants of the biochar project meetings for their valuable comments and suggestions. Financial support from the Leibniz Association under the Joint Initiative for Research and Innovation (SAW) within the project "Biochar in Agriculture - Perspectives for Germany and Malaysia" is gratefully acknowledged.

2 German Institute for Economic Research (DIW Berlin) and Humboldt University Berlin, e-mail: iteichmann@diw.de
} 


\section{1) Introduction}

In order to contribute to the fight against climate change, Germany aims to cut its annual greenhouse-gas (GHG) emissions by $40 \%$ by $2020,55 \%$ by $2030,70 \%$ by 2040 and $80-95 \%$ by 2050 below the 1990 level (BMWi and BMU 2010). Based on its total $1990 \mathrm{GHG}$ emissions of about 1,251 million tonnes (Mt) of carbon-dioxide equivalents $\left(\mathrm{CO}_{2} \mathrm{e}\right)$ (UBA 2013: Table 1), ${ }^{3}$ this would amount to an annual reduction of $688 \mathrm{Mt} \mathrm{CO}_{2} \mathrm{e}$ by 2030 and at least $1,001 \mathrm{Mt} \mathrm{CO}_{2} \mathrm{e}$ by 2050 . This paper analyzes whether biochar deployment in agricultural soils in Germany could be an economically viable mitigation strategy to contribute to achieving these reduction targets. Thereby, it extends the study by Teichmann (2014a, b), which focused on the calculation of the technically feasible GHG mitigation potentials of biochar soil incorporation in Germany, i.e. abstracting from any cost considerations.

Biochar is a carbon-rich solid obtained from the heating of biomass in the (near) absence of oxygen, most commonly in a process known as pyrolysis. ${ }^{4,5}$ It can be made from many feedstocks, like wood, straw, green waste, organic municipal solid waste, sewage sludge, animal manure, or digestates. Thereby, biochar from wood is often better known as charcoal. When the organic material is pyrolyzed, it decomposes into gaseous, liquid and solid substances. A unit of the solid substance - biochar - does not only have a higher content of carbon than a unit of the original feedstock (Libra et al. 2011), but the carbon also tends to be more resistant to chemical and biological decay and, thus, to degradation into $\mathrm{CO}_{2}$ (e.g., Lehmann et al. 2009; Baldock and Smernik 2002). ${ }^{6}$ In addition to the high carbon stability, biochar is also characterized by a high nutrient-retention capacity. That is, the capacity of biochar to hold nutrients, such as nitrogen, phosphorus and potassium, tends to exceed that of other soil organic matter (Lehmann 2007a). ${ }^{7}$ Moreover, biochar might also improve the waterholding capacity of soils (e.g., Basso et al. 2013; Novak et al. 2009).

Due to its favorable properties, biochar is discussed both as a soil amendment to improve soil quality and as a promising means to sequester carbon in soils and, thus, to mitigate climate change (Lehmann et al. 2006; Lehmann 2007a; Sohi 2012). ${ }^{8}$ The idea behind carbon sequestration is that - by converting biomass into biochar and incorporating it in soils - part of the biochar carbon will be stored in the soil for much longer periods of time than

\footnotetext{
${ }^{3}$ Excluding net emissions of carbon dioxide $\left(\mathrm{CO}_{2}\right)$ from land use, land-use change and forestry.

${ }^{4}$ In general, the conversion of biomass into biochar can be performed in a range of thermochemical processes, including pyrolysis, gasification and hydrothermal carbonization (HTC). While the biomass is heated in the absence of oxygen during pyrolysis, gasification makes use of some oxygen; HTC, in turn, is distinguished from pyrolysis and gasification by the heating of the biomass in the presence of water and pressure (Libra et al. 2011). Moreover, the yields of biochar differ greatly across the different processes (see, e.g., Libra et al. 2011: Table 1). ${ }^{5}$ Pyrolysis can be carried out at different reaction times and temperatures (e.g., slow and fast pyrolysis) and with the help of a variety of production technologies, ranging from small-scale traditional kilns (e.g., pit or mound kilns) to advanced large-scale pyrolysis units (e.g., drum and screw pyrolysers or rotary kilns) (Brown 2009).

${ }^{6}$ The main reason for the recalcitrance of biochar carbon seems to be its high proportion of aromatic, i.e. stable, carbon compounds that are formed during pyrolysis at the cost of other more easily degradable carbon structures (e.g., Lehmann 2007a; Baldock and Smernik 2002; Kloss et al. 2012). Thereby, the carbon stability is mainly influenced by the production conditions and feedstock types. In soils, the biochar carbon stability might also be strongly influenced by a wide range of additional factors, such as soil type, climate, and other environmental conditions (e.g., Mašek et al. 2013; Schmidt et al. 2011; Lehmann et al. 2009; Bird et al. 1999).

7 For example, the long-term fertility of the Terra Preta (do Indio) - a dark earth located in small spots throughout the Amazon Basin and created by humans in pre-Columbian times - is, among others, traced back to biochar being one of its key ingredients (e.g., Glaser et al. 2001).

${ }^{8}$ Alternatively to its potential use in agriculture as a soil amendment and carbon sink, biochar can also be used as an energy source, for example, co-firing it in conventional power plants.
} 
other soil organic matter. In this way, biochar can be used to stabilize and sequester the atmospheric $\mathrm{CO}_{2}$ removed during photosynthesis (Lehmann 2007b). ${ }^{9}$

In addition to the direct carbon sequestration by stabilizing the biomass carbon in biochar and storing it in soils, biochar might also involve further indirect channels of carbon sequestration and could result in reductions of GHG emissions. In particular, the high nutrient-holding capacity of biochar and complex interactions taking place in biocharamended soils might lead to increased carbon sequestration due to better plant growth and increases in non-biochar soil organic carbon (SOC) as well as potential reductions in soil emissions of nitrous oxide $\left(\mathrm{N}_{2} \mathrm{O}\right)$ and methane $\left(\mathrm{CH}_{4}\right)$ (e.g., Gaunt and Cowie 2009). Furthermore, reductions in $\mathrm{N}_{2} \mathrm{O}$ and $\mathrm{CH}_{4}$ emissions could also result from potential fertilizer savings following biochar additions to soil (e.g., Gaunt and Cowie 2009). Moreover, the gases and liquids from pyrolysis obtained as by-products of biochar formation can be used as renewable sources of energy and, thus, offset emissions from fossil fuels (e.g., Lehmann 2007a). However, the emission savings or GHG removals have to be balanced against any additional biochar-related GHG emissions, such as those from biochar production, biomass and biochar transportation or biochar soil addition (Woolf et al. 2010a).

Based on the outlined mitigation channels of biochar (without those relating to possible agricultural benefits) and covering the GHGs $\mathrm{CO}_{2}, \mathrm{CH}_{4}$ and $\mathrm{N}_{2} \mathrm{O}$, Teichmann (2014a, b) has calculated the technical GHG mitigation potentials of slow-pyrolysis biochar in 2015, 2030 and 2050 when the biochar is incorporated into agricultural soils in Germany and when the pyrolysis by-products are used energetically. Focusing on a wide range of feedstocks (including, for example, cereal straw, forestry residues, certain types of wood waste and green waste, organic municipal solid waste, and solid animal manures) and scenarios (mainly differentiated by biomass availability, pyrolysis scales, types of fossil fuels), and against the baseline of conventional feedstock management, she has found that biochar might allow for an annual technical GHG mitigation potential in Germany in the range of 2.8-10.2 $\mathrm{Mt} \mathrm{CO}_{2} \mathrm{e}$ by 2030 and 2.9-10.6 $\mathrm{Mt} \mathrm{CO}_{2} \mathrm{e}$ by 2050 if any cost considerations are neglected. This would correspond to approximately $0.4-1.5 \%$ and $0.3-1.1 \%$ of the respective German GHG reduction targets in 2030 and 2050.

Turning to a detailed economic assessment of the technically feasible GHG mitigation potentials of biochar, the aim of this paper is to provide estimates of the associated GHG mitigation costs - for the same set of feedstocks and scenarios as used in Teichmann (2014a, b) and for a range of further assumptions concerning future price developments of fossil fuels and GHG emission allowances, for example. Combined with the technical GHG mitigation potentials, the GHG mitigation costs are used to construct so-called bottom-up marginal abatement cost curves (MACCs). In the bottom-up MACCs, the biochar options (as characterized by the type of feedstock turned into biochar) of a given scenario are first ranked by their respective costs - expressed in 2012 euros per tonne of $\mathrm{CO}_{2} \mathrm{e}\left(€_{2012} / \mathrm{CO}_{2} \mathrm{e}\right)$ - and then plotted against the associated mitigation potentials - in kilotons of $\mathrm{CO}_{2} \mathrm{e}$ per annum (kt $\mathrm{CO}_{2} \mathrm{e} / \mathrm{a}$ ). With the additional use of a certain given $\mathrm{CO}_{2}$ price (such as for GHG emission allowances), the MACCs allow to detect the most cost-effective biochar options and to read off the economically viable GHG mitigation potential of biochar.

The analysis reveals that only a fraction of the technically feasible GHG mitigation potential of biochar is viable from an economic point of view. Restricting attention to biochar options at or below $45 €_{2012} / \mathrm{t} \mathrm{CO}_{2} \mathrm{e}$ in 2030 and $75 €_{2012} / \mathrm{t} \mathrm{CO}_{2} \mathrm{e}$ in 2050 - the maximum prices for GHG emission allowances assumed for these years -, the greatest GHG mitigation potential to be achieved in 2030 amounts to $3,143 \mathrm{kt} \mathrm{CO}_{2} \mathrm{e} / \mathrm{a}$; and to $3,778 \mathrm{kt} \mathrm{CO}_{2} \mathrm{e} / \mathrm{a}$ in 2050 .

\footnotetext{
${ }^{9}$ As a method to actively remove GHGs from the atmosphere, (large-scale) biochar soil incorporation belongs to so-called climate- or geo-engineering measures (e.g., Rickels et al. 2011; Royal Society 2009).
} 
Thereby, the most promising feedstocks in terms of costs are mainly organic municipal solid waste, commercial and industrial waste, green waste from extensive grassland, open-country biomass residues, biomass from habitat-connectivity areas, and wood in municipal solid waste. In 2050, also cereal straw and green waste from compensation areas are among the efficient biochar options.

To the best of our knowledge, we are the first to provide a comprehensive analysis of the GHG mitigation potentials and GHG mitigation costs of biochar soil incorporation in Germany. In general, economy-wide assessments of biochar and, thus, MACCs for biochar are still rare. In particular, biochar has not been covered in the numerous MACC studies analyzing GHG mitigation in agriculture, such as McKinsey (2009a) and Smith et al. (2008) on a global scale, De Cara et al. (2005) for the European Union (EU) as well as Moran et al. (2011) and MacLeod et al. (2010) for the United Kingdom (UK). Likewise, the only bottomup MACC for Germany (McKinsey 2007, 2009b) covers the agricultural sector only very broadly and does not contain any biochar. ${ }^{10}$ Among the few studies that consider biochar deployment in soils in a MACC context are Pratt and Moran (2010) with a global focus and Shackley et al. (2011) for the UK..$^{11,12}$

The study by Pratt and Moran (2010) constructs a MACC for biochar projects in developed and developing regions set up until 2030, covering residue biomass from agriculture and forestry transformed in large-scale slow- and fast-pyrolysis plants in developed regions (North America, Europe and Developed Pacific) and biomass resources collected for stoves in rural areas transformed in small-scale slow-pyrolysis projects in developing regions (Africa, Aisa and Latin America). Given their assumptions, Pratt and Moran (2010) find that small-scale biochar stove and kiln projects in developing regions tend to be more cost-effective and abate more GHG emissions than large-scale pyrolysis-plant scenarios in developed regions. Moreover, biochar projects in developing Asian countries seem to have the highest abatement potentials. For the group of developed regions, fastpyrolysis projects in Europe were the most cost-effective. Further including the biochar options in a global MACC of abatement technologies, Pratt and Moran (2010) also show that biochar projects in both developed and developing regions compare favorably with carbon, capture and storage (CCS) in terms of costs.

Shackley et al. (2011), in turn, focus on a variety of slow-pyrolysis biochar scenarios in the UK. The biochar options and scenarios in their study are differentiated by the types and availability of feedstocks as well as pyrolysis-plant scales. Including the provision of renewable energy by the pyrolysis by-products, but abstracting from potential agricultural

\footnotetext{
${ }^{10}$ MACCs can also be derived from computable general equilibrium (CGE) or partial equilibrium models in a so-called top-down or model-based approach (see Section 2). However, none of the existing CGE-based MACCs for Germany (e.g., Schumacher and Sands 2006; Sands and Schumacher 2009) covers biochar.

11 Not capturing any mitigation costs, Woolf et al. (2010a) provide a study of the global technical GHG mitigation potential of biochar. Including both direct and indirect channels of carbon sequestration due to biochar soil incorporation as well as emission reductions through the substitution of fossil fuels by the pyrolysis by-products, they arrive at an annual global net GHG mitigation potential of 1.0-1.8 petagrams (Pg) of carbon (C) equivalents (equal to 3.7-6.6 $\mathrm{Pg} \mathrm{CO}_{2} \mathrm{e}$ ) by 2050. Compared to the current global GHG emissions of $13.7 \mathrm{Pg}$ C equivalents per year (cp. Ciais et al. 2013), the contribution of biochar towards climate-change mitigation would be considerable, amounting to 7-13\%. Other studies (e.g., Hammond et al. 2011; Roberts et al. 2010; Gaunt and Cowie 2009) analyze the GHG emissions that can be avoided per tonne of biomass turned into biochar; however, without providing an estimate of the biomass potentials that could be available for biochar.

${ }^{12}$ Exclusive cost calculations, in turn, are provided by McCarl et al. (2009) for slow- and fast-pyrolysis biochar from maize stover in the United States. Including revenues from GHG offsets due to biochar soil application, considering agricultural benefits of biochar and assuming that the pyrolysis by-products are used energetically, they have found that the slow-pyrolysis biochar would cost about $\mathrm{USD}_{2007} 70$ per tonne of feedstock - equivalent to $51 €_{2007} / \mathrm{t}$ feedstock, based on the 2007 average exchange rate of 1.3705 USD/€ (Deutsche Bundesbank 2012).
} 
benefits of biochar soil incorporation, Shackley et al. (2011) find that an annual abatement of up to $6 \mathrm{Mt} \mathrm{CO}_{2} \mathrm{e}$ could be economically viable, at costs of about $29 \mathrm{USD}_{2007} / \mathrm{t} \mathrm{CO}_{2} \mathrm{e}\left(21 €_{2007} / \mathrm{t}\right.$ $\left.\mathrm{CO}_{2} \mathrm{e}\right){ }^{13}$ Thereby, the most promising feedstocks in terms of costs seem to be commercial and domestic organic waste, sewage sludge, and waste wood, where waste wood also provides for the highest GHG mitigation potential (see Shackley et al. 2011: Figure 6).

The remainder of the paper is organized as follows: In Section 2, we present our methodology. Section 3 contains a summary of the technical GHG mitigation potentials from Teichmann (2014a, b). The detailed calculation of the associated GHG mitigation costs, both per dry tonne of feedstock turned into biochar and per tonne of $\mathrm{CO}_{2} \mathrm{e}$ abated, can be found in Section 4. Section 5, in turn, contains a collection of relevant MACCs for 2015, 2030 and 2050. Finally, we conclude.

\section{2) Methodology}

For the economic assessment of slow-pyrolysis biochar deployment in soils in Germany in 2015, 2030 and 2050, we combine the technical GHG mitigation potentials obtained from Teichmann (2014a, b) with the corresponding GHG mitigation costs derived in this study and illustrate them with the help of MACCs. ${ }^{14,15}$ The analysis is conducted for the same biochar options and scenarios as developed in Teichmann (2014a, b). More precisely, the biochar options are differentiated by the types of feedstock used for biochar production. Thereby, we largely focus on biomass residues, covering both solid biomass residues (particularly, cereal straw, forestry residues, open-country biomass residues, industrial wood waste, wood in municipal solid waste, certain types of green waste, and short-rotation coppice) ${ }^{16}$ and those that can be anaerobically digested (in particular, solid cattle, swine and poultry manure, commercial and industrial waste, and organic municipal solid waste). ${ }^{17}$ A detailed feedstock list and description can be found in Table 1 in the Appendix. The scenarios, in turn, refer to the availability of biomass for biochar production, different technology scales of the pyrolysis plants, whether process heat is recovered during pyrolyis, and the development of future prices for fossil fuels and GHG emission allowances.

The MACC construction follows a so-called bottom-up or technology-driven approach since it starts from the biochar options, i.e. from specific GHG mitigation options or technologies (see Moran et al. 2011). For each biochar option, it involves the calculation of

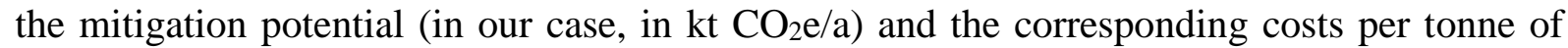
$\mathrm{CO}_{2} \mathrm{e}$ abated $\left(€_{2012} / \mathrm{tCO}_{2} \mathrm{e}\right)$ in a specific year. After ranking the GHG mitigation options from the lowest to the highest mitigation costs, the associated mitigation potentials are plotted against the mitigation costs. For a given mitigation level, the resulting MACC allows, thus, to

\footnotetext{
13 The conversion is based on the 2007 average exchange rate of 1.3705 USD/€ (Deutsche Bundesbank 2012).

14 The focus of the analysis being soil carbon sequestration with biochar, slow pyrolysis is chosen as the conversion process from biomass to biochar in order to maximize the yields of stable biochar carbon. For a discussion, see Teichmann (2014a).

15 Technical mitigation potentials refer to those potentials that are obtained when certain technological restrictions are applied to the maximally possible - theoretical - potentials (i.e. those that are only limited by laws of nature), without taking into account any economic considerations - which, in turn, would lead to economic potentials (cp. Slade et al. 2011).

${ }^{16}$ Short-rotation coppice - cultivated on erosion areas - is the only energy crop we consider. For the ease of exposition, it is included under solid biomass residues.

17 Note that we assume that possible contaminations of biochar with heavy metals or organic pollutants are manageable and that any legal issues for the use of biochar as a soil amendment will be resolved. - So far, only charcoal from chemically untreated wood is allowed to be spread on fields in Germany (DüMV 2012: Table 7).
} 
read off the costs that are associated with the next unit of GHG emissions abated, i.e. the marginal abatement costs. From the pool of technically feasible GHG mitigation options, a bottom-up MACC shows which are viable from an economic perspective. That is, for a given emission reduction target, it illustrates which mitigation options are the most efficient to implement. Likewise, for a given $\mathrm{CO}_{2}$ price (such as for GHG emission allowances), it reveals the amount of GHG emissions that could be abated by the most efficient mitigation measures, i.e. those measures with mitigation costs smaller than or equal to the $\mathrm{CO}_{2}$ price. ${ }^{18}$

The MACCs in our study are derived against the business-as-usual or baseline scenario of no biochar production and soil addition. That is, both the GHG mitigation potential and the GHG mitigation costs of a given biochar option refer to the difference in the GHG emissions - respectively, costs - associated with the biochar strategy and those from the baseline scenario (cp. Gaunt and Cowie 2009; McKinsey 2009a; McCarl et al. 2009). Since the biochar options are differentiated by the type of feedstock, the baseline scenario for each biochar option refers to the respective conventional feedstock management, i.e. the assumed use of the given feedstock would it not be turned into biochar. As detailed in Table 1, the business-as-usual scenario is based on current or projected conventional feedstockmanagement practices, covering $(i)$ decomposition on site for cereal straw, forestry residues and green waste from compensation areas; (ii) storage and direct land spread for the solid manures; (iii) energetic use for industrial wood waste and short-rotation coppice; and (iv) composting plus subsequent land spread for the remaining biomass residues. ${ }^{19,20}$

The GHG mitigation costs are calculated from a social perspective in the sense that they do not include any taxes, subsidies or tariffs (cp. McKinsey 2009a). Moreover, the valuation of any benefits, such as from the energetic use of the pyrolysis by-products, is based on the costs offset rather than on possible revenues gained. The GHG mitigation costs are expressed in constant 2012 euros and calculated both per tonne of dry-matter (DM) feedstock turned into biochar $\left(€_{2012} / \mathrm{t}_{\mathrm{DM}}\right.$ feedstock $)$ and per tonne of $\mathrm{CO}_{2} \mathrm{e}$ abated $\left(€_{2012} / \mathrm{t} \mathrm{CO}_{2} \mathrm{e}\right)$. We focus on cost items most relevant to the analysis (see Section 4). Consistent with our MACC approach, in which we evaluate the GHG mitigation costs against a given $\mathrm{CO}_{2}$ price, we do not account for any potential revenues from net GHG offsets associated with biochar soil application. ${ }^{21}$ Assuming that biochar could be included in the future in some GHG trading mechanism, such as the EU ETS, the comparison of the marginal abatement costs with the prevailing $\mathrm{CO}_{2}$ price will indicate whether the revenues from GHG offsets will outhweigh the GHG mitigation

\footnotetext{
${ }^{18}$ A different method to derive a MACC is the so-called top-down or model-based approach, in which a MACC is constructed within a model framework - either using an economy-wide model in the form of a CGE model or a sectoral, partial-equilibrium model (e.g., Moran et al. 2011). Although the top-down approach allows for feedback effects with the economy, it lacks technological detail. In particular, it does not reveal the ranking of each single abatement technology within the curve, hiding its contribution to the mitigation potential and costs.

${ }^{19}$ Note that untreated organic wastes cannot legally be deposited in German landfills (UBA 2013).

${ }^{20}$ Alternatively, all the feedstocks could be used energetically in the baseline scenario. In accordance with Teichmann (2014a), however, we refrain from this assumption since the biomass availability scenarios have been constructed in a way that they respect the possible competition between biomass to be used for energetic purposes and biomass for biochar production (see also Section 3.1). Moreover, with the chosen types of conventional feedstock management as baseline, the analysis is readily extendable to a comparison of the mitigation potentials and costs of biochar with those of various alternative energetic uses of biomass, such as for electricity generation, for heat generation, or for transport fuels obtained in a variety of technological processes).

${ }^{21}$ As an exception, however, we consider potential cost savings from GHG offsets arising from the replacement of fossil fuels by the pyrolysis by-products or by the biomass that is used energetically in the baseline scenario. The reason is that, in the EU, power plants (and a wide range of energy-intensive industry sectors and commercial airlines) are usually required to participate in the EU Emissions Trading System (EU ETS) (for an overview, see EC 2013). Biochar, instead, is currently not included in any major GHG trading scheme; likewise, it is not possible to earn carbon credits from biochar projects within the Clean Development Mechanism (CDM).
} 
costs of biochar. As already indicated, the cost calculations follow the same framework as used by Teichmann (2014a) for the derivation of the GHG mitigation potentials (Figure 1).

That is, the cost caluclations are based on four different biomass scenarios (indicating the potentially available amount of biomass for biochar) and on three different pyrolysis scales (i.e. different annual capacities of the pyrolysis plants). Assuming that all the biomass available in a given period is turned into biochar, the biomass scenarios together with the pyrolysis scales determine the number of pyrolysis units to be installed and, thus, the transport distances for the biomass and biochar. Since biochar production creates new demand for energy, the energy inputs required to dry the feedstocks and to run the pyrolysis process are obtained from fossil fuels (lignite, hard coal, or natural gas). During pyrolysis, process heat is recovered or not. The liquid (in particular, bio-oil) and gaseous by-products from biochar production are used for electricity generation, ${ }^{22}$ substituting for lignite, hard coal, or natural gas and, thus, eliminating the need to buy corresponding GHG emission allowances from the fossil-fuel use. The biochar is incorporated into agricultural soils as a one-time supplement at three different deployment rates. As in Teichmann (2014a), we do not consider any agricultural benefits of biochar soil addition due to the great uncertainties behind the (longterm) effects of biochar on plant growth, non-biochar SOC and other soil processes. ${ }^{23}$

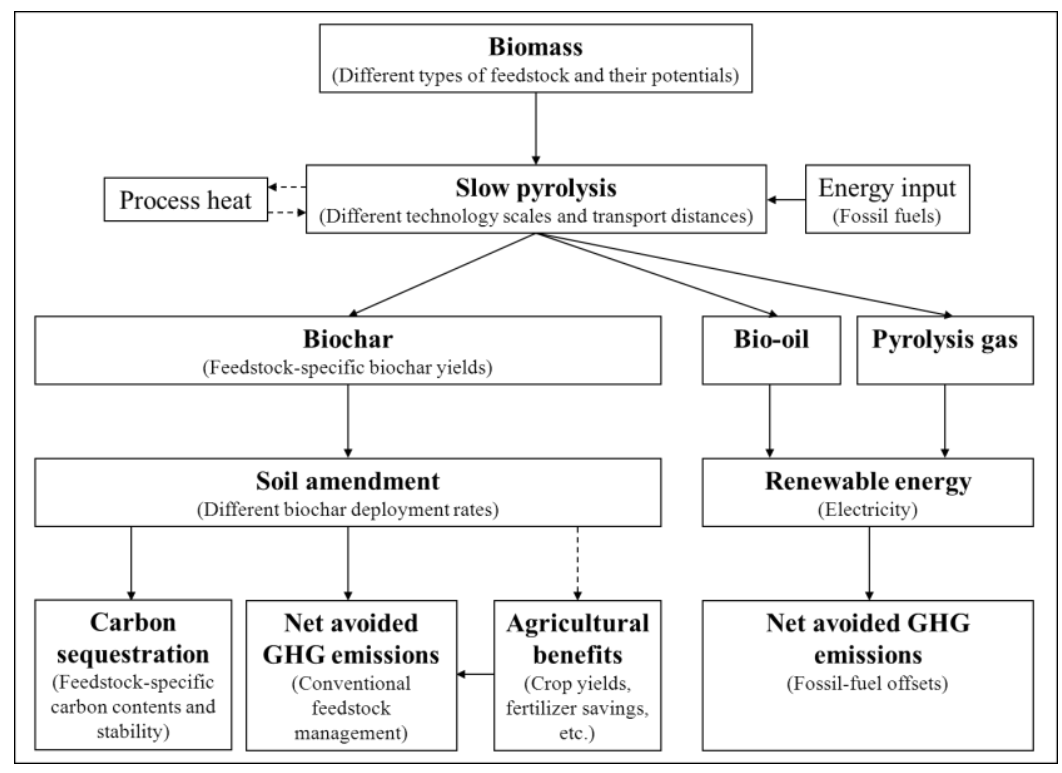

Figure 1: Framework of the analysis

Source: Teichmann (2014a).

\footnotetext{
${ }^{22}$ Alternatively to electricity generation, the bio-oils could be used as a source for heat or - after upgrading to bio-diesel - as a transport fuel (Slade et al. 2011). Depending on the conversion process used, the pyrolysis gases mainly consist of carbon monoxide $(\mathrm{CO}), \mathrm{CH}_{4}, \mathrm{CO}_{2}$, hydrogen $\left(\mathrm{H}_{2}\right)$ and hydrocarbons $\left(\mathrm{C}_{\mathrm{x}} \mathrm{H}_{\mathrm{y}}\right)$. In particular, the valuable synthesis gas (or syngas), a mixture of $\mathrm{CO}$ and $\mathrm{H}_{2}$, can be used for heat and power generation or be transformed into transport fuels (Slade et al. 2011). In practice, the precise application is dependent on the quality of the pyrolysis by-product (Mahinpey et al. 2009).

${ }^{23}$ Abstracting from agricultural benefits allows us to work with an average soil quality before biochar is applied. This means that the biochar options are independent of each other. Thus, we can calculate so-called stand-alone mitigation measures, where the effectiveness of one biochar option is not influenced by interactions with other biochar measures (cp. Moran et al. 2011). Instead, accounting for different pre-biochar soil qualities and given that both the type of crop grown on a certain land and its growth performance depend on soil quality, the agricultural impact of a given biochar would depend on the type of soil it is applied to and, thus, on the previously implemented biochar options - if it is assumed that biochar is added to the lowest-quality soils first and then successively to better soils.
} 
As detailed in Section 4, further assumptions refer to the way in which biomass and biochar are transported, stored and otherwise handled, the means by which biochar is applicated to soils, and future price developments. In particular, we assume three possible price paths for the prices of fossil fuels and GHG emission allowances. Explicitly accounting for dynamic effects, we further apply learning curves over time for the biochar production technology. That is, the capital costs for the pyrolysis plants are assumed to decrease with installed capacity. Thereby, we assume that full-scale biochar production starts in 2015. Finally, biochar is added to soils in the year of its production and no biochar exports take place.

\section{3) Technical GHG Mitigation Potentials of Biochar}

The technical GHG mitigation potentials of biochar soil incorporation in Germany for 2015, 2030 and 2050 in combination with the energetic use of the pyrolysis by-products have been derived in detail by Teichmann (2014a, b), covering the greenhouse gases $\mathrm{CO}_{2}, \mathrm{CH}_{4}$ and $\mathrm{N}_{2} \mathrm{O}$. This section provides a summary of the basic procedure and relevant assumptions applied for their calculation. Basically, the technical GHG mitigation potentials of biochar were obtained by multiplying the total net avoided GHG emissions per tonne of dry-matter feedstock by the respective technical biomass potentials for biochar production.

\section{1) Biomass Potentials for Biochar}

Following the procedure applied by Shackley et al. (2011), Teichmann (2014a, b) derived the type and amount of feedstocks that could be used for biochar production from the (technical) biomass potentials for bioenergy production. Thereby, the technical biomass potentials for bioenergy production in Germany were largely obtained from Nitsch et al. (2004), in the version of their "NaturschutzPlus" (nature conservation plus) potential, with some updates for current developments. ${ }^{24,}{ }^{25}$ The biomass potentials for biochar production, in turn, were derived as shares off the technical biomass potentials for bioenergy, constructing a number of scenarios with varying percentages of biomass for biochar to deal with possible rivalries between the energetic use of biomass and biochar production.

For the purposes of this study, we use the biomass potentials for biochar from biomass scenarios Max 1, Min 1, Max 2, and Min 2 outlined in Teichmann (2014a). Thereby, Max 1 and Min 1 refer to the maximum and minimum biomass potentials for biochar when all the solid and digestable biomass residues covered in the study are considered for biochar production. Scenarios Max 2 and Min 2, in turn, refer to the maximum and minimum biomass potentials for biochar when only the solid biomass residues are chosen for biochar production, while the digestable biomass residues are not diverted from renewable energy generation. To arrive at the same overall amount of primary energy deducted from the biomass potentials for bioenergy, the Max 2 and Min 2 scenarios, thus, allow for an increase in the share of the solid biomass residues turned into biochar compared to the Max 1 and Min 1 scenarios.

\footnotetext{
${ }^{24}$ Technical biomass potentials account for ecological, land-area, agro-technological or topographic constraints, i.e. they leave aside land for food, housing or environmental purposes (Slade et al. 2011). Thereby, the "NaturschutzPlus" potential places particular emphasis on diverse environmental aspects, such as the expansion of organic farming, nature conservation, and water and soil protection (Nitsch et al. 2004).

${ }^{25}$ The study by Nitsch et al. (2004), in turn, is an extended version of the "Umwelt" (environment) scenario of Fritsche et al. (2004). Teichmann (2014b: Section A.2) contains a general discussion of the biomass potentials obtained by Nitsch et al. (2004, "NaturschutzPlus" scenario) and Fritsche et al. (2004, "Umwelt" scenario).
} 


\section{2) Net Avoided GHG Emissions per Dry Tonne of Feedstock}

For the calculation of the GHG emissions that are avoided per dry tonne of feedstock turned into biochar, against the baseline scenario of conventional feedstock management, Teichmann (2014a) considered $(i)$ the amount of biochar carbon sequestered in soils; ( $i i)$ changes in GHG emissions associated with the shift from conventional feedstock management to the conversion of biomass into biochar; (iii) avoided emissions due to the substitution of fossil fuels by renewable energy from the pyrolysis liquids and gases; and (iv) net GHG emissions from the transportation of biomass and biochar as well as from biochar soil addition. ${ }^{26}$

To reflect that the biochar yields obtained from the various feedstocks and the biochars' physical and chemical properties depend on both the conversion process and the specific type of feedstock used (see, e.g., Cantrell et al. 2012; Libra et al. 2011; Amonette and Joseph 2009; Krull et al. 2009; Antal and Grønli 2003; Antal et al. 2000), the calculations of the net avoided GHG emissions were based on the feedstock-specific slow-pyrolysis biochar yields and properties given in Teichmann (2014a: Table 8). The feedstock-specific characteristics, in turn, were derived as averages from suitable reference feedstocks from an extensive literature survey (Teichmann 2014b: Table A.7 and Section A.3) covering typical slow-pyrolysis processes with peak temperatures of $350^{\circ} \mathrm{C}$ to $700^{\circ} \mathrm{C}$. The average pyrolysis temperatures for the different feedstocks obtained in this way vary from ca. $420^{\circ} \mathrm{C}$ to $570^{\circ} \mathrm{C}$, while the total average pyrolysis temperature amounts to nearly $500^{\circ} \mathrm{C}$ (Teichmann $2014 \mathrm{~b}$ : Table A.7).

Carbon sequestration with biochar. Concerning the amount of biochar carbon that can possibly be sequestered in soils, Teichmann (2014a) assumed for the biochars from solid biomass residues that $68 \%$ of the biochar carbon would persist for at least 100 years. ${ }^{27}$ To take account of the findings that high-ash biochars tend to be less stable than low-ash biochars (e.g., Enders et al. 2012), she further assumed that only half of this share, i.e. 34\%, would be applicable for biochar carbon from digestable biomass residues. This long-term carbon storage potential was accounted for in the year of biochar production and soil addition. ${ }^{28}$

Changes in emissions due to different feedstock management. The calculation of the net avoided GHG emissions from the change in feedstock management was mainly based on the methodologies provided by the 2006 IPCC Guidelines for National Greenhouse Gas Inventories (in particular, De Klein et al. 2006; Dong et al. 2006; Pipatti et al. 2006; Gómez et al. 2006) and the National Inventory Report for the German Greenhouse Gas Inventory 19902011 (UBA 2013). The net avoided GHG emissions include foregone $\mathrm{CH}_{4}$ and $\mathrm{N}_{2} \mathrm{O}$ emissions from manure management, composting and the stationary combustion of biomass for energetic use. Furthermore, they cover foregone $\mathrm{N}_{2} \mathrm{O}$ emissions from soil additions of biomass (including manures and composts), adjusted for $\mathrm{N}_{2} \mathrm{O}$ emissions from the soil application of biochar and from the SOC losses associated with the soil removal of the fresh

\footnotetext{
${ }^{26}$ Note that the focus was on emissions considered most relevant. In particular, Teichmann (2014a) did not include any construction-related emissions, such as from the construction of pyrolysis units, power plants or composting facilities, due to the negligible GHG emissions from plant construction and dismantling found by Roberts et al. (2010). Moreover, abstracting from agricultural benefits of biochar addition to soils, it was assumed that biochar did not interfere with the usual agricultural practices, such as application rates of mineral or organic fertilizers. To keep the analysis tractable, it was further assumed that no biomass and biochar losses would occur during transport, storage, soil application or any other handling.

${ }^{27}$ This assumption is in line with Shackley et al. (2011) and Hammond et al. (2011).

${ }^{28}$ Following Woolf et al. (2010b), it was further assumed that biochar would not contribute to increases in nonbiochar SOC. Moreover, abstracting from agricultural benefits, Teichmann (2014a) did not consider any impact of biochar on increases in below- or above-ground biomass yields that could contribute to increases in SOC.
} 
biomass or composts used for biochar production. ${ }^{29,} 30$ Another source of $\mathrm{CO}_{2}$ emissions refers to the foregone carbon sequestration that would occur from the SOC formation following the soil incorporation of the unpyrolyzed biomass. Following the literature, Teichmann (2014a) assumed that $10 \%$ of the carbon in the biomass would remain stable in the long-term. Finally, the diversion of biomass away from an energetic use into biochar production raises $\mathrm{CO}_{2}$ emissions due to the foregone substitution of fossil fuels (lignite, hard coal, and natural gas) in electricity generation.

Net avoided GHG emissions due to fossil-fuel substitution. On the one hand, it was assumed by Teichmann (2014a) that the pyrolysis by-products were used to replace fossil fuels (lignite, hard coal, and natural gas) in electricity generation. To calculate the corresponding avoided GHG emissions, she provided a detailed derivation of the energy recovered in the by-products, $E_{\text {out }}$, to offset for the fossil-fuel combustion. On the other hand, Teichmann (2014a) assumed that GHG emissions would arise from biochar production in the form of fossil-fuel energy inputs required to dry the feedstocks and to run the pyrolysis process, the fossil fuels being either lignite, hard coal, or natural gas. Again, she provided a detailed derivation of the heat energy required for biochar production, both for the case when no process heat recovery takes place, $E_{i n}$, and when some of the process heat is recovered and used in the biochar production process, $E^{\prime}{ }_{i n}$.

Net GHG emissions from transports and soil additions. Finally, Teichmann (2014a) included $\mathrm{CO}_{2}$ emissions from the transportation of biomass to the pyrolysis units, from the transportation of biochar from the pyrolysis units to the farms where biochar soil application takes place, and from the agricultural machinery used for biochar soil application - adjusted for the corresponding emissions from biomass transports and soil additions arising under conventional feedstock management. Only $\mathrm{CO}_{2}$ emissions were considered due to the minor relevance of non- $\mathrm{CO}_{2}$ emissions (cp. Teichmann 2014a).

Total net avoided GHG emissions per dry tonne of feedstock. Assuming that the type of fossil fuel used as an energy input into the pyrolysis process is also the one which is replaced by the pyrolysis by-products or - under conventional feedstock management - the original biomass, Teichmann (2014a) has found that the total net avoided GHG emissions vary considerably across the feedstocks. Generally, the solid biomass residues tend to avoid more net GHG emissions than the digestable biomass residues. However, industrial wood waste and short-rotation coppice lead to positive net avoided GHG emissions only if natural gas is used as fossil fuel (for short-rotation coppice, this is even restricted to the case of process heat recovery); otherwise, the biochar strategy avoids less GHG emissions than conventional biomass combustion. According to Teichmann (2014a), these latter results reveal that biochar production and soil application can be more profitable than biomass combustion from a GHG-mitigation perspective only if a fossil fuel with a low carbon intensity is replaced and if the pyrolysis process is most efficient. ${ }^{31,32}$

\footnotetext{
${ }^{29}$ Note that Teichmann (2014a) treated increases in biochar carbon stocks in soil like general increases in SOC stocks in that they were not counted as measures of nitrogen sequestration. Moreover, biochar inputs to soil were assumed not to lead to increases in non-biochar SOC stocks (see above).

${ }^{30}$ Also note that Teichmann (2014a) assumed that no replacement of lost nutrients (in particular, nitrogen) would take place in the form of mineral fertilizers for the feedstocks diverted from arable land, i.e. cereal straw, solid manures and composts, since nutrients would be returned to the fields via biochar. While being a strong simplification, this was the best to be done given that Teichmann (2014a) abstracted from any agricultural impact of biochar. - A thorough calculation of possible nutrient replacements would require a detailed consideration of the agricultural effects of biochar. - Moreover, the approach is in line with the literature (e.g., Woolf et al. 2010a). For a further discussion, see Teichmann (2014a).

${ }^{31}$ Note that the GHG mitigation balance for the other feedstocks could also change substantially if it would be assumed that they were also used energetically in the baseline scenario (cp. Teichmann 2014a).
} 
Finally, the study by Teichmann (2014a) has shown that $(i)$ the amount of carbon sequestered by the soil addition of biochar and (ii) the substitution of fossil fuels by the pyrolysis by-products stand out among the factors that lead to carbon-dioxide removals or avoided GHG emissions, the former at least for solid biomass residues. Moreover, avoided baseline $\mathrm{CH}_{4}$ and/or $\mathrm{N}_{2} \mathrm{O}$ emissions are also crucial for certain feedstocks. The single most important contributor to GHG emissions, in turn, is the energy required for biochar production; however, only for digestable biomass residues (with the exception of solid poultry manure).

\section{3) Technical GHG Mitigation Potentials}

Multiplying the technical biomass potentials for biochar production by the respective total net avoided GHG emissions per dry tonne of feedstock, Teichmann (2014a) has found that the technical GHG mitigation potential of biochar ranges from 2,136-3,169 kt $\mathrm{CO}_{2} \mathrm{e} / \mathrm{a}$ in 2015, from 2,804-10,157 kt $\mathrm{CO}_{2} \mathrm{e} / \mathrm{a}$ in 2030 and from 2,920-10,587 kt $\mathrm{CO}_{2} \mathrm{e} / \mathrm{a}$ in 2050 (see also Tables $2-11$ in this study). This is equivalent to about $0.4-1.5 \%$ of the annual GHG reduction target of $688 \mathrm{Mt} \mathrm{CO}_{2} \mathrm{e}$ to be achieved by 2030 and to $0.3-1.1 \%$ of the annual reduction target of 1,001 Mt $\mathrm{CO}_{2} \mathrm{e}$ envisaged for 2050. Mainly driven by its huge biomass potential, the greatest single contribution, by far, is made by forestry residues, with $868-1,824 \mathrm{kt} \mathrm{CO}_{2} \mathrm{e} / \mathrm{a}$ in 2015, 981-4,632 kt CO 2 e/a in 2030, and 1,060-5,004 kt CO 2 e/a in 2050 (Teichmann 2014a). ${ }^{33}$

As a general pattern, Teichmann (2014a) has found that the technical GHG mitigation potentials are highest for small-scale pyrolysis units and lowest for large-scale pyrolysis units, caused by the lower transport distances for the smaller technology scales. Moreover, based on the more favorable energy balance, process heat recovery is associated with greater GHG mitigation potentials than no process heat recovery. Furthermore, the use of lignite as fossil fuel leads to the greatest GHG mitigation potentials; the use of natural gas to the lowest. Thus, for each given biomass scenario and year, the maximum technical GHG mitigation potential of biochar is always obtained for small-scale pyrolysis units in combination with process heat recovery and the choice of lignite as fossil fuel. Likewise, the minimum technical GHG mitigation potential is always achieved for large-scale pyrolysis units, where no process heat is recovered and where natural gas is used as fossil fuel.

Differentiated by the biomass scenarios, the technical GHG mitigation potential of biochar in 2015 is largest in the Max 1 (= Min 1) scenario for all the cases where natural gas is used as fossil fuel and else in the Max 2 (= Min 2) scenario (Teichmann 2014a; Tables 2-3). For 2030 and 2050, in turn, the greatest technical GHG mitigation potentials are always achieved in the Max 1 scenario, while the Min 1 scenario always leads to the smallest GHG mitigation potentials (Teichmann 2014a; Tables 4-11).

\footnotetext{
32 Further note that Teichmann (2014a) obtained negative total net avoided GHG emissions also for other feedstocks not considered in this analysis (sewage sludge, liquid cattle and swine manure, sugar-beet leaf and potato haulm, and digestates), mainly driven by the huge amount of energy required to dry these wet feedstocks.

${ }^{33}$ The realization of the maximum technical GHG mitigation potentials does not seem to be constrained by the availability of land. Exploiting the respective maximum technical biomass potential available for biochar in each year and assuming that biochar is added as a one-time supplement on a given soil, the acreage of arable land assumed available in Germany over the period from 2015 to 2050 would not be exhausted before 2050 at biochar deployment rates of $25 \mathrm{t}$ and $50 \mathrm{t}$ per hectare (ha), and only shortly before 2050 at a biochar deployment rate of 10 t/ha (Teichmann 2014a).
} 


\section{4) Net GHG Mitigation Costs}

The net GHG mitigation costs of biochar are derived both per dry tonne of feedstock turned into biochar and per tonne of $\mathrm{CO}_{2} \mathrm{e}$ abated. The latter are calculated by dividing the net GHG mitigation costs per dry tonne of feedstock by the corresponding GHG mitigation potential per dry tonne of feedstock as obtained from Teichmann (2014a, b).

Like the net avoided GHG emissions, the costs for a tonne of dry feedstock turned into biochar and deployed in soil are measured against the baseline of conventional feedstock management (cp. Table 1). Thereby, the net costs of biochar include (i) net feedstock costs; (ii) costs for the construction and operation of the pyrolysis units, including energy costs for drying the feedstocks and running the pyrolysis process; (iii) avoided costs and/or forgone benefits from conventional feedstock management; (iv) benefits from the use of the pyrolysis by-products as renewable energy sources; and $(v)$ net costs of biomass and biochar transports as well as biochar storage and soil addition (e.g., Shackley et al. 2011; McCarl et al. 2009). ${ }^{34}$

\section{1) Net Feedstock Costs}

The costs of the feedstocks used for biochar production are calculated net of the costs of the feedstocks that would occur in the baseline scenario. The corresponding net feedstock costs per dry tonne of feedstock are summarized in Table 12, column 3.

For the feedstocks that are assumed to decompose on site under conventional feedstock management (cereal straw, forestry residues, green waste from compensation areas), the net feedstock costs refer to the costs for their harvesting or collection. ${ }^{35}$ As detailed in Table 12, they are based on cost estimates given in FNR (2005). To simplify the analysis, we assume that these costs remain constant over time. ${ }^{36}$ We further assume that cereal straw and green waste from compensation areas are provided free field edge and that forestry residues are provided in the form of wood chips free forest road. In line with the calculations of the net avoided GHG emissions, we do not include any nutrient-replacement costs for the cereal straw removed from the fields (cp. above).

Turning to the feedstocks that are used energetically in the baseline scenario (industrial wood waste and short-rotation coppice), we assume that the same price has to be paid for the feedstocks regardless whether they are used for biochar or for electricity generation. Thus, the respective net feedstock costs are zero. The same assumption is applied for the solid manures as well as for the feedstocks that are composted in the baseline scenario. As for cereal straw, we do not assign any nutrient-replacement costs to the solid manures and feedstocks to be composted when they are turned into biochar and, thus, diverted from land spread.

\footnotetext{
${ }^{34}$ Since we abstract from any potential agricultural benefits of biochar soil application, we do not assign any revenues from increased crop yields, fertilizer savings or the like.

35 Since cereal straw and forestry residues are by-products of crop cultivation and timber production, respectively, we do not assign any costs for their cultivation (cp. FNR 2005). The same holds for green waste from compensation areas since the corresponding biomass is assumed to be grown and cut in any case (Table 1).

36 This is a conservative assumption, however, since the competition for biomass for energetic uses, food production and - potentially - biochar is expected to increase over time (cp. BMELV and BMU 2010), giving an upward pressure to feedstock prices. However, a detailed economic assessment of these competing biomass uses is beyond the scope of this study.
} 


\section{2) Pyrolysis-Unit and Biochar-Production Costs}

The slow-pyrolysis biochar is assumed to be produced in low-emission biochar processing plants able to recover the resulting pyrolysis gases and liquids for energy generation. In order to reflect the possible trade-off between scale effects and transport distances, Teichmann (2014a) considered three pyrolysis-unit scales: A small-scale unit with an annual capacity of 2,000 tonnes of dry feedstock to be converted into biochar, a medium-scale unit of 16,000 tDM feedstock/a and a large-scale unit of 184,800 tDM feedstock/a. ${ }^{37}$ Assuming that an appropriate capacity of pyrolysis units would be installed to turn all the potentially available biomass into biochar, the required annual number of pyrolysis units in operation in each period for all the biomass scenarios was established by applying a common load factor of 0.8 (Teichmann 2014a: Table 39). Moreover, it was assumed that biochar production would fully start in 2015, with each pyrolysis unit having a lifetime of 20 years as in Shackley et al. (2011).

The costs for the construction and operation of the pyrolysis units consist of $(i)$ the specific capital costs for the pyrolysis plants; (ii) the energy costs for feedstock drying and the pyrolysis process itself; as well as (iii) any other operational costs.

Capital costs. The specific capital costs for a pyrolysis unit depend both on its size and on learning effects over time. To start with, we assign the same capital costs to our small-, medium- and large-scale pyrolysis units as applied by Shackley et al. (2011). Transformed into 2012 euros, they can be found in Table S.1 in the data documentation accompanying this study, i.e. Teichmann (2015). ${ }^{38}$ The capital costs include "all design, equipment, construction, civils and commissioning costs" (Shackley et al. 2011: 344). Using the values from Shackley et al. (2011) is the best we can do given that biochar is not (yet) produced commercially.

Over time, we apply so-called learning curves to capture possible reductions in the investment costs as the knowledge about the production of the pyrolysis units accumulates. That is, abstracting from inflation, the specific capital costs for a pyrolysis unit at time $t \in$ $\{2015,2020,2030,2035,2040,2050\},{ }^{39} C_{t}$, are assumed to decrease according to the following formula (Fritsche et al. 2004):

$$
C_{t}=C_{t-i} \cdot\left(P_{t} / P_{t-i}\right)^{\left(\log f_{t} / \log 2\right)},
$$

where $C_{t-i}$ are the specific capital costs in period $t-i$, with $i=10$ for $t \in\{2030,2050\}$ and $i=5$ for $t \in\{2020,2035,2040\}$. The capital costs in 2015, $C_{2015}$, refer to those given in Table S.1, column 2. That is, we assume that the capital costs obtained for 2012 also apply to 2015. Furthermore, $P_{t-i}$ and $P_{t}$ reflect the cumulative number of pyrolysis units produced at times $t-i$ and $t$, respectively, as given in Table S.2; and $f_{t}$ is the factor by which the costs decrease over time with more pyrolysis units produced. The degression factors $f_{t}$ applied in each period are given in Table S.3, along with the corresponding specific capital costs for each pyrolysis unit.

With an average lifetime of a pyrolysis unit of 20 years and a discount rate of $6 \%,{ }^{40}$ the annual capital costs per plant for each pyrolysis-unit scale and biomass scenario are given in Table S.4. Expressed per dry tonne of feedstock, they can be found in Table S.5. Finally, Table 13 provides the average annual capital costs per dry tonne of feedstock weighted by the

\footnotetext{
37 The size distributions follow Shackley et al. (2011: Table 2). The lower value of 2,000 $\mathrm{t}_{\mathrm{DM}}$ feedstock/a compares well with the average size of biogas plants currently available in Germany (Teichmann 2014a).

${ }^{38}$ All tables starting with 'S.' refer to Teichmann (2015).

39 The period $t=2035$ is included since the pyrolysis units installed in 2015 are to be replaced in 2035 .

40 A 6\% discount rate is also applied by Nitsch et al. (2012a) for investments in power plants (biomass and fossil) and renewable energy generation technologies in Germany.
} 
number of pyrolysis units from different construction dates available in a given year (cp. Table S.2). These are the specific capital costs that enter our analysis.

Energy costs. The energy costs for drying the feedstocks and running the pyrolysis process consist of the costs of the fossil fuels used - either lignite, hard coal, or natural gas and the costs of the associated GHG emission allowances. Note that we assume that GHG emission allowances have to be obtained for the fossil fuels used during pyrolysis for consistency reasons with the fossil-fuel use in power generation.

As already outlined above, the heat energy required for drying the feedstocks and running the pyrolysis process, measured in megajoule (MJ) per kilogram $(\mathrm{kg})$ of feedstock on a dry base $(\mathrm{db})$ - turned into biochar (i.e. $\mathrm{MJ} / \mathrm{kg}_{\mathrm{db}}$ ), was derived in detail by Teichmann (2014a: Table 21), both for the case of process heat recovery $\left(E_{i n}\right)$ and for the case of no process heat recovery $\left(E^{\prime}{ }_{i n}\right) .{ }^{41}$ In calculating the corresponding total fuel requirements for the heat provision, also measured in $\mathrm{MJ} / \mathrm{kg}_{\mathrm{db}}$, we follow Teichmann (2014a) and apply different thermal efficiencies of the fossil fuels, based on new industrial boilers (Table S.6). The associated GHG emissions from the fossil-fuel use for biochar production (Table S.7), in turn, are taken from Teichmann (2014a: Tables 22 and 23).

The fuel prices for lignite, hard coal, and natural gas as well as the prices for the associated $\mathrm{GHG}$ emission allowances ( $\mathrm{CO}_{2}$ prices) are taken from Nitsch et al. (2012a: Figure 2.5 and Table 2-3). ${ }^{42}$ To reflect the uncertainty behind any future price developments, price paths A, B and C from Nitsch et al. (2012a) are used. While price path A corresponds to substantial increases in future fossil-fuel and $\mathrm{CO}_{2}$ prices, price paths $\mathrm{B}$ and $\mathrm{C}$, respectively, reflect moderate and very low price increases (Nitsch et al. 2012a). ${ }^{43}$ As further reported by Nitsch et al. (2012a), these price paths cover a wide range of possible developments and are broadly in line with other scenarios found in the literature. Under climate-change aspects, price path A is considered the most relevant one by Nitsch et al. (2012a), while price path C tends to reflect the scenario assumptions that were established for the German government's energy concept outlined in BMWi and BMU (2010). The fossil-fuel prices for 2015 to 2050, free power plant and measured in $€_{2012} / \mathrm{MJ}$, can be found in Table S.9, columns 8-12 (with some derivations performed in Table S.8), while the prices for the GHG emission allowances per tonne of $\mathrm{CO}_{2}$ are given in Table S.10, columns 7-11.44

Multiplying the fuel requirements by the respective fossil-fuel prices, the fossil-fuel costs per dry tonne of feedstock turned into biochar are summarized in Tables S.11-S.12 and 14 for the case of no process heat recovery; those for process heat recovery can be found in Tables S.13-S.14 and 15. ${ }^{45}$ Likewise, multiplying the GHG emissions from the fossil-fuel use in biochar production by the respective $\mathrm{CO}_{2}$ prices, the corresponding costs for the $\mathrm{GHG}$

\footnotetext{
${ }^{41}$ For the respective values of $E_{i n}$ and $E^{\prime}{ }_{i n}$, see also Table S.6, columns 1 and 5 . The great variability in the energy inputs per type of feedstock is mainly driven by the differences in the feedstocks' water contents and, thus, the energy necessary to dry the feedstocks (Teichmann 2014a).

${ }^{42}$ Nitsch et al. (2012a) provide a set of long-term scenarios for renewable energies in Germany. It is among the studies that form the data base for the German government's energy reform.

${ }^{43}$ Due to the lack of more specific data, however, only price path A is used for lignite fuel costs. Arguably, there is less variability in the costs for lignite since lignite is extracted in Germany and, thus, less influenced by worldmarket developments than natural gas or hard coal. Thereby, the costs for lignite tend to refer to its extraction costs since the lignite power plants are usually located next to the excavation sites (Schröder et al. 2013).

${ }^{44}$ As revealed by Table S.10, columns 7-11, the maximum $\mathrm{CO}_{2}$ price assumed is $75 €_{2012} / \mathrm{CO}_{2}$ in 2050 (price path A). According to Nitsch et al. (2012a), this $\mathrm{CO}_{2}$ price includes external costs, such as future damage costs of unmitigated climate change. It largely coincides with the best-practice assumption of future damage costs of $80 €_{2010} / \mathrm{CO}_{2}$ by UBA (2014). As also shown by UBA (2014: Table B1), however, the best-practice assumption is a conservative estimate and much higher damage costs might be expected in the medium- to long-term.

${ }^{45}$ For the ease of illustration, this study mainly displays the costs involving price path B, i.e. the intermediate price path, and biomass scenario Max 1, while all the remaining costs are given in Teichmann (2015).
} 
emission allowances without process heat recovery are presented in Tables S.15-S.16 and 16; those for process heat recovery in Tables S.17-S.18 and 17.

Other operational costs. Our estimate of the remaining operational costs (Table 18, column 4) is based on the total operating costs (i.e. costs for natural gas as well as labor and plant costs) given in Shackley et al. (2011), net of the costs for natural gas inputs into pyrolysis. Thus, the other operational costs include any labor and plant costs, such as for the reception of the biomass and the feeding of the pyrolysis plant (cp. Shackley et al. 2011). To simplify the analysis, we assume that they remain constant over time.

\section{3) Changes in Costs Due to Different Feedstock Management}

Compared to conventional feedstock management, the diversion of biomass into biochar production can be associated with avoided costs and/or forgone benefits. In particular, this applies to $(i)$ the feedstocks that are used energetically in the baseline scenario; $(i i)$ the solid manures; and (iii) the feedstocks to be composted. For the feedstocks assumed to decompose on site, in turn, no additional costs occur beyond the net feedstock costs outlined above. ${ }^{46}$

Energetic use of biomass. Starting with the feedstocks that are used energetically in the baseline scenario (industrial wood waste and short-rotation coppice), the conversion of the biomass into biochar, on the one hand, saves the costs that would otherwise occur for the combustion of the biomass. In accordance with Teichmann (2014a), we assume that industrial wood waste and short-rotation coppice are conventionally used for electricity generation. The costs associated with biomass combustion refer to the specific capital costs and operational costs of biomass power plants, obtained from Nitsch et al. (2012b: Table 1-5) and expressed per dry tonne of feedstock combusted (Table S.19, rows G and H). ${ }^{47}$ To simplify the analysis, the costs are exclusively based on new biomass power plants, i.e. those installed in the respective period under consideration. Note that the feedstock costs for biomass combustion have already been accounted for in the calculation of the net feedstock costs for biochar.

On the other hand, however, the diversion of industrial wood waste and short-rotation coppice from biomass combustion into biochar production misses the opportunity to substitute for fossil fuels in electricity generation. The benefits from fossil-fuel substitution by biomass combustion in the form of foregone fossil-fuel costs, foregone $\mathrm{CO}_{2}$ costs, and foregone capital and operational costs constitute a cost item for biochar production. ${ }^{48}$ Based on information about electrical efficiencies, biomass heating values and avoided GHG emissions from Teichmann (2014a), the fossil-fuel prices from Table S.9, the $\mathrm{CO}_{2}$ prices from Table S.10, and the specific capital costs and operational costs for newly installed fossil-fuel power plants from Table S.8, the foregone benefits from fossil-fuel substitution for the two feedstocks are listed in Table S.20, rows J-O. While the $\mathrm{CO}_{2}$ costs as well as the capital and operational costs are the lowest for natural gas, this fuel is associated with the highest fossilfuel costs. The opposite holds for lignite, meaning that it has the lowest fuel costs, but the highest $\mathrm{CO}_{2}$ costs and the highest capital and operational costs. Hard coal, in turn, comes always in between. Driven by the fuel costs, the total electricity generation costs from fossil fuels that are avoided by the energetic use of industrial wood waste and short-rotation coppice are the highest for natural gas and the lowest for lignite.

\footnotetext{
${ }^{46}$ Note that any transport-related costs from conventional feedstock management will be analyzed in Section 4.5 below. The same holds for the costs related to the land spread of the solid manures and composts.

${ }^{47}$ Following the approach by Nitsch et al. (2012a), the electricity generation costs are calculated free power plant, i.e. not including any network and transmission costs.

${ }^{48}$ As already indicated above, fossil-fuel power plants are required to participate in the EU ETS (EC 2013).
} 
The net costs imposed on biochar from the foregone biomass combustion (Table 19) i.e. when subtracting the costs of biomass combustion from the associated benefits from fossil-fuel substitution - reveal that the change in feedstock management from the energetic use of biomass to the production of biochar tends to be beneficial when lignite is replaced (except for price path A in 2040 and 2050, and price path B in 2050), while it tends to be costly when hard coal (except for all price paths in 2015 and price path $C$ in 2020) and natural gas are substituted for by the biomass.

Manure management. Turning to the solid manures, their diversion from conventional manure management into biochar production saves the storage costs for the manures since we assume in accordance with Teichmann (2014a) that all feedstocks are turned into biochar immediately after their occurance. We refer to the storage costs as the capital costs for manure trays as obtained from KTBL (2014). Combining the capital costs, expressed per animal place, with information from Fritsche et al. (2004: Table 44) about the amount of solid manure per animal, the costs of manure management per dry tonne of feedstock are given in Table 20, column 6. They are assumed to be constant over time.

Composting. Finally, the costs for biomass composting depend on the technology and load capacity of the composting facilities as well as on the type of input material (Kern et al. 2010). According to Kern et al. (2012: 42), the specific treatment costs for a fresh tonne of biowaste in Germany in 2011 amounted to $€_{201130-80}$; those for a fresh tonne of green waste to $€_{20115-30}$. Due to the lack of more specific data, the composting costs for biowaste will be assigned to both commercial and industrial waste and organic municipal solid waste. The composting costs for green waste, in turn, will be used for all remaining feedstocks to be composted. The feedstock-specific composting costs per dry tonne of feedstock can be found in Table 21. Again, they are assumed to be constant over time.

\section{4) Benefits from Pyrolysis By-Products}

The liquids and gases obtained as by-products of biochar production are assumed to replace fossil fuels - lignite, hard coal, or natural gas - in electricity generation (cp. Teichmann 2014a). Thereby, the pyrolysis by-products are treated as a combined residual of the pyrolysis process, capturing all the energy in the dried feedstocks that is not transferred to biochar or subject to inefficiencies in the energy recovery (cp. Woolf et al. 2010b). The detailed derivation of the energy recovered in the pyrolysis by-products $\left(E_{\text {out }}\right)$ per dry tonne of feedstock put into the pyrolysis process (in $\mathrm{MJ} / \mathrm{kg}_{\mathrm{db}}$ ) can be found in Teichmann (2014a). ${ }^{49}$ The corresponding GHG emissions that can be offset by the energetic use of the pyrolysis byproducts - as summarized in Table S.21 - are also obtained from Teichmann (2014a).

The net benefits associated with the energetic use of the pyrolysis by-products refer to the foregone costs of the electricity generation in fossil-fuel power plants minus the costs that arise from the combustion of the pyrolysis by-products themselves. Thereby, the former consist of avoided fossil-fuel costs (Tables S.22-S.24), avoided costs for GHG emission allowances (Tables S.25-S.27), and avoided capital and operational costs of the fossil-fuel power plants (Table S.28). ${ }^{50}$ The latter, in turn, refer to the capital and operational costs of the power stations that transform the pyrolysis by-products into electricity (Table S.29, rows GT). For the ease of exposition, we assume that the corresponding power stations are located at the sites of the pyrolysis plants. Due to the lack of more specific data, we apply block-type

\footnotetext{
49 The values for $E_{\text {out }}$ are re-stated, for example, in Table S.22, column 1.

${ }^{50}$ As for biomass combustion, the fossil-fuel costs are highest for natural gas and lowest for lignite, while the opposite holds for the GHG emission costs and the capital and operational costs of the fossil-fuel power plants.
} 
thermal power stations using gas from purification plants as a reference although we consider electricity generation only, i.e. no combined heat and power (CHP). To simplify the analysis, we do not differentiate between different scales of these power stations.

Driven by the high capital and operational costs for the combustion of the pyrolysis byproducts (cp. Table S.29), the net benefits from the energetic use of the pyrolysis liquids and gases are often negative (Tables S.30-S.31 and 22). That is, the pyrolysis-by-products combustion usually generates costs rather than benefits. The only exceptions occur for hard coal in 2050 under price path A, for natural gas in 2030-2050 under price paths A and B, and for natural gas in 2050 under price path C. In other words, the energetic use of the pyrolysis by-products induces the greatest costs if lignite is used as the reference fossil fuel and the lowest costs or greatest benefits if natural gas is considered.

\section{5) Costs of Transports, Storage, and Soil Additions}

Finally, costs arise from $(i)$ the road transportation of biomass to the pyrolysis units; (ii) the road transportation of biochar from the pyrolysis units to the farms; (iii) the storage of biochar; and (iv) the biochar soil application - adjusted for the corresponding costs from biomass transports and soil additions occurring under conventional feedstock management. ${ }^{51}$

Biomass road transports. The transportation of the feedstocks from their sources to the pyrolysis units where they are transformed into biochar causes costs for $(i)$ the loading of the biomass onto trucks; (ii) all the necessary equipment and labor; and (iii) the transport fuels. ${ }^{52}$ These costs have to be balanced against the avoided costs of any biomass transports occurring under conventional feedstock management. In particular, this applies to the feedstocks that are used energetically in the baseline scenario and to those that are composted. In the baseline scenario, however, no road transports take place for the feedstocks assumed to decompose on site. The same holds for the solid manures since it is assumed that both manure management and soil application of the manures take place at or close to the sites where the manures become available (cp. Teichmann 2014a). ${ }^{53}$

Both the transport-related equipment and labor costs and the transport-fuel costs for the biomass to be turned into biochar depend on the transport distances between the biomass sources and pyrolysis units. Thereby, the transport distances are determined by the pyrolysis technology scales and, thus, the number of pyrolysis units in operation in each year. Assuming symmetric distances for the transportation of biomass to the pyrolysis units and for the transportation of biochar from the pyrolysis units, Teichmann (2014b: Table A.67) has derived the mean transport distances applicable for both biomass and biochar road transports. They are based on the formula $D_{i t s}=1 / 2 \cdot\left(\text { area/PU } U_{i t s}\right)^{1 / 2}$ obtained from Woolf et al. $(2010 \mathrm{~b})$, where $D_{i t s}$ is the mean transport distance in kilometers $(\mathrm{km})$, area $=348,672 \mathrm{~km}^{2}$ is Germany's total land area (CIA 2013) and $P U_{i t s}$ is the number of pyrolysis units of scale $i$ at time $t$ for biomass scenario $s$ (see Table S.2). The mean transport distances are summarized in Table S.32.

Loading costs. As detailed in Table 23, any biomass loading costs have been derived from FNR (2005), assuming that the biomass is loaded onto the transport vehicles with a front loader. Accounting for biomass loading under conventional feedstock management, positive

\footnotetext{
${ }^{51}$ Like Teichmann (2014a), we abstract from different packing densities of the single biomass and biochar types.

${ }^{52}$ The transport sector outside commercial aviation currently not being covered by the EU ETS (EC 2013), we do not include any costs for potential GHG emission allowances.

${ }^{53}$ The biomass unloading at the pyrolysis units is assumed to be covered by the operational costs associated with the pyrolysis units (cp. Section 4.2). In the baseline scenario, we assume analogously that the costs for the biomass unloading at the composting facilities and power plants are covered by the respective operational costs.
} 
net loading costs occur only for the feedstocks assumed to decompose on site in the baseline scenario and for the solid manures. For the feedstocks to be used energetically and for those to be composted, in turn, the net loading costs are zero since biomass road transports do not only occur when the biomass is turned into biochar, but also when it is treated conventionally. The net biomass loading costs, assumed to be constant, are displayed in Table 23, column 4.

Equipment and labor costs. In accordance with Teichmann (2014a), it is assumed that any biomass road transports are carried out with truck combinations of a transport volume of 80 cubic meters $\left(\mathrm{m}^{3}\right)$ and a payload of $23 \mathrm{t}$. The costs for the trucks and the workforce operating it are constant over time, but differ by length of journey to account for possible scale effects. Based on derivations in Table S.33, the equipment and labor costs for the biochar-related biomass transports per dry tonne of feedstock and kilometer are displayed in Table S.34. Multiplying these values by the mean transport distances from Table S.32, the equipment and labor costs per dry tonne of feedstock are given in Tables 24 and S.35-S.37.

In the baseline scenario, biomass transports take place for the feedstocks to be used energetically and for those to be composted. Following Teichmann (2014a), the associated transport distances from the biomass sources to the power plants and composting facilities, respectively, are held constant at $9 \mathrm{~km}$. Table 25, column 2 contains the corresponding equipment and labor costs for the biomass transports occurring under conventional feedstock management. They constitute a benefit when the biomass is diverted into biochar production.

Fuel costs. As in Teichmann (2014a), the trucks transporting the biomass are powered by diesel fuel, with a constant share of $7 \%$ biodiesel, and the average load per truck is $18 \mathrm{t}^{54}$ Using a heating value of $35.87 \mathrm{MJ}$ per liter (1) of diesel (FNR 2012: 28), the average diesel fuel consumption in liters per tonne of freight and kilometer applied for any road transports is further taken from Teichmann (2014b: Table A.19) and displayed in Table S.38, row J. ${ }^{55}$

Analogously to lignite, hard coal, and natural gas, we consider three different price paths for the future development of diesel prices, referring to price paths $\mathrm{A}, \mathrm{B}$ and $\mathrm{C}$ from Nitsch et al. (2012a: Table 7-5). ${ }^{56}$ Combining the respective diesel prices (Table S.38, rows G-I) with the diesel fuel consumption from Table S.38, column J, the diesel costs per tonne of freight (on a fresh-weight basis) and kilometer are given in Table S.38, rows K-M. Table S.39, in turn, contains the diesel costs for any biochar-related biomass transports per dry tonne of feedstock and kilometer, while the respective costs solely expressed per dry tonne of feedstock are displayed in Tables S.40-S.50 and 26.

Applying the same assumptions to the biomass transports occuring under conventional feedstock management and using the different average transport distance of $9 \mathrm{~km}$, the diesel costs for the transportation of the feedstocks to be composted in the baseline scenario and for those to be used energetically are summarized in Table 27.

Biochar road transports. The costs associated with the road transportation of the biochar from the pyrolysis units to the farms where it is stored and applied to soil include the costs for $(i)$ the necessary equipment and labor; (ii) the transport fuels; and (iii) the unloading

\footnotetext{
54 The average load was derived by Teichmann (2014a) by applying an average load factor of 0.8 to the payload of $23 \mathrm{t}$. While the volume constraint of $80 \mathrm{~m}^{3}$ might be violated at $18 \mathrm{t}$ for freight densities below $0.225 \mathrm{t} / \mathrm{m}^{3}$, we follow Teichmann (2014a) in abstracting from the volume constraint due to the lack of sufficient data for the transport densities of all the feedstocks (and biochars) (cp. above).

${ }_{55}$ As in Teichmann (2014b: Table A.19), we do not differentiate between fossil diesel and biodiesel since they have nearly the same heating values - 35.87 MJ/1 for fossil diesel and 32.65 MJ/1 for biodiesel (FNR 2012: 28).

${ }^{56}$ The prices given in Nitsch et al. (2012a: Table 7-5) refer to average prices for diesel and gasoline. To simplify the analysis, we assign them on a one-to-one basis to diesel fuel. Since the tax-free gasoline prices in Germany undercut those for diesel (cp. Radke 2014), our diesel-price assumptions should be considered as lower bounds. Furthermore, we do not differentiate between fossil diesel and biodiesel due to the assumed small share of biodiesel - and consistent with the derivation of the average diesel fuel consumption given in Table S.38, row J.
} 
of the biochar. For the feedstocks assumed to be composted in the baseline scenario, they are corrected for the respective costs occurring for the transportation of the composts from the composting facilities to the farms. Thereby, the assumptions for the biochar and compost transports are the same as those for the biomass transports. In particular, we abstract from different transport densities of the biochars and composts. ${ }^{57}$

Equipment and labor costs. Based on the average costs for equipment and labor in road transports derived in Table S.33, column 7 and the char yields from Teichmann (2014a: Table 8, column 6), Table S.51 displays the equipment and labor costs for biochar transports per dry tonne of feedstock and kilometer. Thereby, we follow Teichmann (2014a) in that we do not differentiate between biochar fresh weight and biochar dry weight due to the negligible water contents of biochar. Multiplied by the respective mean transport distances (Table S.32), the equipment and labor costs per dry tonne of feedstock are given in Tables 28 and S.52-S.54.

Compared to the baseline scenario, the conversion of biomass into biochar saves the costs for the transportation of the composts from the composting facilities to the farms where they are applied to soil. The respective equipment and labor costs, assumed to be constant over time, can be found in Table 29. As in Teichmann (2014a), we assume that the average transport distance for the composted biomass is $9 \mathrm{~km}$, i.e. the same as for the transportation of the original biomass to the composting facilities. Also following Teichmann (2014a), we further assume that the compost yield, on a dry basis, is $64 \%$ of the respective dry feedstocks and that fresh-weight composts have an average water content of $40 \% .^{58}$

Fuel costs. Combining the diesel prices from Table S.38, rows K-M with the char yields from Teichmann (2014a: Table 8, column 6), the diesel fuel costs for the transportation of biochar per dry tonne of feedstock and kilometer can be found in Table S.55. Tables S.56S.66 and 30, in turn, display the respective diesel costs per dry tonne of feedstock only, i.e. after multiplying the values from Table S.55 by the mean transport distances from Table S.32. Turning to conventional feedstock management, the diesel fuel costs associated with the transportation of the composts are given in Table 31 .

Unloading costs. Applying the same costs for a front loader of $3.3 €_{2012} / t_{\mathrm{FW}}$ freight as for any biomass transports (Table 23, column 2), the costs for unloading the biochar at the farms are given in Table 32, column 2. Deducting the respective costs for the unloading of the composts taking place under conventional feedstock management (Table 32, column 3), the net biochar unloading costs per dry tonne of feedstock are displayed in Table 32, column 4. They are assumed to be constant over time.

Biochar storage. Assuming that biomass is turned into biochar as it becomes available (cp. Teichmann 2014a), no storage costs occur for the biomass feedstocks. However, in this way, the biochar has to be stored in order to bridge the time span between biochar production and biochar soil addition. Thereby, we assume that the biochar storage takes place at or near the farm where it will be applied to soil. Following Shackley et al. (2011: Box 1), it is further assumed that biochar from small-scale pyrolysis units is stored in existing farm facilities, while biochar from medium- and large-scale pyrolysis units is stored in dedicated storage facilities. The associated costs, assumed to be constant over time, are derived in Table 33. ${ }^{59}$

Soil additions. As in Teichmann (2014a), we assume that biochar is deployed in the top 15-30 centimeters of soils at rates of $10 \mathrm{t} / \mathrm{ha}, 25 \mathrm{t} / \mathrm{ha}$ and $50 \mathrm{t} / \mathrm{ha}$ by first adding it to soils

\footnotetext{
${ }^{57}$ As for the unloading of the biomass at the pyrolysis units, it is assumed that the loading of the biochar for the journey to the farms is covered by the operational costs associated with the pyrolysis units. Analogously, we assume that the loading of the composts is included in the operational costs of the composting facilities.

58 These assumptions are based on data for household biowaste and green waste published in Knappe et al. (2012: Figures D-2 and D-5). For further details, see Teichmann (2014a: 33).

${ }^{59}$ Note that we do not consider any storage costs for composts since composting usually takes several weeks.
} 
mechanically and then incorporating it during usual tillage, i.e. not causing any additional operations for the soil incorporation beyond the soil addition. Thereby, the soil addition of biochar induces costs for $(i)$ the necessary equipment and labor and (ii) the fuel to operate the agricultural machinery. These costs have to be reduced by the respective costs for the soil addition of the solid manures and composts. ${ }^{60}$

Equipment and labor costs. Following Shackley et al. (2011: Box 3) and consistent with Teichmann (2014a), it is assumed that biochar soil addition always takes place with a fertilizer spreader pulled by a tractor and carrying $6 \mathrm{t}$ of biochar per journey. ${ }^{61}$ Moreover, we assume along Shackley et al. (2011: Box 3) that two persons are necessary for the loading and wetting of the biochar, its transportation to the field, its soil application, and the return journey of the tractor. The corresponding equipment and labor costs are given in Table 34, column 3 .

To simplify the analysis, the equipment and labor costs for the soil addition of the solid manures and composts taking place in the baseline scenario (Table 34, column 4) are based on the same assumptions as those used for biochar soil addition. Furthermore, we follow Fritsche et al. (2004: 83) in assuming that $70 \%$ of the fresh solid manures remain after storage. The assumptions for the yields and water contents of the composts, in turn, are the same as above.

Subtracting the equipment and labor costs for the baseline soil additions from the corresponding costs for the soil application of biochar, the constant net equipment and labor costs for biochar soil addition can be found in Table 34, column 5.

Fuel costs. Finally, assuming that each tractor journey takes $3 \mathrm{~km}$ and that tractors are powered by diesel fuel with a 7\% share of biodiesel (cp. Teichmann 2014a), the fuel costs for the biochar soil addition under price paths A, B and C can be found in Table 35. They are based on the tractor-related diesel prices per tonne of freight and kilometer as derived in Table S.38, rows O-Q. The diesel fuel costs for the soil addition of the solid manures and composts, in turn, are displayed in Table 36.

\section{7) Total Net GHG Mitigation Costs}

Summarizing all the single cost items, the total net GHG mitigation costs per dry tonne of feedstock turned into slow-pyrolysis biochar are obtained. They will be further transformed into the total net GHG mitigation costs per tonne of $\mathrm{CO}_{2} \mathrm{e}$ abated. As in Teichmann (2014a), we assume that the type of fossil fuel that is used as an energy input into the pyrolysis process is also the one which is replaced by the pyrolysis by-products or, under conventional feedstock management, the original biomass.

Total net GHG mitigation costs per dry tonne of feedstock. With some preparatory steps performed in Tables S.67-S.85, ${ }^{62}$ the total net GHG mitigation costs of biochar per dry tonne of feedstock for the year 2015 are presented in Tables S.86-S.89 and 37-38; those for 2030 in Tables S.90-S.100 and 39; and those for 2050 in Tables S.101-S.111 and 40. Overall, the total net GHG mitigation costs differ greatly, both across the feedstocks and across the

\footnotetext{
${ }^{60}$ Note that we assume that the soil addition of the solid manures and composts leaves usual tillage unaffected. Furthermore, no soil incorporation takes place for forestry residues and green waste from compensation areas. The soil incorporation of cereal straw (cp. Table 1), in turn, is assumed to take place during usual tillage and, thus, not to cause any additional costs.

${ }^{61}$ As for the road transports of biomass and biochar, we abstract from differences in the densities of the biochars. Assuming that $6 \mathrm{t}$ of biochar are carried per journey regardless of the amount of biochar applied per hectare further means that we ignore any scale effects in biochar soil addition, as do Shackley et al. (2011).

${ }^{62}$ While Table S.67 contains a summary of the time-constant net costs of biochar, Tables S.68-S.73 display the fossil-fuel dependent net costs of biochar (including the price-path dependent costs which do not vary across the biomass scenarios), and Tables S.74-S.85 the biomass-scenario dependent net costs of biochar.
} 
specific assumptions concerning technology scale, process heat recovery, fossil-fuel type, price path, biomass scenario, and year. Still, the following common patterns can be detected.

For any given year, price path and biomass scenario, the net GHG mitigation costs across all feedstocks tend to be highest for medium-scale pyrolysis units and lowest for largescale pyrolysis units. ${ }^{63}$ This is mainly driven by the capital and other operational costs for pyrolysis units, which are highest for medium-scale pyrolysis units and lowest for large-scale pyrolysis units (cp. Tables 13 and 18). Furthermore, the net GHG mitigation costs are always lower when process heat is recovered than when it is not recovered.

Everything else held constant, the net GHG mitigation costs for the solid biomass residues tend to decrease from lignite to hard coal to natural gas - with the exception of industrial wood waste and short-rotation coppice, for which the costs increase from lignite to hard coal to natural gas. The general pattern is explained by the clear dominance of the energy recovered in the pyrolysis by-products, $E_{\text {out }}$, over the energy input requirements for biochar production, $E_{\text {in }}$ and $E^{\prime}{ }_{i n}$, irrespective of process heat recovery (cp. Table S.22, column 1; Table S.6, columns 1 and 5). Lignite being the cheapest fossil fuel and natural gas the most expensive one (cp. Table S.9), more fossil-fuel costs are avoided by the energetic use of the pyrolysis by-products if natural gas is substituted for than if lignite or hard coal are replaced. ${ }^{64}$ However, this pattern changes for industrial wood waste and short-rotation coppice since these feedstocks are used energetically in the baseline scenario and, thus, the foregone benefits from the fossil-fuel substitution under conventional feedstock management rest more heavily on natural gas than on lignite or hard coal (cp. Table 19).

Turning to the digestable biomass residues, their net GHG mitigation costs tend to increase from lignite to hard coal to natural gas - with the exception of solid poultry manure as well as commercial and industrial waste (the latter under process heat recovery), which usually see the costs decrease from lignite to hard coal to natural gas. ${ }^{65}$ The change in the general pattern as compared to the solid biomass residues results from the observation that the energy recovered in the pyrolysis by-products from the digestable biomass residues does not dominate the energy required for biochar production or dominates it only slightly. The exceptions for solid poultry manure and commercial and industrial waste under process heat recovery, in turn, are driven by their more favorable relation between the energy recovery in the pyrolysis by-products and the energy requirements for biochar production.

Further comparing the price paths for any given biomass scenario and holding everything else constant, we find that the net GHG mitigation costs tend to increase from price path $\mathrm{A}$ to $\mathrm{B}$ to $\mathrm{C}$ for those feedstocks that see their costs decline from lignite to hard coal to natural gas; and vice versa. The reason is that, for the feedstocks where the energy recovered in the pyrolysis by-products greatly dominates the energy requirements for pyrolysis, the benefits from the fossil-fuel substitution by the energetic use of the pyrolysis by-products decrease from price path $\mathrm{A}$ to $\mathrm{C}$ due to the lower fossil-fuel prices found in price path C (cp. Table S.9), while the opposite is true for the other feedstocks. ${ }^{66}$

\footnotetext{
${ }^{63}$ As an exception to this rule, solid swine manure is associated with the lowest costs for small-scale pyrolysis units in the Min 1 scenario. Solid swine manure being the feedstock with the highest water content (see, e.g., Table S.34, column 1) combined with the long transport distances for large-scale pyrolysis units in the Min 1 scenario (see Table S.32), the high equipment and labor costs for biomass transportation (Table S.35) seem to be the main reason for the loss of the cost advantage of large-scale pyrolysis units for solid swine manure.

${ }^{64}$ While the costs for the GHG emission allowances move in the opposite direction (Tables S.25-S.27), their contribution is only minor and, thus, not driving the results.

${ }^{65}$ Note that the costs for commercial and industrial waste under process heat recovery in 2015 decrease from lignite to hard coal, but remain constant or rise for natural gas (Tables S.86, 37 and S.88).

${ }^{66}$ Note that the differences in the costs for lignite are driven by the costs for the GHG emission allowances rather than the fuel costs since the price for lignite fuel does not change across the price paths (cp. Table S.9).
} 
Moreover, for any given price path, the net GHG mitigation costs in the 2015 Max 1 (Max 2) scenario coincide with the corresponding costs in the Min 1 (Min 2) scenario (Tables S.86-S.89 and 37-38). In 2030 and 2050, the costs associated with the Max 1 (Max 2) scenario are always lower than those in the Min 1 (Min 2) scenario (Tables S.90-S.111 and 39-40).

Under certain constellations, some feedstocks are associated with negative total net GHG mitigation costs. That is, the diversion of these feedstocks from conventional feedstock management into biochar production would actually save costs. ${ }^{67}$ In 2015 , this is the case for organic municipal solid waste if the reference fuels are lignite or hard coal in small-scale or large-scale pyrolysis units in the Max $1=$ Min 1 scenario. In 2030 and 2050, negative costs appear also for other feedstocks, mostly for those to be composted in the baseline scenario. Thereby, the solid biomass residues have a higher tendency to see negative costs if natural gas is replaced, while the digestable biomass residues are more likely to become beneficial for the case of lignite (natural gas) if their costs increase (decrease) from lignite to natural gas. Overall, the number of beneficial cases increases with time. The driver behind these results tends to be the above-described relation between the ratio of the energy requirements for pyrolysis to the energy recovered in the pyrolysis by-products and the associated type of fossil fuel, combined with the avoided costs of composting - which are particularly high for organic municipal solid waste and commercial and industrial waste (cp. Table 21).

Analyzing in greater detail the single components of the total net GHG mitigation costs, Figure 2 - giving a snapshot of the costs for 2030 for biomass scenario Max 1 in combination with price path B, small-scale pyrolysis units, process heat recovery, and natural gas - reveals that the fuel costs for pyrolysis are among the biggest cost items for the digestable biomass residues, except for solid poultry manure. The reason is the considerable amount of energy required to dry these wet feedstocks (cp. Teichmann 2014a). In addition to the pyrolysis fuel costs, pyrolysis capital costs and other operational costs for pyrolysis tend to be important for the considered small-scale pyrolysis units, while the costs for the emissions from the fossilfuel use during biochar production are negligible. Furthermore, for the feedstocks assumed to decompose on site in the baseline scenario (cereal straw, forestry residues, green waste from compensation areas), the net feedstock costs are substantial. For forestry residues, they even outweigh all pyrolysis-related costs. Similarly, the net costs of foregone biomass combustion are the dominating cost component for industrial wood waste and short-rotation coppice, the feedstocks diverted from an energetic use. By contrast, huge cost reductions in the form of avoided costs from composting can be observed for the digestable biomass residues assumed to be composted in the baseline (commercial and industrial waste and organic municipal solid waste). This is driven by their high water contents, which inflate the composting costs when they are expressed per dry tonne of feedstock (cp. Table 21). All remaining cost items tend to be minor. In particular, this is the case for the net benefits from the pyrolysis by-products, which are found to be positive in the considered example (cp. the discussion above).

Total net GHG mitigation costs per tonne of $\mathrm{CO}_{2} \mathrm{e}$ abated. Dividing the total net GHG mitigation costs per dry tonne of feedstock (Tables 37-40 and S.86-S.111) by the corresponding total net avoided GHG emissions per dry tonne of feedstock (Tables 41-44 and S.112-S.117) as obtained from Teichmann (2014a, b), the total net GHG mitigation costs of biochar per tonne of $\mathrm{CO}_{2} \mathrm{e}$ abated can be found in Tables 45-62 and S.118-S.129.

Since the $\mathrm{CO}_{2}$ prices are constant in 2015 (cp. Table S.10), we further find that the 2015 net GHG mitigation costs associated with lignite remain constant for all the price paths.

${ }^{67}$ Note that the existence of such 'no-regret' mitigation options is often doubted (for an overview, see Koch et al. 2003). In particular, there might exist specific preferences, hidden costs, possible side effects and market imperfections which keep the decision makers from implementing such mitigation options. For the case of biochar, a hidden cost is clearly the uncertainty behind its effects in soil. 


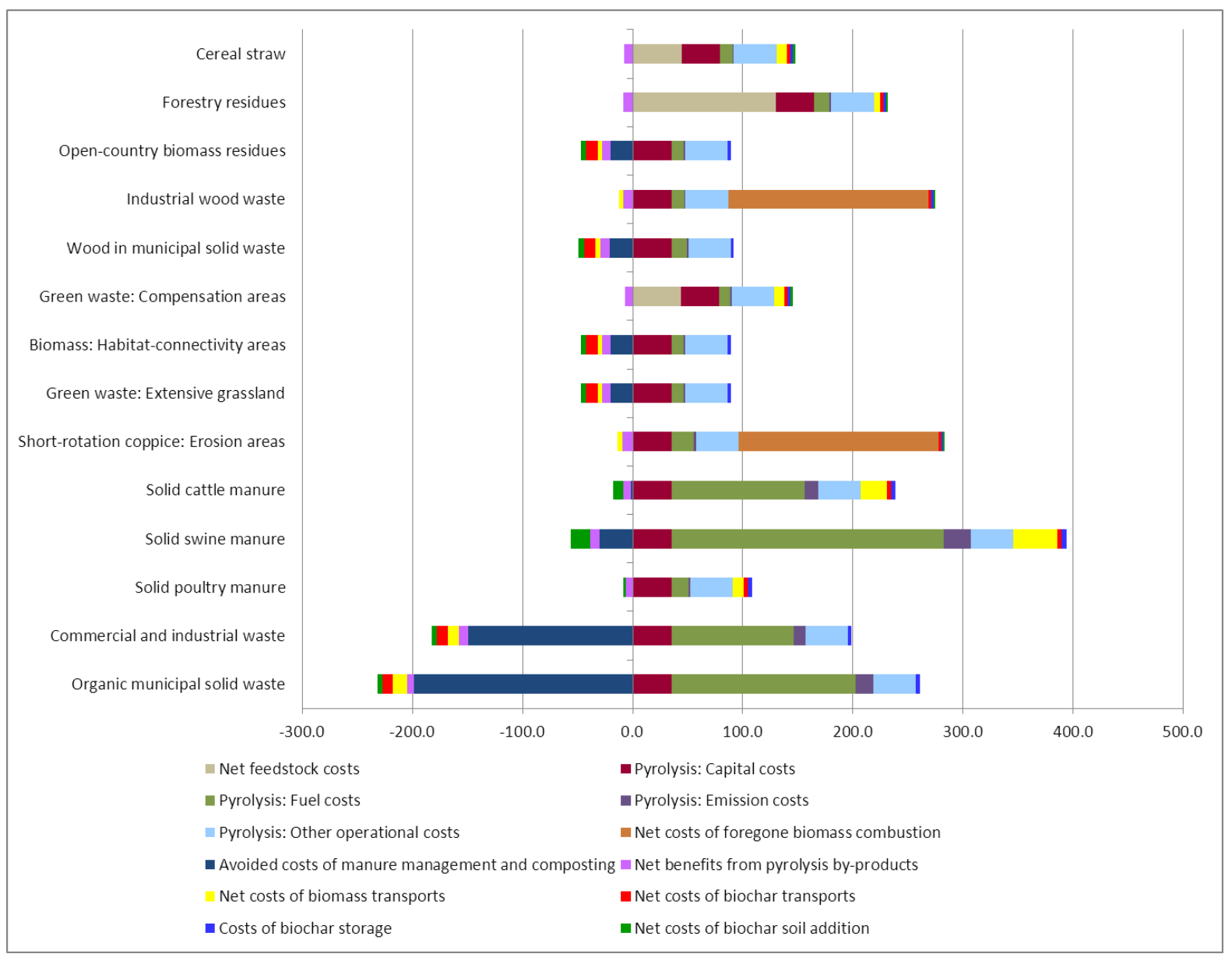

Figure 2: Components of the total net GHG mitigation costs $\left(\epsilon_{2012} / t_{\text {DM }}\right.$ feedstock $)$ for 2030, biomass scenario Max 1, price path B, small-scale pyrolysis units, process heat recovery, and natural gas

Sources: Net feedstock costs: Table S.67, column 1; Pyrolysis: Capital costs: Table 13, row A, column 3; Pyrolyis: Fuel costs: Table 15, column 13; Pyrolysis: Emission costs: Table 17, column 13; Pyrolysis: Other operational costs: Table S.67, column 2a; Net costs of foregone biomass combustion: Table 19, rows B and E, column 13; Avoided costs of manure management and composting: Table S.67, columns 3 and 4; Net benefits from pyrolysis by-products: Table 22, column 13 (entered with a negative sign); Net costs of biomass transports: Table S.67 (column 5) + Table 24 (column 3) + Table S.67 (column 6) + Table 26 (column 3) - Table 27, column 9; Net costs of biochar transports: Table 28 (column 3) + Table S.67 (column 7) + Table 30 (column 3) - Table 31 (column 8) + Table S.67 (column 8); Costs of biochar storage: Table S.67, column 9a; Net costs of biochar soil addition: Table S.67 (column 10) + Table 35 (column 9) - Table 36 (column 9).

Note: Any net benefits (i.e. negative net costs) are displayed with negative sign; positive net costs with positive sign.

As Tables 45-62 and S.118-S.129 show, the division by the net avoided GHG emissions increases the variation in the costs compared to those expressed per dry tonne of feedstock. Thereby, extreme cases with costs above $1,000 €_{2012} / \mathrm{t} \mathrm{CO}_{2} \mathrm{e}$ occur for industrial wood waste and short-rotation coppice since these feedstocks are associated with very small amounts of net avoided GHG emissions - if at all (Tables 41-44 and S.112-S.117; also see the discussion above). In general, however, the above observed cost trends remain largely the same. The major exception is that no clear pattern is left concerning the costs related to the fossil fuels used as reference since the net GHG mitigation costs and the net avoided GHG emissions, both expressed per dry tonne of feedstock, tend to move in the same direction (cp. Teichmann 2014a). As a consequence, for example, the cost advantage of the solid biomass residues (except for industrial wood waste and short-rotation coppice) for natural gas is eroded by the relatively low amount of net avoided GHG emissions associated with this fossil fuel. Likewise, the high net GHG mitigation costs for these feedstocks associated with lignite are compensated for by the comparably large amount of net avoided GHG emissions for lignite. 
The relation between the net GHG mitigation costs per tonne of $\mathrm{CO}_{2} \mathrm{e}$ abated, the net GHG mitigation costs per dry tonne of feedstock, and the net avoided GHG emissions per dry tonne of feedstock is further illustrated in Figure 3. It shows that the net GHG mitigation costs per tonne of $\mathrm{CO}_{2} \mathrm{e}$ are exacerbated for all feedstocks where the net avoided GHG emissions are less than unity and reduced whenever more than one tonne of $\mathrm{CO}_{2} \mathrm{e}$ can be abated per dry tonne of feedstock.
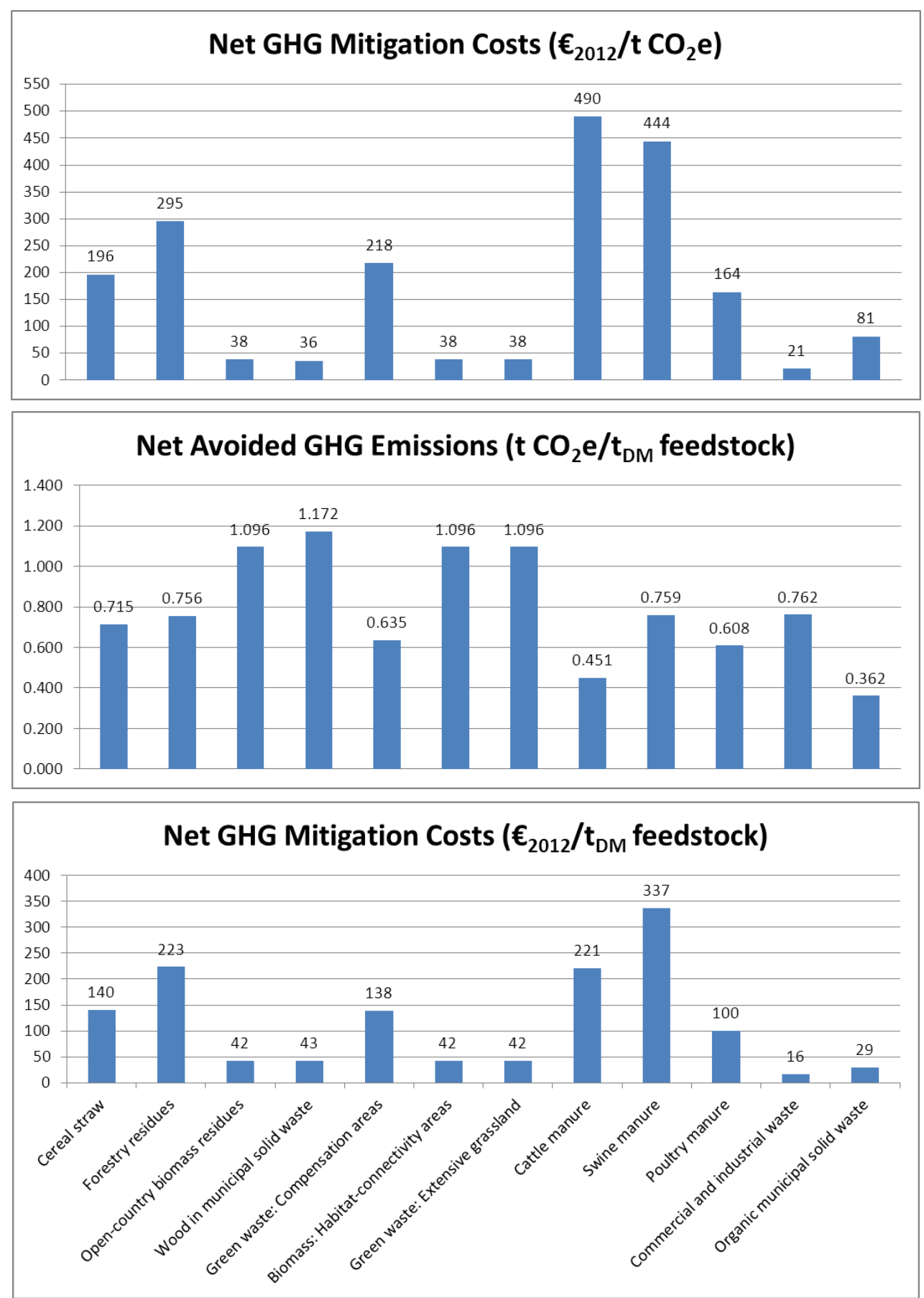

Figure 3: Relation between costs and avoided emissions for 2030, biomass scenario Max 1, price path B, small-scale pyrolysis units, process heat recovery, and natural gas

Sources: Table 39, column 6; Table 43, column 6; Table 53, column 6.

Note: Without industrial wood waste and short-rotation coppice due to their extremely high costs per tonne of $\mathrm{CO}_{2} \mathrm{e}$ abated. 
Sorting the feedstocks from the lowest to the highest net GHG mitigation costs per tonne of $\mathrm{CO}_{2} \mathrm{e}$ abated, the ranking - at least within some groupings - is largely irrespective of the time period, biomass scenario, price path, technology scale, process heat recovery, and fossil-fuel type (Tables 45-62 and S.118-S.129). In particular, we find that the feedstocks associated with the highest costs are always industrial wood waste and short-rotation coppice (given that they lead to positive net avoided GHG emissions). The next most expensive feedstocks are solid cattle manure and solid swine manure. Medium costs, in turn, are associated with cereal straw, forestry residues, green waste from compensation areas, and solid poultry manure. The lowest costs usually occur for open-country biomass residues, wood in municipal solid waste, biomass from habitat-connectivity areas, green waste from extensive grassland, as well as commercial and industrial waste. Finally, depending mainly on the type of fossil fuel used and the chosen price path, organic municipal solid waste can either be found in the group of the low-cost feedstocks or in the group of the medium-cost feedstocks. ${ }^{6}$

\section{5) Marginal Abatement Cost Curves}

The economic assessment of the GHG mitigation strategy of biochar production and soil application combined with the energetic use of the pyrolysis by-products is based on bottomup MACCs. Having ranked the biochar feedstocks from the lowest to the highest net GHG mitigation costs per tonne of $\mathrm{CO}_{2} \mathrm{e}$ abated, the MACCs are derived by plotting the ordered costs against the corresponding total technical GHG mitigation potentials of the feedstocks. To identify the most cost-effective biochar options (i.e. feedstocks) among all the feasible ones considered in a given MACC, the net GHG mitigation costs per tonne of $\mathrm{CO}_{2} \mathrm{e}$ abated are compared to the $\mathrm{CO}_{2}$ price assumed to prevail in the specific period under investigation. All biochar options with net GHG mitigation costs below the $\mathrm{CO}_{2}$ price are considered to be economically viable from a social perspective; and vice versa. ${ }^{69}$ Consistent with our cost calculations, the respective $\mathrm{CO}_{2}$ prices used as cut-offs are the prices for the GHG emission allowances (Table S.10) already applied to any fossil-fuel use in stationary combustion.

For each period (2015, 2030 and 2050), MACCs are first derived for the assumptions associated with the maximum total technical GHG mitigation potential in a given year as obtained from Teichmann (2014a). After calculating the share of each respective maximum mitigation potential that could be realized at marginal costs at or below the given $\mathrm{CO}_{2}$ price, it is analyzed whether the total cost-effective GHG mitigation potential could be increased by focusing on the greatest mitigation potential to be obtained at or below the $\mathrm{CO}_{2}$ price rather than on the maximum GHG mitigation potential per se.

\section{1) MACCs for 2015}

The maximum total technical GHG mitigation potential that could be reached in 2015 is associated with the Max 2 (= Min 2) scenario where biochar is produced in small-scale pyrolysis units with process heat recovery and where lignite is used as fossil fuel; it amounts

\footnotetext{
${ }^{68}$ Note that the cost differences within the medium-cost group of feedstocks can sometimes be relatively large. Moreover, the cost differences between the most expensive low-cost feedstock and the least expensive mediumcost feedstock can be more or less pronounced.

${ }^{69}$ Assuming that biochar would be included in the future in a GHG emission trading scheme (such as the EU ETS) or could otherwise earn carbon-offset credits, the $\mathrm{CO}_{2}$ price determines the revenue to be obtained from the GHG mitigation potential of a given biochar option.
} 
to $3,169 \mathrm{kt} \mathrm{CO}_{2} \mathrm{e} / \mathrm{a}$ (Teichmann 2014a; Tables 2-3). If this mitigation potential would be fully realized, it would be associated with marginal costs of $319 €_{2012} / \mathrm{t} \mathrm{CO}_{2} \mathrm{e}$ (Figure 4; Table 46, column 4), i.e. the net GHG mitigation costs of biochar from forestry residues. ${ }^{70}$ Under the assumed $2015 \mathrm{CO}_{2}$ price of $5 €_{2012} / \mathrm{CO}_{2} \mathrm{e}$ (Table S.10), however, none of this maximum GHG mitigation potential could be realized at reasonable costs (Figure 4; Tables 45-50).

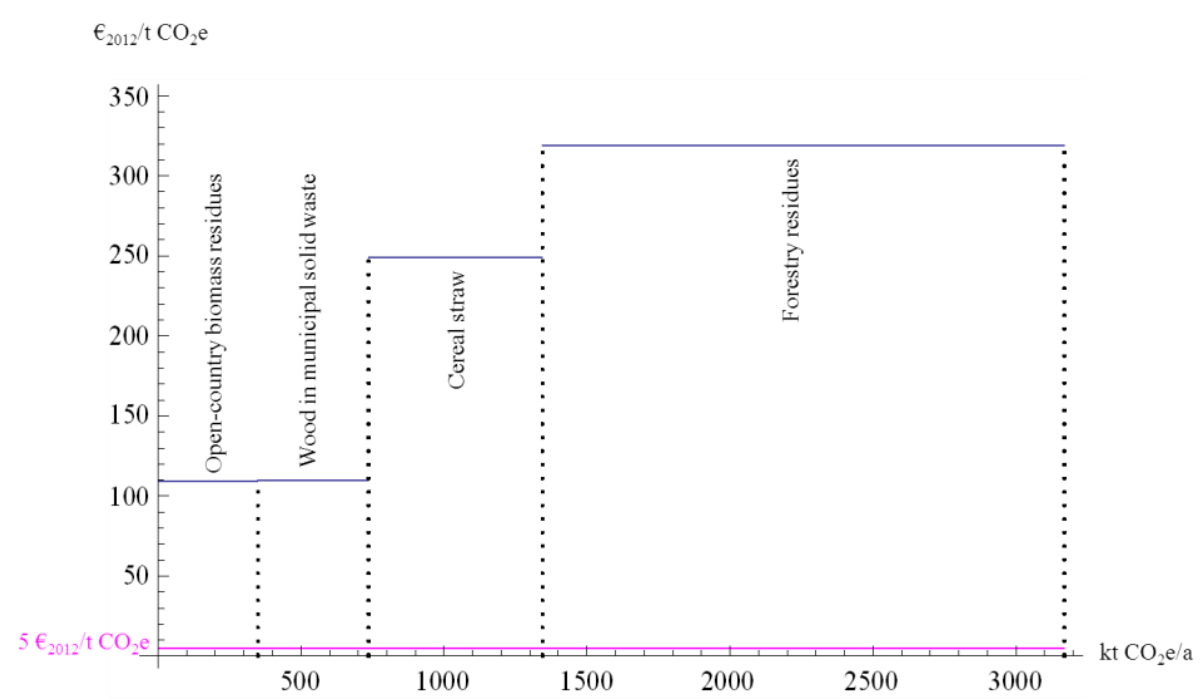

Figure 4: MACC for 2015, biomass scenario $\operatorname{Max} 2$ (= Min 2), small-scale pyrolysis units, process heat recovery, and lignite

Sources: Table 3, column 4; Table 46, column 4.

Focusing, in turn, on the net GHG mitigation costs of biochar per tonne of $\mathrm{CO}_{2} \mathrm{e}$ abated, only organic municipal solid waste is sometimes associated with costs below $5 €_{2012} / \mathrm{t} \mathrm{CO}_{2} \mathrm{e}$ (Tables 45-50). Precisely, this is the case when organic municipal solid waste gives rise to negative net costs, i.e. net benefits. Thereby, the greatest technical GHG mitigation potential of biochar from organic municipal solid waste - amounting to $71 \mathrm{kt} \mathrm{CO}_{2} \mathrm{e} / \mathrm{a}$ - occurs under the Max 1 (= Min 1) scenario in combination with small-scale pyrolysis units, process heat recovery, and hard coal (Table 2). Under price path $\mathrm{C}$, this potential could be obtained at a net benefit of $49 €_{2012} / \mathrm{t} \mathrm{CO}_{2} \mathrm{e}$ (Table 49, column 5).

\section{2) MACCs for 2030}

In the year 2030, the maximum total technical GHG mitigation potential $-10,157 \mathrm{kt} \mathrm{CO}_{2} \mathrm{e} / \mathrm{a}-$ is associated with the Max 1 scenario, small-scale pyrolysis units, process heat recovery, and lignite (Teichmann 2014a; Tables 4-7). Depending on the price path, the realization of this entire GHG mitigation potential would result in marginal costs of 471-492 $€_{2012} / \mathrm{t} \mathrm{CO}_{2} \mathrm{e}$ (Figure 5; Table 51, column 4; Table 53, column 4; Table 55, column 4), i.e. the net GHG mitigation costs of biochar from solid swine manure. Considering only efficient biochar options, i.e. those at or below the respective $\mathrm{CO}_{2}$ price, $362 \mathrm{kt} \mathrm{CO}_{2} \mathrm{e} / \mathrm{a}$ of this maximum total technical GHG mitigation potential could be abated under price paths $\mathrm{A}$ and $\mathrm{B}$ (at $\mathrm{CO}_{2}$ prices of $45 €_{2012} / \mathrm{t} \mathrm{CO} 2 \mathrm{e}$ and $34 €_{2012} / \mathrm{CO}_{2} \mathrm{e}$, respectively); and $166 \mathrm{kt} \mathrm{CO}_{2} \mathrm{e} / \mathrm{a}$ under price path $\mathrm{C}$ (at

\footnotetext{
70 The lignite fuel price and the $2015 \mathrm{CO}_{2}$ price are constant across all price paths (Tables S.9 and S.10).
} 

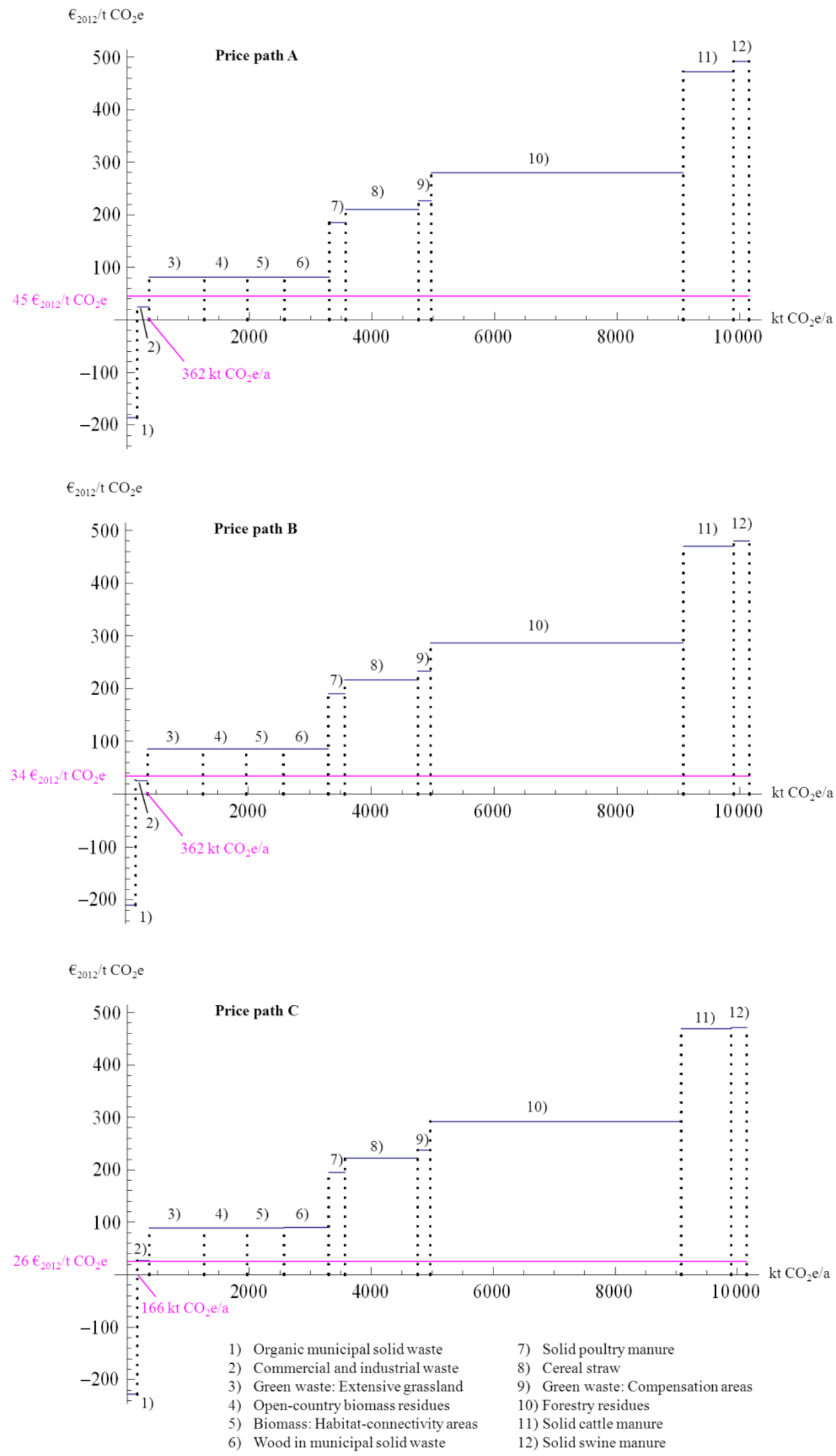

Figure 5: MACCs for 2030, biomass scenario Max 1, small-scale pyrolysis units, process heat recovery, and lignite

Sources: Table 4, column 4; Table 51, column 4 (price path A); Table 53, column 4 (price path B); Table 55, column 4 (price path C). 
a $\mathrm{CO}_{2}$ price of $26 €_{2012} / \mathrm{t} \mathrm{CO}_{2} \mathrm{e}$ ) (Figure 5). ${ }^{71}$ The feedstocks associated with these efficient mitigation potentials are organic municipal solid waste as well as commercial and industrial waste for price paths $\mathrm{A}$ and $\mathrm{B}$, and organic municipal solid waste for price path $\mathrm{C}$.

The greatest technical GHG mitigation potential that could be achieved at costs at or below the respective thresholds from price paths $\mathrm{A}, \mathrm{B}$ and $\mathrm{C}$, however, is substantially higher than the efficient GHG mitigation potential just obtained. In particular, 3,143 kt $\mathrm{CO}_{2} \mathrm{e} / \mathrm{a}$ could be mitigated at costs below $45 €_{2012} / \mathrm{CO}_{2} \mathrm{e}$ (price path A) in the Max 1 scenario when largescale pyrolysis units under process heat recovery are considered and when hard coal is used as fossil fuel (Figure 6). The feedstocks contributing to this mitigation potential are organic municipal solid waste, commercial and industrial waste, green waste from extensive grassland, open-country biomass residues, biomass from habitat-connectivity areas, and wood in municipal solid waste. The same feedstocks would lead to a GHG mitigation potential of $2,832 \mathrm{kt} \mathrm{CO} 2 \mathrm{e} / \mathrm{a}$ below $34 €_{2012} / \mathrm{t} \mathrm{CO}_{2} \mathrm{e}$ (price path B) and $26 €_{2012} / \mathrm{t} \mathrm{CO}_{2} \mathrm{e}$ (price path $\mathrm{C}$ ) for the Max 1 scenario in combination with large-scale pyrolysis units, process heat recovery, and natural gas (Table 4, column 18; Table 53, column 18; Table 55, column 18).

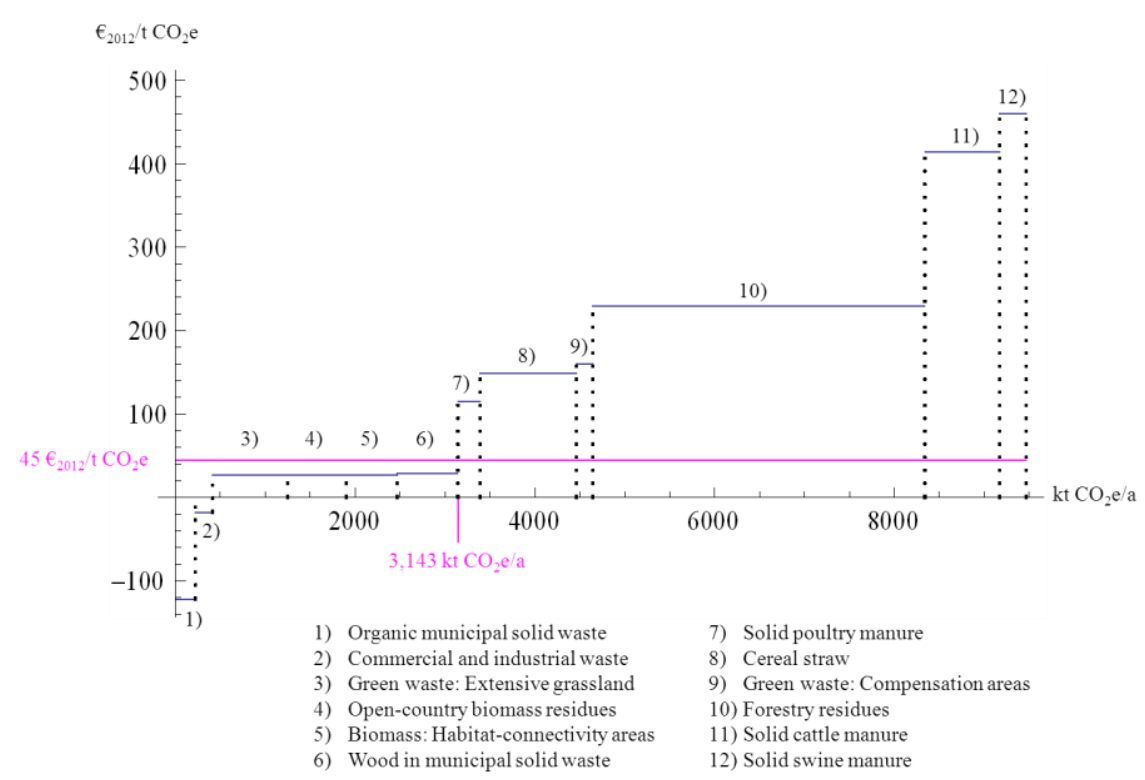

Figure 6: MACC for 2030, biomass scenario Max 1, price path A, large-scale pyrolysis units, process heat recovery, and hard coal

Sources: Table 4, column 17; Table 51, column 17.

\section{3) MACCs for 2050}

Finally, in 2050, the Max 1 scenario combined with small-scale pyrolysis units, process heat recovery, and lignite leads to the maximum total technical GHG mitigation potential of 10,587 kt $\mathrm{CO}_{2} \mathrm{e} / \mathrm{a}$ (Teichmann 2014a; Tables 8-11). This mitigation potential could be fully realized at marginal costs of 489-523 $€_{2012} / \mathrm{t} \mathrm{CO}_{2} \mathrm{e}$ (Figure 7; Table 57, column 4; Table 59, column 4; Table 61, column 4), i.e. the net GHG mitigation costs associated with solid swine

\footnotetext{
${ }^{71}$ The mitigation potentials are read off from the horizontal axis of Figure 5 at the intersection of the MACC with the respective $\mathrm{CO}_{2}$ price. Alternatively, they are obtained from Table 4 , column 4 by summing up the feedstock-specific GHG mitigation potentials of the feedstocks associated with costs at or below the $\mathrm{CO}_{2}$ price.
} 

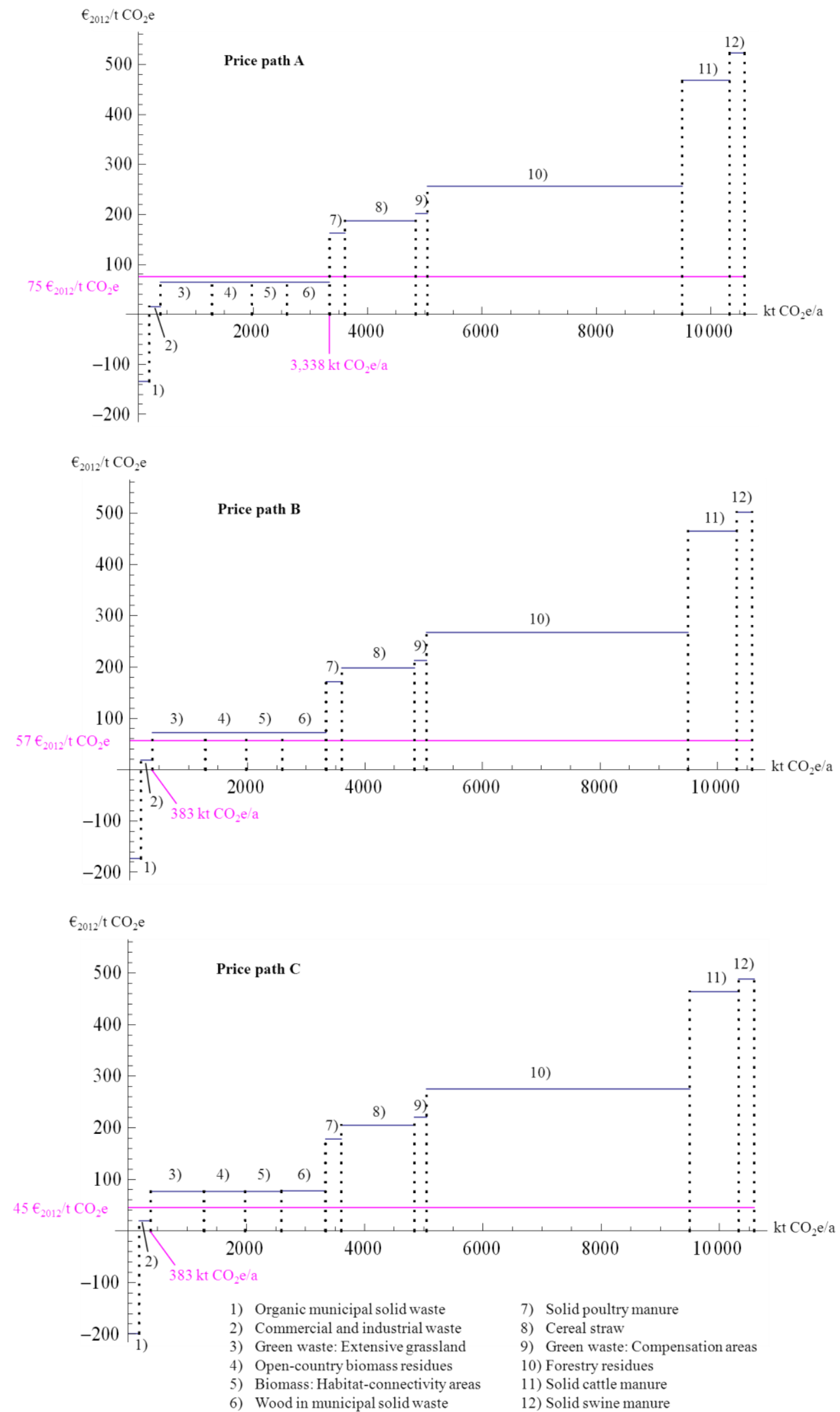

Figure 7: MACCs for 2050, biomass scenario Max 1, small-scale pyrolysis units, process heat recovery, and lignite

Sources: Table 8, column 4; Table 57, column 4 (price path A); Table 59, column 4 (price path B); Table 61, column 4 (price path C). 
manure. By contrast, only a fraction of this mitigation potential could be obtained at the costs defined by the respective $\mathrm{CO}_{2}$ prices. For price path $\mathrm{A}$ (i.e. a $\mathrm{CO}_{2}$ price of $75 €_{2012} / \mathrm{CO}_{2} \mathrm{e}$ ), it would amount to $3,338 \mathrm{kt} \mathrm{CO} 2 \mathrm{e} / \mathrm{a}$; for price paths $\mathrm{B}\left(57 €_{2012} / \mathrm{tCO}_{2} \mathrm{e}\right)$ and $\mathrm{C}\left(45 €_{2012} / \mathrm{t} \mathrm{CO}_{2} \mathrm{e}\right)$ to $383 \mathrm{kt} \mathrm{CO}_{2} \mathrm{e} / \mathrm{a}$ (Figure 7). The feedstocks associated with the efficient GHG mitigation potential under price path A are organic municipal solid waste, commercial and industrial waste, green waste from extensive grassland, open-country biomass residues, biomass from habitat-connectivity areas, and wood in municipal solid waste; those under price paths B and $\mathrm{C}$ are organic municipal solid waste as well as commercial and industrial waste.

Again, paying more attention to the greatest GHG mitigation potential achievable at reasonable costs than to the maximum total technical GHG mitigation potential per se, up to $3,778 \mathrm{kt} \mathrm{CO}_{2} \mathrm{e} / \mathrm{a}$ could be mitigated at or below the $\mathrm{CO}_{2}$ price of $75 €_{2012} / \mathrm{t} \mathrm{CO}_{2} \mathrm{e}$ (price path A) in the Max 2 biomass scenario in combination with large-scale pyrolysis units, process heat recovery, and natural gas (Figure 8). The feedstocks contributing to this potential are wood in municipal solid waste, green waste from extensive grassland, open-country biomass residues, biomass from habitat-connectivity areas, cereal straw, and green waste from compensation areas. Under price path B, the greatest GHG mitigation potential that could be achieved at or below $57 €_{2012} / \mathrm{t} \mathrm{CO}_{2} \mathrm{e}$ amounts to $3,332 \mathrm{kt} \mathrm{CO}_{2} \mathrm{e} / \mathrm{a}$, referring to the Max 1 scenario, large-scale pyrolysis units, process heat recovery, and lignite (Table 8, column 16; Table 59, column 16). The efficient GHG mitigation potential under price path $\mathrm{C}$ (at the $\mathrm{CO}_{2}$ price of $45 €_{2012} / \mathrm{t} \mathrm{CO}_{2} \mathrm{e}$ ), in turn, is $3,186 \mathrm{kt} \mathrm{CO} 2 \mathrm{e} / \mathrm{a}$ for the combination of the Max 1 scenario with large-scale pyrolysis units, process heat recovery, and hard coal (Table 8, column 17; Table 61, column 17). For these latter two cases, the feedstocks referring to the respective mitigation potentials are organic municipal solid waste, commercial and industrial waste, green waste from extensive grassland, open-country biomass residues, biomass from habitatconnectivity areas, and wood in municipal solid waste.

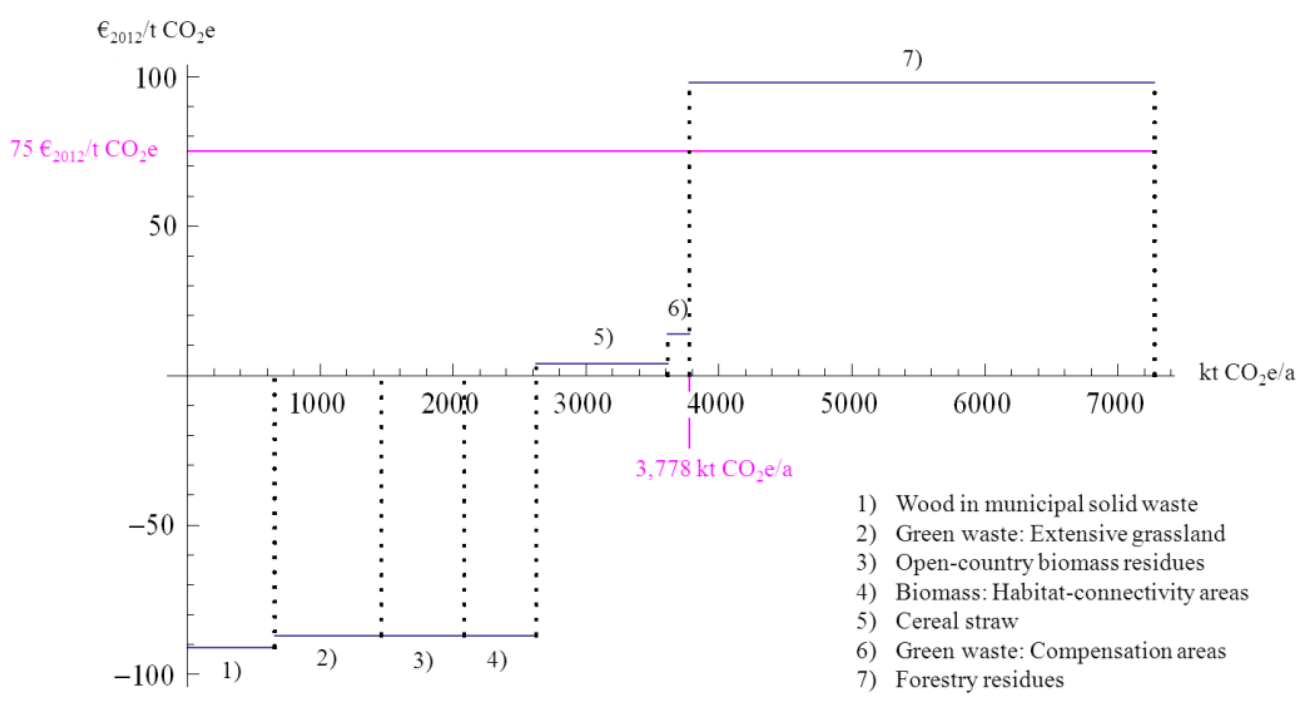

Figure 8: MACC for 2050, biomass scenario Max 2, price path A, large-scale pyrolysis units, process heat recovery, and natural gas

Sources: Table 10, column 18; Table 58, column 18.

Note: Without industrial wood waste and short-rotation coppice due to their extremely high costs per tonne of $\mathrm{CO}_{2} \mathrm{e}$ abated.

Note that the 2050 Max 2 scenario combined with large-scale pyrolysis units, process heat recovery, natural gas, and price path $\mathrm{A}$ is one of the only two constellations where forestry residues - by far the most prominent feedstock in terms of GHG mitigation (cp. Teichmann 
$2014 \mathrm{a}$ ) - are associated with costs at or below $100 €_{2012} / \mathrm{t} \mathrm{CO}_{2} \mathrm{e}$ (Tables 45-62 and S.118S.129; cp. Figure 8). ${ }^{72}$ For cereal straw, the next promising feedstock, this is also observed under certain assumptions, mainly for constellations involving price path $\mathrm{A}$ and natural gas.

\section{4) Discussion}

Abstracting from any cost considerations, the maximum total technical GHG mitigation potentials of biochar attainable refer to $3,169 \mathrm{kt} \mathrm{CO}_{2} \mathrm{e} / \mathrm{a}$ in $2015,10,157 \mathrm{kt} \mathrm{CO}_{2} \mathrm{e} / \mathrm{a}$ in 2030 , and 10,587 kt $\mathrm{CO}_{2} \mathrm{e} / \mathrm{a}$ in 2050 (Teichmann 2014a). However, only fractions of these potentials are viable from an economic point of view. Focusing on the greatest mitigation potentials that could be obtained at reasonable costs, only $71 \mathrm{kt} \mathrm{CO}_{2} \mathrm{e} / \mathrm{a}$ could be abated in $2015,3,143 \mathrm{kt}$ $\mathrm{CO}_{2} \mathrm{e} / \mathrm{a}$ in 2030 , and $3,778 \mathrm{kt} \mathrm{CO} 2 \mathrm{e} / \mathrm{a}$ in $2050 .{ }^{73}$ These numbers refer to price path $\mathrm{A}$, i.e. the highest fossil-fuel and $\mathrm{CO}_{2}$ prices assumed. The feedstocks contributing to these economic potentials are mainly from the low-cost group (organic municipal solid waste, commercial and industrial waste, green waste from extensive grassland, open-country biomass residues, biomass from habitat-connectivity areas, and wood in municipal solid waste) and, in 2050, also from the medium-cost group (cereal straw and green waste from compensation areas).

Even at considerably higher $\mathrm{CO}_{2}$ prices or much lower GHG mitigation costs, the realization of the entire maximum GHG mitigation potentials seems impossible due to the extraordinarily high costs for industrial wood waste and short-rotation coppice and the very high costs for solid cattle and swine manure (cp. Tables 45-62 and S.118-S.129). However, tapping the potential of the medium-cost group of feedstocks - highly desirable from a mitigation perspective - seems more within reach, as revealed by the 2050 example. Possible cost reductions for forestry residues, in particular, might start with the feedstock costs, shown to be a substantial cost item (Figure 2) and based on averages of wide-spanning harvesting costs (Table 12). ${ }^{74}$ At the same time, however, a possible future increase in the competition for biomass might also raise feedstock prices. Potential agricultural benefits of biochar soil application, not considered in this study, might be another source for cost reductions.

As for the technical GHG mitigation potentials of biochar (cp. Teichmann 2014a), comparisons of the mitigation costs of biochar with other mitigation measures lead to mixed results. Against a far-reaching implementation of CCS in Germany as assumed by McKinsey (2007), for example, the GHG mitigation potential of biochar seems modest and its costs seem high. ${ }^{75}$ In particular, for 2030, McKinsey (2007) arrived at an annual GHG mitigation

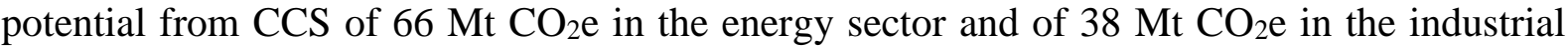
sectors, at respective costs of 30-50 $€_{2005} / \mathrm{t} \mathrm{CO}_{2} \mathrm{e}$ and 45-55 $€_{2005} / \mathrm{t} \mathrm{CO}_{2} \mathrm{e}$ as calculated from a decision-maker perspective. However, biochar compares more favorably with many potential measures to be taken in the transport sector, for example, such as the introduction of hybrid engines or vehicle optimizations. McKinsey (2007) assume such measures to lead to net GHG emission reductions well below the technically feasible 10-11 $\mathrm{Mt} \mathrm{CO}_{2} \mathrm{e} / \mathrm{a}$ that could be reached with biochar in 2030-2050 and expect their costs to vary considerably, from net benefits to well above $1,000 €_{2005} / \mathrm{t} \mathrm{CO}_{2} \mathrm{e}$.

\footnotetext{
72 The other constellation is the 2050 Max 1 scenario combined with the same set of just-mentioned assumptions.

${ }^{73}$ Note, however, that different sets of scenario assumptions are associated with the maximum total technical GHG mitigation potentials and the greatest mitigation potentials obtained under cost considerations.

${ }^{74}$ The harvesting costs for forestry residues depend on the degree of mechanisation during harvest and the diameter at breast height (cp. Table 12).

${ }^{75}$ While the timing for the implementation of CCS assumed by McKinsey (2007) seems outdated (cp. von Hirschhausen et al. 2012), the orders of magnitude of the mitigation potentials and costs can still be compared.
} 


\section{6) Conclusion}

Extending the analysis by Teichmann (2014a, b) of the technical GHG mitigation potentials of biochar soil incorporation in Germany, this study has calculated the corresponding net GHG mitigation costs for each biochar option and scenario and performed an economic assessement of biochar for 2015, 2030 and 2050.

While the net GHG mitigation costs of biochar per tonne of $\mathrm{CO}_{2} \mathrm{e}$ abated strongly depend on the type of feedstock and the associated conventional feedstock management, the wide variety of feedstocks covered in the analysis still allows for some general conclusions to be drawn. First of all, other than for the technical GHG mitigation potentials, there is no clear division between dry and wet feedstocks. Rather, second, the baseline scenario seems to be the dominating factor in the determination of the net GHG mitigation costs. In particular, biochar produced from feedstocks that are assumed to be composted under conventional feedstock management tends to be the least expensive, regardless of the feedstocks' water contents. Third, the diversion of industrial wood waste and short-rotation coppice from its assumed energetic use into biochar production is not a viable strategy.

Comparing the marginal abatement costs of biochar with the assumed maximum prices for GHG emission allowances of $45 €_{2012} / \mathrm{t} \mathrm{CO}_{2} \mathrm{e}$ in 2030 and $75 €_{2012} / \mathrm{t} \mathrm{CO}_{2} \mathrm{e}$ in 2050 , the greatest GHG mitigation potentials considered economically viable in 2030 and 2050 amount to $3,143 \mathrm{kt} \mathrm{CO}_{2} \mathrm{e} / \mathrm{a}$ and $3,778 \mathrm{kt} \mathrm{CO} 2 \mathrm{e} / \mathrm{a}$, respectively. These potentials correspond to a third of the respective 2030 and 2050 upper bounds of the technical GHG mitigation potentials of biochar of 10,157 kt $\mathrm{CO}_{2} \mathrm{e} / \mathrm{a}$ and 10,587 kt $\mathrm{CO}_{2} \mathrm{e} / \mathrm{a}$ (cp. Teichmann 2014a). The complete realiziation of the maximum technically feasible GHG mitigation potentials, in turn, could only be achieved at considerable costs. Driven by industrial wood waste and short-rotation coppice, the corresponding marginal abatement costs would exceed 1,000 $€_{2012} / \mathrm{t}^{\mathrm{CO}_{2} \mathrm{e}}$. Moreover, the feedstock contributing the most to the technical GHG mitigation potentials forestry residues - is not among the most cost-effective biochar options.

While this study has covered a broad spectrum of scenarios, the conclusions drawn here might change for alternative assumptions with regard to the baseline scenario, technological advances, developments of the prices for fossil fuels and GHG emission allowances, or any other condition. For example, $2050 \mathrm{CO}_{2}$ prices in excess of $100 €_{2012} / \mathrm{CO}_{2} \mathrm{e}$ could open up the huge GHG mitigation potential of forestry residues. As judged from industrial wood waste and short-rotation coppice, however, assuming that forestry residues (and, potentially, all the other feedstocks) would be used energetically in the baseline scenario could deteriorate their prospects considerably. Finally, future research should reveal whether possible agricultural benefits - if present - might greatly reduce the costs of the biochar strategy.

\section{References}

Amonette, J. E. and S. Joseph. 2009. Characteristics of biochar: Microchemical properties. In: Biochar for environmental management: Science and technology. Lehmann, J. and S. Joseph (eds). Earthscan, London, UK and Sterling, VA, USA: 33-52.

Antal, M. J. Jr. and M. Grønli. 2003. The art, science, and technology of charcoal production. Industrial \& Engineering Chemistry Research 42(8): 1619-1640.

Antal, M. J. Jr., S. G. Allen, X. Dai, B. Shimizu, M. S. Tam, and M. Grønli. 2000. Attainment of the theoretical yield of carbon from biomass. Industrial \& Engineering Chemistry Research 39(11): 4024-4031.

Baldock, J. A. and R. J. Smernik. 2002. Chemical composition and bioavailability of thermally altered Pinus resinosa (Red pine) wood. Organic Geochemistry 33(9): 1093-1109.

Basso, A. S., F. E. Miguez, D. A. Laird, R. Horton, and M. Westgate. 2013. Assessing potential of biochar for increasing water-holding capacity of sandy soils. GCB Bioenergy 5(2): 132-143. 
Bird, M. I., C. Moyo, E. M. Veenendaal, J. Lloyd, and P. Frost. 1999. Stability of elemental carbon in a savannah soil. Global Biogeochemical Cycles 13(4): 923-932.

BMELV and BMU (eds). 2010. Nationaler Biomasseaktionsplan für Deutschland - Beitrag der Biomasse für eine nachhaltige Energieversorgung. Bundesministerium für Ernährung, Landwirtschaft und Verbraucherschutz (BMELV), Bundesministerium für Umwelt, Naturschutz und Reaktorsicherheit (BMU).

BMWi and BMU (eds). 2010. Energiekonzept für eine umweltschonende, zuverlässige und bezahlbare Energieversorgung. Bundesministerium für Wirtschaft und Technologie (BMWi), Bundesministerium für Umwelt, Naturschutz und Reaktorsicherheit (BMU).

Brown, R. 2009. Biochar production technology. In: Biochar for environmental management: Science and technology. Lehmann, J. and S. Joseph (eds). Earthscan, London, UK and Sterling, VA, USA: 127-146.

Cantrell, K. B., P. G. Hunt, M. Uchimiya, J. M. Novak, and K. S. Ro. 2012. Impact of pyrolysis temperature and manure source on physicochemical characteristics of biochar. Bioresource Technology 107: 419-428.

CIA. 2013. The world factbook: Germany. Central Intelligence Agency (CIA). Online available at: https://www.cia.gov/library/publications/the-world-factbook/geos/gm.html (accessed on 28 November 2013).

Ciais, P., C. Sabine, G. Bala, L. Bopp, V. Brovkin, J. Canadell, A. Chhabra, R. DeFries, J. Galloway, M. Heimann, C. Jones, C. Le Quere, R. B. Myneni, S. Piao, and P. Thornton. 2013. Carbon and other biogeochemical cycles. In: Climate change 2013: The physical science basis. Contribution of Working Group I to the Fifth Assessment Report of the Intergovernmental Panel on Climate Change. Stocker, T. F., D. Qin, G.-K. Plattner, M. Tignor, S. K. Allen, J. Boschung, A. Nauels, Y. Xia, V. Bex, and P. M. Midgley (eds). Cambridge University Press, Cambridge, United Kingdom and New York, NY, USA.

De Cara, S., M. Houzé, and P.-A. Jayet. 2005. Methane and nitrous oxide emissions from agriculture in the EU: A spatial assessment of sources and abatement costs. Environmental \& Resource Economics 32(4): 551583.

De Klein, C., R. S. A. Novoa, S. Ogle, K. A. Smith, P. Rochette, T. C. Wirth, B. G. McConkey, A. Mosier, K. Rypdal, M. Walsh, and S. A. Williams. 2006. $\mathrm{N}_{2} \mathrm{O}$ emissions from managed soils, and $\mathrm{CO}_{2}$ emissions from lime and urea application. In: 2006 IPCC guidelines for national greenhouse gas inventories. Eggleston, S., L. Buendia, K. Miwa, T. Ngara, and K. Tanabe (eds). IGES, Japan: Volume 4, Chapter 11.

Deutsche Bundesbank. 2012. Euro reference exchange rates of the European Central Bank: End-of-year rates and annual averages. Exchange rate statistics as of Dec 31, 2012. Online available at: http://www.bundesbank.de/Navigation/EN/Statistics/Time_series_databases/Macro_economic_time_serie s/its_details_tables_node.html?listId=www_s331_b01012_1\&tsId=BBK01.WJ5636 (accessed on 10 December 2013).

Deutsche Bundesbank. 2015. Time series BBDP1.A.DE.N.EPG.G.GP09SA000000.I10.L: Index of producer prices of industrial products sold on the domestic market, Germany, unadjusted figure, total. Online available at:

http://www.bundesbank.de/Navigation/EN/Statistics/Time_series_databases/Macro_economic_time_serie s/its_details_value_node.html?listId=www_s311_lr_pr\&tsId=BBDP1.A.DE.N.EPG.G.GP09SA000000.I1 0.L (accessed on 21 January 2015).

Dong, H., J. Mangino, T. A. McAllister, J. L. Hatfield, D. E. Johnson, K. R. Lassey, M. A. de Lima, A. Romanovskaya, D. Bartram, D. Gibb, and J. H. Martin, Jr. 2006. Emissions from livestock and manure management. In: 2006 IPCC guidelines for national greenhouse gas inventories. Eggleston, S., L. Buendia, K. Miwa, T. Ngara, and K. Tanabe (eds). IGES, Japan: Volume 4, Chapter 10.

DüMV. 2012. Verordnung über das Inverkehrbringen von Düngemitteln, Bodenhilfsstoffen, Kultursubstraten und Pflanzenhilfsmitteln (Düngemittelverordnung - DüMV). 5. Dezember 2012 (BGB1. I S. 2482).

EC. 2013. The EU Emissions Trading System (EU ETS). EU ETS Factsheet. European Commission (EC), Brussels. Online available at: http://ec.europa.eu/clima/policies/ets/index_en.htm (accessed on 20 February 2015).

Enders, A., K. Hanley, T. Whitman, S. Joseph, and J. Lehmann. 2012. Characterization of biochars to evaluate recalcitrance and agronomic performance. Bioresource Technology 114: 644-653.

FNR (ed). 2005. Leitfaden Bioenergie: Planung, Betrieb und Wirtschaftlichkeit von Bioenergieanlagen. Fachagentur Nachwachsende Rohstoffe e. V. (FNR). Gülzow.

FNR (ed). 2012. Basisdaten Bioenergie Deutschland. Fachagentur Nachwachsende Rohstoffe e. V. (FNR). Gülzow.

Fritsche, U. R., G. Dehoust, W. Jenseit, K. Hünecke, L. Rausch, D. Schüler, K. Wiegemann, A. Heinz, M. Hiebel, M. Ising, S. Kabasci, C. Unger, D. Thrän, N. Fröhlich, F. Scholwin, G. Reinhardt, S. Gärtner, A. Patyk, F. Baur, U. Bemmann, B. Groß, M. Heib, C. Ziegler, M. Flake, M. Schmehl, and S. Simon. 2004. Stoffstromanalyse zur nachhaltigen energetischen Nutzung von Biomasse. Final report. Darmstadt, Berlin, Oberhausen, Leipzig, Heidelberg, Saarbrücken, Braunschweig, München. 
Gaunt, J. and A. Cowie. 2009. Biochar, greenhouse gas accounting and emissions trading. In: Biochar for environmental management: Science and technology. Lehmann, J. and S. Joseph (eds). Earthscan, London, UK and Sterling, VA, USA: 317-340.

Glaser, B., L. Haumaier, G. Guggenberger, and W. Zech. 2001. The Terra Preta phenomenon: A model for sustainable agriculture in the humid tropics. Naturwissenschaften 88(1): 37-41.

Gómez, D. R., J. D. Watterson, B. B. Americano, C. Ha, G. Marland, E. Matsika, L. N. Namayanga, B. OsmanElasha, J. D. Kalenga Saka, and K. Treanton. 2006. Stationary combustion. In: 2006 IPCC guidelines for national greenhouse gas inventories. Eggleston, S., L. Buendia, K. Miwa, T. Ngara, and K. Tanabe (eds). IGES, Japan: Volume 2, Chapter 2.

Hammond, J., S. Shackley, S. Sohi, and P. Brownsort. 2011. Prospective life cycle carbon abatement for pyrolysis biochar systems in the UK. Energy Policy 39(5): 2646-2655.

Kaltschmitt, M., H. Hartmann, and H. Hofbauer (eds). 2009. Energie aus Biomasse. Grundlagen, Techniken und Verfahren. Springer, Heidelberg.

Kern, M., T. Raussen, K. Funda, A. Lootsma, and H. Hofmann. 2010. Aufwand und Nutzen einer optimierten Bioabfallverwertung hinsichtlich Energieeffizienz, Klima- und Ressourcenschutz. Umweltbundesamt (ed), Dessau-Roßlau: 43/2010.

Kern, M., T. Raussen, T. Graven, C.-G. Bergs, and T. Hermann. 2012. Ökologisch sinnvolle Verwertung von Bioabfällen: Anregungen für kommunale Entscheidungsträger. Bundesministerium für Umwelt, Naturschutz und Reaktorsicherheit and Umweltbundesamt (eds).

Kloss, S., F. Zehetner, A. Dellantonio, R. Hamid. F. Ottner, V. Liedtke, M. Schwanninger, M. H. Gerzabek, and G. Soja. 2012. Characterization of slow pyrolysis biochars: Effects of feedstocks and pyrolysis temperature on biochar properties. Journal of Environmental Quality 41(4): 990-1000.

Knappe, F., R. Vogt, S. Lazar, and S. Höke. 2012. Optimierung der Verwertung organischer Abfälle. Umweltbundesamt (ed), Dessau-Roßlau: 31/2012.

Koch, M., J. Harnisch, and K. Blok. 2003. A systematic analysis of the characteristics of energy models with regard to their suitability for practical policy recommendations for developing future strategies to mitigate climate change. Climate Change 03/2003. Umweltbundesamt (ed), Berlin.

Krull, E. S., J. A. Baldock, J. O. Skjemstad, and R. J. Smernik. 2009. Characteristics of biochar: Organochemical properties. In: Biochar for environmental management: Science and technology. Lehmann, J. and S. Joseph (eds). Earthscan, London, UK and Sterling, VA, USA: 53-65.

KTBL. 2014. Baukost 2.10. Investitionsbedarf und Jahreskosten für landwirtschaftliche Betriebsgebäude. Kuratorium für Technik und Bauwesen in der Landwirtschaft (KTBL). Online available at: http://daten.ktbl.de/baukost2/?tx_ktblsso_checktoken\%5Btoken\%5D=d4975103bf9ffe67f97e56e5e6b6a2 bb (accessed on 21 January 2015).

Lehmann, J. 2007a. Bio-energy in the black. Frontiers in Ecology and the Environment 5(7): 381-387.

Lehmann, J. 2007b. A handful of carbon. Nature 447: 143-144.

Lehmann, J., C. Czimczik, D. Laird, and S. Sohi. 2009. Stability of biochar in the soil. In: Biochar for environmental management: Science and technology. Lehmann, J. and S. Joseph (eds). Earthscan, London, UK and Sterling, VA, USA: 183-205.

Lehmann, J., J. Gaunt, and M. Rondon. 2006. Bio-char sequestration in terrestrial ecosystems - A review. Mitigation and Adaptation Strategies for Global Change 11(2): 403-427.

Libra, J. A., K. S. Ro, C. Kammann, A. Funke, N. D. Berge, Y. Neubauer, M.-M. Titirici, C. Fühner, O. Bens, J. Kern, and K.-H. Emmerich. 2011. Hydrothermal carbonization of biomass residuals: A comparative review of the chemistry, processes and applications of wet and dry pyrolysis. Biofuels 2(1): 89-124.

MacLeod, M., D. Moran, V. Eory, R. M. Rees, A. Barnes, C. F. E. Topp, B. Ball, S. Hoad, E. Wall, A. McVittie, G. Pajot, R. Matthews, P. Smith, and A. Moxey. 2010. Developing greenhouse gas marginal abatement cost curves for agricultural emissions from crops and soils in the UK. Agricultural Systems 103(4): 198209.

Mahinpey, N., P. Murugan, T. Mani, and R. Raina. 2009. Analysis of bio-oil, biogas, and biochar from pressurized pyrolysis of wheat straw using a tubular reactor. Energy \& Fuels 23(5): 2736-2742.

Mašek, O., P. Brownsort, A. Cross, and S. Sohi. 2013. Influence of production conditions on the yield and environmental stability of biochar. Fuel 103: 151-155.

McCarl, B. A., C. Peacocke, R. Chrisman, C.-C. Kung, and R. D. Sands. 2009. Economics of biochar production, utilization and greenhouse gas offsets. In: Biochar for environmental management: Science and technology. Lehmann, J. and S. Joseph (eds). Earthscan, London, UK and Sterling, VA, USA: 341357.

McKinsey. 2007. Costs and potentials of greenhouse gas abatement in Germany. A report by McKinsey \& Company, Inc., on behalf of "BDI initiativ - Business for Climate."

McKinsey. 2009a. Pathways to a low-carbon economy: Version 2 of the global greenhouse gas abatement cost curve. McKinsey \& Company. 
McKinsey. 2009b. Kosten und Potenziale der Vermeidung von Treibhausgasemissionen in Deutschland. Eine Studie von McKinsey \& Company, Inc., erstellt im Auftrag von "BDI initiativ - Wirtschaft für Klimaschutz". Aktualisierte Energieszenarien und -sensitivitäten, März 2009.

Moran, D., M. Macleod, E. Wall, V. Eory, A. McVittie, A. Barnes, R. Rees, C. F. E. Topp, and A. Moxey. 2011. Marginal abatement cost curves for UK agricultural greenhouse gas emissions. Journal of Agricultural Economics 62(1): 93-118.

Nitsch, J., W. Krewitt, M. Nast, P. Viebahn, S. Gärtner, M. Pehnt, G. Reinhardt, R. Schmidt, A. Uihlein, K. Scheurlen, C. Barthel, M. Fischedick, and F. Merten. 2004. Ökologisch optimierter Ausbau der Nutzung erneuerbarer Energien in Deutschland. Long version. Stuttgart, Heidelberg, Wuppertal.

Nitsch, J., T. Pregger, T. Naegler, D. Heide, D. L. de Tena, F. Trieb, Y. Scholz, K. Nienhaus, N. Gerhardt, M. Sterner, T. Trost, A. von Oehsen, R. Schwinn, C. Pape, H. Hahn, M. Wickert, and B. Wenzel. 2012a. Langfristszenarien und Strategien für den Ausbau der erneuerbaren Energien in Deutschland bei Berücksichtigung der Entwicklung in Europa und global. Schlussbericht. Stuttgart, Kassel, Teltow.

Nitsch, J., T. Pregger, T. Naegler, D. Heide, D. L. de Tena, F. Trieb, Y. Scholz, K. Nienhaus, N. Gerhardt, M. Sterner, T. Trost, A. von Oehsen, R. Schwinn, C. Pape, H. Hahn, M. Wickert, and B. Wenzel. 2012 b. Langfristszenarien und Strategien für den Ausbau der erneuerbaren Energien in Deutschland bei Berücksichtigung der Entwicklung in Europa und global. Datenanhang II zum Schlussbericht. Stuttgart, Kassel, Teltow.

Novak, J. M., I. Lima, B. Xing, J. W. Gaskin, C. Steiner, K. C. Das, M. Ahmedna, D. Rehrah, D. W. Watts, W. J. Busscher, and H. Schomberg. 2009. Characterization of designer biochar produced at different temperatures and their effects on a loamy sand. Annals of Environmental Science 3: 195-206.

Pipatti, R., J. W. Silva Alves, Q. Gao, C. López Cabrera, K. Mareckova, H. Oonk, E. Scheehle, C. Sharma, A. Smith, P. Svardal, and M. Yamada. 2006. Biological treatment of solid waste. In: 2006 IPCC guidelines for national greenhouse gas inventories. Eggleston, S., L. Buendia, K. Miwa, T. Ngara, and K. Tanabe (eds). IGES, Japan: Volume 5, Chapter 4.

Pratt, K. and D. Moran. 2010. Evaluating the cost-effectiveness of global biochar mitigation potential. Biomass and Bioenergy 34(8): 1149-1158.

Radke, S. 2014. Verkehr in Zahlen 2014/2015. Bundesministerium für Verkehr und digitale Infrastruktur (ed). DVV Media Group, Hamburg.

Rickels, W., G. Klepper, J. Dovern, G. Betz, N. Brachatzek, S. Cacean, K. Güssow, J. Heintzenberg, S. Hiller, C. Hoose, T. Leisner, A. Oschlies, U. Platt, A. Proelß, O. Renn, S. Schäfer, and M. Zürn. 2011. Large-scale intentional interventions into the climate system? Assessing the climate engineering debate. Scoping report conducted on behalf of the German Federal Ministry of Education and Research (BMBF), Kiel Earth Institute, Kiel.

Roberts, K. G., B. A. Gloy, S. Jospeh, N. R. Scott, and J. Lehmann. 2010. Life cycle assessment of biochar systems: Estimating the energetic, economic, and climate change potential. Environmental Science \& Technology 44(2): 827-833.

Royal Society. 2009. Geoengineering the climate: Science, governance and uncertainty. RS Policy document $10 / 09$.

Sands, R. D. and K. Schumacher. 2009. Economic comparison of greenhouse gas mitigation options in Germany. Energy Efficiency 2(1): 17-36.

Schmidt, M. W. I., M. S. Torn, S. Abiven, T. Dittmar, G. Guggenberger, I. A. Janssens, M. Kleber, I. KögelKnabner, J. Lehmann, D. A. C. Manning, P. Nannipieri, D. P. Rasse, S. Weiner, and S. E. Trumbore. 2011. Persistence of soil organic matter as an ecosystem property. Nature 478: 49-56.

Schröder, A., F. Kunz, J. Meiss, R. Mendelevitch, and C. von Hirschhausen. 2013. Current and prospective costs of electricity generation until 2050. Data Documentation 68. DIW Berlin.

Schumacher, K. and R. D. Sands. 2006. Innovative energy technologies and climate policy in Germany. Energy Policy 34(18): 3929-3941.

Shackley, S., J. Hammond, J. Gaunt, and R. Ibarrola. 2011. The feasibility and costs of biochar deployment in the UK. Carbon Management 2(3): 335-356.

Slade, R., R. Saunders, R. Gross, and A. Bauen. 2011. Energy from biomass: The size of the global resource. Imperial College Centre for Energy Policy and Technology and UK Energy Research Centre, London.

Smith, P., D. Martino, Z. Cai, D. Gwary, H. Janzen, P. Kumar, B. McCarl, S. Ogle, F. O’Mara, C. Rice, B. Scholes, O. Sirotenko, M. Howden, T. McAllister, G. Pan, V. Romanenkov, U. Schneider, S. Towprayoon, M. Wattenbach, and J. Smith. 2008. Greenhouse gas mitigation in agriculture. Philosophical Transactions of the Royal Society B 363(1492): 789-813.

Sohi, S. P. 2012. Carbon storage with benefits. Science 338: 1034-1035.

Statistisches Bundesamt. 2015a. Producer prices of agricultural products: Yearly averages. Online available at: https://www.destatis.de/DE/ZahlenFakten/GesamtwirtschaftUmwelt/Preise/PreisindizesLandForstwirtsch 
aft/Tabellen/ErzeugerpreiseLandwirtschaft.html?cms_gtp=146548_slot\%253D2\&https=1 (accessed on 4 February 2015).

Statistisches Bundesamt. 2015b. Producer prices of logging products: Yearly averages. Online available at: https://www.destatis.de/DE/ZahlenFakten/GesamtwirtschaftUmwelt/Preise/PreisindizesLandForstwirtsch aft/Tabellen/ErzeugerpreiseForstwirtschaft.html?cms_gtp=146560_slot\%253D2\&https=1 (accessed on 30 January 2015).

Teichmann, I. 2014a. Technical greenhouse-gas mitigation potentials of biochar soil incorporation in Germany. DIW Discussion Paper 1406.

Teichmann, I. 2014b Technical greenhouse-gas mitigation potentials of biochar soil incorporation in Germany: Data documentation. Data Documentation 73. DIW Berlin.

Teichmann, I. 2015. An economic assessment of soil carbon sequestration with biochar in Germany: Data documentation. Data Documentation 78. DIW Berlin.

UBA (ed). 2014. Best-Practice-Kostensätze für Luftschadstoffe, Verkehr, Strom- und Wärmeerzeugung: Anhang B der "Methodenkonvention 2.0 zur Schätzung von Umweltkosten." Umweltbundesamt (UBA). Actualized version February 2014.

UBA. 2013. Submission under the United Nations Framework Convention on Climate Change and the Kyoto Protocol 2013: National inventory report for the German greenhouse gas inventory 1990-2011. Umweltbundesamt (UBA), Dessau-Roßlau: 09/2013.

von Hirschhausen, C., J. Herold, P.-Y. Oei, and C. Haftendorn. 2012. CCTS-Technologie ein Fehlschlag Umdenken in der Energiewende notwendig. DIW Wochenbericht 6/2012: 3-9.

Woolf, D., J. E. Amonette, F. A. Street-Perrott, J. Lehmann and S. Joseph. 2010a. Sustainable biochar to mitigate global climate change. Nature Communications 1: 56.

Woolf, D., J. E. Amonette, F. A. Street-Perrott, J. Lehmann, and S. Joseph. 2010b. Sustainable biochar to mitigate global climate change: Supplementary information. Online available at: http://www.nature.com/ncomms/journal/v1/n5/abs/ncomms1053.html (accessed on 12 April 2014). 


\section{Appendix}

Table 1: Feedstock Description and Baseline Scenario for Feedstock Management

\begin{tabular}{|c|c|c|c|}
\hline Feedstocks & Feedstock description ${ }^{a}$ & $\begin{array}{l}\text { Conventional feedstock } \\
\text { management }^{\text {b }}\end{array}$ & $\begin{array}{l}\text { Comments concerning conventional } \\
\text { feedstock management }\end{array}$ \\
\hline Cereal straw & $\begin{array}{l}\text { Straw from wheat, rye and other } \\
\text { cereals }\end{array}$ & Decomposition in field & $\begin{array}{l}\text { If not used otherwise, straw usually remains } \\
\text { in the field (Kaltschmitt et al. 2009) and is } \\
\text { incorporated into the soil. }\end{array}$ \\
\hline Forestry residues & $\begin{array}{l}\text { Forestry residues (i.e. logging } \\
\text { residues and smallwood from oak, } \\
\text { beech, spruce and pine) and } \\
\text { additional forestry residues from } \\
\text { historical-forest formation }\end{array}$ & Decomposition in forest & $\begin{array}{l}\text { If not used otherwise, forestry residues } \\
\text { usually remain in the forest (Kaltschmitt et al. } \\
2009 \text { ). }\end{array}$ \\
\hline $\begin{array}{l}\text { Open-country biomass } \\
\text { residues }\end{array}$ & $\begin{array}{l}\text { Woody biomass and green waste } \\
\text { from trimming of shrubberies and } \\
\text { reeds }\end{array}$ & Composting, land spread & $\begin{array}{l}\text { According to Nitsch et al. (2004), biomass } \\
\text { obtained from open-country conservation } \\
\text { measures should not remain on site. }\end{array}$ \\
\hline Industrial wood waste & $\begin{array}{l}\text { Wood waste from sawmills, the } \\
\text { wood material industry and the } \\
\text { forest and furniture industry }\end{array}$ & Energetic use & $\begin{array}{l}\text { If not considered for material use, industrial } \\
\text { wood waste is usually used energetically } \\
\text { (Fritsche et al. 2004). We assume stationary } \\
\text { combustion. }\end{array}$ \\
\hline $\begin{array}{l}\text { Wood in municipal } \\
\text { solid waste }\end{array}$ & $\begin{array}{l}\text { Woody components of municipal } \\
\text { garden and park waste }\end{array}$ & Composting, land spread & $\begin{array}{l}\text { Wood in municipal solid waste is usually } \\
\text { composted (Fritsche et al. 2004; Kaltschmitt } \\
\text { et al. 2009). }\end{array}$ \\
\hline $\begin{array}{l}\text { Green waste: } \\
\text { Compensation areas }\end{array}$ & Herbaceous biomass & Decomposition on site & $\begin{array}{l}\text { It is assumed that compensation areas are } \\
\text { under less strict nature-conservation } \\
\text { restrictions than habitat-connectivity areas. } \\
\text { Therefore, it is assumed that green waste can } \\
\text { remain on site after cutting (cp. Fritsche et al. } \\
\text { 2004; Kaltschmitt et al. 2009). }\end{array}$ \\
\hline $\begin{array}{l}\text { Biomass: Habitat- } \\
\text { connectivity areas }\end{array}$ & Woody and herbaceous biomass & Composting, land spread & $\begin{array}{l}\text { Biomass from nature-conservation areas often } \\
\text { has to be removed from site (Fritsche et al. } \\
\text { 2004; Kaltschmitt et al. 2009). }\end{array}$ \\
\hline $\begin{array}{l}\text { Green waste: Extensive } \\
\text { grassland }\end{array}$ & Woody and herbaceous biomass & Composting, land spread & $\begin{array}{l}\text { Most of the extensive grassland covers } \\
\text { habitat-connectivity areas (Nitsch et al. 2004; } \\
\text { Table A.1); green waste from nature- } \\
\text { conservation areas often has to be removed } \\
\text { from site (Fritsche et al. 2004; Kaltschmitt et } \\
\text { al. 2009). }\end{array}$ \\
\hline $\begin{array}{l}\text { Short-rotation coppice: } \\
\text { Erosion areas }\end{array}$ & Poplar and willow & Energetic use & $\begin{array}{l}\text { It is assumed that energy crops are primarily } \\
\text { grown for energetic use. We assume } \\
\text { stationary combustion. }\end{array}$ \\
\hline Solid cattle manure & Solid cattle manure & Solid storage, land spread & \multirow{3}{*}{$\begin{array}{l}\text { Solid manure is usually directly spread on } \\
\text { land (Fritsche et al. 2004; Kaltschmitt et al. } \\
\text { 2009). Before land spreading, it is stored in } \\
\text { straw-based systems (UBA 2013). }\end{array}$} \\
\hline Solid swine manure & Solid swine manure & Solid storage, land spread & \\
\hline Solid poultry manure & Solid poultry manure & Solid storage, land spread & \\
\hline $\begin{array}{l}\text { Commercial and } \\
\text { industrial waste }\end{array}$ & $\begin{array}{l}\text { Waste from beer production, fruit } \\
\text { and wine press houses, distilleries, } \\
\text { the dairy-processing industry and } \\
\text { sugar manufacture }\end{array}$ & Composting, land spread & $\begin{array}{l}\text { According to Fritsche et al. (2004), ways of } \\
\text { disposal for this waste category are not } \\
\text { sufficiently known. Since most of this waste } \\
\text { can usually be used as fertilizer (Fritsche et al. } \\
\text { 2004; Kaltschmitt et al. 2009), composting is } \\
\text { assumed. }\end{array}$ \\
\hline $\begin{array}{l}\text { Organic municipal solid } \\
\text { waste }\end{array}$ & $\begin{array}{l}\text { Biowaste from the organic-waste } \\
\text { collection bin, kitchen and garden } \\
\text { waste, non-woody components of } \\
\text { municipal garden and park waste }\end{array}$ & Composting, land spread & $\begin{array}{l}\text { If not used otherwise, organic municipal solid } \\
\text { waste is usually composted (Fritsche et al. } \\
\text { 2004; Kaltschmitt et al. 2009). }\end{array}$ \\
\hline
\end{tabular}

Sources:

a) For more detailed feedstock descriptions of the solid biomass residues, see Teichmann (2014b: Table A.1); for those of the digestable biomass residues, see Teichmann (2014b: Table A.2).

b) Own assumptions based on Fritsche et al. (2004), Nitsch et al. (2004), Kaltschmitt et al. (2009) and UBA (2013). 
Table 2: GHG Mitigation Potentials, 2015, Scenarios Max 1, Min 1*

\begin{tabular}{|c|c|c|c|c|c|c|c|c|c|c|c|c|c|c|c|c|c|c|}
\hline \multirow[b]{5}{*}{ Feedstocks } & \multicolumn{6}{|c|}{ Small-scale pyrolysis units } & \multicolumn{6}{|c|}{ Medium-scale pyrolysis units } & \multicolumn{6}{|c|}{ Large-scale pyrolysis units } \\
\hline & \multicolumn{3}{|c|}{ No process heat recovery } & \multicolumn{3}{|c|}{ Process heat recovery } & \multicolumn{3}{|c|}{ No process heat recovery } & \multicolumn{3}{|c|}{ Process heat recovery } & \multicolumn{3}{|c|}{ No process heat recovery } & \multicolumn{3}{|c|}{ Process heat recovery } \\
\hline & Lignite & $\begin{array}{c}\text { Hard } \\
\text { coal }\end{array}$ & $\begin{array}{l}\text { Natu- } \\
\text { ral gas }\end{array}$ & Lignite & $\begin{array}{c}\text { Hard } \\
\text { coal }\end{array}$ & $\begin{array}{l}\text { Natu- } \\
\text { ral gas }\end{array}$ & Lignite & $\begin{array}{c}\text { Hard } \\
\text { coal }\end{array}$ & $\begin{array}{l}\text { Natu- } \\
\text { ral gas }\end{array}$ & Lignite & $\begin{array}{c}\text { Hard } \\
\text { coal }\end{array}$ & $\begin{array}{l}\text { Natu- } \\
\text { ral gas }\end{array}$ & Lignite & $\begin{array}{c}\text { Hard } \\
\text { coal }\end{array}$ & $\begin{array}{l}\text { Natu- } \\
\text { ral gas }\end{array}$ & Lignite & \begin{tabular}{c|} 
Hard \\
coal
\end{tabular} & $\begin{array}{l}\text { Natu- } \\
\text { ral gas }\end{array}$ \\
\hline & \multicolumn{6}{|c|}{ kt CO $2 \mathrm{e} / \mathrm{a}$} & \multicolumn{6}{|c|}{$\mathrm{kt} \mathrm{CO}{ }_{2} \mathrm{e} / \mathrm{a}$} & \multicolumn{6}{|c|}{$\mathrm{kt} \mathrm{CO} 2 \mathrm{e} / \mathrm{a}$} \\
\hline & (1) & (2) & (3) & (4) & (5) & (6) & (7) & (8) & (9) & (10) & (11) & (12) & (13) & (14) & (15) & (16) & (17) & (18) \\
\hline Cereal straw & 400 & 365 & 295 & 456 & 412 & 325 & 400 & 364 & 295 & 456 & 411 & 325 & 398 & 363 & 294 & 455 & 410 & 324 \\
\hline Forestry residues & 1,206 & 1,093 & 872 & 1,368 & 1,229 & 958 & 1,205 & 1,092 & 871 & 1,367 & 1,228 & 957 & 1,202 & 1,089 & 868 & 1,364 & 1,225 & 954 \\
\hline Open-country biomass residues & 238 & 224 & 195 & 262 & 244 & 208 & 238 & 224 & 195 & 262 & 243 & 208 & 238 & 223 & 195 & 261 & 243 & 207 \\
\hline Industrial wood waste & - & - & 35 & - & - & 66 & - & - & 34 & - & - & 66 & - & - & 33 & - & - & 65 \\
\hline Wood in municipal solid waste & 265 & 248 & 214 & 290 & 269 & 227 & 265 & 248 & 214 & 290 & 269 & 227 & 265 & 247 & 214 & 290 & 268 & 227 \\
\hline Green waste: Compensation areas & 0 & 0 & 0 & 0 & 0 & 0 & 0 & 0 & 0 & 0 & 0 & 0 & 0 & 0 & 0 & 0 & 0 & 0 \\
\hline Biomass: Habitat-connectivity areas & 0 & 0 & 0 & 0 & 0 & 0 & 0 & 0 & 0 & 0 & 0 & 0 & 0 & 0 & 0 & 0 & 0 & 0 \\
\hline Green waste: Extensive grassland & 0 & 0 & 0 & 0 & 0 & 0 & 0 & 0 & 0 & 0 & 0 & 0 & 0 & 0 & 0 & 0 & 0 & 0 \\
\hline Short-rotation coppice: Erosion areas & - & - & - & - & - & 0 & - & - & - & - & - & 0 & - & - & - & - & - & 0 \\
\hline Solid biomass residues & 2,110 & 1,930 & 1,611 & 2,377 & 2,153 & 1,785 & 2,108 & 1,928 & 1,609 & 2,375 & 2,151 & 1,783 & 2,103 & 1,923 & 1,603 & 2,370 & 2,146 & 1,777 \\
\hline Solid cattle manure & 224 & 245 & 278 & 307 & 315 & 323 & 223 & 244 & 277 & 306 & 314 & 322 & 218 & 240 & 273 & 302 & 309 & 318 \\
\hline Solid swine manure & 76 & 99 & 138 & 99 & 118 & 150 & 76 & 98 & 138 & 99 & 117 & 150 & 74 & 96 & 136 & 97 & 115 & 148 \\
\hline Solid poultry manure & 73 & 68 & 56 & 85 & 77 & 62 & 73 & 68 & 56 & 85 & 77 & 62 & 73 & 67 & 56 & 85 & 77 & 62 \\
\hline Commercial and industrial waste & 63 & 63 & 62 & 74 & 72 & 68 & 62 & 63 & 62 & 74 & 72 & 68 & 62 & 62 & 61 & 73 & 71 & 67 \\
\hline Organic municipal solid waste & 19 & 44 & 87 & 52 & 71 & 104 & 19 & 43 & 86 & 51 & 70 & 103 & 17 & 41 & 84 & 49 & 68 & 101 \\
\hline Digestable biomass residues & 455 & 518 & 622 & 617 & 653 & 708 & 453 & 515 & 619 & 614 & 650 & 705 & 444 & 507 & 611 & 605 & 641 & 696 \\
\hline TOTAL & 2,565 & 2,448 & 2,233 & 2,993 & 2,805 & 2,493 & 2,561 & 2,444 & 2,229 & 2,989 & 2,802 & 2,489 & 2,547 & 2,429 & 2,213 & 2,975 & 2,787 & 2,473 \\
\hline
\end{tabular}

Sources: Teichmann (2014a: Table 46).

Notes: $\mathrm{a}=$ year. $\mathrm{kt}=$ kiloton. - = not applicable. No GHG mitigation potentials were calculated for cases of negative total net avoided GHG emissions per tonne of dry-matter feedstock.

* In 2015, the Max 1 and Min 1 scenarios coincide (Teichmann 2014a). 
Table 3: GHG Mitigation Potentials, 2015, Scenarios $\operatorname{Max} 2$, Min 2*

\begin{tabular}{|c|c|c|c|c|c|c|c|c|c|c|c|c|c|c|c|c|c|c|}
\hline \multirow[b]{5}{*}{ Feedstocks } & \multicolumn{6}{|c|}{ Small-scale pyrolysis units } & \multicolumn{6}{|c|}{ Medium-scale pyrolysis units } & \multicolumn{6}{|c|}{ Large-scale pyrolysis units } \\
\hline & \multicolumn{3}{|c|}{ No process heat recovery } & \multicolumn{3}{|c|}{ Process heat recovery } & \multicolumn{3}{|c|}{ No process heat recovery } & \multicolumn{3}{|c|}{ Process heat recovery } & \multicolumn{3}{|c|}{ No process heat recovery } & \multicolumn{3}{|c|}{ Process heat recovery } \\
\hline & Lignite & $\begin{array}{c}\text { Hard } \\
\text { coal }\end{array}$ & $\begin{array}{l}\text { Natu- } \\
\text { ral gas }\end{array}$ & Lignite & $\begin{array}{c}\text { Hard } \\
\text { coal }\end{array}$ & $\begin{array}{l}\text { Natu- } \\
\text { ral gas }\end{array}$ & Lignite & $\begin{array}{c}\text { Hard } \\
\text { coal }\end{array}$ & $\begin{array}{l}\text { Natu- } \\
\text { ral gas }\end{array}$ & Lignite & $\begin{array}{c}\text { Hard } \\
\text { coal }\end{array}$ & $\begin{array}{l}\text { Natu- } \\
\text { ral gas }\end{array}$ & Lignite & $\begin{array}{c}\text { Hard } \\
\text { coal }\end{array}$ & $\begin{array}{l}\text { Natu- } \\
\text { ral gas }\end{array}$ & Lignite & $\begin{array}{c}\text { Hard } \\
\text { coal }\end{array}$ & $\begin{array}{l}\text { Natu- } \\
\text { ral gas }\end{array}$ \\
\hline & \multicolumn{6}{|c|}{$\mathrm{kt} \mathrm{CO}_{2} \mathrm{e} / \mathrm{a}$} & \multicolumn{6}{|c|}{$\mathrm{kt} \mathrm{CO}_{2} \mathrm{e} / \mathrm{a}$} & \multicolumn{6}{|c|}{$\mathrm{kt} \mathrm{CO} \mathrm{CO}_{2} / \mathrm{a}$} \\
\hline & (1) & (2) & (3) & $(4)$ & (5) & (6) & (7) & (8) & (9) & \begin{tabular}{|l|}
$(10)$ \\
\end{tabular} & (11) & (12) & (13) & (14) & (15) & (16) & (17) & (18) \\
\hline Cereal straw & 533 & 486 & 394 & 608 & 549 & 434 & 533 & 486 & 393 & 608 & 548 & 433 & 531 & 484 & 391 & 606 & 547 & 431 \\
\hline Forestry residues & 1,608 & 1,458 & 1,162 & 1,824 & 1,638 & 1,278 & 1,607 & 1,456 & 1,161 & 1,823 & 1,637 & 1,276 & 1,602 & 1,452 & 1,156 & 1,818 & 1,632 & 1,272 \\
\hline Open-country biomass residues & 318 & 298 & 260 & 349 & 325 & 277 & 318 & 298 & 260 & 349 & 325 & 277 & 317 & 297 & 259 & 349 & 324 & 276 \\
\hline Industrial wood waste & - & - & 46 & - & - & 89 & - & - & 46 & - & - & 88 & - & - & 44 & - & - & 86 \\
\hline Wood in municipal solid waste & 354 & 331 & 286 & 387 & 358 & 303 & 354 & 331 & 285 & 387 & 358 & 303 & 353 & 330 & 285 & 386 & 358 & 302 \\
\hline Green waste: Compensation areas & 0 & 0 & 0 & 0 & 0 & 0 & 0 & 0 & 0 & 0 & 0 & 0 & 0 & 0 & 0 & 0 & 0 & 0 \\
\hline Biomass: Habitat-connectivity areas & 0 & 0 & 0 & 0 & 0 & 0 & 0 & 0 & 0 & 0 & 0 & 0 & 0 & 0 & 0 & 0 & 0 & 0 \\
\hline Green waste: Extensive grassland & 0 & 0 & 0 & 0 & 0 & 0 & 0 & 0 & 0 & 0 & 0 & 0 & 0 & 0 & 0 & 0 & 0 & 0 \\
\hline Short-rotation coppice: Erosion areas & - & - & & - & - & 0 & - & - & - & - & - & 0 & - & - & - & - & - & 0 \\
\hline Solid biomass residues $=$ TOTAL & 2,813 & 2,573 & 2,148 & 3,169 & 2,870 & 2,380 & 2,811 & 2,571 & 2,146 & 3,167 & 2,868 & 2,377 & 2,803 & 2,563 & 2,136 & 3,159 & 2,861 & 2,368 \\
\hline
\end{tabular}

Sources: Teichmann (2014a: Table 47).

Notes: $\mathrm{a}=$ year. $\mathrm{kt}=$ kiloton. - = not applicable. No GHG mitigation potentials were calculated for cases of negative total net avoided GHG emissions per tonne of dry-matter feedstock.

* In 2015, the Max 2 and Min 2 scenarios coincide (Teichmann 2014a). 
Table 4: GHG Mitigation Potentials, 2030, Scenario Max 1

\begin{tabular}{|c|c|c|c|c|c|c|c|c|c|c|c|c|c|c|c|c|c|c|}
\hline \multirow[b]{5}{*}{ Feedstocks } & \multicolumn{6}{|c|}{ Small-scale pyrolysis units } & \multicolumn{6}{|c|}{ Medium-scale pyrolysis units } & \multicolumn{6}{|c|}{ Large-scale pyrolysis units } \\
\hline & \multicolumn{3}{|c|}{ No process heat recovery } & \multicolumn{3}{|c|}{ Process heat recovery } & \multicolumn{3}{|c|}{ No process heat recovery } & \multicolumn{3}{|c|}{ Process heat recovery } & \multicolumn{3}{|c|}{ No process heat recovery } & \multicolumn{3}{|c|}{ Process heat recovery } \\
\hline & Lignite & $\begin{array}{c}\text { Hard } \\
\text { coal }\end{array}$ & $\begin{array}{l}\text { Natu- } \\
\text { ral gas }\end{array}$ & Lignite & $\begin{array}{c}\text { Hard } \\
\text { coal }\end{array}$ & $\begin{array}{l}\text { Natu- } \\
\text { ral gas }\end{array}$ & Lignite & $\begin{array}{c}\text { Hard } \\
\text { coal }\end{array}$ & $\begin{array}{l}\text { Natu- } \\
\text { ral gas }\end{array}$ & Lignite & $\begin{array}{c}\text { Hard } \\
\text { coal }\end{array}$ & $\begin{array}{l}\text { Natu- } \\
\text { ral gas }\end{array}$ & Lignite & $\begin{array}{c}\text { Hard } \\
\text { coal }\end{array}$ & $\begin{array}{l}\text { Natu- } \\
\text { ral gas }\end{array}$ & Lignite & \begin{tabular}{c|}
$\begin{array}{c}\text { Hard } \\
\text { coal }\end{array}$ \\
\end{tabular} & $\begin{array}{l}\text { Natu- } \\
\text { ral gas }\end{array}$ \\
\hline & \multicolumn{6}{|c|}{$\mathrm{kt} \mathrm{CO}_{2} \mathrm{e} / \mathrm{a}$} & \multicolumn{6}{|c|}{ kt CO $\mathrm{CO}_{2} \mathrm{e} / \mathrm{a}$} & \multicolumn{6}{|c|}{ kt CO $2 \mathrm{e} / \mathrm{a}$} \\
\hline & (1) & (2) & (3) & (4) & (5) & (6) & (7) & (8) & (9) & $(10)$ & (11) & $(12)$ & (13) & (14) & (15) & (16) & (17) & (18) \\
\hline Cereal straw & 1,044 & 952 & 771 & 1,191 & 1,075 & 849 & 1,044 & 952 & 771 & 1,191 & 1,075 & 849 & 1,043 & 950 & 769 & 1,190 & 1,073 & 848 \\
\hline Forestry residues & 3,630 & 3,290 & 2,624 & 4,117 & 3,698 & 2,884 & 3,629 & 3,289 & 2,623 & 4,116 & 3,697 & 2,883 & 3,625 & 3,285 & 2,619 & 4,112 & 3,693 & 2,879 \\
\hline Open-country biomass residues & 636 & 597 & 520 & 699 & 650 & 554 & 635 & 597 & 520 & 699 & 650 & 554 & 635 & 596 & 520 & 698 & 649 & 553 \\
\hline Industrial wood waste & - & - & 93 & - & - & 177 & - & - & 93 & - & - & 177 & - & - & 91 & - & - & 176 \\
\hline Wood in municipal solid waste & 670 & 626 & 541 & 732 & 679 & 574 & 670 & 626 & 541 & 732 & 678 & 574 & 669 & 626 & 540 & 732 & 678 & 573 \\
\hline Green waste: Compensation areas & 176 & 161 & 130 & 205 & 184 & 145 & 176 & 161 & 130 & 205 & 184 & 145 & 176 & 160 & 129 & 204 & 184 & 144 \\
\hline Biomass: Habitat-connectivity areas & 553 & 519 & 453 & 608 & 565 & 482 & 553 & 519 & 453 & 608 & 565 & 482 & 553 & 519 & 452 & 608 & 565 & 482 \\
\hline Green waste: Extensive grassland & 820 & 770 & 671 & 901 & 838 & 714 & 819 & 769 & 671 & 901 & 838 & 714 & 819 & 769 & 670 & 900 & 837 & 714 \\
\hline Short-rotation coppice: Erosion areas & - & - & - & - & - & 22 & - & - & - & - & - & 21 & - & - & - & - & - & 19 \\
\hline Solid biomass residues & 7,529 & 6,915 & 5,803 & 8,454 & 7,689 & 6,402 & $\mathbf{7 , 5 2 7}$ & 6,913 & 5,800 & 8,452 & 7,686 & 6,399 & 7,519 & 6,905 & 5,791 & 8,444 & 7,678 & 6,387 \\
\hline Solid cattle manure & 594 & 651 & 740 & 816 & 836 & 858 & 593 & 650 & 738 & 815 & 835 & 857 & 588 & 645 & 734 & 810 & 830 & 852 \\
\hline Solid swine manure & 197 & 255 & 356 & 255 & 304 & 387 & 196 & 254 & 356 & 255 & 303 & 387 & 194 & 252 & 354 & 253 & 301 & 385 \\
\hline Solid poultry manure & 232 & 214 & 178 & 269 & 245 & 198 & 232 & 214 & 178 & 269 & 245 & 198 & 232 & 214 & 178 & 269 & 245 & 198 \\
\hline Commercial and industrial waste & 167 & 167 & 166 & 196 & 192 & 181 & 167 & 167 & 165 & 196 & 192 & 181 & 166 & 167 & 165 & 196 & 191 & 181 \\
\hline Organic municipal solid waste & 63 & 140 & 277 & 166 & 226 & 332 & 62 & 139 & 277 & 165 & 226 & 332 & 59 & 137 & 274 & 162 & 223 & 329 \\
\hline Digestable biomass residues & 1,253 & 1,427 & 1,717 & 1,703 & 1,803 & 1,957 & 1,250 & 1,424 & 1,715 & $\mathbf{1 , 7 0 0}$ & 1,800 & 1,954 & 1,240 & 1,414 & 1,704 & 1,690 & 1,790 & 1,944 \\
\hline TOTAL & 8,782 & 8,342 & 7,520 & 10,157 & 9,492 & 8,359 & 8,777 & 8,337 & 7,515 & 10,152 & 9,487 & 8,353 & 8,759 & 8,319 & 7,495 & 10,134 & 9,468 & $\overline{8,331}$ \\
\hline
\end{tabular}

Sources: Teichmann (2014a: Table 48).

Notes: a = year. $\mathrm{kt}=$ kiloton. - = not applicable. No GHG mitigation potentials were calculated for cases of negative total net avoided GHG emissions per tonne of dry-matter feedstock. 
Table 5: GHG Mitigation Potentials, 2030, Scenario Min 1

\begin{tabular}{|c|c|c|c|c|c|c|c|c|c|c|c|c|c|c|c|c|c|c|}
\hline \multirow[b]{5}{*}{ Feedstocks } & \multicolumn{6}{|c|}{ Small-scale pyrolysis units } & \multicolumn{6}{|c|}{ Medium-scale pyrolysis units } & \multicolumn{6}{|c|}{ Large-scale pyrolysis units } \\
\hline & \multicolumn{3}{|c|}{ No process heat recovery } & \multicolumn{3}{|c|}{ Process heat recovery } & \multicolumn{3}{|c|}{ No process heat recovery } & \multicolumn{3}{|c|}{ Process heat recovery } & \multicolumn{3}{|c|}{ No process heat recovery } & \multicolumn{3}{|c|}{ Process heat recovery } \\
\hline & Lignite & $\begin{array}{c}\text { Hard } \\
\text { coal }\end{array}$ & $\begin{array}{l}\text { Natu- } \\
\text { ral gas }\end{array}$ & Lignite & $\begin{array}{c}\text { Hard } \\
\text { coal } \\
\end{array}$ & $\begin{array}{l}\text { Natu- } \\
\text { ral gas }\end{array}$ & Lignite & $\begin{array}{c}\text { Hard } \\
\text { coal }\end{array}$ & $\begin{array}{l}\text { Natu- } \\
\text { ral gas }\end{array}$ & Lignite & $\begin{array}{c}\text { Hard } \\
\text { coal } \\
\end{array}$ & $\begin{array}{l}\text { Natu- } \\
\text { ral gas }\end{array}$ & Lignite & $\begin{array}{c}\text { Hard } \\
\text { coal }\end{array}$ & $\begin{array}{l}\text { Natu- } \\
\text { ral gas }\end{array}$ & Lignite & \begin{tabular}{c|} 
Hard \\
coal
\end{tabular} & $\begin{array}{l}\text { Natu- } \\
\text { ral gas }\end{array}$ \\
\hline & \multicolumn{6}{|c|}{ kt $\mathrm{CO}_{2} \mathrm{e} / \mathrm{a}$} & \multicolumn{6}{|c|}{$\mathrm{kt} \mathrm{CO} \mathrm{CO}_{2} \mathrm{e} / \mathrm{a}$} & \multicolumn{6}{|c|}{$\mathrm{kt} \mathrm{CO} \mathrm{CO}_{2} / \mathrm{a}$} \\
\hline & (1) & (2) & (3) & (4) & (5) & (6) & (7) & (8) & (9) & (10) & (11) & (12) & (13) & (14) & (15) & (16) & (17) & (18) \\
\hline Cereal straw & 392 & 357 & 289 & 447 & 403 & 318 & 391 & 357 & 289 & 446 & 403 & 318 & 391 & 356 & 288 & 446 & 402 & 317 \\
\hline Forestry residues & 1,361 & 1,234 & 984 & 1,544 & 1,387 & 1,081 & 1,360 & 1,233 & 983 & 1,543 & 1,386 & 1,081 & 1,358 & 1,231 & 981 & 1,541 & 1,383 & 1,078 \\
\hline Open-country biomass residues & 238 & 224 & 195 & 262 & 244 & 208 & 238 & 224 & 195 & 262 & 244 & 208 & 238 & 223 & 195 & 262 & 243 & 207 \\
\hline Industrial wood waste & - & - & 35 & - & - & 66 & - & - & 35 & - & - & 66 & - & - & 34 & - & - & 65 \\
\hline Wood in municipal solid waste & 251 & 235 & 203 & 275 & 254 & 215 & 251 & 235 & 203 & 275 & 254 & 215 & 251 & 234 & 202 & 274 & 254 & 215 \\
\hline Green waste: Compensation areas & 66 & 60 & 49 & 77 & 69 & 54 & 66 & 60 & 49 & 77 & 69 & 54 & 66 & 60 & 48 & 77 & 69 & 54 \\
\hline Biomass: Habitat-connectivity areas & 207 & 195 & 170 & 228 & 212 & 181 & 207 & 195 & 170 & 228 & 212 & 181 & 207 & 194 & 169 & 228 & 212 & 180 \\
\hline Green waste: Extensive grassland & 307 & 289 & 252 & 338 & 314 & 268 & 307 & 288 & 251 & 338 & 314 & 268 & 307 & 288 & 251 & 337 & 314 & 267 \\
\hline Short-rotation coppice: Erosion areas & - & - & - & - & - & 8 & - & - & - & - & - & 8 & - & - & - & - & - & 6 \\
\hline Solid biomass residues & 2,823 & 2,593 & 2,176 & 3,170 & 2,883 & 2,400 & 2,822 & 2,592 & 2,174 & 3,169 & 2,882 & 2,398 & 2,817 & 2,587 & 2,168 & 3,164 & 2,877 & 2,391 \\
\hline Solid cattle manure & 223 & 244 & 277 & 306 & 313 & 322 & 222 & 243 & 276 & 305 & 313 & 321 & 219 & 240 & 274 & 302 & 310 & 318 \\
\hline Solid swine manure & 74 & 95 & 134 & 96 & 114 & 145 & 73 & 95 & 133 & 95 & 113 & 145 & 72 & 94 & 132 & 94 & 112 & 144 \\
\hline Solid poultry manure & 87 & 80 & 67 & 101 & 92 & 74 & 87 & 80 & 67 & 101 & 92 & 74 & 87 & 80 & 67 & 101 & 92 & 74 \\
\hline Commercial and industrial waste & 63 & 63 & 62 & 74 & 72 & 68 & 62 & 63 & 62 & 74 & 72 & 68 & 62 & 62 & 62 & 73 & 72 & 68 \\
\hline Organic municipal solid waste & 23 & 52 & 104 & 62 & 85 & 125 & 23 & 52 & 103 & 62 & 84 & 124 & 21 & 50 & 102 & 60 & 83 & 122 \\
\hline Digestable biomass residues & 470 & 535 & 644 & 638 & 676 & 734 & 468 & 533 & 642 & 636 & 674 & 732 & 461 & 527 & 636 & 630 & 668 & 725 \\
\hline TOTAL & 3,293 & 3,128 & 2,819 & 3,808 & 3,559 & 3,134 & 3,290 & 3,125 & 2,816 & $\mathbf{3 , 8 0 5}$ & 3,556 & $\mathbf{3 , 1 3 0}$ & 3,278 & 3,113 & 2,804 & 3,794 & 3,544 & 3,117 \\
\hline
\end{tabular}

Sources: Teichmann (2014a: Table 49).

Notes: $\mathrm{a}=$ year. $\mathrm{kt}=$ kiloton. - = not applicable. No GHG mitigation potentials were calculated for cases of negative total net avoided GHG emissions per tonne of dry-matter feedstock. 
Table 6: GHG Mitigation Potentials, 2030, Scenario Max 2

\begin{tabular}{|c|c|c|c|c|c|c|c|c|c|c|c|c|c|c|c|c|c|c|}
\hline \multirow[b]{5}{*}{ Feedstocks } & \multicolumn{6}{|c|}{ Small-scale pyrolysis units } & \multicolumn{6}{|c|}{ Medium-scale pyrolysis units } & \multicolumn{6}{|c|}{ Large-scale pyrolysis units } \\
\hline & \multicolumn{3}{|c|}{ No process heat recovery } & \multicolumn{3}{|c|}{ Process heat recovery } & \multicolumn{3}{|c|}{ No process heat recovery } & \multicolumn{3}{|c|}{ Process heat recovery } & \multicolumn{3}{|c|}{ No process heat recovery } & \multicolumn{3}{|c|}{ Process heat recovery } \\
\hline & Lignite & $\begin{array}{c}\text { Hard } \\
\text { coal }\end{array}$ & $\begin{array}{l}\text { Natu- } \\
\text { ral gas }\end{array}$ & Lignite & $\begin{array}{c}\text { Hard } \\
\text { coal }\end{array}$ & $\begin{array}{l}\text { Natu- } \\
\text { ral gas }\end{array}$ & Lignite & $\begin{array}{c}\text { Hard } \\
\text { coal }\end{array}$ & $\begin{array}{l}\text { Natu- } \\
\text { ral gas }\end{array}$ & Lignite & $\begin{array}{c}\text { Hard } \\
\text { coal }\end{array}$ & $\begin{array}{l}\text { Natu- } \\
\text { ral gas }\end{array}$ & Lignite & $\begin{array}{c}\text { Hard } \\
\text { coal }\end{array}$ & $\begin{array}{l}\text { Natu- } \\
\text { ral gas }\end{array}$ & Lignite & \begin{tabular}{c|} 
Hard \\
coal
\end{tabular} & $\begin{array}{l}\text { Natu- } \\
\text { ral gas }\end{array}$ \\
\hline & \multicolumn{6}{|c|}{$\mathrm{kt} \mathrm{CO} 2 \mathrm{e} / \mathrm{a}$} & \multicolumn{6}{|c|}{$\mathrm{kt} \mathrm{CO} \mathrm{C}_{2} / \mathrm{a}$} & \multicolumn{6}{|c|}{ kt CO $2 \mathrm{e} / \mathrm{a}$} \\
\hline & (1) & (2) & (3) & (4) & (5) & (6) & (7) & (8) & (9) & (10) & (11) & (12) & (13) & (14) & (15) & (16) & (17) & (18) \\
\hline Cereal straw & 1,175 & 1,071 & 867 & 1,340 & 1,209 & 955 & 1,174 & 1,071 & 867 & 1,340 & 1,209 & 955 & 1,173 & 1,069 & 865 & 1,338 & 1,207 & 953 \\
\hline Forestry residues & 4,083 & 3,702 & 2,952 & 4,632 & 4,160 & 3,244 & 4,082 & 3,700 & 2,951 & 4,630 & 4,159 & 3,243 & 4,077 & 3,695 & 2,946 & 4,625 & 4,154 & 3,238 \\
\hline Open-country biomass residues & 715 & 671 & 585 & 786 & 731 & 623 & 715 & 671 & 585 & 786 & 731 & 623 & 714 & 670 & 584 & 785 & 730 & 622 \\
\hline Industrial wood waste & - & - & 104 & - & - & 199 & - & - & 104 & - & - & 199 & - & - & 102 & - & - & 197 \\
\hline Wood in municipal solid waste & 754 & 705 & 608 & 824 & 763 & 646 & 753 & 704 & 608 & 824 & 763 & 646 & 753 & 704 & 607 & 823 & 763 & 645 \\
\hline Green waste: Compensation areas & 199 & 181 & 146 & 230 & 207 & 163 & 198 & 181 & 146 & 230 & 207 & 163 & 198 & 180 & 146 & 230 & 207 & 162 \\
\hline Biomass: Habitat-connectivity areas & 622 & 584 & 509 & 684 & 636 & 542 & 622 & 584 & 509 & 684 & 636 & 542 & 622 & 583 & 509 & 684 & 635 & 542 \\
\hline Green waste: Extensive grassland & 922 & 866 & 755 & 1,014 & 942 & 804 & 922 & 865 & 755 & 1,014 & 942 & 804 & 921 & 865 & 754 & 1,013 & 941 & 803 \\
\hline Short-rotation coppice: Erosion areas & - & - & - & - & - & 25 & - & & - & - & - & 24 & - & - & - & - & - & 21 \\
\hline Solid biomass residues $=$ TOTAL & 8,470 & 7,779 & 6,528 & 9,511 & 8,650 & 7,202 & 8,467 & 7,777 & 6,525 & $\mathbf{9 , 5 0 8}$ & 8,647 & 7,198 & 8,457 & $\mathbf{7 , 7 6 7}$ & 6,513 & 9,498 & 8,637 & 7,184 \\
\hline
\end{tabular}

\section{Sources: Teichmann (2014a: Table 50).}

Notes: $\mathrm{a}=$ year. $\mathrm{kt}=$ kiloton. - = not applicable. No GHG mitigation potentials were calculated for cases of negative total net avoided GHG emissions per tonne of dry-matter feedstock. 
Table 7: GHG Mitigation Potentials, 2030, Scenario Min 2

\begin{tabular}{|c|c|c|c|c|c|c|c|c|c|c|c|c|c|c|c|c|c|c|}
\hline \multirow[b]{5}{*}{ Feedstocks } & \multicolumn{6}{|c|}{ Small-scale pyrolysis units } & \multicolumn{6}{|c|}{ Medium-scale pyrolysis units } & \multicolumn{6}{|c|}{ Large-scale pyrolysis units } \\
\hline & \multicolumn{3}{|c|}{ No process heat recovery } & \multicolumn{3}{|c|}{ Process heat recovery } & \multicolumn{3}{|c|}{ No process heat recovery } & \multicolumn{3}{|c|}{ Process heat recovery } & \multicolumn{3}{|c|}{ No process heat recovery } & \multicolumn{3}{|c|}{ Process heat recovery } \\
\hline & Lignite & $\begin{array}{c}\text { Hard } \\
\text { coal }\end{array}$ & $\begin{array}{l}\text { Natu- } \\
\text { ral gas }\end{array}$ & Lignite & $\begin{array}{c}\text { Hard } \\
\text { coal }\end{array}$ & $\begin{array}{c}\text { Natu- } \\
\text { ral gas }\end{array}$ & Lignite & $\begin{array}{c}\text { Hard } \\
\text { coal }\end{array}$ & $\begin{array}{l}\text { Natu- } \\
\text { ral gas }\end{array}$ & Lignite & $\begin{array}{c}\text { Hard } \\
\text { coal }\end{array}$ & $\begin{array}{l}\text { Natu- } \\
\text { ral gas }\end{array}$ & Lignite & $\begin{array}{c}\text { Hard } \\
\text { coal }\end{array}$ & $\begin{array}{c}\text { Natu- } \\
\text { ral gas }\end{array}$ & Lignite & $\begin{array}{c}\text { Hard } \\
\text { coal }\end{array}$ & $\begin{array}{l}\text { Natu- } \\
\text { ral gas }\end{array}$ \\
\hline & \multicolumn{6}{|c|}{ kt CO $2 \mathrm{e} / \mathrm{a}$} & \multicolumn{6}{|c|}{ kt $\mathrm{CO}_{2} \mathrm{e} / \mathrm{a}$} & \multicolumn{6}{|c|}{ kt CO $2 \mathrm{e} / \mathrm{a}$} \\
\hline & (1) & (2) & (3) & (4) & (5) & (6) & (7) & (8) & (9) & (10) & (11) & (12) & (13) & (14) & (15) & (16) & (17) & (18) \\
\hline Cereal straw & 522 & 476 & 385 & 596 & 537 & 425 & 522 & 476 & 385 & 595 & 537 & 424 & 521 & 475 & 384 & 594 & 536 & 423 \\
\hline Forestry residues & 1,815 & 1,645 & 1,312 & 2,058 & 1,849 & 1,442 & 1,814 & 1,644 & 1,311 & 2,058 & 1,848 & 1,441 & 1,810 & 1,641 & 1,308 & 2,054 & 1,844 & 1,437 \\
\hline Open-country biomass residues & 318 & 298 & 260 & 349 & 325 & 277 & 318 & 298 & 260 & 349 & 325 & 277 & 317 & 298 & 260 & 349 & 324 & 276 \\
\hline Industrial wood waste & - & - & 46 & - & - & 89 & - & - & 46 & - & - & 88 & - & - & 45 & - & - & 87 \\
\hline Wood in municipal solid waste & 335 & 313 & 270 & 366 & 339 & 287 & 335 & 313 & 270 & 366 & 339 & 287 & 334 & 313 & 270 & 366 & 339 & 286 \\
\hline Green waste: Compensation areas & 88 & 80 & 65 & 102 & 92 & 72 & 88 & 80 & 65 & 102 & 92 & 72 & 88 & 80 & 65 & 102 & 92 & 72 \\
\hline Biomass: Habitat-connectivity areas & 277 & 260 & 226 & 304 & 283 & 241 & 276 & 260 & 226 & 304 & 283 & 241 & 276 & 259 & 226 & 304 & 282 & 241 \\
\hline Green waste: Extensive grassland & 410 & 385 & 335 & 451 & 419 & 357 & 410 & 385 & 335 & 450 & 419 & 357 & 409 & 384 & 335 & 450 & 418 & 356 \\
\hline Short-rotation coppice: Erosion areas & - & - & - & - & - & 11 & - & - & - & - & - & 10 & - & - & - & - & - & 8 \\
\hline Solid biomass residues $=$ TOTAL & 3,764 & 3,457 & 2,901 & 4,227 & 3,844 & 3,201 & 3,762 & $\mathbf{3 , 4 5 5}$ & 2,899 & 4,225 & $\mathbf{3 , 8 4 2}$ & 3,198 & 3,756 & 3,449 & 2,891 & 4,218 & $\mathbf{3 , 8 3 6}$ & 3,188 \\
\hline
\end{tabular}

Sources: Teichmann (2014b: Table A.96).

Notes: $\mathrm{a}=$ year. $\mathrm{kt}=$ kiloton. - = not applicable. No GHG mitigation potentials were calculated for cases of negative total net avoided GHG emissions per tonne of dry-matter feedstock. 
Table 8: GHG Mitigation Potentials, 2050, Scenario Max 1

\begin{tabular}{|c|c|c|c|c|c|c|c|c|c|c|c|c|c|c|c|c|c|c|}
\hline \multirow[b]{5}{*}{ Feedstocks } & \multicolumn{6}{|c|}{ Small-scale pyrolysis units } & \multicolumn{6}{|c|}{ Medium-scale pyrolysis units } & \multicolumn{6}{|c|}{ Large-scale pyrolysis units } \\
\hline & \multicolumn{3}{|c|}{ No process heat recovery } & \multicolumn{3}{|c|}{ Process heat recovery } & \multicolumn{3}{|c|}{ No process heat recovery } & \multicolumn{3}{|c|}{ Process heat recovery } & \multicolumn{3}{|c|}{ No process heat recovery } & \multicolumn{3}{|c|}{ Process heat recovery } \\
\hline & Lignite & $\begin{array}{c}\text { Hard } \\
\text { coal }\end{array}$ & $\begin{array}{l}\text { Natu- } \\
\text { ral gas }\end{array}$ & Lignite & $\begin{array}{c}\text { Hard } \\
\text { coal }\end{array}$ & $\begin{array}{l}\text { Natu- } \\
\text { ral gas }\end{array}$ & Lignite & $\begin{array}{c}\text { Hard } \\
\text { coal }\end{array}$ & $\begin{array}{l}\text { Natu- } \\
\text { ral gas }\end{array}$ & Lignite & $\begin{array}{c}\text { Hard } \\
\text { coal }\end{array}$ & $\begin{array}{l}\text { Natu- } \\
\text { ral gas }\end{array}$ & Lignite & $\begin{array}{c}\text { Hard } \\
\text { coal }\end{array}$ & $\begin{array}{c}\text { Natu- } \\
\text { ral gas }\end{array}$ & Lignite & $\begin{array}{c}\text { Hard } \\
\text { coal }\end{array}$ & $\begin{array}{l}\text { Natu- } \\
\text { ral gas }\end{array}$ \\
\hline & \multicolumn{6}{|c|}{$\mathrm{kt} \mathrm{CO} 2 \mathrm{e} / \mathrm{a}$} & \multicolumn{6}{|c|}{ kt CO $2 \mathrm{e} / \mathrm{a}$} & \multicolumn{6}{|c|}{$\mathrm{kt} \mathrm{CO} \mathrm{CO}_{2} / \mathrm{a}$} \\
\hline & (1) & (2) & (3) & (4) & (5) & (6) & (7) & (8) & (9) & $(10)$ & (11) & (12) & (13) & (14) & $(15)$ & $(16)$ & (17) & (18) \\
\hline Cereal straw & 1,083 & 987 & 800 & 1,235 & 1,115 & 881 & 1,083 & 987 & 799 & 1,235 & 1,114 & 880 & 1,082 & 986 & 798 & 1,234 & 1,113 & 879 \\
\hline Forestry residues & 3,922 & 3,555 & 2,835 & 4,448 & 3,995 & 3,116 & 3,921 & 3,554 & 2,834 & 4,447 & 3,994 & 3,115 & 3,917 & 3,550 & 2,830 & 4,443 & 3,990 & 3,111 \\
\hline Open-country biomass residues & 636 & 597 & 520 & 699 & 650 & 554 & 635 & 597 & 520 & 699 & 649 & 554 & 635 & 596 & 520 & 698 & 649 & 553 \\
\hline Industrial wood waste & - & - & 93 & - & - & 177 & - & - & 93 & - & - & 177 & - & - & 91 & - & - & 176 \\
\hline Wood in municipal solid waste & 683 & 639 & 552 & 747 & 692 & 586 & 683 & 639 & 552 & 747 & 692 & 586 & 683 & 638 & 551 & 747 & 692 & 585 \\
\hline Green waste: Compensation areas & 176 & 161 & 130 & 205 & 184 & 145 & 176 & 161 & 130 & 205 & 184 & 145 & 176 & 160 & 129 & 204 & 184 & 144 \\
\hline Biomass: Habitat-connectivity areas & 553 & 519 & 453 & 608 & 565 & 482 & 553 & 519 & 453 & 608 & 565 & 482 & 553 & 519 & 452 & 608 & 565 & 482 \\
\hline Green waste: Extensive grassland & 820 & 769 & 671 & 901 & 838 & 714 & 819 & 769 & 671 & 901 & 838 & 714 & 819 & 769 & 670 & 900 & 837 & 714 \\
\hline Short-rotation coppice: Erosion areas & - & - & - & - & - & 22 & - & - & - & - & - & 22 & - & - & - & - & - & 19 \\
\hline Solid biomass residues & 7,873 & 7,227 & 6,053 & 8,844 & 8,039 & 6,677 & 7,871 & 7,225 & 6,051 & 8,842 & 8,037 & 6,674 & 7,864 & 7,218 & 6,042 & $\mathbf{8 , 8 3 5}$ & 8,030 & 6,663 \\
\hline Solid cattle manure & 605 & 662 & 753 & 831 & 851 & 873 & 604 & 661 & 752 & 829 & 850 & 872 & 600 & 657 & 748 & 825 & 846 & 868 \\
\hline Solid swine manure & 200 & 259 & 362 & 259 & 308 & 394 & 199 & 258 & 361 & 259 & 308 & 393 & 198 & 256 & 360 & 257 & 306 & 391 \\
\hline Solid poultry manure & 232 & 214 & 178 & 269 & 245 & 198 & 232 & 214 & 178 & 269 & 245 & 198 & 232 & 214 & 178 & 269 & 245 & 198 \\
\hline Commercial and industrial waste & 167 & 167 & 166 & 196 & 192 & 181 & 167 & 167 & 165 & 196 & 192 & 181 & 166 & 167 & 165 & 196 & 191 & 181 \\
\hline Organic municipal solid waste & 70 & 158 & 313 & 187 & 255 & 375 & 70 & 157 & 312 & 186 & 255 & 374 & 67 & 155 & 310 & 183 & 252 & 372 \\
\hline Digestable biomass residues & 1,275 & 1,461 & 1,772 & 1,743 & 1,852 & 2,021 & 1,272 & 1,458 & 1,769 & 1,740 & 1,849 & 2,018 & 1,262 & 1,448 & 1,760 & 1,730 & 1,840 & 2,009 \\
\hline TOTAL & 9,147 & 8,688 & $\mathbf{7 , 8 2 5}$ & 10,587 & 9,891 & 8,698 & 9,143 & 8,683 & $\mathbf{7 , 8 2 0}$ & 10,582 & 9,887 & 8,693 & 9,126 & 8,667 & 7,802 & 10,565 & 9,870 & 8,672 \\
\hline
\end{tabular}

Sources: Teichmann (2014b: Table A.97).

Notes: a = year. kt = kiloton. - = not applicable. No GHG mitigation potentials were calculated for cases of negative total net avoided GHG emissions per tonne of dry-matter feedstock. 
Table 9: GHG Mitigation Potentials, 2050, Scenario Min 1

\begin{tabular}{|c|c|c|c|c|c|c|c|c|c|c|c|c|c|c|c|c|c|c|}
\hline \multirow[b]{5}{*}{ Feedstocks } & \multicolumn{6}{|c|}{ Small-scale pyrolysis units } & \multicolumn{6}{|c|}{ Medium-scale pyrolysis units } & \multicolumn{6}{|c|}{ Large-scale pyrolysis units } \\
\hline & \multicolumn{3}{|c|}{ No process heat recovery } & \multicolumn{3}{|c|}{ Process heat recovery } & \multicolumn{3}{|c|}{ No process heat recovery } & \multicolumn{3}{|c|}{ Process heat recovery } & \multicolumn{3}{|c|}{ No process heat recovery } & \multicolumn{3}{|c|}{ Process heat recovery } \\
\hline & Lignite & $\begin{array}{c}\text { Hard } \\
\text { coal }\end{array}$ & $\begin{array}{c}\text { Natu- } \\
\text { ral gas }\end{array}$ & Lignite & $\begin{array}{c}\text { Hard } \\
\text { coal }\end{array}$ & $\begin{array}{l}\text { Natu- } \\
\text { ral gas }\end{array}$ & Lignite & $\begin{array}{c}\text { Hard } \\
\text { coal }\end{array}$ & $\begin{array}{l}\text { Natu- } \\
\text { ral gas }\end{array}$ & Lignite & $\begin{array}{c}\text { Hard } \\
\text { coal }\end{array}$ & $\begin{array}{c}\text { Natu- } \\
\text { ral gas }\end{array}$ & Lignite & $\begin{array}{c}\text { Hard } \\
\text { coal }\end{array}$ & $\begin{array}{c}\text { Natu- } \\
\text { ral gas }\end{array}$ & Lignite & $\begin{array}{c}\text { Hard } \\
\text { coal }\end{array}$ & \begin{tabular}{|c|} 
Natu- \\
ral gas
\end{tabular} \\
\hline & \multicolumn{6}{|c|}{ kt $\mathrm{CO}_{2} \mathrm{e} / \mathrm{a}$} & \multicolumn{6}{|c|}{ kt $\mathrm{CO}_{2} \mathrm{e} / \mathrm{a}$} & \multicolumn{6}{|c|}{ kt $\mathrm{CO}_{2} \mathrm{e} / \mathrm{a}$} \\
\hline & (1) & (2) & (3) & (4) & (5) & (6) & (7) & (8) & (9) & (10) & (11) & (12) & (13) & (14) & (15) & (16) & (17) & (18) \\
\hline Cereal straw & 406 & 370 & 300 & 463 & 418 & 330 & 406 & 370 & 300 & 463 & 418 & 330 & 405 & 369 & 299 & 462 & 417 & 329 \\
\hline Forestry residues & 1,470 & 1,333 & 1,063 & 1,668 & 1,498 & 1,168 & 1,470 & 1,332 & 1,062 & 1,667 & 1,497 & 1,168 & 1,467 & 1,330 & 1,060 & 1,665 & 1,495 & 1,165 \\
\hline Open-country biomass residues & 238 & 224 & 195 & 262 & 244 & 208 & 238 & 224 & 195 & 262 & 244 & 208 & 238 & 223 & 195 & 262 & 243 & 207 \\
\hline Industrial wood waste & - & - & 35 & - & - & 66 & - & - & 35 & - & - & 66 & - & - & 34 & & - & 66 \\
\hline Wood in municipal solid waste & 256 & 240 & 207 & 280 & 260 & 220 & 256 & 240 & 207 & 280 & 260 & 220 & 256 & 239 & 207 & 280 & 259 & 219 \\
\hline Green waste: Compensation areas & 66 & 60 & 49 & 77 & 69 & 54 & 66 & 60 & 49 & 77 & 69 & 54 & 66 & 60 & 48 & 77 & 69 & 54 \\
\hline Biomass: Habitat-connectivity areas & 207 & 195 & 170 & 228 & 212 & 181 & 207 & 195 & 170 & 228 & 212 & 181 & 207 & 194 & 169 & 228 & 212 & 180 \\
\hline Green waste: Extensive grassland & 307 & 289 & 252 & 338 & 314 & 268 & 307 & 288 & 251 & 338 & 314 & 268 & 307 & 288 & 251 & 337 & 314 & 267 \\
\hline Short-rotation coppice: Erosion areas & - & - & & - & - & 8 & - & - & & - & - & 8 & - & - & - & - & - & 7 \\
\hline Solid biomass residues & 2,952 & 2,710 & 2,270 & 3,316 & 3,015 & 2,503 & 2,951 & 2,709 & 2,268 & 3,315 & 3,013 & 2,502 & 2,946 & 2,704 & 2,263 & 3,311 & 3,009 & $\overline{2,495}$ \\
\hline Solid cattle manure & 227 & 248 & 282 & 311 & 319 & 327 & 226 & 248 & 281 & 311 & 318 & 327 & 223 & 245 & 279 & 308 & 316 & 324 \\
\hline Solid swine manure & 75 & 97 & 136 & 97 & 116 & 148 & 75 & 97 & 135 & 97 & 115 & 147 & 74 & 96 & 134 & 96 & 114 & 146 \\
\hline Solid poultry manure & 87 & 80 & 67 & 101 & 92 & 74 & 87 & 80 & 67 & 101 & 92 & 74 & 87 & 80 & 67 & 101 & 92 & 74 \\
\hline Commercial and industrial waste & 63 & 63 & 62 & 74 & 72 & 68 & 63 & 63 & 62 & 74 & 72 & 68 & 62 & 62 & 62 & 73 & 72 & 68 \\
\hline Organic municipal solid waste & 26 & 59 & 117 & 70 & 96 & 141 & 26 & 59 & 117 & 70 & 95 & 140 & 24 & 57 & 115 & 68 & 94 & 138 \\
\hline Digestable biomass residues & 478 & 547 & 664 & 653 & 694 & 758 & 476 & 546 & 662 & 652 & 693 & 756 & 470 & 540 & 657 & 646 & 687 & $\overline{750}$ \\
\hline TOTAL & $3, \mathbf{4 3 0}$ & 3,257 & 2,934 & 3,969 & 3,709 & 3,261 & $3, \mathbf{4 2 7}$ & 3,255 & 2,931 & 3,967 & 3,706 & 3,258 & $3, \mathbf{3 1 7}$ & 3,244 & 2,920 & 3,956 & 3,696 & 3,245 \\
\hline
\end{tabular}

Sources: Teichmann (2014b: Table A.99).

Notes: $\mathrm{a}=$ year. $\mathrm{kt}=$ kiloton. - = not applicable. No GHG mitigation potentials were calculated for cases of negative total net avoided GHG emissions per tonne of dry-matter feedstock. 
Table 10: GHG Mitigation Potentials, 2050, Scenario Max 2

\begin{tabular}{|c|c|c|c|c|c|c|c|c|c|c|c|c|c|c|c|c|c|c|}
\hline \multirow[b]{5}{*}{ Feedstocks } & \multicolumn{6}{|c|}{ Small-scale pyrolysis units } & \multicolumn{6}{|c|}{ Medium-scale pyrolysis units } & \multicolumn{6}{|c|}{ Large-scale pyrolysis units } \\
\hline & \multicolumn{3}{|c|}{ No process heat recovery } & \multicolumn{3}{|c|}{ Process heat recovery } & \multicolumn{3}{|c|}{ No process heat recovery } & \multicolumn{3}{|c|}{ Process heat recovery } & \multicolumn{3}{|c|}{ No process heat recovery } & \multicolumn{3}{|c|}{ Process heat recovery } \\
\hline & Lignite & $\begin{array}{c}\text { Hard } \\
\text { coal }\end{array}$ & $\begin{array}{c}\text { Natu- } \\
\text { ral gas }\end{array}$ & Lignite & $\begin{array}{c}\text { Hard } \\
\text { coal }\end{array}$ & $\begin{array}{l}\text { Natu- } \\
\text { ral gas }\end{array}$ & Lignite & $\begin{array}{c}\text { Hard } \\
\text { coal }\end{array}$ & $\begin{array}{l}\text { Natu- } \\
\text { ral gas }\end{array}$ & Lignite & $\begin{array}{c}\text { Hard } \\
\text { coal }\end{array}$ & $\begin{array}{l}\text { Natu- } \\
\text { ral gas }\end{array}$ & Lignite & $\begin{array}{c}\text { Hard } \\
\text { coal }\end{array}$ & $\begin{array}{l}\text { Natu- } \\
\text { ral gas }\end{array}$ & Lignite & $\begin{array}{c}\text { Hard } \\
\text { coal }\end{array}$ & \begin{tabular}{|l|} 
Natu- \\
ral gas
\end{tabular} \\
\hline & \multicolumn{6}{|c|}{ kt $\mathrm{CO}_{2} \mathrm{e} / \mathrm{a}$} & \multicolumn{6}{|c|}{ kt $\mathrm{CO}_{2} \mathrm{e} / \mathrm{a}$} & \multicolumn{6}{|c|}{ kt $\mathrm{CO}_{2} \mathrm{e} / \mathrm{a}$} \\
\hline & (1) & (2) & (3) & (4) & (5) & (6) & (7) & (8) & (9) & (10) & (11) & (12) & (13) & (14) & $(15)$ & (16) & (17) & (18) \\
\hline Cereal straw & 1,218 & 1,111 & 899 & 1,390 & 1,254 & 991 & 1,218 & 1,110 & 899 & 1,389 & 1,254 & 990 & 1,217 & 1,109 & 898 & 1,388 & 1,252 & 989 \\
\hline Forestry residues & 4,412 & 3,999 & 3,189 & 5,004 & 4,494 & 3,505 & 4,410 & 3,998 & 3,188 & 5,003 & 4,493 & 3,504 & 4,406 & 3,993 & 3,183 & 4,998 & 4,488 & 3,499 \\
\hline Open-country biomass residues & 715 & 671 & 585 & 786 & 731 & 623 & 715 & 671 & 585 & 786 & 731 & 623 & 714 & 671 & 585 & 785 & 730 & 623 \\
\hline Industrial wood waste & - & - & 104 & - & - & 199 & - & - & 104 & - & - & 199 & - & - & 103 & - & - & 198 \\
\hline Wood in municipal solid waste & 769 & 719 & 621 & 841 & 779 & 659 & 769 & 719 & 621 & 841 & 779 & 659 & 768 & 718 & 620 & 840 & 778 & 658 \\
\hline Green waste: Compensation areas & 199 & 181 & 146 & 230 & 207 & 163 & 198 & 181 & 146 & 230 & 207 & 163 & 198 & 180 & 146 & 230 & 207 & 163 \\
\hline Biomass: Habitat-connectivity areas & 622 & 584 & 509 & 684 & 636 & 542 & 622 & 584 & 509 & 684 & 636 & 542 & 622 & 584 & 509 & 684 & 635 & 542 \\
\hline Green waste: Extensive grassland & 922 & 866 & 755 & 1,014 & 942 & 804 & 922 & 865 & 755 & 1,014 & 942 & 804 & 921 & 865 & 754 & 1,013 & 941 & 803 \\
\hline Short-rotation coppice: Erosion areas & - & - & - & - & - & 25 & - & - & - & - & - & 24 & - & - & - & - & - & 21 \\
\hline Solid biomass residues $=$ TOTAL & $\mathbf{8 , 8 5 7}$ & 8,131 & 6,809 & 9,949 & 9,044 & 7,511 & 8,854 & 8,128 & 6,807 & 9,947 & 9,042 & 7,508 & 8,845 & 8,119 & 6,796 & 9,938 & 9,033 & 7,495 \\
\hline
\end{tabular}

Sources: Teichmann (2014b: A.100).

Notes: $\mathrm{a}=$ year. $\mathrm{kt}=$ kiloton. - = not applicable. No GHG mitigation potentials were calculated for cases of negative total net avoided GHG emissions per tonne of dry-matter feedstock. 
Table 11: GHG Mitigation Potentials, 2050, Scenario Min 2

\begin{tabular}{|c|c|c|c|c|c|c|c|c|c|c|c|c|c|c|c|c|c|c|}
\hline \multirow[b]{5}{*}{ Feedstocks } & \multicolumn{6}{|c|}{ Small-scale pyrolysis units } & \multicolumn{6}{|c|}{ Medium-scale pyrolysis units } & \multicolumn{6}{|c|}{ Large-scale pyrolysis units } \\
\hline & \multicolumn{3}{|c|}{ No process heat recovery } & \multicolumn{3}{|c|}{ Process heat recovery } & \multicolumn{3}{|c|}{ No process heat recovery } & \multicolumn{3}{|c|}{ Process heat recovery } & \multicolumn{3}{|c|}{ No process heat recovery } & \multicolumn{3}{|c|}{ Process heat recovery } \\
\hline & Lignite & $\begin{array}{c}\text { Hard } \\
\text { coal }\end{array}$ & $\begin{array}{l}\text { Natu- } \\
\text { ral gas }\end{array}$ & Lignite & $\begin{array}{c}\text { Hard } \\
\text { coal }\end{array}$ & $\begin{array}{l}\text { Natu- } \\
\text { ral gas }\end{array}$ & Lignite & $\begin{array}{c}\text { Hard } \\
\text { coal }\end{array}$ & $\begin{array}{l}\text { Natu- } \\
\text { ral gas }\end{array}$ & Lignite & $\begin{array}{c}\text { Hard } \\
\text { coal }\end{array}$ & $\begin{array}{l}\text { Natu- } \\
\text { ral gas }\end{array}$ & Lignite & $\begin{array}{c}\text { Hard } \\
\text { coal }\end{array}$ & $\begin{array}{l}\text { Natu- } \\
\text { ral gas }\end{array}$ & Lignite & $\begin{array}{c}\text { Hard } \\
\text { coal }\end{array}$ & \begin{tabular}{|l|} 
Natu- \\
ral gas
\end{tabular} \\
\hline & \multicolumn{6}{|c|}{ kt $\mathrm{CO}_{2} \mathrm{e} / \mathrm{a}$} & \multicolumn{6}{|c|}{ kt $\mathrm{CO}_{2} \mathrm{e} / \mathrm{a}$} & \multicolumn{6}{|c|}{ kt $\mathrm{CO}_{2} \mathrm{e} / \mathrm{a}$} \\
\hline & (1) & (2) & (3) & (4) & (5) & (6) & (7) & (8) & (9) & (10) & (11) & (12) & (13) & (14) & (15) & (16) & (17) & (18) \\
\hline Cereal straw & 541 & 494 & 400 & 618 & 557 & 440 & 541 & 493 & 399 & 617 & 557 & 440 & 540 & 492 & 398 & 616 & 556 & 439 \\
\hline Forestry residues & 1,961 & 1,777 & 1,417 & 2,224 & 1,997 & 1,558 & 1,960 & 1,776 & 1,417 & 2,223 & 1,997 & 1,557 & 1,956 & 1,773 & 1,413 & 2,220 & 1,993 & 1,554 \\
\hline Open-country biomass residues & 318 & 298 & 260 & 349 & 325 & 277 & 318 & 298 & 260 & 349 & 325 & 277 & 317 & 298 & 260 & 349 & 324 & 276 \\
\hline Industrial wood waste & - & - & 46 & - & - & 89 & - & - & 46 & - & - & 88 & - & - & 45 & - & - & 87 \\
\hline Wood in municipal solid waste & 342 & 319 & 276 & 374 & 346 & 293 & 342 & 319 & 276 & 374 & 346 & 293 & 341 & 319 & 275 & 373 & 346 & 292 \\
\hline Green waste: Compensation areas & 88 & 80 & 65 & 102 & 92 & 72 & 88 & 80 & 65 & 102 & 92 & 72 & 88 & 80 & 65 & 102 & 92 & 72 \\
\hline Biomass: Habitat-connectivity areas & 277 & 260 & 226 & 304 & 283 & 241 & 276 & 260 & 226 & 304 & 283 & 241 & 276 & 259 & 226 & 304 & 282 & 241 \\
\hline Green waste: Extensive grassland & 410 & 385 & 335 & 451 & 419 & 357 & 410 & 385 & 335 & 450 & 419 & 357 & 409 & 384 & 335 & 450 & 418 & 357 \\
\hline Short-rotation coppice: Erosion areas & - & - & & - & - & 11 & - & - & & - & - & 10 & - & - & - & - & - & 9 \\
\hline Solid biomass residues $=$ TOTAL & 3,936 & 3,613 & 3,026 & 4,422 & 4,019 & $\mathbf{3 , 3 3 8}$ & 3,934 & 3,612 & 3,024 & 4,420 & 4,018 & 3,336 & 3,928 & 3,606 & 3,017 & 4,414 & 4,012 & 3,327 \\
\hline
\end{tabular}

Sources: Teichmann (2014b: Table A.102).

Notes: $\mathrm{a}=$ year. $\mathrm{kt}=$ kiloton. - = not applicable. No GHG mitigation potentials were calculated for cases of negative total net avoided GHG emissions per tonne of dry-matter feedstock. 
Table 12: Net Feedstock Costs

\begin{tabular}{|c|c|c|c|c|c|}
\hline \multirow[t]{3}{*}{ Feedstocks } & \multirow{3}{*}{$\begin{array}{l}\text { Conventional feedstock } \\
\text { management } \\
\text { (see Table 1) }\end{array}$} & \multicolumn{3}{|l|}{$\begin{array}{l}\text { Feedstock costs } \\
\text { (excluding VAT) }\end{array}$} & \multirow{2}{*}{$\begin{array}{c}\text { Net feedstock } \\
\text { costs } \\
€_{2012} / \mathrm{t}_{\mathrm{DM}} \\
\text { feedstock } \\
\end{array}$} \\
\hline & & & $\begin{array}{l}€_{\sim 2} \\
\text { fee }\end{array}$ & $\begin{array}{l}t_{\mathrm{DM}} \\
\mathrm{ock}\end{array}$ & \\
\hline & & (1) & \multicolumn{2}{|c|}{ (2) } & (3) \\
\hline Cereal straw & Decomposition in field & $\begin{array}{l}\text { Harvesting: Baling pressing by } \\
\text { contractor }^{\mathrm{a}} \\
\text { Loading of bales on field: Front } \\
\text { loader }+ \text { agricultural trailer }^{\mathrm{a}}\end{array}$ & \multicolumn{2}{|r|}{$33.1^{\mathrm{b}}$} & \multirow[b]{2}{*}{$129.7^{8}$} \\
\hline Forestry residues & Decomposition in forest & $\begin{array}{l}\text { Spruce chips (free forest road) } \\
\text { Beech chips (free forest road) }\end{array}$ & $\begin{array}{l}95.9^{\mathrm{d}} \\
65.6^{\mathrm{e}}\end{array}$ & $80.7^{f}$ & \\
\hline Open-country biomass residues & Composting, land spread & \multicolumn{3}{|l|}{ ( } & $\mathbf{0}^{\mathrm{h}}$ \\
\hline Industrial wood waste & Energetic use & - & & - & $\mathbf{0}^{\mathrm{h}}$ \\
\hline Wood in municipal solid waste & Composting, land spread & - & & - & $\mathbf{0}^{\mathrm{h}}$ \\
\hline Green waste: Compensation areas & Decomposition on site & - & & $32.6^{\mathrm{i}}$ & $43.5^{c}$ \\
\hline Biomass: Habitat-connectivity areas & Composting, land spread & - & & - & $\mathbf{0}^{\mathrm{h}}$ \\
\hline Green waste: Extensive grassland & Composting, land spread & - & & - & $\mathbf{0}^{\mathrm{h}}$ \\
\hline Short-rotation coppice: Erosion areas & Energetic use & - & & - & $\mathbf{0}^{\mathrm{h}}$ \\
\hline Solid cattle manure & Solid storage, land spread & - & & - & $\mathbf{0}^{\mathrm{h}}$ \\
\hline Solid swine manure & Solid storage, land spread & - & & - & $\mathbf{0}^{\mathrm{h}}$ \\
\hline Solid poultry manure & Solid storage, land spread & - & & - & $\mathbf{0}^{\mathrm{h}}$ \\
\hline Commercial and industrial waste & Composting, land spread & - & & - & $\mathbf{0}^{\mathrm{h}}$ \\
\hline Organic municipal solid waste & Composting, land spread & - & & - & $\mathbf{0}^{\mathrm{h}}$ \\
\hline
\end{tabular}

Sources:

a) FNR (2005).

b) Own calculation, based on $30.5 € / \mathrm{t}_{\mathrm{Fw}}$ from FNR (2005: Table 6-21) and a water content ${ }^{*}$ of cereal straw of $7.9 \%$ as given in Teichmann (2014a: Table 8, column 4), i.e. $33.1=30.5 /(1-0.079)$.

c) Own calculation, based on the producer price index for agricultural products of 89.4 for 2002 and 119.4 for 2012 (Statistisches Bundesamt 2015a).

d) Own calculation, based on the average of 38-133€/ $\mathrm{t}_{\mathrm{FW}}$ (depending on the degree of mechanisation during harvest and the diameter at breast height) as given in FNR (2005: Table 6-33) and a water content ${ }^{*}$ of forestry residues of $10.8 \%$ as given in Teichmann (2014a: Table 8 , column 4), i.e. $95.9=85.5 /(1-0.108)$.

e) Own calculation, based on the average of $26-91 € / t_{\mathrm{FW}}$ (depending on the degree of mechanisation during harvest and the diameter at breast height) as given in FNR (2005: Table 6-33) and a water content ${ }^{*}$ of forestry residues of $10.8 \%$ as given in Teichmann (2014a: Table 8 , column 4), i.e. $65.6=58.5 /(1-0.108)$.

f) Simple average of the values for spruce chips and beech chips, broadly corresponding to the distribution of hardwood and softwood in forestry residues (cp. notes 2 and 3 in Teichmann 2014b: Table A.7).

g) Own calculation, based on the producer price index for logging products (total raw wood) of 74.1 for 2002 and 119.1 for 2012 (Statistisches Bundesamt 2015b).

h) Own assumption.

i) Own assumption, as for cereal straw (i.e. $30.5 € / t_{\mathrm{FW}}$, see note b), however, with a water content ${ }^{*}$ of green waste from compensation areas of $6.3 \%$ as given in Teichmann (2014a: Table 8, column 4). Note that green waste from compensation areas is assumed to be cut in any case, i.e. also under conventional feedstock management (cp. Table 1).

Notes: Values rounded. $\mathrm{DM}=$ dry mass. $\mathrm{FW}=$ fresh weight. $\mathrm{t}=$ tonne. $\mathrm{VAT}=$ value-added tax. $-=$ not applicable.

$*=$ Note that the feedstock water contents are based on as-received fresh weight. 
Table 13: Average Annual Capital Costs for Pyrolysis Units in Germany, Weighted by the Composition of Pyrolysis Units, 2015-2050

\begin{tabular}{|c|c|c|c|c|c|c|c|c|c|c|c|c|c|c|c|c|}
\hline & & \multicolumn{5}{|c|}{$\begin{array}{l}\text { Small-scale pyrolysis units } \\
\text { (à } 2,000 t_{D M} \text { feedstock/a) }\end{array}$} & \multicolumn{5}{|c|}{$\begin{array}{l}\text { Medium-scale pyrolysis units } \\
\text { (à } 16,000 t_{\mathrm{DM}} \text { feedstock/a) }\end{array}$} & \multicolumn{5}{|c|}{$\begin{array}{l}\text { Large-scale pyrolysis units } \\
\text { (à } 184,800 t_{\mathrm{DM}} \text { feedstock/a) }\end{array}$} \\
\hline & & 2015 & 2020 & 2030 & 2040 & 2050 & 2015 & 2020 & 2030 & 2040 & 2050 & 2015 & 2020 & 2030 & 2040 & 2050 \\
\hline & & \multicolumn{5}{|c|}{$\epsilon_{2012} / t_{\mathrm{DM}}$ feedstock } & \multicolumn{5}{|c|}{$\epsilon_{2012} / t_{\mathrm{DM}}$ feedstock } & \multicolumn{5}{|c|}{$\epsilon_{2012} / t_{\mathrm{DM}}$ feedstock } \\
\hline \multicolumn{2}{|l|}{ Biomass scenarios } & (1) & (2) & (3) & (4) & (5) & (6) & (7) & (8) & (9) & (10) & (11) & (12) & (13) & (14) & (15) \\
\hline Scenario Max 1 & (A) & 39 & 37 & 35 & 32 & 32 & 44 & 42 & 39 & 36 & 35 & 19 & 19 & 17 & 16 & $\overline{16}$ \\
\hline Scenario Min 1 & (B) & 39 & 39 & 39 & 36 & 36 & 44 & 44 & 43 & 41 & 40 & 19 & 19 & 19 & 18 & 18 \\
\hline Scenario $\operatorname{Max} 2$ & (C) & 39 & 38 & 35 & 33 & 32 & 44 & 42 & 39 & 36 & 35 & 19 & 19 & 18 & 16 & $\overline{16}$ \\
\hline Scenario $\operatorname{Min} 2$ & (D) & 39 & 39 & 39 & 36 & 36 & 44 & 44 & 43 & 40 & 40 & 19 & 19 & 19 & 18 & 18 \\
\hline
\end{tabular}

Sources: Weighted averages of the annual capital costs per $\mathrm{t}_{\mathrm{DM}}$ feedstock from Table S.5, where the weights are given by the shares of pyrolysis units constructed at a given date in the total annual number of pyrolysis units in operation in the respective period. The distribution of pyrolysis units by construction date can be found in Table S.2.

Notes: Values rounded. $\mathrm{DM}=$ dry mass. $\mathrm{a}=$ year. $\mathrm{t}=$ tonne. All tables numbered with the leading 'S.' refer to Teichmann (2015). 
Table 14: Costs for the Fossil Fuels Used During Pyrolysis When Process Heat is Not Recovered, Germany, 2015-2050 - Price Path B

\begin{tabular}{|c|c|c|c|c|c|c|c|c|c|c|c|c|c|c|c|}
\hline \multirow[b]{4}{*}{ Feedstocks } & \multicolumn{5}{|c|}{ Lignite } & \multicolumn{5}{|c|}{ Hard coal } & \multicolumn{5}{|c|}{ Natural gas } \\
\hline & 2015 & 2020 & 2030 & 2040 & 2050 & 2015 & 2020 & 2030 & 2040 & 2050 & 2015 & 2020 & 2030 & 2040 & 2050 \\
\hline & \multicolumn{5}{|c|}{$€_{2012} / t_{\mathrm{DM}}$ feedstock ${ }^{\mathrm{a}}$} & \multicolumn{5}{|c|}{$€_{2012} / t_{\mathrm{DM}}$ feedstock ${ }^{\mathrm{b}}$} & \multicolumn{5}{|c|}{$\epsilon_{2012} / t_{\mathrm{DM}}$ feedstock $^{\mathrm{c}}$} \\
\hline & (1) & (2) & (3) & (4) & (5) & (6) & (7) & $(8)$ & (9) & (10) & (11) & (12) & (13) & (14) & (15) \\
\hline Cereal straw & 4.0 & 4.0 & 4.3 & 4.3 & 5.0 & 10.9 & 11.8 & 14.6 & 17.4 & 19.2 & 23.9 & 27.7 & 34.5 & 40.0 & 44.1 \\
\hline Forestry residues & 4.4 & 4.4 & 4.8 & 4.8 & 5.4 & 11.9 & 12.9 & 16.0 & 19.0 & 21.1 & 26.2 & 30.4 & 37.9 & 43.9 & 48.4 \\
\hline Open-country biomass residues & 4.1 & 4.1 & 4.4 & 4.4 & 5.0 & 10.9 & 11.9 & 14.7 & 17.5 & 19.4 & 24.2 & 27.9 & 34.8 & 40.4 & 44.5 \\
\hline Industrial wood waste & 4.2 & 4.2 & 4.5 & 4.5 & 5.1 & 11.2 & 12.2 & 15.1 & 17.9 & 19.9 & 24.7 & 28.6 & 35.7 & 41.4 & 45.6 \\
\hline Wood in municipal solid waste & 4.4 & 4.4 & 4.8 & 4.8 & 5.4 & 11.9 & 12.9 & 16.0 & 19.1 & 21.1 & 26.3 & 30.4 & 38.0 & 44.0 & 48.5 \\
\hline Green waste: Compensation areas & 3.9 & 3.9 & 4.2 & 4.2 & 4.8 & 10.5 & 11.4 & 14.1 & 16.8 & 18.6 & 23.1 & 26.8 & 33.4 & 38.7 & 42.6 \\
\hline Biomass: Habitat-connectivity areas & 4.1 & 4.1 & 4.4 & 4.4 & 5.0 & 10.9 & 11.9 & 14.7 & 17.5 & 19.4 & 24.2 & 27.9 & 34.8 & 40.4 & 44.5 \\
\hline Green waste: Extensive grassland & 4.1 & 4.1 & 4.4 & 4.4 & 5.0 & 10.9 & 11.9 & 14.7 & 17.5 & 19.4 & 24.2 & 27.9 & 34.8 & 40.4 & 44.5 \\
\hline Short-rotation coppice: Erosion areas & 5.2 & 5.2 & 5.6 & 5.6 & 6.4 & 13.9 & 15.1 & 18.7 & 22.2 & 24.6 & 30.7 & 35.5 & 44.2 & 51.3 & 56.5 \\
\hline Solid cattle manure & 16.7 & 16.7 & 18.0 & 18.0 & 20.6 & 45.0 & 48.8 & 60.4 & 72.0 & 79.7 & 99.3 & 114.9 & 143.2 & 165.9 & 183.0 \\
\hline Solid swine manure & 31.4 & 31.4 & 33.8 & 33.8 & 38.6 & 84.5 & 91.8 & 113.5 & 135.3 & 149.8 & 186.6 & 215.9 & 269.2 & 311.9 & 343.8 \\
\hline Solid poultry manure & 4.3 & 4.3 & 4.6 & 4.6 & 5.3 & 11.5 & 12.5 & 15.5 & 18.4 & 20.4 & 25.4 & 29.4 & 36.7 & 42.5 & 46.9 \\
\hline Commercial and industrial waste & 15.6 & 15.6 & 16.8 & 16.8 & 19.3 & 42.1 & 45.7 & 56.6 & 67.4 & 74.6 & 93.0 & 107.6 & 134.1 & 155.4 & 171.3 \\
\hline Organic municipal solid waste & 21.9 & 21.9 & 23.6 & 23.6 & 27.0 & 59.0 & 64.1 & 79.3 & 94.5 & 104.6 & 130.3 & 150.8 & 188.0 & 217.8 & 240.1 \\
\hline
\end{tabular}

Sources:

a) Own calculation, multiplying the fossil-fuel requirements from Table S.6, column 2 by the lignite prices for price path A* (Table S.9, row A, columns 8-12) and expressing the resulting costs per dry tonne of feedstock, e.g., $(1)=$ Table S.6 (column 2) $\cdot$ Table S.9 (row A, column 8) $\cdot 1,000$.

b) Own calculation, multiplying the fossil-fuel requirements from Table S.6, column 3 by the hard-coal prices for price path B (Table S.9, row E, columns 8-12) and expressing the resulting costs per dry tonne of feedstock, e.g., $(6)=$ Table S.6 (column 3) · Table S.9 (row E, column 8) $\cdot 1,000$.

c) Own calculation, multiplying the fossil-fuel requirements from Table S.6, column 4 by the natural-gas prices for price path B (Table S.9, row K, columns 8-12) and expressing the resulting costs per dry tonne of feedstock, e.g., (11) = Table S.6 (column 4) $\cdot$ Table S.9 (row K, column 8) $\cdot 1,000$.

Notes: Values rounded. DM = dry mass. $\mathrm{t}=$ tonne. All tables numbered with the leading 'S.' refer to Teichmann (2015).

$*$ = Note that the fuel prices for lignite do not vary across the price paths, but refer to price path A throughout. 
Table 15: Costs for the Fossil Fuels Used During Pyrolysis When Process Heat is Recovered, Germany, 2015-2050 - Price Path B

\begin{tabular}{|c|c|c|c|c|c|c|c|c|c|c|c|c|c|c|c|}
\hline \multirow[b]{4}{*}{ Feedstocks } & \multicolumn{5}{|c|}{ Lignite } & \multicolumn{5}{|c|}{ Hard coal } & \multicolumn{5}{|c|}{ Natural gas } \\
\hline & 2015 & 2020 & 2030 & 2040 & 2050 & 2015 & 2020 & 2030 & 2040 & 2050 & 2015 & 2020 & 2030 & 2040 & 2050 \\
\hline & \multicolumn{5}{|c|}{$€_{2012} / t_{\mathrm{DM}}$ feedstock ${ }^{\mathrm{a}}$} & \multicolumn{5}{|c|}{$€_{2012} / \mathrm{t}_{\mathrm{DM}}$ feedstock ${ }^{\mathrm{b}}$} & \multicolumn{5}{|c|}{$\epsilon_{2012} / t_{\mathrm{DM}}$ feedstock $^{\mathrm{c}}$} \\
\hline & (1) & (2) & (3) & (4) & (5) & (6) & (7) & $(8)$ & (9) & (10) & (11) & (12) & (13) & (14) & (15) \\
\hline Cereal straw & 1.3 & 1.3 & 1.4 & 1.4 & 1.6 & 3.6 & 3.9 & 4.8 & 5.8 & 6.4 & 7.9 & 9.2 & 11.5 & 13.3 & 14.6 \\
\hline Forestry residues & 1.6 & 1.6 & 1.8 & 1.8 & 2.0 & 4.4 & 4.8 & 5.9 & 7.0 & 7.8 & 9.7 & 11.2 & 14.0 & 16.2 & 17.9 \\
\hline Open-country biomass residues & 1.3 & 1.3 & 1.4 & 1.4 & 1.6 & 3.6 & 3.9 & 4.8 & 5.8 & 6.4 & 7.9 & 9.2 & 11.5 & 13.3 & 14.6 \\
\hline Industrial wood waste & 1.4 & 1.4 & 1.5 & 1.5 & 1.7 & 3.7 & 4.0 & 5.0 & 5.9 & 6.6 & 8.2 & 9.5 & 11.8 & 13.7 & 15.1 \\
\hline Wood in municipal solid waste & 1.6 & 1.6 & 1.8 & 1.8 & 2.0 & 4.4 & 4.8 & 5.9 & 7.1 & 7.8 & 9.8 & 11.3 & 14.1 & 16.3 & 18.0 \\
\hline Green waste: Compensation areas & 1.2 & 1.2 & 1.3 & 1.3 & 1.5 & 3.2 & 3.5 & 4.3 & 5.1 & 5.7 & 7.1 & 8.2 & 10.2 & 11.9 & 13.1 \\
\hline Biomass: Habitat-connectivity areas & 1.3 & 1.3 & 1.4 & 1.4 & 1.6 & 3.6 & 3.9 & 4.8 & 5.8 & 6.4 & 7.9 & 9.2 & 11.5 & 13.3 & 14.6 \\
\hline Green waste: Extensive grassland & 1.3 & 1.3 & 1.4 & 1.4 & 1.6 & 3.6 & 3.9 & 4.8 & 5.8 & 6.4 & 7.9 & 9.2 & 11.5 & 13.3 & 14.6 \\
\hline Short-rotation coppice: Erosion areas & 2.4 & 2.4 & 2.6 & 2.6 & 2.9 & 6.4 & 7.0 & 8.6 & 10.3 & 11.4 & 14.2 & 16.4 & 20.4 & 23.7 & 26.1 \\
\hline Solid cattle manure & 14.2 & 14.2 & 15.3 & 15.3 & 17.4 & 38.1 & 41.4 & 51.2 & 61.0 & 67.6 & 84.2 & 97.4 & 121.5 & 140.7 & 155.1 \\
\hline Solid swine manure & 28.9 & 28.9 & 31.1 & 31.1 & 35.6 & 77.8 & 84.5 & 104.5 & 124.5 & 137.8 & 171.7 & 198.7 & 247.8 & 287.0 & 316.5 \\
\hline Solid poultry manure & 1.8 & 1.8 & 2.0 & 2.0 & 2.2 & 4.9 & 5.3 & 6.6 & 7.8 & 8.7 & 10.8 & 12.5 & 15.6 & 18.0 & 19.9 \\
\hline Commercial and industrial waste & 12.9 & 12.9 & 13.9 & 13.9 & 15.9 & 34.8 & 37.8 & 46.8 & 55.8 & 61.7 & 76.9 & 89.0 & 111.0 & 128.5 & 141.7 \\
\hline Organic municipal solid waste & 19.5 & 19.5 & 21.0 & 21.0 & 24.0 & 52.5 & 56.9 & 70.4 & 83.9 & 92.9 & 115.8 & 133.9 & 167.0 & 193.5 & 213.3 \\
\hline
\end{tabular}

Sources:

a) Own calculation, multiplying the fossil-fuel requirements from Table S.6, column 6 by the lignite prices for price path A* (Table S.9, row A, columns 8-12) and expressing the resulting costs per dry tonne of feedstock, e.g., (1) = Table S.6 (column 6) · Table S.9 (row A, column 8) 1,000 .

b) Own calculation, multiplying the fossil-fuel requirements from Table S.6, column 7 by the hard-coal prices for price path B (Table S.9, row E, columns 8-12) and expressing the resulting costs per dry tonne of feedstock, e.g., (6) = Table S.6 (column 7) · Table S.9 (row E, column 8) $11,000$.

c) Own calculation, multiplying the fossil-fuel requirements from Table S.6, column 8 by the natural-gas prices for price path B (Table S.9, row K, columns 8-12) and expressing the resulting costs per dry tonne of feedstock, e.g., (11) = Table S.6 (column 8) - Table S.9 (row K, column 8) 1 1,000.

Notes: Values rounded. $\mathrm{DM}=$ dry mass. $\mathrm{t}=$ tonne. All tables numbered with the leading 'S.' refer to Teichmann (2015).

$*=$ Note that the fuel prices for lignite do not vary across the price paths, but refer to price path A throughout. 
Table 16: GHG Emission Costs Associated with Pyrolysis When Process Heat is Not Recovered, Germany, 2015-2050 - Price Path B

\begin{tabular}{|c|c|c|c|c|c|c|c|c|c|c|c|c|c|c|c|}
\hline \multirow[b]{4}{*}{ Feedstocks } & \multicolumn{5}{|c|}{ Lignite } & \multicolumn{5}{|c|}{ Hard coal } & \multicolumn{5}{|c|}{ Natural gas } \\
\hline & 2015 & 2020 & 2030 & 2040 & 2050 & 2015 & 2020 & 2030 & 2040 & 2050 & 2015 & 2020 & 2030 & 2040 & 2050 \\
\hline & \multicolumn{5}{|c|}{$\epsilon_{2012} / \mathrm{t}_{\mathrm{DM}}$ feedstock $^{\mathrm{a}}$} & \multicolumn{5}{|c|}{$\epsilon_{2012} / \mathrm{t}_{\mathrm{DM}}$ feedstock ${ }^{\mathrm{b}}$} & \multicolumn{5}{|c|}{$€_{2012} / t_{\mathrm{DM}}$ feedstock ${ }^{\mathrm{c}}$} \\
\hline & (1) & (2) & (3) & (4) & (5) & (6) & (7) & $(8)$ & (9) & (10) & (11) & $(12)$ & $(13)$ & (14) & (15) \\
\hline Cereal straw & 0.9 & 4.3 & 6.3 & 8.3 & 10.5 & 0.8 & 3.6 & 5.3 & 7.0 & 8.8 & 0.5 & 2.3 & 3.4 & 4.4 & 5.6 \\
\hline Forestry residues & 1.0 & 4.7 & 6.9 & 9.1 & 11.6 & 0.8 & 3.9 & 5.8 & 7.6 & 9.7 & 0.5 & 2.5 & 3.7 & 4.9 & 6.2 \\
\hline Open-country biomass residues & 0.9 & 4.3 & 6.3 & 8.4 & 10.6 & 0.8 & 3.6 & 5.3 & 7.0 & 8.9 & 0.5 & 2.3 & 3.4 & 4.5 & 5.7 \\
\hline Industrial wood waste & 1.0 & 4.4 & 6.5 & 8.6 & 10.9 & 0.8 & 3.7 & 5.4 & 7.2 & 9.1 & 0.5 & 2.3 & 3.5 & 4.6 & 5.8 \\
\hline Wood in municipal solid waste & 1.0 & 4.7 & 6.9 & 9.1 & 11.6 & 0.8 & 3.9 & 5.8 & 7.6 & 9.7 & 0.5 & 2.5 & 3.7 & 4.9 & 6.2 \\
\hline Green waste: Compensation areas & 0.9 & 4.1 & 6.1 & 8.0 & 10.2 & 0.7 & 3.4 & 5.1 & 6.7 & 8.5 & 0.5 & 2.2 & 3.2 & 4.3 & 5.4 \\
\hline Biomass: Habitat-connectivity areas & 0.9 & 4.3 & 6.3 & 8.4 & 10.6 & 0.8 & 3.6 & 5.3 & 7.0 & 8.9 & 0.5 & 2.3 & 3.4 & 4.5 & 5.7 \\
\hline Green waste: Extensive grassland & 0.9 & 4.3 & 6.3 & 8.4 & 10.6 & 0.8 & 3.6 & 5.3 & 7.0 & 8.9 & 0.5 & 2.3 & 3.4 & 4.5 & 5.7 \\
\hline Short-rotation coppice: Erosion areas & 1.2 & 5.5 & 8.1 & 10.7 & 13.5 & 1.0 & 4.6 & 6.7 & 8.9 & 11.3 & 0.6 & 2.9 & 4.3 & 5.7 & 7.2 \\
\hline Solid cattle manure & 3.8 & 17.6 & 26.1 & 34.5 & 43.7 & 3.2 & 14.8 & 21.8 & 28.9 & 36.6 & 2.0 & 9.4 & 13.9 & 18.4 & 23.3 \\
\hline Solid swine manure & 7.2 & 33.2 & 49.0 & 64.9 & 82.2 & 6.0 & 27.7 & 41.0 & 54.2 & 68.7 & 3.8 & 17.7 & 26.1 & 34.6 & 43.8 \\
\hline Solid poultry manure & 1.0 & 4.5 & 6.7 & 8.8 & 11.2 & 0.8 & 3.8 & 5.6 & 7.4 & 9.4 & 0.5 & 2.4 & 3.6 & 4.7 & 6.0 \\
\hline Commercial and industrial waste & 3.6 & 16.5 & 24.4 & 32.3 & 40.9 & 3.0 & 13.8 & 20.4 & 27.0 & 34.2 & 1.9 & 8.8 & 13.0 & 17.2 & 21.8 \\
\hline Organic municipal solid waste & 5.0 & 23.2 & 34.2 & 45.3 & 57.4 & 4.2 & 19.4 & 28.6 & 37.9 & 48.0 & 2.7 & 12.3 & 18.2 & 24.1 & 30.6 \\
\hline
\end{tabular}

Sources:

a) Own calculation, multiplying the GHG emissions from the fossil-fuel use in biochar production from Table S.7, column 1 by the $\mathrm{CO}_{2}$ prices for price path B (Table S.10, row B, columns 7-11), e.g., (1) = Table S.7 (column 1) · Table S.10 (row B, column 7).

b) Own calculation, multiplying the GHG emissions from the fossil-fuel use in biochar production from Table S.7, column 2 by the $\mathrm{CO}_{2}$ prices for price path B (Table S.10, row B, columns 7-11), e.g., (6) = Table S.7 (column 2) · Table S.10 (row B, column 7).

c) Own calculation, multiplying the GHG emissions from the fossil-fuel use in biochar production from Table S.7, column 3 by the $\mathrm{CO}_{2}$ prices for price path B (Table S.10, row B, columns 7-11), e.g., (11) = Table S.7 (column 3) - Table S.10 (row B, column 7).

Notes: Values rounded. $\mathrm{DM}=$ dry mass. $\mathrm{t}=$ tonne. All tables numbered with the leading 'S.' refer to Teichmann (2015). 
Table 17: GHG Emission Costs Associated with Pyrolysis When Process Heat is Recovered, Germany, 2015-2050 - Price Path B

\begin{tabular}{|c|c|c|c|c|c|c|c|c|c|c|c|c|c|c|c|}
\hline \multirow[b]{4}{*}{ Feedstocks } & \multicolumn{5}{|c|}{ Lignite } & \multicolumn{5}{|c|}{ Hard coal } & \multicolumn{5}{|c|}{ Natural gas } \\
\hline & 2015 & 2020 & 2030 & 2040 & 2050 & 2015 & 2020 & 2030 & 2040 & 2050 & 2015 & 2020 & 2030 & 2040 & 2050 \\
\hline & \multicolumn{5}{|c|}{$€_{2012} / t_{\mathrm{DM}}$ feedstock ${ }^{\mathrm{a}}$} & \multicolumn{5}{|c|}{$€_{2012} / \mathrm{t}_{\mathrm{DM}}$ feedstock ${ }^{\mathrm{b}}$} & \multicolumn{5}{|c|}{$€_{2012} / \mathrm{t}_{\mathrm{DM}}$ feedstock ${ }^{\mathrm{c}}$} \\
\hline & (1) & (2) & (3) & (4) & (5) & (6) & (7) & $(8)$ & (9) & (10) & (11) & (12) & (13) & (14) & (15) \\
\hline Cereal straw & 0.3 & 1.4 & 2.1 & 2.8 & 3.5 & 0.3 & 1.2 & 1.7 & 2.3 & 2.9 & 0.2 & 0.8 & 1.1 & 1.5 & 1.9 \\
\hline Forestry residues & 0.4 & 1.7 & 2.6 & 3.4 & 4.3 & 0.3 & 1.4 & 2.1 & 2.8 & 3.6 & 0.2 & 0.9 & 1.4 & 1.8 & 2.3 \\
\hline Open-country biomass residues & 0.3 & 1.4 & 2.1 & 2.8 & 3.5 & 0.3 & 1.2 & 1.7 & 2.3 & 2.9 & 0.2 & 0.8 & 1.1 & 1.5 & 1.9 \\
\hline Industrial wood waste & 0.3 & 1.5 & 2.2 & 2.8 & 3.6 & 0.3 & 1.2 & 1.8 & 2.4 & 3.0 & 0.2 & 0.8 & 1.1 & 1.5 & 1.9 \\
\hline Wood in municipal solid waste & 0.4 & 1.7 & 2.6 & 3.4 & 4.3 & 0.3 & 1.5 & 2.1 & 2.8 & 3.6 & 0.2 & 0.9 & 1.4 & 1.8 & 2.3 \\
\hline Green waste: Compensation areas & 0.3 & 1.3 & 1.9 & 2.5 & 3.1 & 0.2 & 1.1 & 1.6 & 2.1 & 2.6 & 0.1 & 0.7 & 1.0 & 1.3 & 1.7 \\
\hline Biomass: Habitat-connectivity areas & 0.3 & 1.4 & 2.1 & 2.8 & 3.5 & 0.3 & 1.2 & 1.7 & 2.3 & 2.9 & 0.2 & 0.8 & 1.1 & 1.5 & 1.9 \\
\hline Green waste: Extensive grassland & 0.3 & 1.4 & 2.1 & 2.8 & 3.5 & 0.3 & 1.2 & 1.7 & 2.3 & 2.9 & 0.2 & 0.8 & 1.1 & 1.5 & 1.9 \\
\hline Short-rotation coppice: Erosion areas & 0.5 & 2.5 & 3.7 & 4.9 & 6.2 & 0.5 & 2.1 & 3.1 & 4.1 & 5.2 & 0.3 & 1.3 & 2.0 & 2.6 & 3.3 \\
\hline Solid cattle manure & 3.3 & 15.0 & 22.1 & 29.3 & 37.1 & 2.7 & 12.5 & 18.5 & 24.5 & 31.0 & 1.7 & 8.0 & 11.8 & 15.6 & 19.8 \\
\hline Solid swine manure & 6.6 & 30.5 & 45.1 & 59.7 & 75.6 & 5.5 & 25.5 & 37.7 & 49.9 & 63.2 & 3.5 & 16.3 & 24.0 & 31.8 & 40.3 \\
\hline Solid poultry manure & 0.4 & 1.9 & 2.8 & 3.7 & 4.7 & 0.3 & 1.6 & 2.4 & 3.1 & 4.0 & 0.2 & 1.0 & 1.5 & 2.0 & 2.5 \\
\hline Commercial and industrial waste & 3.0 & 13.7 & 20.2 & 26.7 & 33.9 & 2.5 & 11.4 & 16.9 & 22.4 & 28.3 & 1.6 & 7.3 & 10.8 & 14.2 & 18.0 \\
\hline Organic municipal solid waste & 4.5 & 20.6 & 30.4 & 40.3 & 51.0 & 3.7 & 17.2 & 25.4 & 33.7 & 42.6 & 2.4 & 11.0 & 16.2 & 21.4 & 27.2 \\
\hline
\end{tabular}

Sources:

a) Own calculation, multiplying the GHG emissions from the fossil-fuel use in biochar production from Table S.7, column 4 by the $\mathrm{CO}_{2}$ prices for price path B (Table S.10, row B, columns 7-11), e.g., (1) = Table S.7 (column 4) · Table S.10 (row B, column 7).

b) Own calculation, multiplying the GHG emissions from the fossil-fuel use in biochar production from Table S.7, column 5 by the $\mathrm{CO}_{2}$ prices for price path B (Table S.10, row B, columns 7-11), e.g., (6) = Table S.7 (column 5) $\cdot$ Table S.10 (row B, column 7).

c) Own calculation, multiplying the GHG emissions from the fossil-fuel use in biochar production from Table S.7, column 6 by the $\mathrm{CO}_{2}$ prices for price path B (Table S.10, row B, columns 7-11), e.g., (11) = Table S.7 (column 6) - Table S.10 (row B, column 7).

Notes: Values rounded. $\mathrm{DM}=$ dry mass. $\mathrm{t}=$ tonne. All tables numbered with the leading 'S.' refer to Teichmann (2015). 
Table 18: Other Operational Costs for Pyrolysis

\begin{tabular}{|c|c|c|c|c|c|c|}
\hline \multirow{3}{*}{\multicolumn{3}{|c|}{ Pyrolysis scale }} & \multirow{2}{*}{$\begin{array}{l}\text { Total operating costs }^{\mathrm{a}} \\
\mathrm{USD}_{2007} / \mathrm{t}_{\mathrm{DM}} \text { feedstock } \\
\end{array}$} & \multirow{2}{*}{$\begin{array}{c}\text { Share of natural-gas costs in (1) } \\
\% \\
\end{array}$} & \multicolumn{2}{|c|}{ Other operational costs for pyrolysis } \\
\hline & & & & & \multirow{2}{*}{$\frac{\mathrm{USD}_{2007} / \mathrm{t}_{\mathrm{DM}} \text { feedstock }}{\mathrm{c}}$} & $€_{2012} / \mathrm{t}_{\mathrm{DM}}$ feedstock ${ }^{\mathrm{d}}$ \\
\hline & & & (1) & (2) & & $(4)$ \\
\hline 2,000 & \multirow{3}{*}{$t_{\mathrm{DM}}$ feedstock/a } & (A) & 54.5 & 11 & 48.5 & 38.8 \\
\hline 16,000 & & (B) & 60.5 & 9 & 55.1 & 44.1 \\
\hline 184,800 & & (C) & 5.0 & 10 & 4.5 & 3.6 \\
\hline
\end{tabular}

Sources:

a) Shackley et al. (2011: Table 6).

b) Own calculation, derived from Shackley et al. (2011: Tables 8-10) as the share of natural-gas costs in the total costs of natural gas as well as labor and plant costs.

c) Own calculation, $(3)=(1) \cdot[1-(2) / 100]$

d) Own calculation, based on the 2007 average exchange rate of 1.3705 USD/€ (Deutsche Bundesbank 2012) and the 2007 and 2012 producer price indices of 97.5 and 107.0 , respectively (Deutsche Bundesbank 2015), i.e. $(4)=(3) / 1.3705 \cdot 107.0 / 97.5$.

Notes: Values rounded. $\mathrm{DM}=$ dry mass. $\mathrm{a}=$ year. $\mathrm{t}=$ tonne.

Table 19: Net Costs of Biochar from Foregone Biomass Combustion, Germany, 2015-2050

\begin{tabular}{|c|c|c|c|c|c|c|c|c|c|c|c|c|c|c|c|c|c|}
\hline \multirow[b]{4}{*}{ Feedstocks } & & & \multicolumn{5}{|c|}{ Lignite } & \multicolumn{5}{|c|}{ Hard coal } & \multicolumn{5}{|c|}{ Natural gas } \\
\hline & & & 2015 & 2020 & 2030 & 2040 & 2050 & 2015 & 2020 & 2030 & 2040 & 2050 & 2015 & 2020 & 2030 & 2040 & 2050 \\
\hline & & & \multicolumn{5}{|c|}{$\epsilon_{2012} / t_{\mathrm{DM}}$ feedstock } & \multicolumn{5}{|c|}{$\epsilon_{2012} / t_{\mathrm{DM}}$ feedstock } & \multicolumn{5}{|c|}{$\epsilon_{2012} / \mathrm{t}_{\mathrm{DM}}$ feedstock } \\
\hline & & & (1) & (2) & (3) & (4) & (5) & (6) & (7) & $(8)$ & (9) & (10) & (11) & $(12)$ & (13) & (14) & (15) \\
\hline \multirow{3}{*}{ Industrial wood waste } & Price path $A^{a}$ & (A) & -76.0 & -35.5 & -6.4 & 17.1 & 45.8 & -19.6 & 29.3 & 87.0 & 143.4 & 205.0 & 84.1 & 147.6 & 244.0 & 338.0 & 434.9 \\
\hline & Price path $\mathrm{B}^{\mathrm{b}}$ & (B) & -76.0 & -41.8 & -23.7 & -6.4 & 17.6 & -24.8 & 10.9 & 49.0 & 87.0 & 118.5 & 64.4 & 116.1 & 181.5 & 235.6 & 279.2 \\
\hline & Price path $\mathrm{C}^{\mathrm{c}}$ & (C) & -76.0 & -46.5 & -36.2 & -20.5 & -1.2 & -35.3 & -3.5 & 14.9 & 41.1 & 63.4 & 50.3 & 82.6 & 127.0 & 157.7 & 187.6 \\
\hline \multirow{3}{*}{$\begin{array}{l}\text { Short-rotation coppice: } \\
\text { Erosion areas }\end{array}$} & Price path $A^{d}$ & (D) & -76.0 & -35.5 & -6.4 & 17.1 & 45.8 & -19.6 & 29.3 & 87.0 & 143.4 & 205.0 & 84.1 & 147.6 & 244.0 & 338.0 & 434.9 \\
\hline & Price path $B^{e}$ & $(\mathrm{E})$ & -76.0 & -41.8 & -23.7 & -6.4 & 17.6 & -24.8 & 10.9 & 49.0 & 87.0 & 118.5 & 64.4 & 116.1 & 181.5 & 235.6 & 279.2 \\
\hline & Price path $C^{f}$ & (F) & -76.0 & -46.5 & -36.2 & -20.5 & -1.2 & -35.3 & -3.5 & 14.9 & 41.1 & 63.4 & 50.3 & 82.6 & 127.0 & 157.7 & 187.6 \\
\hline
\end{tabular}

Sources:

a) Own calculation, $(\mathrm{A})=$ Table S.20 (row J) - Table S.19 (row G).

b) Own calculation, (B) = Table S.20 (row K) - Table S.19 (row G)

c) Own calculation, $(\mathrm{C})=$ Table S.20 (row L) - Table S.19 (row G).

d) Own calculation, (D) = Table S.20 (row M) - Table S.19 (row H).

e) Own calculation, $(\mathrm{E})=$ Table S.20 (row N) - Table S.19 (row H).

f) Own calculation, $(\mathrm{F})=$ Table S.20 (row O) - Table S.19 (row H)

Notes: Values rounded. $\mathrm{DM}=$ dry mass. $\mathrm{t}=$ tonne. All tables numbered with the leading ' $\mathrm{S}$.' refer to Teichmann (2015). 
Table 20: Costs of Manure Management

\begin{tabular}{|c|c|c|c|c|c|c|c|c|}
\hline \multirow[t]{3}{*}{ Feedstocks } & \multicolumn{2}{|c|}{$\begin{array}{l}\text { Total capital costs } \\
\text { for manure trays } \\
\text { (excluding VAT) }\end{array}$} & $\begin{array}{c}\text { Annual capital } \\
\text { costs for manure } \\
\text { trays }^{\mathrm{f}}\end{array}$ & \multicolumn{3}{|c|}{ Solid manure per animal } & \multirow{2}{*}{$\begin{array}{c}\text { Solid } \\
\text { manure per } \\
\text { animal } \\
\text { place }^{\mathbf{k}} \\
\mathrm{t}_{\mathrm{DM}} / \text { animal }^{2} \\
\text { place }\end{array}$} & \multirow{2}{*}{$\begin{array}{c}\begin{array}{c}\text { Costs of } \\
\text { manure } \\
\text { manage- } \\
\text { ment }\end{array} \\
€_{2012} / t_{\mathrm{DM}} \\
\text { feedstock }\end{array}$} \\
\hline & \multicolumn{2}{|c|}{$€_{2012} /$ animal place } & $€_{2012} /$ animal place & \multicolumn{2}{|c|}{$\mathrm{t}_{\mathrm{FW}} /$ animal } & $\mathrm{t}_{\mathrm{DM}} / \mathrm{animal}^{\mathrm{j}}$ & & \\
\hline & \multicolumn{2}{|l|}{ (1) } & (2) & \multicolumn{2}{|l|}{ (3) } & (4) & (5) & (6) \\
\hline \multirow{2}{*}{ Solid cattle manure } & $\begin{array}{l}\text { Dairy cattle: } \\
30.7^{\mathrm{a}}\end{array}$ & \multirow{2}{*}{$82.7^{\mathrm{c}}$} & \multirow{2}{*}{6.0} & $\begin{array}{l}\text { Dairy cattle: } \\
12.6^{\mathrm{g}}\end{array}$ & \multirow{2}{*}{$9.3^{\mathrm{c}}$} & \multirow{2}{*}{3.4} & \multirow{2}{*}{3.4} & \multirow{2}{*}{1.8} \\
\hline & $\begin{array}{l}\text { Beef cattle: } \\
164.1^{\mathrm{b}}\end{array}$ & & & $\begin{array}{l}\text { Beef cattle: } \\
4.1^{\mathrm{h}}\end{array}$ & & & & \\
\hline Solid swine manure & & $41.0^{\mathrm{d}}$ & 3.0 & & $0.6^{\mathrm{i}}$ & 0.1 & 0.1 & 30.0 \\
\hline Solid poultry manure & & $0^{\mathrm{e}}$ & 0 & & - & - & - & $\mathbf{0}$ \\
\hline
\end{tabular}

\section{Sources:}

a) Own calculation; simple average of the total capital costs for manure trays of $€_{2014} 15.93-44.69$ per animal place (without horned dairy cattle) as derived from KTBL (2014), ${ }^{*}$ transformed with the help of the 2014 and 2012 producer price indices of 105.8 and 107.0 , respectively (Deutsche Bundesbank 2015), i.e. $30.7=(15.93+44.69) / 2 \cdot 107.0 / 105.8$.

b) Own calculation; simple average of the total capital costs for manure trays of $€_{2010} 107.39-199.27$ per animal place as derived from KTBL (2014), ${ }^{*}$ transformed with the help of the 2010 and 2012 producer price indices of 100.0 and 107.0, respectively (Deutsche Bundesbank 2015), i.e. $164.1=(107.39+199.27) / 2 \cdot 107.0 / 100.0$.

c) Own calculation; weighted average of the respective values for dairy cattle and beef cattle, where the weights are based on the distribution of dairy cows $(61 \%)$ and other cattle $(39 \%)$ in Germany in 2000 as derived from the livestock populations given in Teichmann (2014b: Table A.9, column 3).

d) Own calculation; simple average of the total capital costs for manure trays of $€_{2009} 15.46-59.98$ per animal place for fattening pigs in systems with bedding as derived from KTBL (2014), ${ }^{*}$ transformed with the help of the 2009 and 2012 producer price indices of 98.5 and 107.0 , respectively (Deutsche Bundesbank 2015), i.e. $41.0=(15.46+59.98) / 2 \cdot 107.0 / 98.5$.

e) As derived from KTBL (2014), no manure trays are constructed in poultry systems.

f) Own calculation, based on the total capital costs in column 1, a lifetime of manure trays of 30 years as assumed by KTBL (2014) and a discount rate of $6 \%$, i.e. $(2)=(1) \cdot\left[(1+0.06)^{30} \cdot 0.06\right] /\left[(1+0.06)^{30}-1\right]$.

g) Own calculation; weighted average of $1.28 \mathrm{t}_{\mathrm{FW}}$ solid manure per cow fed with corn silage or grass silage and $38.9 \mathrm{t}_{\mathrm{FW}}$ solid manure per cow kept under ecological conditions (Fritsche et al. 2004: Table 44), where a weight of $30 \%$ is attached to the latter in accordance with the assumptions by Fritsche et al. (2004: "Umwelt" scenario) for the year 2030. To simplify the analysis, the weights are kept constant.

h) Own calculation; simple average of $1.28 \mathrm{t}_{\mathrm{FW}}$ solid manure per bull fed with corn silage or grass silage and $6.93 \mathrm{t}_{\mathrm{FW}}$ solid manure per ox from dairy cow (Fritsche et al. 2004: Table 44)

i) Own calculation; weighted average of $0.59 \mathrm{t}_{\mathrm{FW}}$ solid manure per swine kept in systems with bedding and $0.61 \mathrm{t}_{\mathrm{FW}}$ solid manure per swine kept under ecological conditions (Fritsche et al. 2004: Table 44), where a weight of $30 \%$ is attached to the latter in accordance with the assumptions by Fritsche et al. (2004: "Umwelt" scenario) for the year 2030. To simplify the analysis, the weights are kept constant.

j) Own calculation, transforming the values from column 3 into dry tonnes per animal using the respective water contents ${ }^{* *}$ of solid cattle manure of $63.6 \%$ and of solid swine manure of $78.5 \%$ (Teichmann 2014a: Table 8, column 4).

k) The same values as in column 4 since it is assumed in accordance with Teichmann (2014b: Table A.11, note e) that cows and pigs are alive for an entire year.

1) Own calculation, $(6)=(2) /(5)$.

Notes: Values rounded. $\mathrm{DM}=$ dry mass. $\mathrm{FW}=$ fresh weight. $\mathrm{t}=$ tonne. $\mathrm{VAT}=$ value-added tax. $-=$ not applicable.

$*$ Note that the data obtained from KTBL (2014) satisfy the minimum requirements for livestock populations applied by Fritsche et al. (2004: Table 43) in the derivation of the manure potentials, i.e. $>50$ animals for cattle and >100 animals for swine.

$* *=$ Note that the feedstock water contents are based on as-received fresh weight. 
Table 21: Costs of Composting

\begin{tabular}{|c|c|c|c|c|}
\hline \multirow[t]{3}{*}{ Feedstocks } & \multirow{3}{*}{\begin{tabular}{|l} 
Conventional feedstock \\
management \\
(see Table 1)
\end{tabular}} & \multirow{2}{*}{$\begin{array}{c}\begin{array}{c}\text { Feedstock water } \\
\text { content }^{\mathrm{a}}\end{array} \\
\text { wt } \% \\
\end{array}$} & \multicolumn{2}{|c|}{ Costs of composting } \\
\hline & & & $€_{2012} / t_{\mathrm{FW}}$ feedstock & $€_{2012} / t_{\text {DM }}$ feedstock ${ }^{d}$ \\
\hline & & (1) & (2) & (3) \\
\hline Cereal straw & Decomposition in field & 7.9 & - & \\
\hline Forestry residues & Decomposition in forest & 10.8 & - & \\
\hline Open-country biomass residues & Composting, land spread & 7.8 & $18.4^{\mathrm{b}}$ & $\mathbf{2 0 . 0}$ \\
\hline Industrial wood waste & Energetic use & 8.1 & - & \\
\hline Wood in municipal solid waste & Composting, land spread & 10.9 & $18.4^{\mathrm{b}}$ & 20.7 \\
\hline Green waste: Compensation areas & Decomposition on site & 6.3 & - & \\
\hline Biomass: Habitat-connectivity areas & Composting, land spread & 7.8 & $18.4^{\mathrm{b}}$ & 20.0 \\
\hline Green waste: Extensive grassland & Composting, land spread & 7.8 & $18.4^{\mathrm{b}}$ & $\mathbf{2 0 . 0}$ \\
\hline Short-rotation coppice: Erosion areas & Energetic use & 17.9 & - & - \\
\hline Solid cattle manure & Solid storage, land spread & 63.6 & - & - \\
\hline Solid swine manure & Solid storage, land spread & 78.5 & - & - \\
\hline Solid poultry manure & Solid storage, land spread & 13.4 & - & \\
\hline Commercial and industrial waste & Composting, land spread & 61.3 & $57.9^{\mathrm{c}}$ & 149.6 \\
\hline Organic municipal solid waste & Composting, land spread & 70.9 & $57.9^{\mathrm{c}}$ & 199.0 \\
\hline
\end{tabular}

Sources:

a) Teichmann (2014a: Table 8, column 4). The feedstock water contents are based on as-received fresh weight.

b) Own calculation, based on the average composting costs for green waste of 5-30 $€_{2011} / \mathrm{t}_{\mathrm{FW}}$ (Kern et al. 2012: 42) and the producer price indices for agricultural products of 113.4 for 2011 and 119.4 for 2012 (Statistisches Bundesamt 2015a), i.e. 18.4 = (5 + 30$) / 2$. 119.4/113.4.

c) Own calculation, based on the average composting costs for biowaste of 30-80 $€_{2011} / \mathrm{t}_{\mathrm{FW}}$ (Kern et al. 2012: 42) and the producer price indices for agricultural products of 113.4 for 2011 and 119.4 for 2012 (Statistisches Bundesamt 2015a), i.e. $57.9=(30+80) / 2$. 119.4/113.4.

d) Own calculation, $(3)=(2) /(1-(1) / 100)$.

Notes: Values rounded. $\mathrm{DM}=$ dry mass. $\mathrm{FW}=$ fresh weight. $\mathrm{t}=$ tonne. $\mathrm{wt} \%=$ weight percent. $-=$ not applicable. 
Table 22: Net Benefits Associated with the Energetic Use of the Pyrolysis By-Products, Germany, 2015-2050 - Price Path B

\begin{tabular}{|c|c|c|c|c|c|c|c|c|c|c|c|c|c|c|c|}
\hline \multirow[b]{4}{*}{ Feedstocks } & \multicolumn{5}{|c|}{ Lignite $^{\mathrm{a}}$} & \multicolumn{5}{|c|}{ Hard coal $^{\text {b }}$} & \multicolumn{5}{|c|}{ Natural gas $^{\mathrm{c}}$} \\
\hline & 2015 & 2020 & 2030 & 2040 & 2050 & 2015 & 2020 & 2030 & 2040 & 2050 & 2015 & 2020 & 2030 & 2040 & 2050 \\
\hline & \multicolumn{5}{|c|}{$\epsilon_{2012} / t_{\mathrm{DM}}$ feedstock } & \multicolumn{5}{|c|}{$€_{2012} / \mathrm{t}_{\mathrm{DM}}$ feedstock } & \multicolumn{5}{|c|}{$\epsilon_{2012} / \mathrm{t}_{\mathrm{DM}}$ feedstock } \\
\hline & (1) & (2) & (3) & (4) & (5) & (6) & (7) & $(8)$ & (9) & (10) & (11) & (12) & $(13)$ & (14) & (15) \\
\hline Cereal straw & -100.6 & -86.3 & -78.6 & -71.4 & -61.3 & -79.1 & -64.1 & -48.1 & -32.2 & -18.9 & -41.7 & -19.9 & 7.5 & 30.3 & 48.6 \\
\hline Forestry residues & -114.0 & -97.7 & -89.1 & -80.9 & -69.4 & -89.6 & -72.6 & -54.5 & -36.4 & -21.4 & -47.2 & -22.6 & 8.5 & 34.3 & 55.0 \\
\hline Open-country biomass residues & -100.2 & -85.9 & -78.3 & -71.1 & -61.0 & -78.8 & -63.8 & -47.9 & -32.0 & -18.9 & -41.5 & -19.8 & 7.5 & 30.1 & 48.4 \\
\hline Industrial wood waste & -111.4 & -95.4 & -87.0 & -79.0 & -67.8 & -87.6 & -70.9 & -53.3 & -35.6 & -21.0 & -46.1 & -22.1 & 8.3 & 33.5 & 53.8 \\
\hline Wood in municipal solid waste & -114.0 & -97.7 & -89.1 & -80.9 & -69.4 & -89.6 & -72.6 & -54.5 & -36.4 & -21.4 & -47.2 & -22.6 & 8.5 & 34.3 & 55.0 \\
\hline Green waste: Compensation areas & -91.8 & -78.6 & -71.7 & -65.1 & -55.9 & -72.2 & -58.5 & -43.9 & -29.3 & -17.3 & -38.0 & -18.2 & 6.9 & 27.6 & 44.3 \\
\hline Biomass: Habitat-connectivity areas & -100.2 & -85.9 & -78.3 & -71.1 & -61.0 & -78.8 & -63.8 & -47.9 & -32.0 & -18.9 & -41.5 & -19.8 & 7.5 & 30.1 & 48.4 \\
\hline Green waste: Extensive grassland & -100.2 & -85.9 & -78.3 & -71.1 & -61.0 & -78.8 & -63.8 & -47.9 & -32.0 & -18.9 & -41.5 & -19.8 & 7.5 & 30.1 & 48.4 \\
\hline Short-rotation coppice: Erosion areas & -125.5 & -107.6 & -98.1 & -89.1 & -76.5 & -98.7 & -80.0 & -60.0 & -40.1 & -23.6 & -52.0 & -24.9 & 9.4 & 37.7 & 60.6 \\
\hline Solid cattle manure & -89.7 & -76.8 & -70.1 & -63.6 & -54.6 & -70.5 & -57.1 & -42.9 & -28.6 & -16.9 & -37.1 & -17.8 & 6.7 & 27.0 & 43.3 \\
\hline Solid swine manure & -114.9 & -98.5 & -89.8 & -81.5 & -70.0 & -90.3 & -73.2 & -54.9 & -36.7 & -21.6 & -47.6 & -22.8 & 8.6 & 34.5 & 55.5 \\
\hline Solid poultry manure & -81.8 & -70.1 & -63.9 & -58.0 & -49.8 & -64.3 & -52.1 & -39.1 & -26.1 & -15.4 & -33.9 & -16.2 & 6.1 & 24.6 & 39.5 \\
\hline Commercial and industrial waste & -108.5 & -93.0 & -84.8 & -77.0 & -66.1 & -85.3 & -69.1 & -51.9 & -34.7 & -20.4 & -44.9 & -21.5 & 8.1 & 32.6 & 52.4 \\
\hline Organic municipal solid waste & -75.2 & -64.5 & -58.8 & -53.4 & -45.8 & -59.1 & -47.9 & -36.0 & -24.0 & -14.2 & -31.1 & -14.9 & 5.6 & 22.6 & 36.3 \\
\hline
\end{tabular}

Sources:

a) Own calculation, Table 22 (columns 1-5) = Table S.23 (columns 2-6) + Table S.26 (columns 1-5) + Table S.28 (columns 2-6) - Table S.29 (columns 1-5)

b) Own calculation, Table 22 (columns 6-10) = Table S.23 (columns 7-11) + Table S.26 (columns 6-10) + Table S.28 (columns 7-11) - Table S.29 (columns 1-5)

c) Own calculation, Table 22 (columns 11-15) = Table S.23 (columns 12-16) + Table S.26 (columns 11-15) + Table S.28 (columns 12-16) - Table S.29 (columns 1-5)

Notes: Values rounded. $\mathrm{DM}=$ dry mass. $\mathrm{t}=$ tonne. All tables numbered with the leading ' $\mathrm{S}$.' refer to Teichmann (2015). 
Table 23: Net Loading Costs for Biomass Transports

\begin{tabular}{|c|c|c|c|c|c|}
\hline \multirow[t]{3}{*}{ Feedstocks } & \multirow{3}{*}{$\begin{array}{l}\text { Conventional feedstock } \\
\text { management } \\
\text { (see Table 1) }\end{array}$} & \multirow{2}{*}{$\begin{array}{c}\begin{array}{c}\text { Feedstock } \\
\text { water content }^{\mathrm{a}}\end{array} \\
\mathrm{wt} \% \\
\end{array}$} & \multicolumn{2}{|c|}{$\begin{array}{c}\text { Costs of loading with a } \\
\text { front loader }\end{array}$} & \multirow{2}{*}{$\begin{array}{c}\begin{array}{c}\text { Net loading costs for } \\
\text { biomass transports }\end{array} \\
€_{2012} / t_{\text {DM }} \text { feedstock }\end{array}$} \\
\hline & & & $\begin{array}{l}€_{2012} / \mathrm{t}_{\mathrm{FW}} \\
\text { freight }^{\mathrm{b}}\end{array}$ & $\begin{array}{c}€_{2012} / \mathrm{t}_{\mathrm{DM}} \\
\text { feedstock }^{\mathrm{c}}\end{array}$ & \\
\hline & & (1) & (2) & (3) & (4) \\
\hline Cereal straw & Decomposition in field & 7.9 & \multirow{14}{*}{3.3} & 3.6 & 3.6 \\
\hline Forestry residues & Decomposition in forest & 10.8 & & $0^{\mathrm{d}}$ & $\mathbf{0}$ \\
\hline Open-country biomass residues & Composting, land spread & 7.8 & & - & $\mathbf{0}$ \\
\hline Industrial wood waste & Energetic use & 8.1 & & - & $\mathbf{0}$ \\
\hline Wood in municipal solid waste & Composting, land spread & 10.9 & & - & $\mathbf{0}$ \\
\hline Green waste: Compensation areas & Decomposition on site & 6.3 & & 3.5 & 3.5 \\
\hline Biomass: Habitat-connectivity areas & Composting, land spread & 7.8 & & - & $\mathbf{0}$ \\
\hline Green waste: Extensive grassland & Composting, land spread & 7.8 & & - & $\mathbf{0}$ \\
\hline Short-rotation coppice: Erosion areas & Energetic use & 17.9 & & - & $\mathbf{0}$ \\
\hline Solid cattle manure & Solid storage, land spread & 63.6 & & 9.1 & 9.1 \\
\hline Solid swine manure & Solid storage, land spread & 78.5 & & 15.3 & 15.3 \\
\hline Solid poultry manure & Solid storage, land spread & 13.4 & & 3.8 & 3.8 \\
\hline Commercial and industrial waste & Composting, land spread & 61.3 & & - & $\mathbf{0}$ \\
\hline Organic municipal solid waste & Composting, land spread & 70.9 & & - & $\mathbf{0}$ \\
\hline
\end{tabular}

Sources:

a) Teichmann (2014a: Table 8, column 4). The feedstock water contents are based on as-received fresh weight.

b) Own calculation, based on the difference in the 5-km transport costs (using truck combinations with a transport volume of $80 \mathrm{~m}^{3}$ and a payload of $23 \mathrm{t}$ ) for spruce chips of $6.5 €_{\sim 2002} / \mathrm{t}_{\mathrm{FW}}\left(\mathrm{FNR} 2005\right.$ : Table 6-11) and for poplar chips of 9.0 $€_{\sim 2002} / \mathrm{t}_{\mathrm{FW}}(\mathrm{FNR} 2005$ : Table 6-16), where the transport costs for spruce chips exclude loading costs (FNR 2005: 211), but those for poplar chips include costs for loading with a front loader (FNR 2005: 214). The resulting difference of $2.5 €_{\sim 2002} / \mathrm{t}_{\mathrm{FW}}$ freight is transformed into 2012 euros with the help of the producer price index for agricultural products of 89.4 for 2002 and 119.4 for 2012 (Statistisches Bundesamt 2015a), i.e. 3.3 = (9.0-6.5) 119.4/89.4. Note that we have chosen the producer price index for agricultural products since more specific producer price indices for transport-related services are not available before 2006. Further note that the entire difference in the transport costs is assigned to loading since spruce chips and poplar chips have similar bulk densities of $0.232 \mathrm{t}_{\mathrm{FW}} / \mathrm{m}^{3}$ (FNR 2005: Table 6-11) and $0.215 \mathrm{t}_{\mathrm{FW}} / \mathrm{m}^{3}$ (FNR 2005 : Table 6-16), respectively. Thus, any other factors influencing the transport costs are assumed negligible. Due to the lack of more specific data, it is further assumed that the loading costs are constant across the feedstocks.

c) Own calculation, expressing the value from column 2 per dry tonne of feedstock, i.e. $(3)=(2) /(1-(1) / 100)$.

d) Following FNR (2005: 211), it is assumed that wood chips are directly filled into trucks by woodchippers or via woodchipper containers, such that there are no extra costs for loading with a front loader.

e) Own calculation, (4) = (3) for the feedstocks assumed to decompose on site in the baseline scenario and for the solid manures; for all other feedstocks, the net loading costs are zero.

Notes: Values rounded. $\mathrm{DM}=$ dry mass. $\mathrm{FW}=$ fresh weight. $\mathrm{t}=$ tonne. $\mathrm{wt} \%=$ weight percent. $\mathrm{km}=$ kilometer. $\mathrm{m}^{3}=$ cubic meter. $-=$ not applicable. 
Table 24: Equipment and Labor Costs for Biomass Transportation, Germany, 2015-2050, Scenario Max 1

\begin{tabular}{|c|c|c|c|c|c|c|c|c|c|c|c|c|c|c|c|}
\hline \multirow[b]{4}{*}{ Feedstocks } & \multicolumn{5}{|c|}{ Small-scale pyrolysis units } & \multicolumn{5}{|c|}{ Medium-scale pyrolysis units } & \multicolumn{5}{|c|}{ Large-scale pyrolysis units } \\
\hline & 2015 & 2020 & 2030 & 2040 & 2050 & 2015 & 2020 & 2030 & 2040 & 2050 & 2015 & 2020 & 2030 & 2040 & 2050 \\
\hline & \multicolumn{5}{|c|}{$€_{2012} / t_{\text {DM }}$ feedstock } & \multicolumn{5}{|c|}{$€_{2012} / t_{\text {DM }}$ feedstock } & \multicolumn{5}{|c|}{$\epsilon_{2012} / \mathrm{t}_{\mathrm{DM}}$ feedstock } \\
\hline & (1) & (2) & (3) & $(4)$ & (5) & (6) & (7) & $(8)$ & (9) & (10) & (11) & $(12)$ & (13) & (14) & (15) \\
\hline Cereal straw & 10.9 & 8.1 & 5.7 & 5.6 & 5.6 & 14.6 & 10.7 & 7.6 & 7.5 & 7.4 & 24.8 & 18.3 & 12.9 & 12.7 & 12.7 \\
\hline Forestry residues & 11.3 & 8.3 & 5.9 & 5.8 & 5.8 & 15.0 & 11.1 & 7.8 & 7.7 & 7.7 & 25.6 & 18.9 & 13.3 & 13.2 & 13.1 \\
\hline Open-country biomass residues & 10.9 & 8.1 & 5.7 & 5.6 & 5.6 & 14.6 & 10.7 & 7.6 & 7.5 & 7.4 & 24.7 & 18.2 & 12.9 & 12.7 & 12.6 \\
\hline Industrial wood waste & 11.0 & 8.1 & 5.7 & 5.6 & 5.6 & 14.6 & 10.8 & 7.6 & 7.5 & 7.5 & 24.8 & 18.3 & 12.9 & 12.8 & 12.7 \\
\hline Wood in municipal solid waste & 11.3 & 8.3 & 5.9 & 5.8 & 5.8 & 15.1 & 11.1 & 7.8 & 7.8 & 7.7 & 25.6 & 18.9 & 13.3 & 13.2 & 13.1 \\
\hline Green waste: Compensation areas & 10.8 & 7.9 & 5.6 & 5.5 & 5.5 & 14.3 & 10.6 & 7.5 & 7.4 & 7.3 & 24.3 & 17.9 & 12.7 & 12.5 & 12.4 \\
\hline Biomass: Habitat-connectivity areas & 10.9 & 8.1 & 5.7 & 5.6 & 5.6 & 14.6 & 10.7 & 7.6 & 7.5 & 7.4 & 24.7 & 18.2 & 12.9 & 12.7 & 12.6 \\
\hline Green waste: Extensive grassland & 10.9 & 8.1 & 5.7 & 5.6 & 5.6 & 14.6 & 10.7 & 7.6 & 7.5 & 7.4 & 24.7 & 18.2 & 12.9 & 12.7 & 12.6 \\
\hline Short-rotation coppice: Erosion areas & 12.3 & 9.1 & 6.4 & 6.3 & 6.3 & 16.3 & 12.1 & 8.5 & 8.4 & 8.4 & 27.8 & 20.5 & 14.4 & 14.3 & 14.2 \\
\hline Solid cattle manure & 27.7 & 20.4 & 14.4 & 14.3 & 14.2 & 36.9 & 27.2 & 19.2 & 19.0 & 18.8 & 62.7 & 46.2 & 32.6 & 32.3 & 32.0 \\
\hline Solid swine manure & 46.9 & 34.6 & 24.4 & 24.1 & 24.0 & 62.4 & 46.0 & 32.5 & 32.1 & 31.9 & 106.1 & 78.2 & 55.2 & 54.6 & 54.2 \\
\hline Solid poultry manure & 11.6 & 8.6 & 6.1 & 6.0 & 6.0 & 15.5 & 11.4 & 8.1 & 8.0 & 7.9 & 26.3 & 19.4 & 13.7 & 13.6 & 13.5 \\
\hline Commercial and industrial waste & 26.1 & 19.2 & 13.6 & 13.4 & 13.3 & 34.7 & 25.6 & 18.0 & 17.9 & 17.7 & 58.9 & 43.5 & 30.7 & 30.3 & 30.1 \\
\hline Organic municipal solid waste & 34.6 & 25.6 & 18.0 & 17.8 & 17.7 & 46.1 & 34.0 & 24.0 & 23.7 & 23.6 & 78.4 & 57.8 & 40.8 & 40.3 & 40.1 \\
\hline
\end{tabular}

Sources: Own calculation, multiplying the equipment and labor costs for biomass transports from Table S.34, columns 2-4 by the mean transport distances of scenario Max 1 given in Table S.32, row A.

Notes: Values rounded. DM = dry mass. $\mathrm{t}=$ tonne. All tables numbered with the leading 'S.' refer to Teichmann (2015). 
Table 25: Equipment and Labor Costs for Biomass Transports in the Baseline Scenario

\begin{tabular}{|c|c|c|c|}
\hline \multirow[t]{3}{*}{ Feedstocks } & \multirow{3}{*}{$\begin{array}{l}\text { Conventional feedstock } \\
\text { management } \\
\text { (see Table 1) }\end{array}$} & Feedstock water content $^{\mathrm{a}}$ & \multirow{2}{*}{$\frac{\text { Costs for equipment and labor }^{\mathbf{b}}}{\epsilon_{2012} / \mathrm{t}_{\mathrm{DM}} \text { feedstock }}$} \\
\hline & & $\mathrm{wt} \%$ & \\
\hline & & (1) & (2) \\
\hline Cereal straw & Decomposition in field & 7.9 & - \\
\hline Forestry residues & Decomposition in forest & 10.8 & - \\
\hline Open-country biomass residues & Composting, land spread & 7.8 & 9.8 \\
\hline Industrial wood waste & Energetic use & 8.1 & 9.8 \\
\hline Wood in municipal solid waste & Composting, land spread & 10.9 & 10.1 \\
\hline Green waste: Compensation areas & Decomposition on site & 6.3 & - \\
\hline Biomass: Habitat-connectivity areas & Composting, land spread & 7.8 & 9.8 \\
\hline Green waste: Extensive grassland & Composting, land spread & 7.8 & 9.8 \\
\hline Short-rotation coppice: Erosion areas & Energetic use & 17.9 & $\mathbf{1 1 . 0}$ \\
\hline Solid cattle manure & Solid storage, land spread & 63.6 & - \\
\hline Solid swine manure & Solid storage, land spread & 78.5 & - \\
\hline Solid poultry manure & Solid storage, land spread & 13.4 & - \\
\hline Commercial and industrial waste & Composting, land spread & 61.3 & 23.3 \\
\hline Organic municipal solid waste & Composting, land spread & 70.9 & 30.9 \\
\hline
\end{tabular}

Sources:

a) Teichmann (2014a: Table 8, column 4). The feedstock water contents are based on as-received fresh weight.

b) Own calculation, based on the $10-\mathrm{km}$ costs for equipment and labor from Table S.33, column 6 of $1.0 €_{2012} /\left(\mathrm{t}_{\mathrm{FW}}\right.$ freight $\left.\cdot \mathrm{km}\right)($ as rounded to one decimal place), the average transport distance of $9 \mathrm{~km}$ (Teichmann $2014 \mathrm{a})$ and the water contents from column 1 , i.e. $(2)=1.0 /(1$ - (1)/100) 9 .

Notes: Values rounded. $\mathrm{DM}=$ dry mass. $\mathrm{FW}=$ fresh weight. $\mathrm{t}=$ tonne. $\mathrm{wt} \%=$ weight percent. $\mathrm{km}=$ kilometer. $-=$ not applicable. All tables numbered with the leading 'S.' refer to Teichmann (2015). 
Table 26: Transport Fuel Costs for Biomass Transportation, Germany, 2015-2050 - Price Path B, Scenario Max 1

\begin{tabular}{|c|c|c|c|c|c|c|c|c|c|c|c|c|c|c|c|}
\hline \multirow[b]{4}{*}{ Feedstocks } & \multicolumn{5}{|c|}{ Small-scale pyrolysis units } & \multicolumn{5}{|c|}{ Medium-scale pyrolysis units } & \multicolumn{5}{|c|}{ Large-scale pyrolysis units } \\
\hline & 2015 & 2020 & 2030 & 2040 & 2050 & 2015 & 2020 & 2030 & 2040 & 2050 & 2015 & 2020 & 2030 & 2040 & 2050 \\
\hline & \multicolumn{5}{|c|}{$€_{2012} / \mathrm{t}_{\mathrm{DM}}$ feedstock } & \multicolumn{5}{|c|}{$€_{2012} / \mathrm{t}_{\mathrm{DM}}$ feedstock } & \multicolumn{5}{|c|}{$\epsilon_{2012} / \mathrm{t}_{\mathrm{DM}}$ feedstock } \\
\hline & (1) & (2) & (3) & $(4)$ & (5) & (6) & (7) & $(8)$ & (9) & (10) & (11) & $(12)$ & $(13)$ & (14) & (15) \\
\hline Cereal straw & 0.096 & 0.084 & 0.073 & 0.078 & 0.082 & 0.270 & 0.238 & 0.207 & 0.220 & 0.233 & 0.918 & 0.810 & 0.703 & 0.748 & 0.791 \\
\hline Forestry residues & 0.099 & 0.087 & 0.076 & 0.080 & 0.085 & 0.279 & 0.246 & 0.214 & 0.227 & 0.240 & 0.948 & 0.837 & 0.726 & 0.772 & 0.817 \\
\hline Open-country biomass residues & 0.095 & 0.084 & 0.073 & 0.078 & 0.082 & 0.270 & 0.238 & 0.207 & 0.220 & 0.233 & 0.917 & 0.809 & 0.703 & 0.747 & 0.790 \\
\hline Industrial wood waste & 0.096 & 0.084 & 0.073 & 0.078 & 0.082 & 0.271 & 0.239 & 0.207 & 0.220 & 0.233 & 0.920 & 0.812 & 0.705 & 0.749 & 0.793 \\
\hline Wood in municipal solid waste & 0.099 & 0.087 & 0.076 & 0.080 & 0.085 & 0.279 & 0.246 & 0.214 & 0.227 & 0.241 & 0.949 & 0.838 & 0.727 & 0.773 & 0.818 \\
\hline Green waste: Compensation areas & 0.094 & 0.083 & 0.072 & 0.076 & 0.081 & 0.266 & 0.234 & 0.203 & 0.216 & 0.229 & 0.903 & 0.796 & 0.691 & 0.735 & 0.778 \\
\hline Biomass: Habitat-connectivity areas & 0.095 & 0.084 & 0.073 & 0.078 & 0.082 & 0.270 & 0.238 & 0.207 & 0.220 & 0.233 & 0.917 & 0.809 & 0.703 & 0.747 & 0.790 \\
\hline Green waste: Extensive grassland & 0.095 & 0.084 & 0.073 & 0.078 & 0.082 & 0.270 & 0.238 & 0.207 & 0.220 & 0.233 & 0.917 & 0.809 & 0.703 & 0.747 & 0.790 \\
\hline Short-rotation coppice: Erosion areas & 0.107 & 0.095 & 0.082 & 0.087 & 0.092 & 0.303 & 0.267 & 0.232 & 0.247 & 0.261 & 1.030 & 0.909 & 0.789 & 0.839 & 0.888 \\
\hline Solid cattle manure & 0.242 & 0.213 & 0.185 & 0.197 & 0.208 & 0.684 & 0.603 & 0.524 & 0.557 & 0.589 & 2.324 & 2.050 & 1.780 & 1.892 & 2.002 \\
\hline Solid swine manure & 0.409 & 0.361 & 0.313 & 0.333 & 0.353 & 1.158 & 1.021 & 0.887 & 0.942 & 0.997 & 3.934 & 3.471 & 3.013 & 3.203 & 3.389 \\
\hline Solid poultry manure & 0.102 & 0.090 & 0.078 & 0.083 & 0.088 & 0.287 & 0.254 & 0.220 & 0.234 & 0.248 & 0.977 & 0.862 & 0.748 & 0.795 & 0.841 \\
\hline Commercial and industrial waste & 0.227 & 0.201 & 0.174 & 0.185 & 0.196 & 0.643 & 0.567 & 0.493 & 0.524 & 0.554 & 2.186 & 1.928 & 1.674 & 1.779 & 1.883 \\
\hline Organic municipal solid waste & 0.302 & 0.267 & 0.232 & 0.246 & 0.260 & 0.855 & 0.755 & 0.655 & 0.696 & 0.737 & 2.907 & 2.564 & 2.226 & 2.366 & 2.504 \\
\hline
\end{tabular}

Sources: Own calculation, multiplying the transport fuel costs for biomass transports from Table S.39, columns 7-11 by the respective mean transport distances of scenario Max 1 given in Table S.32, row A.

Notes: Values rounded. $\mathrm{DM}=$ dry mass. $\mathrm{t}=$ tonne. All tables numbered with the leading 'S.' refer to Teichmann (2015). 
Table 27: Transport Fuel Costs for Biomass Transportation in the Baseline Scenario, Germany, 2015-2050

\begin{tabular}{|c|c|c|c|c|c|c|c|c|c|c|c|c|c|c|c|c|}
\hline \multirow[b]{4}{*}{ Feedstocks } & \multirow{4}{*}{$\begin{array}{c}\begin{array}{c}\text { Feedstock } \\
\text { water } \\
\text { content }^{\mathrm{a}}\end{array} \\
\mathrm{wt} \% \\
(1) \\
\end{array}$} & \multicolumn{5}{|c|}{ Price path $A^{b}$} & \multicolumn{5}{|c|}{ Price path $B^{c}$} & \multicolumn{5}{|c|}{ Price path $C^{d}$} \\
\hline & & 2015 & 2020 & 2030 & 2040 & 2050 & 2015 & 2020 & 2030 & 2040 & 2050 & 2015 & 2020 & 2030 & 2040 & 2050 \\
\hline & & \multicolumn{5}{|c|}{$\epsilon_{2012} / \mathrm{t}_{\mathrm{DM}}$ feedstock } & \multicolumn{5}{|c|}{$\epsilon_{2012} / \mathrm{t}_{\mathrm{DM}}$ feedstock } & \multicolumn{5}{|c|}{$\epsilon_{2012} / \mathrm{t}_{\mathrm{DM}}$ feedstock } \\
\hline & & (2) & (3) & (4) & (5) & (6) & (7) & (8) & (9) & (10) & (11) & (12) & (13) & (14) & (15) & (16) \\
\hline Cereal straw & 7.9 & - & - & - & - & - & - & - & - & - & & - & - & - & - & \\
\hline Forestry residues & 10.8 & - & - & - & - & - & - & - & - & - & & - & - & - & - & \\
\hline Open-country biomass residues & 7.8 & 0.145 & 0.201 & 0.241 & 0.263 & 0.279 & 0.145 & 0.173 & 0.213 & 0.229 & 0.244 & 0.145 & 0.160 & 0.189 & 0.197 & 0.206 \\
\hline Industrial wood waste & 8.1 & 0.145 & 0.201 & 0.242 & 0.264 & 0.280 & 0.145 & 0.174 & 0.214 & 0.230 & 0.245 & 0.145 & 0.160 & 0.190 & 0.198 & 0.206 \\
\hline Wood in municipal solid waste & 10.9 & 0.150 & 0.208 & 0.250 & 0.272 & 0.289 & 0.150 & 0.179 & 0.221 & 0.237 & 0.253 & 0.150 & 0.165 & 0.196 & 0.204 & 0.213 \\
\hline Green waste: Compensation areas & 6.3 & - & - & - & - & - & - & - & - & - & - & - & - & - & - & - \\
\hline Biomass: Habitat-connectivity areas & 7.8 & 0.145 & 0.201 & 0.241 & 0.263 & 0.279 & 0.145 & 0.173 & 0.213 & 0.229 & 0.244 & 0.145 & 0.160 & 0.189 & 0.197 & 0.206 \\
\hline Green waste: Extensive grassland & 7.8 & 0.145 & 0.201 & 0.241 & 0.263 & 0.279 & 0.145 & 0.173 & 0.213 & 0.229 & 0.244 & 0.145 & 0.160 & 0.189 & 0.197 & 0.206 \\
\hline Short-rotation coppice: Erosion areas & 17.9 & 0.163 & 0.225 & 0.271 & 0.295 & 0.313 & 0.163 & 0.195 & 0.239 & 0.257 & 0.274 & 0.163 & 0.179 & 0.212 & 0.221 & 0.231 \\
\hline Solid cattle manure & 63.6 & - & - & - & - & - & - & - & - & - & - & - & - & - & - & - \\
\hline Solid swine manure & 78.5 & - & - & - & - & - & - & - & - & - & - & - & - & - & - & - \\
\hline Solid poultry manure & 13.4 & - & - & - & - & - & - & - & - & - & - & - & - & - & - & - \\
\hline Commercial and industrial waste & 61.3 & 0.345 & 0.478 & 0.575 & 0.626 & 0.664 & 0.345 & 0.413 & 0.508 & 0.546 & 0.581 & 0.345 & 0.380 & 0.450 & 0.470 & 0.490 \\
\hline Organic municipal solid waste & 70.9 & 0.459 & 0.636 & 0.765 & 0.833 & 0.884 & 0.459 & 0.549 & 0.676 & 0.726 & 0.773 & 0.459 & 0.506 & 0.599 & 0.625 & 0.652 \\
\hline
\end{tabular}

Sources:

a) Teichmann (2014a: Table 8, column 4). The feedstock water contents are based on as-received fresh weight.

b) Own calculation, transforming the values from Table S.38, row K (referring to the transportation of fresh-weight feedstocks) into dry-mass basis using the water contents from column 1 and multiplying by the average transport distance of $9 \mathrm{~km}$, e.g., $(2)=$ Table S.38 (row K, column 1)/(1 - (1)/100) $\cdot 9$.

c) Own calculation, transforming the values from Table S.38, row L (referring to the transportation of fresh-weight feedstocks) into dry-mass basis using the water contents from column 1 and multiplying by the average transport distance of $9 \mathrm{~km}$, e.g., $(7)=$ Table S.38 (row L, column 1$) /(1-(1) / 100) \cdot 9$.

d) Own calculation, transforming the values from Table S.38, row M (referring to the transportation of fresh-weight feedstocks) into dry-mass basis using the water contents from column 1 and multiplying by the average transport distance of $9 \mathrm{~km}$, e.g., (12) = Table S.38 (row M, column 1$) /(1-(1) / 100) \cdot 9$.

Notes: Values rounded. $\mathrm{DM}=$ dry mass. $\mathrm{t}=$ tonne. $\mathrm{wt} \%=$ weight percent. $\mathrm{km}=$ kilometer. $-=$ not applicable. All tables numbered with the leading 'S.' refer to Teichmann (2015). 
Table 28: Equipment and Labor Costs for Biochar Transportation, Germany, 2015-2050, Scenario Max 1

\begin{tabular}{|c|c|c|c|c|c|c|c|c|c|c|c|c|c|c|c|}
\hline \multirow[b]{4}{*}{ Feedstocks } & \multicolumn{5}{|c|}{ Small-scale pyrolysis units } & \multicolumn{5}{|c|}{ Medium-scale pyrolysis units } & \multicolumn{5}{|c|}{ Large-scale pyrolysis units } \\
\hline & 2015 & 2020 & 2030 & 2040 & 2050 & 2015 & 2020 & 2030 & 2040 & 2050 & 2015 & 2020 & 2030 & 2040 & 2050 \\
\hline & \multicolumn{5}{|c|}{$€_{2012} / \mathrm{t}_{\mathrm{DM}}$ feedstock } & \multicolumn{5}{|c|}{$€_{2012} / t_{\text {DM }}$ feedstock } & \multicolumn{5}{|c|}{$\epsilon_{2012} / \mathrm{t}_{\mathrm{DM}}$ feedstock } \\
\hline & (1) & (2) & (3) & (4) & (5) & (6) & (7) & $(8)$ & (9) & (10) & (11) & $(12)$ & (13) & (14) & (15) \\
\hline Cereal straw & 3.4 & 2.5 & 1.8 & 1.8 & 1.8 & 4.6 & 3.4 & 2.4 & 2.3 & 2.3 & 7.8 & 5.7 & 4.0 & 4.0 & 4.0 \\
\hline Forestry residues & 3.0 & 2.2 & 1.6 & 1.6 & 1.5 & 4.0 & 3.0 & 2.1 & 2.1 & 2.1 & 6.8 & 5.0 & 3.6 & 3.5 & 3.5 \\
\hline Open-country biomass residues & 3.1 & 2.3 & 1.6 & 1.6 & 1.6 & 4.2 & 3.1 & 2.2 & 2.1 & 2.1 & 7.1 & 5.2 & 3.7 & 3.6 & 3.6 \\
\hline Industrial wood waste & 2.9 & 2.2 & 1.5 & 1.5 & 1.5 & 3.9 & 2.9 & 2.0 & 2.0 & 2.0 & 6.6 & 4.9 & 3.4 & 3.4 & 3.4 \\
\hline Wood in municipal solid waste & 3.0 & 2.2 & 1.6 & 1.6 & 1.5 & 4.0 & 3.0 & 2.1 & 2.1 & 2.1 & 6.8 & 5.0 & 3.6 & 3.5 & 3.5 \\
\hline Green waste: Compensation areas & 3.2 & 2.4 & 1.7 & 1.7 & 1.6 & 4.3 & 3.2 & 2.2 & 2.2 & 2.2 & 7.3 & 5.4 & 3.8 & 3.8 & 3.7 \\
\hline Biomass: Habitat-connectivity areas & 3.1 & 2.3 & 1.6 & 1.6 & 1.6 & 4.2 & 3.1 & 2.2 & 2.1 & 2.1 & 7.1 & 5.2 & 3.7 & 3.6 & 3.6 \\
\hline Green waste: Extensive grassland & 3.1 & 2.3 & 1.6 & 1.6 & 1.6 & 4.2 & 3.1 & 2.2 & 2.1 & 2.1 & 7.1 & 5.2 & 3.7 & 3.6 & 3.6 \\
\hline Short-rotation coppice: Erosion areas & 2.5 & 1.9 & 1.3 & 1.3 & 1.3 & 3.4 & 2.5 & 1.7 & 1.7 & 1.7 & 5.7 & 4.2 & 3.0 & 2.9 & 2.9 \\
\hline Solid cattle manure & 4.7 & 3.5 & 2.5 & 2.4 & 2.4 & 6.3 & 4.7 & 3.3 & 3.2 & 3.2 & 10.7 & 7.9 & 5.6 & 5.5 & 5.5 \\
\hline Solid swine manure & 4.7 & 3.5 & 2.5 & 2.4 & 2.4 & 6.3 & 4.7 & 3.3 & 3.2 & 3.2 & 10.7 & 7.9 & 5.6 & 5.5 & 5.5 \\
\hline Solid poultry manure & 4.4 & 3.3 & 2.3 & 2.3 & 2.3 & 5.9 & 4.4 & 3.1 & 3.0 & 3.0 & 10.0 & 7.4 & 5.2 & 5.2 & 5.1 \\
\hline Commercial and industrial waste & 3.7 & 2.8 & 1.9 & 1.9 & 1.9 & 5.0 & 3.7 & 2.6 & 2.6 & 2.5 & 8.4 & 6.2 & 4.4 & 4.3 & 4.3 \\
\hline Organic municipal solid waste & 4.5 & 3.3 & 2.4 & 2.3 & 2.3 & 6.0 & 4.5 & 3.1 & 3.1 & 3.1 & 10.3 & 7.6 & 5.3 & 5.3 & 5.2 \\
\hline
\end{tabular}

Sources: Own calculation, multiplying the equipment and labor costs for biochar transports from Table S.51, columns 2-4 by the mean transport distances of scenario Max 1 given in Table S.32, row A.

Notes: Values rounded. DM = dry mass. $\mathrm{t}=$ tonne. All tables numbered with the leading 'S.' refer to Teichmann (2015). 
Table 29: Equipment and Labor Costs for Transports of Composts

\begin{tabular}{|c|c|c|}
\hline \multirow[t]{3}{*}{ Feedstocks } & \multirow{3}{*}{$\begin{array}{l}\text { Conventional feedstock } \\
\text { management } \\
\text { (see Table 1) }\end{array}$} & Costs for equipment and labor \\
\hline & & $€_{2012} / \mathrm{t}_{\mathrm{DM}}$ feedstock \\
\hline & & $(1)$ \\
\hline Cereal straw & Decomposition in field & - \\
\hline Forestry residues & Decomposition in forest & \\
\hline Open-country biomass residues & Composting, land spread & 9.6 \\
\hline Industrial wood waste & Energetic use & - \\
\hline Wood in municipal solid waste & Composting, land spread & 9.6 \\
\hline Green waste: Compensation areas & Decomposition on site & - \\
\hline Biomass: Habitat-connectivity areas & Composting, land spread & 9.6 \\
\hline Green waste: Extensive grassland & Composting, land spread & 9.6 \\
\hline Short-rotation coppice: Erosion areas & Energetic use & - \\
\hline Solid cattle manure & Solid storage, land spread & - \\
\hline Solid swine manure & Solid storage, land spread & - \\
\hline Solid poultry manure & Solid storage, land spread & - \\
\hline Commercial and industrial waste & Composting, land spread & 9.6 \\
\hline Organic municipal solid waste & Composting, land spread & 9.6 \\
\hline
\end{tabular}

Sources: Own calculation, based on the 10-km costs for equipment and labor from Table S.33, column 6 of $1.0 €_{2012} /\left(\mathrm{t}_{\mathrm{Fw}}\right.$ freight $\left.\cdot \mathrm{km}\right)(\mathrm{as}$ rounded to one decimal place), the average transport distance of $9 \mathrm{~km}$ (Teichmann 2014a) and the assumptions that $64 \%$ of the biomass (dry mass) to be composted is transformed into compost (dry mass) and that composts (fresh weight) have an average water content of $40 \%$ (derived from Knappe et al. 2012: Figures D-2 and D-5, referring to finished compost from household biowaste and from greenwaste). Due to the lack of more specific data, the respective values were applied to all the composts. Accounting for the fact that composts are transported undry, the costs for equipment and labor are calculated as $(1)=1.0 \cdot 64 /(100-40) \cdot 9$.

Notes: Values rounded. $\mathrm{DM}=$ dry mass. $\mathrm{FW}=$ fresh weight. $\mathrm{t}=$ tonne. $\mathrm{km}=$ kilometer. $-=$ not applicable. All tables numbered with the leading 'S.' refer to Teichmann (2015). 
Table 30: Transport Fuel Costs for Biochar Transportation, Germany, 2015-2050 - Price Path B, Scenario Max 1

\begin{tabular}{|c|c|c|c|c|c|c|c|c|c|c|c|c|c|c|c|}
\hline \multirow[b]{4}{*}{ Feedstocks } & \multicolumn{5}{|c|}{ Small-scale pyrolysis units } & \multicolumn{5}{|c|}{ Medium-scale pyrolysis units } & \multicolumn{5}{|c|}{ Large-scale pyrolysis units } \\
\hline & 2015 & 2020 & 2030 & 2040 & 2050 & 2015 & 2020 & 2030 & 2040 & 2050 & 2015 & 2020 & 2030 & 2040 & 2050 \\
\hline & \multicolumn{5}{|c|}{$€_{2012} / \mathrm{t}_{\mathrm{DM}}$ feedstock } & \multicolumn{5}{|c|}{$€_{2012} / \mathrm{t}_{\mathrm{DM}}$ feedstock } & \multicolumn{5}{|c|}{$\epsilon_{2012} / \mathrm{t}_{\mathrm{DM}}$ feedstock } \\
\hline & (1) & (2) & (3) & $(4)$ & (5) & (6) & (7) & $(8)$ & (9) & (10) & (11) & $(12)$ & $(13)$ & (14) & (15) \\
\hline Cereal straw & 0.030 & 0.026 & 0.023 & 0.024 & 0.026 & 0.085 & 0.075 & 0.065 & 0.069 & 0.073 & 0.288 & 0.254 & 0.220 & 0.234 & 0.248 \\
\hline Forestry residues & 0.026 & 0.023 & 0.020 & 0.021 & 0.023 & 0.075 & 0.066 & 0.057 & 0.061 & 0.064 & 0.254 & 0.224 & 0.194 & 0.207 & 0.219 \\
\hline Open-country biomass residues & 0.027 & 0.024 & 0.021 & 0.022 & 0.023 & 0.077 & 0.068 & 0.059 & 0.063 & 0.066 & 0.262 & 0.231 & 0.201 & 0.213 & 0.226 \\
\hline Industrial wood waste & 0.026 & 0.023 & 0.020 & 0.021 & 0.022 & 0.072 & 0.064 & 0.055 & 0.059 & 0.062 & 0.245 & 0.216 & 0.188 & 0.200 & 0.211 \\
\hline Wood in municipal solid waste & 0.026 & 0.023 & 0.020 & 0.021 & 0.023 & 0.075 & 0.066 & 0.057 & 0.061 & 0.064 & 0.254 & 0.224 & 0.194 & 0.207 & 0.219 \\
\hline Green waste: Compensation areas & 0.028 & 0.025 & 0.022 & 0.023 & 0.024 & 0.080 & 0.070 & 0.061 & 0.065 & 0.069 & 0.271 & 0.239 & 0.207 & 0.220 & 0.233 \\
\hline Biomass: Habitat-connectivity areas & 0.027 & 0.024 & 0.021 & 0.022 & 0.023 & 0.077 & 0.068 & 0.059 & 0.063 & 0.066 & 0.262 & 0.231 & 0.201 & 0.213 & 0.226 \\
\hline Green waste: Extensive grassland & 0.027 & 0.024 & 0.021 & 0.022 & 0.023 & 0.077 & 0.068 & 0.059 & 0.063 & 0.066 & 0.262 & 0.231 & 0.201 & 0.213 & 0.226 \\
\hline Short-rotation coppice: Erosion areas & 0.022 & 0.019 & 0.017 & 0.018 & 0.019 & 0.062 & 0.055 & 0.048 & 0.051 & 0.054 & 0.211 & 0.187 & 0.162 & 0.172 & 0.182 \\
\hline Solid cattle manure & 0.041 & 0.036 & 0.032 & 0.034 & 0.036 & 0.117 & 0.103 & 0.090 & 0.095 & 0.101 & 0.398 & 0.351 & 0.304 & 0.324 & 0.342 \\
\hline Solid swine manure & 0.041 & 0.036 & 0.032 & 0.034 & 0.036 & 0.117 & 0.103 & 0.090 & 0.095 & 0.101 & 0.398 & 0.351 & 0.304 & 0.324 & 0.342 \\
\hline Solid poultry manure & 0.039 & 0.034 & 0.030 & 0.032 & 0.033 & 0.110 & 0.097 & 0.084 & 0.089 & 0.094 & 0.372 & 0.328 & 0.285 & 0.303 & 0.321 \\
\hline Commercial and industrial waste & 0.033 & 0.029 & 0.025 & 0.027 & 0.028 & 0.092 & 0.081 & 0.071 & 0.075 & 0.079 & 0.313 & 0.276 & 0.240 & 0.255 & 0.270 \\
\hline Organic municipal solid waste & 0.040 & 0.035 & 0.030 & 0.032 & 0.034 & 0.112 & 0.099 & 0.086 & 0.091 & 0.096 & 0.381 & 0.336 & 0.292 & 0.310 & 0.328 \\
\hline
\end{tabular}

Sources: Own calculation, multiplying the transport fuel costs for biochar transports from Table S.55, columns 7-11 by the respective mean transport distances of scenario Max 1 given in Table S.32, row A.

Notes: Values rounded. $\mathrm{DM}=$ dry mass. $\mathrm{t}=$ tonne. All tables numbered with the leading 'S.' refer to Teichmann (2015). 
Table 31: Transport Fuel Costs for the Transportation of Composts, Germany, 2015-2050

\begin{tabular}{|c|c|c|c|c|c|c|c|c|c|c|c|c|c|c|c|}
\hline \multirow[b]{4}{*}{ Feedstocks } & \multicolumn{5}{|c|}{ Price path $A^{\mathrm{a}}$} & \multicolumn{5}{|c|}{ Price path $B^{b}$} & \multicolumn{5}{|c|}{ Price path $C^{c}$} \\
\hline & 2015 & 2020 & 2030 & 2040 & 2050 & 2015 & 2020 & 2030 & 2040 & 2050 & 2015 & 2020 & 2030 & 2040 & 2050 \\
\hline & \multicolumn{5}{|c|}{$\epsilon_{2012} / t_{\mathrm{DM}}$ feedstock } & \multicolumn{5}{|c|}{$€_{2012} / \mathrm{t}_{\mathrm{DM}}$ feedstock } & \multicolumn{5}{|c|}{$\epsilon_{2012} / \mathrm{t}_{\mathrm{DM}}$ feedstock } \\
\hline & (1) & (2) & (3) & (4) & (5) & (6) & (7) & $(8)$ & (9) & (10) & (11) & $(12)$ & (13) & (14) & (15) \\
\hline Cereal straw & - & - & - & - & - & - & - & - & - & - & - & - & - & - & - \\
\hline Forestry residues & - & - & - & - & - & - & - & - & - & - & - & - & - & - & - \\
\hline Open-country biomass residues & 0.142 & 0.197 & 0.237 & 0.258 & 0.274 & 0.142 & 0.170 & 0.210 & 0.225 & 0.240 & 0.142 & 0.157 & 0.186 & 0.194 & 0.202 \\
\hline Industrial wood waste & & - & - & - & - & - & - & - & - & & - & - & - & - & \\
\hline Wood in municipal solid waste & 0.142 & 0.197 & 0.237 & 0.258 & 0.274 & 0.142 & 0.170 & 0.210 & 0.225 & 0.240 & 0.142 & 0.157 & 0.186 & 0.194 & 0.202 \\
\hline Green waste: Compensation areas & - & - & - & - & - & - & - & - & - & - & - & - & - & - & - \\
\hline Biomass: Habitat-connectivity areas & 0.142 & 0.197 & 0.237 & 0.258 & 0.274 & 0.142 & 0.170 & 0.210 & 0.225 & 0.240 & 0.142 & 0.157 & 0.186 & 0.194 & 0.202 \\
\hline Green waste: Extensive grassland & 0.142 & 0.197 & 0.237 & 0.258 & 0.274 & 0.142 & 0.170 & 0.210 & 0.225 & 0.240 & 0.142 & 0.157 & 0.186 & 0.194 & 0.202 \\
\hline Short-rotation coppice: Erosion areas & - & - & - & - & - & - & - & - & - & - & - & - & - & - & - \\
\hline Solid cattle manure & - & - & - & - & - & - & - & - & - & - & - & - & - & - & \\
\hline Solid swine manure & - & - & - & - & - & - & - & - & - & - & - & - & - & - & - \\
\hline Solid poultry manure & - & - & - & - & - & - & - & - & - & - & - & - & - & - & - \\
\hline Commercial and industrial waste & 0.142 & 0.197 & 0.237 & 0.258 & 0.274 & 0.142 & 0.170 & 0.210 & 0.225 & 0.240 & 0.142 & 0.157 & 0.186 & 0.194 & 0.202 \\
\hline Organic municipal solid waste & 0.142 & 0.197 & 0.237 & 0.258 & 0.274 & 0.142 & 0.170 & 0.210 & 0.225 & 0.240 & 0.142 & 0.157 & 0.186 & 0.194 & 0.202 \\
\hline
\end{tabular}

Sources:

a) Own calculation, transforming the values from Table S.38, row K (referring to the transportation of fresh-weight composts) into tDM-feedstock basis using the assumptions that $64 \%$ of the biomass (dry mass) to be composted is transformed into compost (dry mass) and that composts (fresh weight) have an average water content of 40\% (derived from Knappe et al. 2012: Figures D-2 and D-5, referring to finished compost from household biowaste and from greenwaste*), and multiplying by the average transport distance of $9 \mathrm{~km}$, e.g. . $(1)=$ Table S.38 (row K, column 1$) \cdot 64 /(100-40) \cdot 9$.

b) Own calculation, transforming the values from Table S.38, row L (referring to the transportation of fresh-weight composts) into tom-feedstock basis using the assumptions that $64 \%$ of the biomass (dry mass) to be composted is transformed into compost (dry mass) and that composts (fresh weight) have an average water content of 40\% (derived from Knappe et al. 2012: Figures D-2 and D-5, referring to finished compost from household biowaste and from greenwaste*), and multiplying by the average transport distance of $9 \mathrm{~km}$, e.g., $(6)=$ Table S.38 (row L, column 1$) \cdot 64 /(100-40) \cdot 9$.

c) Own calculation, transforming the values from Table S.38, row M (referring to the transportation of fresh-weight composts) into tDM-feedstock basis using the assumptions that $64 \%$ of the biomass (dry mass) to be composted is transformed into compost (dry mass) and that composts (fresh weight) have an average water content of 40\% (derived from Knappe et al. 2012: Figures D-2 and D-5, referring to finished compost from household biowaste and from greenwaste ${ }^{*}$ ), and multiplying by the average transport distance of $9 \mathrm{~km}$, e.g., $(11)=$ Table S.38 $($ row M, column 1$) \cdot 64 /(100-40) \cdot 9$

Notes: Values rounded. $\mathrm{DM}=$ dry mass. $\mathrm{t}=$ tonne. $\mathrm{km}=$ kilometer. - = not applicable. All tables numbered with the leading 'S.' refer to Teichmann $(2015)$.

$*=$ Due to the lack of more specific data, the respective values were applied to all the composts. 
Table 32: Net Unloading Costs of Biochar

\begin{tabular}{|c|c|c|c|c|c|}
\hline \multirow[t]{3}{*}{ Feedstocks } & \multirow[t]{3}{*}{$\begin{array}{l}\text { Conventional feedstock } \\
\text { management } \\
\text { (see Table 1) }\end{array}$} & Char yields $^{\mathrm{a}}$ & $\begin{array}{c}\text { Costs of } \\
\text { unloading of }^{\text {biochar }^{\mathrm{b}}}\end{array}$ & $\begin{array}{l}\text { Costs of } \\
\text { unloading of } \\
\text { composts }^{\mathrm{c}}\end{array}$ & $\begin{array}{l}\text { Net unloading } \\
\text { costs of biochar }\end{array}$ \\
\hline & & $\mathrm{wt} \%_{\mathrm{db}}$ & $\begin{array}{c}€_{2012} / \mathrm{t}_{\mathrm{DM}} \\
\text { feedstock }\end{array}$ & $\begin{array}{c}€_{2012} / t_{\mathrm{DM}} \\
\text { feedstock }\end{array}$ & $\begin{array}{c}€_{2012} / t_{\mathrm{DM}} \\
\text { feedstock }\end{array}$ \\
\hline & & (1) & (2) & (3) & (4) \\
\hline Cereal straw & Decomposition in field & 34 & 1.12 & - & 1.1 \\
\hline Forestry residues & Decomposition in forest & 30 & 0.99 & - & 1.0 \\
\hline Open-country biomass residues & Composting, land spread & 31 & 1.02 & 3.52 & -2.5 \\
\hline Industrial wood waste & Energetic use & 29 & 0.96 & - & 1.0 \\
\hline Wood in municipal solid waste & Composting, land spread & 30 & 0.99 & 3.52 & -2.5 \\
\hline Green waste: Compensation areas & Decomposition on site & 32 & 1.06 & - & 1.1 \\
\hline Biomass: Habitat-connectivity areas & Composting, land spread & 31 & 1.02 & 3.52 & -2.5 \\
\hline Green waste: Extensive grassland & Composting, land spread & 31 & 1.02 & 3.52 & -2.5 \\
\hline Short-rotation coppice: Erosion areas & Energetic use & 25 & 0.83 & - & 0.8 \\
\hline Solid cattle manure & Solid storage, land spread & 47 & 1.55 & - & 1.6 \\
\hline Solid swine manure & Solid storage, land spread & 47 & 1.55 & - & 1.6 \\
\hline Solid poultry manure & Solid storage, land spread & 44 & 1.45 & - & 1.5 \\
\hline Commercial and industrial waste & Composting, land spread & 37 & 1.22 & 3.52 & -2.3 \\
\hline Organic municipal solid waste & Composting, land spread & 45 & 1.49 & 3.52 & -2.0 \\
\hline
\end{tabular}

Sources:

a) Teichmann (2014a: Table 8, column 6). The char yields are based on feedstock dry weight. No differentiation takes place between biochar fresh weight and biochar dry weight.

b) Own calculation, based on the costs for loading with a front loader of $3.3 €_{2012} / \mathrm{t}_{\mathrm{FW}}$ freight (Table 23 , column 2 ) and the char yields given in column 1, i.e. $(2)=3.3 \cdot(1) / 100$. Note that we do not differentiate between biochar fresh weight and biochar dry weight.

c) Own calculation, based on the costs for loading with a front loader of $3.3 €_{2012} / \mathrm{t}_{\mathrm{FW}}$ freight (Table 23 , column 2) and the assumptions that $64 \%$ of the biomass (dry mass) to be composted is transformed into compost (dry mass) and that composts (fresh weight) have an average water content of $40 \%$ (derived from Knappe et al. 2012: Figures D-2 and D-5, referring to finished compost from household biowaste and from greenwaste). Due to the lack of more specific data, the respective values were applied to all the composts. That is, (3) $=3.3 \cdot 64 /(100-40)$.

d) Own calculation, $(4)=(2)-(3)$.

Notes: Values rounded. $\mathrm{DM}=$ dry mass. $\mathrm{FW}=$ fresh weight. $\mathrm{t}=$ tonne. $\mathrm{wt} \%=$ weight percent. $\mathrm{db}=$ dry base. $-=$ not applicable. 
Table 33: Costs of Biochar Storage

\begin{tabular}{|c|c|c|c|c|c|}
\hline & & & $\begin{array}{c}\text { Small-scale } \\
\text { pyrolysis units }\end{array}$ & $\begin{array}{l}\text { Medium-scale } \\
\text { pyrolysis units }\end{array}$ & $\begin{array}{c}\text { Large-scale } \\
\text { pyrolysis units }\end{array}$ \\
\hline \multirow{2}{*}{ Annual storage costs } & $£_{2007} /$ biochar $^{\mathrm{a}}$ & (A) & 7 & 15 & 10 \\
\hline & $\epsilon_{2012} /$ biochar $^{\mathrm{b}}$ & (B) & 8.4 & 18.0 & 12.0 \\
\hline \multirow[b]{3}{*}{ Feedstocks } & \multicolumn{2}{|c|}{ Char yields $^{c}$} & \multicolumn{3}{|c|}{ Costs of biochar storage $^{\mathrm{d}}$} \\
\hline & \multicolumn{2}{|c|}{$\mathrm{wt} \%_{\mathrm{db}}$} & \multicolumn{3}{|c|}{$€_{2012} / \mathrm{t}_{\mathrm{DM}}$ feedstock } \\
\hline & \multicolumn{2}{|c|}{ (1) } & (2) & (3) & (4) \\
\hline Cereal straw & \multicolumn{2}{|l|}{34} & 2.9 & 6.1 & 4.1 \\
\hline Forestry residues & \multicolumn{2}{|l|}{30} & 2.5 & 5.4 & 3.6 \\
\hline Open-country biomass residues & \multicolumn{2}{|l|}{31} & 2.6 & 5.6 & 3.7 \\
\hline Industrial wood waste & \multicolumn{2}{|l|}{29} & 2.4 & 5.2 & 3.5 \\
\hline Wood in municipal solid waste & \multicolumn{2}{|l|}{30} & 2.5 & 5.4 & 3.6 \\
\hline Green waste: Compensation areas & \multicolumn{2}{|l|}{32} & 2.7 & 5.8 & 3.8 \\
\hline Biomass: Habitat-connectivity areas & \multicolumn{2}{|l|}{31} & 2.6 & 5.6 & 3.7 \\
\hline Green waste: Extensive grassland & \multicolumn{2}{|l|}{31} & 2.6 & 5.6 & 3.7 \\
\hline Short-rotation coppice: Erosion areas & \multicolumn{2}{|l|}{25} & 2.1 & 4.5 & 3.0 \\
\hline Solid cattle manure & \multicolumn{2}{|l|}{47} & 3.9 & 8.5 & 5.6 \\
\hline Solid swine manure & \multicolumn{2}{|l|}{47} & 3.9 & 8.5 & 5.6 \\
\hline Solid poultry manure & \multicolumn{2}{|l|}{44} & 3.7 & 7.9 & 5.3 \\
\hline Commercial and industrial waste & \multicolumn{2}{|l|}{37} & 3.1 & 6.7 & 4.4 \\
\hline Organic municipal solid waste & \multicolumn{2}{|l|}{45} & 3.8 & 8.1 & 5.4 \\
\hline
\end{tabular}

Sources:

a) Shackley et al. (2011: Box 1 and Tables 8-10), i.e. referring to average storage of 20 weeks with $£_{2007} 0.35$ per tonne of biochar and week in existing farm storage facilities for biochar from small-scale pyrolysis units and to storage of biochar from medium- and large-scale pyrolysis units in specially constructed storage facilities, where a higher load factor - and, thus, a lower storage cost - is assumed for storage facilities for biochar from large-scale pyrolysis units than for those for biochar from medium-scale pyrolysis units. For further details, see Shackley et al. (2011: Box 1).

b) Own calculation, first transforming the costs from row A into US-dollars using the exchange rate of 1.5 USD/£ (Shackley et al. 2011 : Table 6) and then applying the 2007 average exchange rate of 1.3705 USD/ $€$ (Deutsche Bundesbank 2012) and the 2007 and 2012 producer price indices of 97.5 and 107.0, respectively (Deutsche Bundesbank 2015), i.e. $(\mathrm{B})=(\mathrm{A}) \cdot 1.5 / 1.3705 \cdot 107.0 / 97.5$.

c) Teichmann (2014a: Table 8, column 6). The char yields are based on feedstock dry weight. No differentiation takes place between biochar fresh weight and biochar dry weight.

d) Own calculation, expressing the storage costs from row B per dry tonne of feedstock using the char yields from column 1 , e.g., $(2)=8.4$ $\cdot(1) / 100$.

Notes: Values rounded. $\mathrm{DM}=$ dry mass. $\mathrm{t}=$ tonne. $\mathrm{wt} \%=$ weight percent. $\mathrm{db}=$ dry base. 
Table 34: Net Equipment and Labor Costs for Biochar Soil Addition

\begin{tabular}{|c|c|c|c|c|c|c|}
\hline \multirow[t]{4}{*}{ Feedstocks } & \multirow{4}{*}{$\begin{array}{l}\text { Conventional feedstock } \\
\text { management } \\
\text { (see Table 1) }\end{array}$} & \multirow{2}{*}{$\begin{array}{c}\text { Feed- } \\
\text { stock } \\
\text { water } \\
\text { content }^{\mathrm{a}}\end{array}$} & \multirow[t]{2}{*}{$\begin{array}{c}\text { Char } \\
\text { yields }\end{array}$} & \multicolumn{2}{|c|}{$\begin{array}{l}\text { Equipment and labor costs } \\
\text { for the soil addition of }\end{array}$} & \multirow{2}{*}{$\begin{array}{c}\text { Net equipment } \\
\text { and labor costs } \\
\text { for biochar soil } \\
\text { addition }^{\text {e }}\end{array}$} \\
\hline & & & & Biochar $^{\mathrm{c}}$ & $\begin{array}{l}\text { Manures + } \\
\text { composts }^{d}\end{array}$ & \\
\hline & & wt $\%$ & $\mathrm{wt} \%_{\mathrm{db}}$ & $\begin{array}{c}€_{2012} / \mathrm{t}_{\mathrm{DM}} \\
\text { feedstock }\end{array}$ & $\begin{array}{c}€_{2012} / \mathrm{t}_{\mathrm{DM}} \\
\text { feedstock }\end{array}$ & $\begin{array}{c}€_{2012} / t_{\mathrm{DM}} \\
\text { feedstock }\end{array}$ \\
\hline & & (1) & (2) & (3) & (4) & $(5)$ \\
\hline Cereal straw & Decomposition in field & 7.9 & 34 & 2.1 & - & 2.1 \\
\hline Forestry residues & Decomposition in forest & 10.8 & 30 & 1.9 & - & 1.9 \\
\hline Open-country biomass residues & Composting, land spread & 7.8 & 31 & 1.9 & 6.6 & -4.7 \\
\hline Industrial wood waste & Energetic use & 8.1 & 29 & 1.8 & - & 1.8 \\
\hline Wood in municipal solid waste & Composting, land spread & 10.9 & 30 & 1.9 & 6.6 & -4.8 \\
\hline Green waste: Compensation areas & Decomposition on site & 6.3 & 32 & 2.0 & - & 2.0 \\
\hline Biomass: Habitat-connectivity areas & Composting, land spread & 7.8 & 31 & 1.9 & 6.6 & -4.7 \\
\hline Green waste: Extensive grassland & Composting, land spread & 7.8 & 31 & 1.9 & 6.6 & -4.7 \\
\hline Short-rotation coppice: Erosion areas & Energetic use & 17.9 & 25 & 1.6 & - & 1.6 \\
\hline Solid cattle manure & Solid storage, land spread & 63.6 & 47 & 2.9 & 12.0 & -9.1 \\
\hline Solid swine manure & Solid storage, land spread & 78.5 & 47 & 2.9 & 20.3 & -17.4 \\
\hline Solid poultry manure & Solid storage, land spread & 13.4 & 44 & 2.7 & 5.0 & -2.3 \\
\hline Commercial and industrial waste & Composting, land spread & 61.3 & 37 & 2.3 & 6.6 & -4.3 \\
\hline Organic municipal solid waste & Composting, land spread & 70.9 & 45 & 2.8 & 6.6 & -3.8 \\
\hline
\end{tabular}

Sources:

a) Teichmann (2014a: Table 8, column 4). The feedstock water contents are based on as-received fresh weight.

b) Teichmann (2014a: Table 8, column 6). The char yields are based on feedstock dry weight. No differentiation takes place between biochar fresh weight and biochar dry weight.

c) Own calculation, based on equipment and labor costs for biochar soil addition of $6.23 €_{2012} / \mathrm{t}$ biochar and the char yields given in column 2, i.e. $(3)=6.23 \cdot(2) / 100$. Thereby, the costs of $6.23 €_{2012} / t$ biochar have been derived from the average equipment and labor costs for biochar soil addition of $5 £_{2007} / \mathrm{t}$ biochar applied by Shackley et al. (2011: Box 3), first using the exchange rate of 1.5 USD/£ (Shackley et al. 2011: Table 6) and then applying the 2007 average exchange rate of 1.3705 USD/€ (Deutsche Bundesbank 2012) and the producer price index for agricultural products of 104.9 for 2007 and 119.4 for 2012 (Statistisches Bundesamt 2015a), i.e. $6.23=5 \cdot 1.5 / 1.3705 \cdot$ 119.4/104.9. Note that we do not differentiate between biochar fresh weight and biochar dry weight.

d) Own calculation, based on the same equipment and labor costs as for biochar soil addition, i.e. assuming $6.23 €_{2012} / \mathrm{t}_{\mathrm{FW}}$ manure or compost (see note c), and the assumption that $30 \%$ of the solid manures (fresh weight) get lost during storage (Fritsche et al. 2004: 83 ) as well as the assumptions that $64 \%$ of the biomass (dry mass) to be composted is transformed into compost (dry mass) and that composts (fresh weight) have an average water content of 40\% (derived from Knappe et al. 2012: Figures D-2 and D-5, referring to finished compost from household biowaste and from greenwaste). Due to the lack of more specific data, the respective values were applied to all the composts. That is, $(4)=6.23 \cdot 70 /(100-(1))$ for all the solid manures and $(4)=6.23 \cdot 64 /(100-40)$ for all the feedstocks to be composted in the baseline scenario.

e) Own calculation, (5) = (3) - (4).

Notes: Values rounded. $\mathrm{DM}=$ dry mass. $\mathrm{FW}=$ fresh weight. $\mathrm{t}=$ tonne. $\mathrm{wt} \%=$ weight percent. $\mathrm{db}=$ dry base. $-=$ not applicable. 
Table 35: Fuel Costs for Biochar Soil Addition, Germany, 2015-2050

\begin{tabular}{|c|c|c|c|c|c|c|c|c|c|c|c|c|c|c|c|c|}
\hline \multirow[b]{4}{*}{ Feedstocks } & \multirow{4}{*}{$\begin{array}{c}\begin{array}{c}\text { Char } \\
\text { yields }\end{array} \\
\mathrm{wt} \%_{\mathrm{db}} \\
(1)\end{array}$} & \multicolumn{5}{|c|}{ Price path $A^{b}$} & \multicolumn{5}{|c|}{ Price path $B^{c}$} & \multicolumn{5}{|c|}{ Price path $C^{d}$} \\
\hline & & 2015 & 2020 & 2030 & 2040 & 2050 & 2015 & 2020 & 2030 & 2040 & 2050 & 2015 & 2020 & 2030 & 2040 & 2050 \\
\hline & & \multicolumn{5}{|c|}{$\epsilon_{2012} / t_{\mathrm{DM}}$ feedstock } & \multicolumn{5}{|c|}{$\epsilon_{2012} / t_{\text {DM }}$ feedstock } & \multicolumn{5}{|c|}{$\epsilon_{2012} / t_{\text {DM }}$ feedstock } \\
\hline & & (2) & (3) & (4) & (5) & (6) & (7) & (8) & (9) & (10) & (11) & (12) & (13) & (14) & (15) & (16) \\
\hline Cereal straw & 34 & 0.039 & 0.054 & 0.064 & 0.071 & 0.076 & 0.039 & 0.047 & 0.056 & 0.062 & 0.067 & 0.039 & 0.043 & 0.050 & 0.053 & 0.056 \\
\hline Forestry residues & 30 & 0.034 & 0.048 & 0.056 & 0.062 & 0.067 & 0.034 & 0.041 & 0.050 & 0.054 & 0.059 & 0.034 & 0.038 & 0.044 & 0.047 & 0.050 \\
\hline Open-country biomass residues & 31 & 0.035 & 0.049 & 0.058 & 0.064 & 0.069 & 0.035 & 0.043 & 0.051 & 0.056 & 0.061 & 0.035 & 0.039 & 0.046 & 0.048 & 0.051 \\
\hline Industrial wood waste & 29 & 0.033 & 0.046 & 0.054 & 0.060 & 0.065 & 0.033 & 0.040 & 0.048 & 0.052 & 0.057 & 0.033 & 0.037 & 0.043 & 0.045 & 0.048 \\
\hline Wood in municipal solid waste & 30 & 0.034 & 0.048 & 0.056 & 0.062 & 0.067 & 0.034 & 0.041 & 0.050 & 0.054 & 0.059 & 0.034 & 0.038 & 0.044 & 0.047 & 0.050 \\
\hline Green waste: Compensation areas & 32 & 0.036 & 0.051 & 0.060 & 0.066 & 0.072 & 0.036 & 0.044 & 0.053 & 0.058 & 0.063 & 0.036 & 0.041 & 0.047 & 0.050 & 0.053 \\
\hline Biomass: Habitat-connectivity areas & 31 & 0.035 & 0.049 & 0.058 & 0.064 & 0.069 & 0.035 & 0.043 & 0.051 & 0.056 & 0.061 & 0.035 & 0.039 & 0.046 & 0.048 & 0.051 \\
\hline Green waste: Extensive grassland & 31 & 0.035 & 0.049 & 0.058 & 0.064 & 0.069 & 0.035 & 0.043 & 0.051 & 0.056 & 0.061 & 0.035 & 0.039 & 0.046 & 0.048 & 0.051 \\
\hline Short-rotation coppice: Erosion areas & 25 & 0.028 & 0.040 & 0.047 & 0.052 & 0.056 & 0.028 & 0.034 & 0.041 & 0.045 & 0.049 & 0.028 & 0.032 & 0.037 & 0.039 & 0.041 \\
\hline Solid cattle manure & 47 & 0.053 & 0.075 & 0.088 & 0.098 & 0.105 & 0.053 & 0.065 & 0.078 & 0.085 & 0.092 & 0.053 & 0.060 & 0.069 & 0.073 & 0.078 \\
\hline Solid swine manure & 47 & 0.053 & 0.075 & 0.088 & 0.098 & 0.105 & 0.053 & 0.065 & 0.078 & 0.085 & 0.092 & 0.053 & 0.060 & 0.069 & 0.073 & 0.078 \\
\hline Solid poultry manure & 44 & 0.050 & 0.070 & 0.083 & 0.091 & 0.099 & 0.050 & 0.061 & 0.073 & 0.080 & 0.086 & 0.050 & 0.056 & 0.065 & 0.069 & 0.073 \\
\hline Commercial and industrial waste & 37 & 0.042 & 0.059 & 0.070 & 0.077 & 0.083 & 0.042 & 0.051 & 0.061 & 0.067 & 0.073 & 0.042 & 0.047 & 0.054 & 0.058 & 0.061 \\
\hline Organic municipal solid waste & 45 & 0.051 & 0.072 & 0.085 & 0.093 & 0.101 & 0.051 & 0.062 & 0.075 & 0.081 & 0.088 & 0.051 & 0.057 & 0.066 & 0.070 & 0.074 \\
\hline
\end{tabular}
Sources:

a) Teichmann (2014a: Table 8, column 6). The char yields are based on feedstock dry weight. No differentiation takes place between biochar fresh weight and biochar dry weight.

b) Own calculation, transforming the values from Table S.38, row O (referring to the transportation of biochar) into $\mathrm{t}_{\mathrm{DM}}$-feedstock basis using the char yields from column 1 and multiplying by the assumed journey length of $3 \mathrm{~km}$, e.g., (2) = Table S.38 (row O, column 1$) \cdot(1) / 100 \cdot 3$

c) Own calculation, transforming the values from Table S.38, row P (referring to the transportation of biochar) into $\mathrm{t}_{\mathrm{DM}}$-feedstock basis using the char yields from column 1 and multiplying by the assumed journey length of $3 \mathrm{~km}$, e g. (7) = Table S.38 (row P, column 1$) \cdot(1) / 100 \cdot 3$.

d) Own calculation, transforming the values from Table S.38, row Q (referring to the transportation of biochar) into $t_{\mathrm{DM}}$-feedstock basis using the char yields from column 1 and multiplying by the assumed journey length of $3 \mathrm{~km}$, e.g., $(12)=$ Table S.38 (row Q, column 1$) \cdot(1) / 100 \cdot 3$.

Notes: Values rounded. $\mathrm{DM}=$ dry mass. $\mathrm{t}=$ tonne. $\mathrm{wt} \%=$ weight percent. $\mathrm{db}=$ dry base. $\mathrm{km}=$ kilometer. All tables numbered with the leading 'S.' refer to Teichmann (2015). 
Table 36: Fuel Costs for the Soil Addition of Manures and Composts, Germany, 2015-2050

\begin{tabular}{|c|c|c|c|c|c|c|c|c|c|c|c|c|c|c|c|c|}
\hline \multirow[b]{4}{*}{ Feedstocks } & \multirow{4}{*}{$\begin{array}{c}\begin{array}{c}\text { Feedstock } \\
\text { water } \\
\text { content }^{\mathrm{a}}\end{array} \\
\mathrm{wt} \% \\
(1)\end{array}$} & \multicolumn{5}{|c|}{ Price path $A^{b}$} & \multicolumn{5}{|c|}{ Price path $B^{c}$} & \multicolumn{5}{|c|}{ Price path $C^{d}$} \\
\hline & & 2015 & 2020 & 2030 & 2040 & 2050 & 2015 & 2020 & 2030 & 2040 & 2050 & 2015 & 2020 & 2030 & 2040 & 2050 \\
\hline & & \multicolumn{5}{|c|}{$\epsilon_{2012} / \mathrm{t}_{\mathrm{DM}}$ feedstock } & \multicolumn{5}{|c|}{$€_{2012} / \mathrm{t}_{\mathrm{DM}}$ feedstock } & \multicolumn{5}{|c|}{$\epsilon_{2012} / t_{D M}$ feedstock } \\
\hline & & (2) & (3) & (4) & (5) & (6) & (7) & (8) & (9) & (10) & (11) & (12) & (13) & $(14)$ & (15) & (16) \\
\hline Cereal straw & 7.9 & - & - & - & - & - & - & - & - & - & - & - & - & - & - & \\
\hline Forestry residues & 10.8 & - & - & - & - & - & - & - & - & - & - & - & - & - & - & - \\
\hline Open-country biomass residues & 7.8 & 0.121 & 0.170 & 0.200 & 0.222 & 0.239 & 0.121 & 0.147 & 0.177 & 0.193 & 0.209 & 0.121 & 0.135 & 0.157 & 0.166 & 0.176 \\
\hline Industrial wood waste & 8.1 & - & - & - & - & & & - & - & - & & - & - & - & - & \\
\hline Wood in municipal solid waste & 10.9 & 0.121 & 0.170 & 0.200 & 0.222 & 0.239 & 0.121 & 0.147 & 0.177 & 0.193 & 0.209 & 0.121 & 0.135 & 0.157 & 0.166 & 0.176 \\
\hline Green waste: Compensation areas & 6.3 & - & - & - & - & - & - & - & - & - & - & - & - & - & - & - \\
\hline Biomass: Habitat-connectivity areas & 7.8 & 0.121 & 0.170 & 0.200 & 0.222 & 0.239 & 0.121 & 0.147 & 0.177 & 0.193 & 0.209 & 0.121 & 0.135 & 0.157 & 0.166 & 0.176 \\
\hline Green waste: Extensive grassland & 7.8 & 0.121 & 0.170 & 0.200 & 0.222 & 0.239 & 0.121 & 0.147 & 0.177 & 0.193 & 0.209 & 0.121 & 0.135 & 0.157 & 0.166 & 0.176 \\
\hline Short-rotation coppice: Erosion areas & 17.9 & - & - & - & - & & - & - & - & - & - & - & - & - & - & \\
\hline Solid cattle manure & 63.6 & 0.219 & 0.307 & 0.361 & 0.399 & 0.431 & 0.219 & 0.265 & 0.319 & 0.348 & 0.377 & 0.219 & 0.244 & 0.283 & 0.300 & 0.318 \\
\hline Solid swine manure & 78.5 & 0.370 & 0.520 & 0.612 & 0.676 & 0.730 & 0.370 & 0.449 & 0.540 & 0.589 & 0.639 & 0.370 & 0.413 & 0.479 & 0.507 & 0.538 \\
\hline Solid poultry manure & 13.4 & 0.092 & 0.129 & 0.152 & 0.168 & 0.181 & 0.092 & 0.111 & 0.134 & 0.146 & 0.159 & 0.092 & 0.103 & 0.119 & 0.126 & 0.134 \\
\hline Commercial and industrial waste & 61.3 & 0.121 & 0.170 & 0.200 & 0.222 & 0.239 & 0.121 & 0.147 & 0.177 & 0.193 & 0.209 & 0.121 & 0.135 & 0.157 & 0.166 & 0.176 \\
\hline Organic municipal solid waste & 70.9 & 0.121 & 0.170 & 0.200 & 0.222 & 0.239 & 0.121 & 0.147 & 0.177 & 0.193 & 0.209 & 0.121 & 0.135 & 0.157 & 0.166 & 0.176 \\
\hline
\end{tabular}

Sources:

a) Teichmann (2014a: Table 8, column 4). The feedstock water contents are based on as-received fresh weight.

b) Own calculation, transforming the values from Table S.38, row O (referring to the transportation of fresh-weight manures or composts) into tDM-feedstock basis using the assumption that $30 \%$ of the solid manures (fresh weight) get lost during storage (Fritsche et al. 2004: 83) as well as the assumptions that 64\% of the biomass (dry mass) to be composted is transformed into compost (dry mass) and that composts (fresh weight) have an average water content of $40 \%$ (derived from Knappe et al. 2012: Figures D-2 and D-5, referring to finished compost from household biowaste and from greenwaste*), and multiplying by the assumed journey length of $3 \mathrm{~km}$, e.g., (2) = Table S.38 (row O, column 1) $\cdot 70 /(100-(1)) \cdot 3$ for the solid manures and (2) = Table S.38 (row O, column 1$) \cdot 64 /(100-40) \cdot 3$ for all the feedstocks to be composted in the baseline scenario.

c) Own calculation, transforming the values from Table S.38, row P (referring to the transportation of fresh-weight manures or composts) into $\mathrm{t}_{\mathrm{DM}}$-feedstock basis using the assumption that $30 \%$ of the solid manures (fresh weight) get lost during storage (Fritsche et al. 2004: 83) as well as the assumptions that 64\% of the biomass (dry mass) to be composted is transformed into compost (dry mass) and that composts (fresh weight) have an average water content of $40 \%$ (derived from Knappe et al. 2012: Figures D-2 and D-5, referring to finished compost from household biowaste and from greenwaste*), and multiplying by the assumed journey length of $3 \mathrm{~km}$, e.g., (7) = Table S.38 (row P, column 1) $\cdot 70 /(100-(1)) \cdot 3$ for the solid manures and $(7)=$ Table S.38 (row P, column 1$) \cdot 64 /(100-40) \cdot 3$ for all the feedstocks to be composted in the baseline scenario.

d) Own calculation, transforming the values from Table S.38, row Q (referring to the transportation of fresh-weight manures or composts) into $\mathrm{t}_{\mathrm{DM}}$-feedstock basis using the assumption that $30 \%$ of the solid manures (fresh weight) get lost during storage (Fritsche et al. 2004: 83) as well as the assumptions that 64\% of the biomass (dry mass) to be composted is transformed into compost (dry mass) and that composts (fresh weight) have an average water content of $40 \%$ (derived from Knappe et 2.2012 . Figures D-2 and D-5, referring to finished compost from household biowaste and from greenwaste*), and multiplying by the assumed journey length of $3 \mathrm{~km}$, e.g., (12) $=$ Table S.38 (row Q, column 1) $\cdot 70 /(100-(1)) \cdot 3$ for the solid manures and $(12)=$ Table S.38 (row Q, column 1$) \cdot 64 /(100-40) \cdot 3$ for all the feedstocks to be composted in the baseline scenario.

Notes: Values rounded. $\mathrm{DM}=$ dry mass. $\mathrm{t}=$ tonne. $\mathrm{wt} \%$ = weight percent. $\mathrm{km}=$ kilometer. - = not applicable. All tables numbered with the leading 'S.' refer to Teichmann (2015)

$*=$ Due to the lack of more specific data, the respective values were applied to all the composts. 
Table 37: Net GHG Mitigation Costs of Biochar per Dry Tonne of Feedstock, 2015 - Price Path B, Scenarios Max 1, Min 1*

\begin{tabular}{|c|c|c|c|c|c|c|c|c|c|c|c|c|c|c|c|c|c|c|}
\hline \multirow[b]{5}{*}{ Feedstocks } & \multicolumn{6}{|c|}{ Small-scale pyrolysis units } & \multicolumn{6}{|c|}{ Medium-scale pyrolysis units } & \multicolumn{6}{|c|}{ Large-scale pyrolysis units } \\
\hline & \multicolumn{3}{|c|}{ No process heat recovery } & \multicolumn{3}{|c|}{ Process heat recovery } & \multicolumn{3}{|c|}{ No process heat recovery } & \multicolumn{3}{|c|}{ Process heat recovery } & \multicolumn{3}{|c|}{ No process heat recovery } & \multicolumn{3}{|c|}{ Process heat recovery } \\
\hline & $\begin{array}{l}\text { Lig- } \\
\text { nite }^{a}\end{array}$ & $\begin{array}{l}\text { Hard } \\
\text { coal }^{\text {b }}\end{array}$ & $\begin{array}{c}\text { Natu- } \\
\text { ral gas }^{\mathrm{c}}\end{array}$ & $\begin{array}{l}\text { Lig- } \\
\text { nite }^{d}\end{array}$ & $\begin{array}{l}\text { Hard } \\
\text { coal }^{\mathrm{e}}\end{array}$ & $\begin{array}{l}\text { Natu- } \\
\text { ral gas }\end{array}$ & $\begin{array}{l}\text { Lig- } \\
\text { niteg }\end{array}$ & $\begin{array}{l}\text { Hard } \\
\text { coal }^{\text {h }}\end{array}$ & $\begin{array}{l}\text { Natu- } \\
\text { ral gas }\end{array}$ & $\begin{array}{l}\text { Lig- } \\
\text { nite }^{j}\end{array}$ & $\begin{array}{l}\text { Hard } \\
\text { coal }^{k}\end{array}$ & $\begin{array}{l}\text { Natu- } \\
\text { ral gas }\end{array}$ & $\begin{array}{l}\text { Lig- } \\
\text { nite }^{m}\end{array}$ & $\begin{array}{l}\text { Hard } \\
\text { coal }^{n}\end{array}$ & $\begin{array}{l}\text { Natu- } \\
\text { ral gas }\end{array}$ & $\begin{array}{l}\text { Lig- } \\
\text { nite }^{p}\end{array}$ & $\begin{array}{l}\text { Hard } \\
\text { coal }^{q}\end{array}$ & $\begin{array}{c}\text { Natu- } \\
\text { ral gas }^{r}\end{array}$ \\
\hline & \multicolumn{6}{|c|}{$€_{2012} / \mathrm{t}_{\mathrm{DM}}$ feedstock } & \multicolumn{6}{|c|}{$€_{2012} / t_{\mathrm{DM}}$ feedstock } & \multicolumn{6}{|c|}{$€_{2012} / \mathrm{t}_{\mathrm{DM}}$ feedstock } \\
\hline & (1) & (2) & (3) & (4) & (5) & (6) & (7) & (8) & (9) & (10) & (11) & (12) & (13) & (14) & (15) & (16) & (17) & (18) \\
\hline Cereal straw & 252 & 237 & 213 & 249 & 230 & 196 & 270 & 255 & 231 & 267 & 247 & 214 & 218 & 203 & 178 & 214 & 195 & 162 \\
\hline Forestry residues & 347 & 330 & 302 & 344 & 322 & 285 & 365 & 348 & 319 & 361 & 339 & 302 & 312 & 295 & 267 & 309 & 287 & 250 \\
\hline Open-country biomass residues & 153 & 139 & 114 & 150 & 131 & 98 & 171 & 156 & 132 & 167 & 148 & 115 & 118 & 103 & 79 & 115 & 96 & 62 \\
\hline Industrial wood waste & 128 & 162 & 223 & 124 & 154 & 206 & 145 & 179 & 240 & 142 & 171 & 223 & 92 & 127 & 188 & 89 & 119 & 171 \\
\hline Wood in municipal solid waste & 166 & 149 & 121 & 163 & 141 & 104 & 184 & 167 & 139 & 181 & 159 & 122 & 132 & 115 & 86 & 128 & 107 & 69 \\
\hline Green waste: Compensation areas & 242 & 228 & 207 & 238 & 221 & 190 & 259 & 246 & 224 & 256 & 238 & 208 & 206 & 193 & 171 & 203 & 185 & 155 \\
\hline Biomass: Habitat-connectivity areas & 153 & 139 & 114 & 150 & 131 & 98 & 171 & 156 & 132 & 167 & 148 & 115 & 118 & 103 & 79 & 115 & 96 & 62 \\
\hline Green waste: Extensive grassland & 153 & 139 & 114 & 150 & 131 & 98 & 171 & 156 & 132 & 167 & 148 & 115 & 118 & 103 & 79 & 115 & 96 & 62 \\
\hline Short-rotation coppice: Erosion areas & 142 & 175 & 234 & 139 & 167 & 217 & 159 & 192 & 251 & 156 & 184 & 234 & 108 & 141 & 200 & 105 & 133 & 183 \\
\hline Solid cattle manure & 225 & 233 & 253 & 221 & 226 & 237 & 250 & 258 & 278 & 247 & 251 & 263 & 215 & 223 & 243 & 212 & 216 & 227 \\
\hline Solid swine manure & 257 & 284 & 341 & 254 & 277 & 326 & 289 & 316 & 373 & 286 & 309 & 358 & 273 & 300 & 357 & 269 & 293 & 342 \\
\hline Solid poultry manure & 188 & 178 & 161 & 185 & 171 & 146 & 207 & 197 & 180 & 204 & 190 & 165 & 156 & 146 & 129 & 153 & 139 & 114 \\
\hline Commercial and industrial waste & 49 & 52 & 61 & 46 & 44 & 45 & 73 & 75 & 85 & 69 & 68 & 68 & 35 & 38 & 47 & 32 & 30 & 31 \\
\hline Organic municipal solid waste & -22 & -2 & 39 & -25 & -9 & 25 & 5 & 25 & 67 & 2 & 18 & 52 & -23 & -3 & 38 & -26 & -10 & 24 \\
\hline
\end{tabular}

Sources:

a) $\quad(1)=$ Table S.67 (column 11a) + Table S.69 (column 1) + Table S.78 (column 1).

b) (2) = Table S.67 (column 11a) + Table S.69 (column 6) + Table S.78 (column 1)

c) (3) = Table S.67 (column 11a) + Table S.69 (column 11) + Table S.78 (column 1)

d) $\quad$ (4) = Table S.67 (column 11a) + Table S.72 (column 1) + Table S.78 (column 1).

e) $(5)=$ Table S.67 (column 11a) + Table S.72 (column 6) + Table S.78 (column 1).

f) $\quad(6)=$ Table S.67 (column 11a) + Table S.72 (column 11) + Table S.78 (column 1).

g) $\quad(7)=$ Table S.67 (column 11b) + Table S.69 (column 1) + Table S.78 (column 6)

h) $(8)=$ Table S.67 (column 11b) + Table S.69 (column 6) + Table S.78 (column 6).

i) $(9)=$ Table S.67 (column 11b) + Table S.69 (column 11) + Table S.78 (column 6).

Notes: Values rounded. $\mathrm{DM}=$ dry mass. $\mathrm{t}=$ tonne. All tables numbered with the leading 'S.' refer to Teichmann (2015)

j) $\quad(10)=$ Table S.67 (column 11b) + Table S.72 (column 1) + Table S.78 (column 6)

k) $(11)=$ Table S.67 (column 11b) + Table S.72 (column 6) + Table S.78 (column 6)

1) $(12)=$ Table S.67 (column 11b) + Table S.72 (column 11) + Table S.78 (column 6).

m) $(13)=$ Table S.67 (column 11c) + Table S.69 (column 1) + Table S.78 (column 11).

n) $(14)=$ Table S.67 (column 11c) + Table S.69 (column 6) + Table S.78 (column 11).

o) $(15)=$ Table S.67 (column 11c) + Table S.69 (column 11) + Table S.78 (column 11).

p) $\quad(16)=$ Table S.67 (column 11c) + Table S.72 (column 1) + Table S.78 (column 11).

q) $(17)=$ Table S.67 (column 11c) + Table S.72 (column 6) + Table S.78 (column 11).

$(18)=$ Table S.67 (column 11c) + Table S.72 (column 11) + Table S.78 (column 11)

* In 2015, the Max 1 and Min 1 scenarios coincide 
Table 38: Net GHG Mitigation Costs of Biochar per Dry Tonne of Feedstock, 2015 - Price Path B, Scenarios Max 2, Min 2*

\begin{tabular}{|c|c|c|c|c|c|c|c|c|c|c|c|c|c|c|c|c|c|c|}
\hline \multirow[b]{5}{*}{ Feedstocks } & \multicolumn{6}{|c|}{ Small-scale pyrolysis units } & \multicolumn{6}{|c|}{ Medium-scale pyrolysis units } & \multicolumn{6}{|c|}{ Large-scale pyrolysis units } \\
\hline & \multicolumn{3}{|c|}{ No process heat recovery } & \multicolumn{3}{|c|}{ Process heat recovery } & \multicolumn{3}{|c|}{ No process heat recovery } & \multicolumn{3}{|c|}{ Process heat recovery } & \multicolumn{3}{|c|}{ No process heat recovery } & \multicolumn{3}{|c|}{ Process heat recovery } \\
\hline & $\begin{array}{l}\text { Lig- } \\
\text { nite }\end{array}$ & $\begin{array}{l}\text { Hard } \\
\text { coal }^{\text {b }}\end{array}$ & $\begin{array}{l}\text { Natu- } \\
\text { ral gas }^{\mathrm{c}}\end{array}$ & $\begin{array}{l}\text { Lig- } \\
\text { nite }^{\text {d }}\end{array}$ & $\begin{array}{l}\text { Hard } \\
\text { coal }^{\text {e }}\end{array}$ & $\begin{array}{l}\text { Natu- } \\
\text { ral gas }\end{array}$ & $\begin{array}{l}\text { Lig- } \\
\text { niteg }\end{array}$ & $\begin{array}{l}\text { Hard } \\
\text { coal }^{h}\end{array}$ & $\begin{array}{c}\text { Natu- } \\
\text { ral gas }\end{array}$ & $\begin{array}{l}\text { Lig- } \\
\text { nite }^{j}\end{array}$ & $\begin{array}{l}\text { Hard } \\
\text { coal }^{k}\end{array}$ & $\begin{array}{l}\text { Natu- } \\
\text { ral gas }\end{array}$ & $\begin{array}{l}\text { Lig- } \\
\text { nite }^{\mathrm{m}}\end{array}$ & $\begin{array}{l}\text { Hard } \\
\text { coal }^{n}\end{array}$ & $\begin{array}{c}\text { Natu- } \\
\text { ral gas }\end{array}$ & $\begin{array}{l}\text { Lig- } \\
\text { nite }^{p}\end{array}$ & $\begin{array}{l}\text { Hard } \\
\text { coal }^{q}\end{array}$ & $\begin{array}{l}\text { Natu- } \\
\text { ral gas }\end{array}$ \\
\hline & \multicolumn{6}{|c|}{$€_{2012} / \mathrm{t}_{\mathrm{DM}}$ feedstock } & \multicolumn{6}{|c|}{$\epsilon_{2012} / t_{\mathrm{DM}}$ feedstock } & \multicolumn{6}{|c|}{$€_{2012} / t_{\mathrm{DM}}$ feedstock } \\
\hline & (1) & (2) & (3) & (4) & (5) & (6) & (7) & (8) & (9) & (10) & (11) & (12) & (13) & (14) & (15) & (16) & (17) & (18) \\
\hline Cereal straw & 253 & 238 & 214 & 250 & 231 & 197 & 271 & 257 & 232 & 268 & 249 & 216 & 220 & 205 & 181 & 217 & 198 & 164 \\
\hline Forestry residues & 348 & 331 & 303 & 345 & 323 & 286 & 366 & 349 & 321 & 363 & 341 & 304 & 315 & 298 & 269 & 311 & 290 & 253 \\
\hline Open-country biomass residues & 154 & 140 & 115 & 151 & 132 & 99 & 172 & 157 & 133 & 169 & 150 & 116 & 121 & 106 & 82 & 117 & 98 & 65 \\
\hline Industrial wood waste & 129 & 163 & 224 & 125 & 155 & 207 & 146 & 181 & 242 & 143 & 173 & 225 & 95 & 129 & 190 & 91 & 121 & 173 \\
\hline Wood in municipal solid waste & 168 & 151 & 122 & 164 & 142 & 105 & 185 & 168 & 140 & 182 & 160 & 123 & 134 & 117 & 89 & 131 & 109 & 72 \\
\hline Green waste: Compensation areas & 243 & 229 & 208 & 239 & 222 & 191 & 261 & 247 & 226 & 257 & 240 & 209 & 209 & 196 & 174 & 206 & 188 & 158 \\
\hline Biomass: Habitat-connectivity areas & 154 & 140 & 115 & 151 & 132 & 99 & 172 & 157 & 133 & 169 & 150 & 116 & 121 & 106 & 82 & 117 & 98 & 65 \\
\hline Green waste: Extensive grassland & 154 & 140 & 115 & 151 & 132 & 99 & 172 & 157 & 133 & 169 & 150 & 116 & 121 & 106 & 82 & 117 & 98 & 65 \\
\hline Short-rotation coppice: Erosion areas & 143 & 176 & 235 & 140 & 168 & 218 & 161 & 194 & 253 & 157 & 186 & 236 & 111 & 143 & 202 & 107 & 135 & 185 \\
\hline
\end{tabular}

Sources:

a) $(1)=$ Table S.67 (column 11a) + Table S.69 (column 1) + Table S.80 (column 1).

b) $(2)=$ Table S.67 (column 11a) + Table S.69 (column 6) + Table S.80 (column 1)

c) $(3)=$ Table S.67 (column 11a) + Table S.69 (column 11) + Table S.80 (column 1).

j) $\quad(10)=$ Table S.67 (column 11b) + Table S.72 (column 1) + Table S.80 (column 6).

k) $(11)=$ Table S.67 (column 11b) + Table S.72 (column 6) + Table S.80 (column 6).

d) $(4)=$ Table S.67 (column 11a) + Table S.72 (column 1) + Table S.80 (column 1).

e) $\quad(5)=$ Table S.67 (column 11a) + Table S.72 (column 6) + Table S.80 (column 1).

f) $(6)=$ Table S.67 (column 11a) + Table S.72 (column 11) + Table S.80 (column 1).

g) (7) = Table S.67 (column 11b) + Table S.69 (column 1) + Table S.80 (colum 6$)$.

g) $(7)=$ Table S.67 (column 11b) + Table S.69 (collon 1) + Table S.80 (column 6).

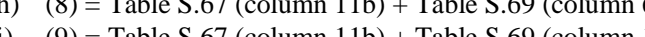

1) $(12)=$ Table S.67 (column 11b) + Table S.72 (column 11) + Table S.80 (column 6).

m) $(13)=$ Table S.67 (column 11c) + Table S.69 (column 1) + Table S.80 (column 11).

n) $(14)=$ Table S.67 (column 11c) + Table S.69 (column 6) + Table S.80 (column 11)

o) $(15)=$ Table S.67 (column 11c) + Table S.69 (column 11) + Table S.80 (column 11)

p) $(16)=$ Table $S .67$ (column 11c) + Table $S .72$ (column 1) + Table S.80 (column 11).

p) $(17)=$ Table $S .67$ (column 11c) + Table $S .72($ column 6) + Table $S .80$ (colunn 11).

r) $(18)=$ Table S.67 (col 11 c) + Table S.72 (colun 11) + Table S.80 (coll 11).

Notes: Values rounded. $\mathrm{DM}=$ dry mass. $\mathrm{t}=$ tonne. All tables numbered with the leading ' $\mathrm{S}$.' refer to Teichmann (2015).

* In 2015, the Max 2 and Min 2 scenarios coincide. 
Table 39: Net GHG Mitigation Costs of Biochar per Dry Tonne of Feedstock, 2030 - Price Path B, Scenario Max 1

\begin{tabular}{|c|c|c|c|c|c|c|c|c|c|c|c|c|c|c|c|c|c|c|}
\hline \multirow[b]{5}{*}{ Feedstocks } & \multicolumn{6}{|c|}{ Small-scale pyrolysis units } & \multicolumn{6}{|c|}{ Medium-scale pyrolysis units } & \multicolumn{6}{|c|}{ Large-scale pyrolysis units } \\
\hline & \multicolumn{3}{|c|}{ No process heat recovery } & \multicolumn{3}{|c|}{ Process heat recovery } & \multicolumn{3}{|c|}{ No process heat recovery } & \multicolumn{3}{|c|}{ Process heat recovery } & \multicolumn{3}{|c|}{ No process heat recovery } & \multicolumn{3}{|c|}{ Process heat recovery } \\
\hline & $\begin{array}{l}\text { Lig- } \\
\text { nite }^{\mathrm{a}}\end{array}$ & $\begin{array}{l}\text { Hard } \\
\text { coal }^{\text {b }}\end{array}$ & $\begin{array}{c}\text { Natu- } \\
\text { ral gas }^{\mathrm{c}}\end{array}$ & $\begin{array}{l}\text { Lig- } \\
\text { nite }^{\text {d }}\end{array}$ & $\begin{array}{l}\text { Hard } \\
\text { coal }^{\mathrm{e}}\end{array}$ & $\begin{array}{l}\text { Natu- } \\
\text { ral gas }^{\mathrm{f}}\end{array}$ & $\begin{array}{l}\text { Lig- } \\
\text { nite }^{\text {g }}\end{array}$ & $\begin{array}{l}\text { Hard } \\
\text { coal }^{\mathrm{h}}\end{array}$ & $\begin{array}{c}\text { Natu- } \\
\text { ral gas }\end{array}$ & $\begin{array}{l}\text { Lig- } \\
\text { nite }^{\text {jo }}\end{array}$ & $\begin{array}{l}\text { Hard } \\
\text { coal }^{\mathrm{k}}\end{array}$ & $\begin{array}{c}\text { Natu- } \\
\text { ral gas }\end{array}$ & $\begin{array}{c}\text { Lig- } \\
\text { nite }^{\mathrm{m}}\end{array}$ & $\begin{array}{l}\text { Hard } \\
\text { coal }^{\mathrm{n}}\end{array}$ & $\begin{array}{c}\text { Natu- } \\
\text { ral gas }^{\circ}\end{array}$ & $\begin{array}{l}\text { Lig- } \\
\text { nite }^{p}\end{array}$ & $\begin{array}{l}\text { Hard } \\
\text { coal }^{q}\end{array}$ & $\begin{array}{l}\text { Natu- } \\
\text { ral gas }\end{array}$ \\
\hline & \multicolumn{6}{|c|}{$€_{2012} / t_{\mathrm{DM}}$ feedstock } & \multicolumn{6}{|c|}{$€_{2012} / t_{D M}$ feedstock } & \multicolumn{6}{|c|}{$\epsilon_{2012} / \mathrm{t}_{\mathrm{DM}}$ feedstock } \\
\hline & (1) & (2) & (3) & (4) & (5) & (6) & (7) & (8) & (9) & (10) & (11) & (12) & (13) & (14) & $(15)$ & (16) & (17) & (18) \\
\hline Cereal straw & 225 & 203 & 166 & 218 & 190 & 140 & 240 & 218 & 181 & 233 & 205 & 155 & 183 & 162 & 124 & 176 & 149 & 99 \\
\hline Forestry residues & 317 & 293 & 250 & 310 & 279 & 223 & 332 & 307 & 264 & 325 & 294 & 238 & 276 & 251 & 208 & 268 & 238 & 182 \\
\hline Open-country biomass residues & 126 & 105 & 67 & 119 & 91 & 42 & 141 & 119 & 82 & 133 & 106 & 57 & 84 & 63 & 26 & 77 & 50 & 0 \\
\hline Industrial wood waste & 151 & 199 & 289 & 143 & 185 & 262 & 165 & 214 & 303 & 158 & 200 & 277 & 109 & 157 & 247 & 101 & 143 & 221 \\
\hline Wood in municipal solid waste & 136 & 112 & 69 & 129 & 98 & 43 & 151 & 127 & 83 & 144 & 113 & 57 & 95 & 70 & 27 & 88 & 57 & 1 \\
\hline Green waste: Compensation areas & 216 & 197 & 164 & 209 & 184 & 138 & 231 & 212 & 179 & 224 & 199 & 153 & 174 & 155 & 122 & 167 & 142 & 97 \\
\hline Biomass: Habitat-connectivity areas & 126 & 105 & 67 & 119 & 91 & 42 & 141 & 119 & 82 & 133 & 106 & 57 & 84 & 63 & 26 & 77 & 50 & 0 \\
\hline Green waste: Extensive grassland & 126 & 105 & 67 & 119 & 91 & 42 & 141 & 119 & 82 & 133 & 106 & 57 & 84 & 63 & 26 & 77 & 50 & 0 \\
\hline Short-rotation coppice: Erosion areas & 163 & 209 & 296 & 156 & 196 & 269 & 177 & 224 & 310 & 170 & 210 & 284 & 122 & 168 & 254 & 114 & 154 & 228 \\
\hline Solid cattle manure & 209 & 220 & 245 & 202 & 207 & 221 & 228 & 239 & 264 & 221 & 227 & 241 & 181 & 191 & 217 & 174 & 179 & 193 \\
\hline Solid swine manure & 247 & 284 & 361 & 240 & 271 & 337 & 270 & 307 & 384 & 263 & 294 & 360 & 232 & 269 & 346 & 226 & 257 & 323 \\
\hline Solid poultry manure & 164 & 149 & 123 & 158 & 137 & 100 & 180 & 165 & 139 & 174 & 153 & 116 & 124 & 109 & 83 & 118 & 97 & 60 \\
\hline Commercial and industrial waste & 29 & 32 & 42 & 22 & 18 & 16 & 47 & 50 & 60 & 40 & 36 & 34 & -2 & 1 & 11 & -9 & -12 & -14 \\
\hline Organic municipal solid waste & -31 & -4 & 52 & -38 & -16 & 29 & -11 & 16 & 73 & -17 & 4 & 50 & -55 & -28 & 29 & -61 & -40 & 6 \\
\hline
\end{tabular}

Sources:

a) (1) = Table S.67 (column 11a) + Table S.69 (column 3)+ Table S.78 (column 3)

b) (2) = Table S.67 (column 11a) + Table S.69 (column 8) + Table S.78 (column 3)

c) $(3)=$ Table S.67 (column 11a) + Table S.69 (column 13) + Table S.78 (column 3).

d) $\quad(4)=$ Table S.67 (column 11a) + Table S.72 (column 3) + Table S.78 (column 3).

e) $(5)=$ Table S.67 (column 11a) + Table S.72 (column 8) + Table S.78 (column 3).

f) $(6)=$ Table S.67 (column 11a) + Table S.72 (column 13) + Table S.78 (column 3).

g) $\quad(7)=$ Table S.67 (column 11b) + Table S.69 (column 3) + Table S.78 (column 8)

h) $(8)=$ Table S.67 (column 11b) + Table S.69 (column 8) + Table S.78 (column 8)

i) (9) = Table S.67 (column 11b) + Table S.69 (column 13) + Table S.78 (column 8).

$(10)=$ Table S.67 (column 11b) + Table S.72 (column 3) + Table S.78 (column 8)

k) $(11)=$ Table S.67 (column 11b) + Table S.72 (column 8) + Table S.78 (column 8).

1) $(12)=$ Table S.67 (column 11b) + Table S.72 (column 13) + Table S.78 (column 8).

m) $(13)=$ Table S.67 (column 11c) + Table S.69 (column 3) + Table S.78 (column 13).

n) $(14)=$ Table S.67 (column 11c) + Table S.69 (column 8) + Table S.78 (column 13).

o) $(15)=$ Table S.67 (column 11c) + Table S.69 (column 13) + Table S.78 (column 13)

p) $(16)=$ Table S.67 (column 11c) + Table S.72 (column 3) + Table S.78 (column 13).

q) $(17)=$ Table S.67 (column 11c) + Table S.72 (column 8) + Table S.78 (column 13).

r) $(18)=$ Table S.67 (column 11c) + Table S.72 (column 13) + Table S.78 (column 13)

Notes: Values rounded. $\mathrm{DM}=$ dry mass. $\mathrm{t}=$ tonne. All tables numbered with the leading 'S.' refer to Teichmann (2015). 
Table 40: Net GHG Mitigation Costs of Biochar per Dry Tonne of Feedstock, 2050 - Price Path B, Scenario Max 1

\begin{tabular}{|c|c|c|c|c|c|c|c|c|c|c|c|c|c|c|c|c|c|c|}
\hline \multirow[b]{5}{*}{ Feedstocks } & \multicolumn{6}{|c|}{ Small-scale pyrolysis units } & \multicolumn{6}{|c|}{ Medium-scale pyrolysis units } & \multicolumn{6}{|c|}{ Large-scale pyrolysis units } \\
\hline & \multicolumn{3}{|c|}{ No process heat recovery } & \multicolumn{3}{|c|}{ Process heat recovery } & \multicolumn{3}{|c|}{ No process heat recovery } & \multicolumn{3}{|c|}{ Process heat recovery } & \multicolumn{3}{|c|}{ No process heat recovery } & \multicolumn{3}{|c|}{ Process heat recovery } \\
\hline & $\begin{array}{l}\text { Lig- } \\
\text { nite }^{\mathrm{a}}\end{array}$ & $\begin{array}{l}\text { Hard } \\
\text { coal }^{\text {b }}\end{array}$ & $\begin{array}{c}\text { Natu- } \\
\text { ral gas }^{\mathrm{c}}\end{array}$ & $\begin{array}{l}\text { Lig- } \\
\text { nite }^{\text {d }}\end{array}$ & $\begin{array}{l}\text { Hard } \\
\text { coal }^{\mathrm{e}}\end{array}$ & $\begin{array}{l}\text { Natu- } \\
\text { ral gas }^{\mathrm{f}}\end{array}$ & $\begin{array}{l}\text { Lig- } \\
\text { nite }^{\text {g }}\end{array}$ & $\begin{array}{l}\text { Hard } \\
\text { coal }^{\mathbf{h}}\end{array}$ & $\begin{array}{l}\text { Natu- } \\
\text { ral gas }^{\mathrm{i}}\end{array}$ & $\begin{array}{l}\text { Lig- } \\
\text { nite }^{\text {jo }}\end{array}$ & $\begin{array}{l}\text { Hard } \\
\text { coal }^{\mathrm{k}}\end{array}$ & $\begin{array}{c}\text { Natu- } \\
\text { ral gas }\end{array}$ & $\begin{array}{c}\text { Lig- } \\
\text { nite }^{\mathrm{m}}\end{array}$ & $\begin{array}{l}\text { Hard } \\
\text { coal }^{\mathrm{n}}\end{array}$ & $\begin{array}{c}\text { Natu- } \\
\text { ral gas }^{\circ}\end{array}$ & $\begin{array}{l}\text { Lig- } \\
\text { nite }^{p}\end{array}$ & $\begin{array}{l}\text { Hard } \\
\text { coal }^{\mathrm{q}}\end{array}$ & $\begin{array}{l}\text { Natu- } \\
\text { ral gas }\end{array}$ \\
\hline & \multicolumn{6}{|c|}{$€_{2012} / \mathrm{t}_{\mathrm{DM}}$ feedstock } & \multicolumn{6}{|c|}{$\epsilon_{2012} / t_{\mathrm{DM}}$ feedstock } & \multicolumn{6}{|c|}{$\epsilon_{2012} / t_{\mathrm{DM}}$ feedstock } \\
\hline & (1) & (2) & (3) & (4) & (5) & (6) & (7) & (8) & (9) & (10) & (11) & (12) & (13) & (14) & (15) & (16) & (17) & (18) \\
\hline Cereal straw & 209 & 179 & 133 & 198 & 160 & 100 & 223 & 193 & 148 & 213 & 175 & 114 & 169 & 139 & 93 & 159 & 120 & 60 \\
\hline Forestry residues & 299 & 265 & 213 & 289 & 246 & 178 & 314 & 279 & 227 & 303 & 260 & 192 & 260 & 225 & 173 & 249 & 206 & 138 \\
\hline Open-country biomass residues & 110 & 80 & 35 & 99 & 61 & 1 & 124 & 95 & 49 & 114 & 76 & 16 & 70 & 40 & -5 & 59 & 21 & -39 \\
\hline Industrial wood waste & 174 & 241 & 350 & 164 & 222 & 315 & 188 & 255 & 364 & 178 & 236 & 329 & 134 & 201 & 309 & 123 & 182 & 275 \\
\hline Wood in municipal solid waste & 118 & 84 & 32 & 108 & 65 & -3 & 133 & 99 & 46 & 122 & 79 & 12 & 79 & 44 & -8 & 68 & 25 & -43 \\
\hline Green waste: Compensation areas & 201 & 175 & 134 & 191 & 156 & 101 & 216 & 189 & 149 & 205 & 170 & 115 & 161 & 135 & 94 & 151 & 116 & 61 \\
\hline Biomass: Habitat-connectivity areas & 110 & 80 & 35 & 99 & 61 & 1 & 124 & 95 & 49 & 114 & 76 & 16 & 70 & 40 & -5 & 59 & 21 & -39 \\
\hline Green waste: Extensive grassland & 110 & 80 & 35 & 99 & 61 & 1 & 124 & 95 & 49 & 114 & 76 & 16 & 70 & 40 & -5 & 59 & 21 & -39 \\
\hline Short-rotation coppice: Erosion areas & 185 & 249 & 354 & 175 & 230 & 319 & 199 & 263 & 367 & 188 & 244 & 333 & 146 & 210 & 314 & 135 & 190 & 280 \\
\hline Solid cattle manure & 210 & 224 & 254 & 200 & 206 & 222 & 229 & 243 & 273 & 219 & 225 & 241 & 183 & 197 & 227 & 173 & 180 & 196 \\
\hline Solid swine manure & 261 & 310 & 402 & 251 & 293 & 371 & 284 & 333 & 425 & 274 & 316 & 394 & 248 & 297 & 389 & 239 & 280 & 359 \\
\hline Solid poultry manure & 152 & 130 & 99 & 142 & 113 & 68 & 168 & 146 & 115 & 158 & 129 & 84 & 113 & 92 & 61 & 104 & 75 & 30 \\
\hline Commercial and industrial waste & 25 & 28 & 40 & 15 & 9 & 6 & 43 & 46 & 57 & 32 & 27 & 24 & -4 & -1 & 11 & -14 & -19 & -22 \\
\hline Organic municipal solid waste & -22 & 15 & 82 & -31 & -2 & 52 & -2 & 35 & 103 & -11 & 18 & 72 & -44 & -7 & 61 & -53 & -24 & 30 \\
\hline
\end{tabular}

Sources:

a) (1) = Table S.67 (column 11a)+ Table S.69 (column 5)+ Table S.78 (column 5)

b) (2) = Table S.67 (column 11a) + Table S.69( (column 10)+ Table S.78 (column 5)

c) (3) = Table S.67 (column 11a) + Table S.69 (column 10) + Table S.78 (column 5).

d) (4) = Table S.67 (column 11a) + Table S.72 (column 5) + Table S.78 (column 5).

e) $\quad(5)=$ Table S.67 (column 11a) + Table S.72 (column 10) + Table S.78 (column 5).

f) $\quad(6)=$ Table S.67 (column 11a) + Table S.72 (column 15) + Table S.78 (column 5).

g) $\quad(7)=$ Table S.67 (column 11b) + Table S.69 (column 5) + Table S.78 (column 10).

h) $(8)=$ Table S.67 (column 11b) + Table S.69 (column 10) + Table S.78 (column 10)

i) $\quad(9)=$ Table S.67 (column 11b) + Table S.69 (column 15) + Table S.78 (column 10).

j) $(10)=$ Table S.67 (column 11b) + Table S.72 (column 5) + Table S.78 (column 10)

k) $(11)=$ Table S.67 (column 11b) + Table S.72 (column 10) + Table S.78 (column 10)

1) $(12)=$ Table S.67 (column 11b) + Table S.72 (column 15) + Table S.78 (column 10)

m) $(13)=$ Table S.67 (column 11c) + Table S.69 (column 5) + Table S.78 (column 15).

n) $(14)=$ Table S.67 (column 11c) + Table S.69 $($ column 10) + Table S.78 (column 15)

o) $\quad(15)=$ Table S.67 (column 11c) + Table S.69 (column 15) + Table S.78 (column 15)

p) $(16)=$ Table S.67 (column 11c) + Table S.72 (column 5) + Table S.78 (column 15).

q) $(17)=$ Table S.67 (column 11c) + Table S.72 (column 10) + Table S.78 (column 15)

r) $\quad(18)=$ Table S.67 (column 11c) + Table S.72 (column 15) + Table S.78 (column 15)

Notes: Values rounded. $\mathrm{DM}=$ dry mass. $\mathrm{t}=$ tonne. All tables numbered with the leading 'S.' refer to Teichmann (2015). 
Table 41: Total Net Avoided GHG Emissions, 2015, Scenarios Max 1, Min 1*

\begin{tabular}{|c|c|c|c|c|c|c|c|c|c|c|c|c|c|c|c|c|c|c|}
\hline \multirow[b]{5}{*}{ Feedstocks } & \multicolumn{6}{|c|}{ Small-scale pyrolysis units } & \multicolumn{6}{|c|}{ Medium-scale pyrolysis units } & \multicolumn{6}{|c|}{ Large-scale pyrolysis units } \\
\hline & \multicolumn{3}{|c|}{ No process heat recovery } & \multicolumn{3}{|c|}{ Process heat recovery } & \multicolumn{3}{|c|}{ No process heat recovery } & \multicolumn{3}{|c|}{ Process heat recovery } & \multicolumn{3}{|c|}{ No process heat recovery } & \multicolumn{3}{|c|}{ Process heat recovery } \\
\hline & Lignite & $\begin{array}{c}\text { Hard } \\
\text { coal }\end{array}$ & $\begin{array}{l}\text { Natu- } \\
\text { ral gas }\end{array}$ & Lignite & $\begin{array}{c}\text { Hard } \\
\text { coal }\end{array}$ & $\begin{array}{l}\text { Natu- } \\
\text { ral gas }\end{array}$ & Lignite & $\begin{array}{c}\text { Hard } \\
\text { coal }\end{array}$ & $\begin{array}{l}\text { Natu- } \\
\text { ral gas }\end{array}$ & Lignite & $\begin{array}{c}\text { Hard } \\
\text { coal }\end{array}$ & $\begin{array}{l}\text { Natu- } \\
\text { ral gas }\end{array}$ & Lignite & $\begin{array}{c}\text { Hard } \\
\text { coal }\end{array}$ & $\begin{array}{l}\text { Natu- } \\
\text { ral gas }\end{array}$ & Lignite & $\begin{array}{c}\text { Hard } \\
\text { coal }\end{array}$ & $\begin{array}{l}\text { Natu- } \\
\text { ral gas }\end{array}$ \\
\hline & \multicolumn{6}{|c|}{$\mathrm{t} \mathrm{CO}_{2} \mathrm{e} / \mathrm{t}_{\mathrm{DM}}$ feedstock } & \multicolumn{6}{|c|}{$\mathrm{t} \mathrm{CO}_{2} \mathrm{e} / \mathrm{t}_{\mathrm{DM}}$ feedstock } & \multicolumn{6}{|c|}{$\mathrm{t} \mathrm{CO}_{2} \mathrm{e} / \mathrm{t}_{\mathrm{DM}}$ feedstock } \\
\hline & (1) & (2) & (3) & (4) & (5) & (6) & (7) & (8) & (9) & (10) & (11) & (12) & (13) & (14) & (15) & (16) & (17) & (18) \\
\hline Cereal straw & 0.879 & 0.801 & 0.648 & 1.002 & 0.904 & 0.714 & 0.878 & 0.800 & 0.648 & 1.002 & 0.904 & 0.714 & 0.875 & 0.798 & 0.645 & 0.999 & 0.901 & 0.711 \\
\hline Forestry residues & 0.952 & 0.863 & 0.688 & 1.079 & 0.969 & 0.756 & 0.951 & 0.862 & 0.687 & 1.079 & 0.969 & 0.755 & 0.948 & 0.859 & 0.685 & 1.076 & 0.966 & 0.753 \\
\hline Open-country biomass residues & 1.257 & 1.180 & 1.029 & 1.382 & 1.285 & 1.096 & 1.256 & 1.180 & 1.028 & 1.382 & 1.284 & 1.095 & 1.254 & 1.177 & 1.026 & 1.379 & 1.282 & 1.093 \\
\hline Industrial wood waste & -0.418 & -0.249 & 0.075 & -0.290 & -0.142 & 0.143 & -0.418 & -0.250 & 0.074 & -0.291 & -0.143 & 0.142 & -0.421 & -0.252 & 0.072 & -0.293 & -0.145 & 0.140 \\
\hline Wood in municipal solid waste & 1.367 & 1.278 & 1.104 & 1.495 & 1.385 & 1.172 & 1.366 & 1.277 & 1.103 & 1.494 & 1.384 & 1.171 & 1.364 & 1.275 & 1.100 & 1.492 & 1.382 & 1.168 \\
\hline Green waste: Compensation areas & 0.774 & 0.705 & 0.569 & 0.898 & 0.808 & 0.635 & 0.773 & 0.704 & 0.568 & 0.897 & 0.807 & 0.634 & 0.770 & 0.701 & 0.565 & 0.894 & 0.805 & 0.631 \\
\hline Biomass: Habitat-connectivity areas & 1.257 & 1.180 & 1.029 & 1.382 & 1.285 & 1.096 & 1.256 & 1.180 & 1.028 & 1.382 & 1.284 & 1.095 & 1.254 & 1.177 & 1.026 & 1.379 & 1.282 & 1.093 \\
\hline Green waste: Extensive grassland & 1.257 & 1.180 & 1.029 & 1.382 & 1.285 & 1.096 & 1.256 & 1.180 & 1.028 & 1.382 & 1.284 & 1.095 & 1.254 & 1.177 & 1.026 & 1.379 & 1.282 & 1.093 \\
\hline Short-rotation coppice: Erosion areas & -0.527 & -0.366 & -0.058 & -0.400 & -0.260 & 0.010 & -0.528 & -0.367 & -0.059 & -0.401 & -0.260 & 0.009 & -0.531 & -0.370 & -0.061 & -0.403 & -0.263 & 0.007 \\
\hline Solid cattle manure & 0.312 & 0.342 & 0.389 & 0.429 & 0.439 & 0.451 & 0.311 & 0.340 & 0.387 & 0.427 & 0.438 & 0.449 & 0.305 & 0.334 & 0.381 & 0.421 & 0.432 & 0.443 \\
\hline Solid swine manure & 0.385 & 0.498 & 0.697 & 0.500 & 0.594 & 0.758 & 0.383 & 0.496 & 0.695 & 0.497 & 0.592 & 0.756 & 0.373 & 0.487 & 0.686 & 0.488 & 0.582 & 0.747 \\
\hline Solid poultry manure & 0.713 & 0.658 & 0.548 & 0.827 & 0.752 & 0.608 & 0.713 & 0.657 & 0.547 & 0.826 & 0.752 & 0.607 & 0.710 & 0.654 & 0.544 & 0.823 & 0.749 & 0.605 \\
\hline Commercial and industrial waste & 0.701 & 0.703 & 0.696 & 0.825 & 0.807 & 0.762 & 0.700 & 0.701 & 0.694 & 0.824 & 0.805 & 0.760 & 0.695 & 0.696 & 0.689 & 0.819 & 0.800 & 0.755 \\
\hline Organic municipal solid waste & 0.068 & 0.152 & 0.302 & 0.180 & 0.246 & 0.362 & 0.066 & 0.150 & 0.300 & 0.178 & 0.244 & 0.360 & 0.059 & 0.143 & 0.293 & 0.171 & 0.237 & 0.353 \\
\hline
\end{tabular}

Sources: Teichmann (2014b: Table A.86).

Notes: Values rounded. DM = dry mass. $\mathrm{t}=$ tonne. $\mathrm{GHG}$ emissions are indicated by a negative sign, $\mathrm{C}$ removals or avoided emissions are displayed as positive values. Negative total net avoided GHG emissions are highlighted by grey color.

* In 2015, the Max 1 and Min 1 scenarios coincide (Teichmann 2014a). 
Table 42: Total Net Avoided GHG Emissions, 2015, Scenarios Max 2, Min 2*

\begin{tabular}{|c|c|c|c|c|c|c|c|c|c|c|c|c|c|c|c|c|c|c|}
\hline \multirow[b]{5}{*}{ Feedstocks } & \multicolumn{6}{|c|}{ Small-scale pyrolysis units } & \multicolumn{6}{|c|}{ Medium-scale pyrolysis units } & \multicolumn{6}{|c|}{ Large-scale pyrolysis units } \\
\hline & \multicolumn{3}{|c|}{ No process heat recovery } & \multicolumn{3}{|c|}{ Process heat recovery } & \multicolumn{3}{|c|}{ No process heat recovery } & \multicolumn{3}{|c|}{ Process heat recovery } & \multicolumn{3}{|c|}{ No process heat recovery } & \multicolumn{3}{|c|}{ Process heat recovery } \\
\hline & Lignite & $\begin{array}{c}\text { Hard } \\
\text { coal }\end{array}$ & $\begin{array}{l}\text { Natu- } \\
\text { ral gas }\end{array}$ & Lignite & $\begin{array}{c}\text { Hard } \\
\text { coal }\end{array}$ & $\begin{array}{l}\text { Natu- } \\
\text { ral gas }\end{array}$ & Lignite & $\begin{array}{c}\text { Hard } \\
\text { coal }\end{array}$ & $\begin{array}{l}\text { Natu- } \\
\text { ral gas }\end{array}$ & Lignite & $\begin{array}{c}\text { Hard } \\
\text { coal }\end{array}$ & $\begin{array}{l}\text { Natu- } \\
\text { ral gas }\end{array}$ & Lignite & $\begin{array}{c}\text { Hard } \\
\text { coal }\end{array}$ & $\begin{array}{c}\text { Natu- } \\
\text { ral gas }\end{array}$ & Lignite & $\begin{array}{c}\text { Hard } \\
\text { coal }\end{array}$ & $\begin{array}{l}\text { Natu- } \\
\text { ral gas }\end{array}$ \\
\hline & \multicolumn{6}{|c|}{$\mathrm{t} \mathrm{CO}_{2} \mathrm{e} / \mathrm{t}_{\mathrm{DM}}$ feedstock } & \multicolumn{6}{|c|}{$\mathrm{t} \mathrm{CO}_{2} \mathrm{e} / \mathrm{t}_{\mathrm{DM}}$ feedstock } & \multicolumn{6}{|c|}{$\mathrm{t} \mathrm{CO}_{2} \mathrm{e} / \mathrm{t}_{\mathrm{DM}}$ feedstock } \\
\hline & (1) & (2) & (3) & (4) & (5) & (6) & (7) & (8) & (9) & (10) & (11) & (12) & (13) & (14) & (15) & (16) & (17) & (18) \\
\hline Cereal straw & 0.879 & 0.801 & 0.648 & 1.002 & 0.904 & 0.714 & 0.878 & 0.800 & 0.648 & 1.001 & 0.904 & 0.714 & 0.875 & 0.797 & 0.645 & 0.999 & 0.901 & 0.711 \\
\hline Forestry residues & 0.952 & 0.863 & 0.688 & 1.079 & 0.969 & 0.756 & 0.951 & 0.862 & 0.687 & 1.079 & 0.969 & 0.755 & 0.948 & 0.859 & 0.684 & 1.076 & 0.966 & 0.752 \\
\hline Open-country biomass residues & 1.257 & 1.180 & 1.029 & 1.382 & 1.285 & 1.096 & 1.256 & 1.179 & 1.028 & 1.382 & 1.284 & 1.095 & 1.254 & 1.177 & 1.026 & 1.379 & 1.281 & 1.092 \\
\hline Industrial wood waste & -0.418 & -0.249 & 0.075 & -0.290 & -0.142 & 0.143 & -0.419 & -0.250 & 0.074 & -0.291 & -0.143 & 0.142 & -0.421 & -0.252 & 0.071 & -0.293 & -0.145 & 0.140 \\
\hline Wood in municipal solid waste & 1.367 & 1.278 & 1.104 & 1.495 & 1.385 & 1.172 & 1.366 & 1.277 & 1.103 & 1.494 & 1.384 & 1.171 & 1.363 & 1.275 & 1.100 & 1.491 & 1.381 & 1.168 \\
\hline Green waste: Compensation areas & 0.774 & 0.705 & 0.569 & 0.898 & 0.808 & 0.635 & 0.773 & 0.704 & 0.568 & 0.897 & 0.807 & 0.634 & 0.770 & 0.701 & 0.565 & 0.894 & 0.805 & 0.631 \\
\hline Biomass: Habitat-connectivity areas & 1.257 & 1.180 & 1.029 & 1.382 & 1.285 & 1.096 & 1.256 & 1.179 & 1.028 & 1.382 & 1.284 & 1.095 & 1.254 & 1.177 & 1.026 & 1.379 & 1.281 & 1.092 \\
\hline Green waste: Extensive grassland & 1.257 & 1.180 & 1.029 & 1.382 & 1.285 & 1.096 & 1.256 & 1.179 & 1.028 & 1.382 & 1.284 & 1.095 & 1.254 & 1.177 & 1.026 & 1.379 & 1.281 & 1.092 \\
\hline Short-rotation coppice: Erosion areas & -0.527 & -0.366 & -0.058 & -0.400 & -0.260 & 0.010 & -0.528 & -0.367 & -0.059 & -0.401 & -0.260 & 0.009 & -0.531 & -0.370 & -0.062 & -0.404 & -0.263 & 0.006 \\
\hline
\end{tabular}

Sources: Teichmann (2014b: Table A.87).

Notes: Values rounded. DM $=$ dry mass. $\mathrm{t}=$ tonne. $\mathrm{GHG}$ emissions are indicated by a negative sign, $\mathrm{C}$ removals or avoided emissions are displayed as positive values. Negative total net avoided GHG emissions are highlighted by grey color.

* In 2015, the Max 2 and Min 2 scenarios coincide (Teichmann 2014a). 
Table 43: Total Net Avoided GHG Emissions, 2030, Scenario Max 1

\begin{tabular}{|c|c|c|c|c|c|c|c|c|c|c|c|c|c|c|c|c|c|c|}
\hline \multirow[b]{5}{*}{ Feedstocks } & \multicolumn{6}{|c|}{ Small-scale pyrolysis units } & \multicolumn{6}{|c|}{ Medium-scale pyrolysis units } & \multicolumn{6}{|c|}{ Large-scale pyrolysis units } \\
\hline & \multicolumn{3}{|c|}{ No process heat recovery } & \multicolumn{3}{|c|}{ Process heat recovery } & \multicolumn{3}{|c|}{ No process heat recovery } & \multicolumn{3}{|c|}{ Process heat recovery } & \multicolumn{3}{|c|}{ No process heat recovery } & \multicolumn{3}{|c|}{ Process heat recovery } \\
\hline & Lignite & $\begin{array}{c}\text { Hard } \\
\text { coal }\end{array}$ & $\begin{array}{c}\text { Natu- } \\
\text { ral gas }\end{array}$ & Lignite & $\begin{array}{c}\text { Hard } \\
\text { coal }\end{array}$ & $\begin{array}{l}\text { Natu- } \\
\text { ral gas }\end{array}$ & Lignite & $\begin{array}{c}\text { Hard } \\
\text { coal }\end{array}$ & $\begin{array}{l}\text { Natu- } \\
\text { ral gas }\end{array}$ & Lignite & $\begin{array}{c}\text { Hard } \\
\text { coal }\end{array}$ & $\begin{array}{l}\text { Natu- } \\
\text { ral gas }\end{array}$ & Lignite & $\begin{array}{c}\text { Hard } \\
\text { coal }\end{array}$ & $\begin{array}{l}\text { Natu- } \\
\text { ral gas }\end{array}$ & Lignite & $\begin{array}{c}\text { Hard } \\
\text { coal }\end{array}$ & $\begin{array}{l}\text { Natu- } \\
\text { ral gas }\end{array}$ \\
\hline & \multicolumn{6}{|c|}{$\mathrm{t} \mathrm{CO}_{2} \mathrm{e} / \mathrm{t}_{\mathrm{DM}}$ feedstock } & \multicolumn{6}{|c|}{$\mathrm{t} \mathrm{CO}_{2} \mathrm{e} / \mathrm{t}_{\mathrm{DM}}$ feedstock } & \multicolumn{6}{|c|}{$\mathrm{t} \mathrm{CO}_{2} \mathrm{e} / \mathrm{t}_{\mathrm{DM}}$ feedstock } \\
\hline & (1) & (2) & (3) & (4) & (5) & (6) & (7) & (8) & (9) & $(10)$ & (11) & (12) & (13) & (14) & $(15)$ & (16) & (17) & (18) \\
\hline Cereal straw & 0.879 & 0.801 & 0.649 & 1.002 & 0.905 & 0.715 & 0.879 & 0.801 & 0.648 & 1.002 & 0.904 & 0.714 & 0.877 & 0.800 & 0.647 & 1.001 & 0.903 & 0.713 \\
\hline Forestry residues & 0.952 & 0.863 & 0.688 & 1.080 & 0.970 & 0.756 & 0.952 & 0.863 & 0.688 & 1.079 & 0.969 & 0.756 & 0.950 & 0.861 & 0.687 & 1.078 & 0.968 & 0.755 \\
\hline Open-country biomass residues & 1.257 & 1.180 & 1.029 & 1.382 & 1.285 & 1.096 & 1.257 & 1.180 & 1.029 & 1.382 & 1.285 & 1.096 & 1.256 & 1.179 & 1.028 & 1.381 & 1.284 & 1.094 \\
\hline Industrial wood waste & -0.418 & -0.249 & 0.075 & -0.290 & -0.142 & 0.143 & -0.418 & -0.249 & 0.075 & -0.290 & -0.142 & 0.143 & -0.419 & -0.250 & 0.074 & -0.291 & -0.143 & 0.142 \\
\hline Wood in municipal solid waste & 1.367 & 1.278 & 1.104 & 1.495 & 1.385 & 1.172 & 1.367 & 1.278 & 1.103 & 1.495 & 1.385 & 1.171 & 1.366 & 1.277 & 1.102 & 1.493 & 1.384 & 1.170 \\
\hline Green waste: Compensation areas & 0.774 & 0.705 & 0.569 & 0.898 & 0.808 & 0.635 & 0.774 & 0.705 & 0.569 & 0.898 & 0.808 & 0.635 & 0.773 & 0.703 & 0.567 & 0.896 & 0.807 & 0.633 \\
\hline Biomass: Habitat-connectivity areas & 1.257 & 1.180 & 1.029 & 1.382 & 1.285 & 1.096 & 1.257 & 1.180 & 1.029 & 1.382 & 1.285 & 1.096 & 1.256 & 1.179 & 1.028 & 1.381 & 1.284 & 1.094 \\
\hline Green waste: Extensive grassland & 1.257 & 1.180 & 1.029 & 1.382 & 1.285 & 1.096 & 1.257 & 1.180 & 1.029 & 1.382 & 1.285 & 1.096 & 1.256 & 1.179 & 1.028 & 1.381 & 1.284 & 1.094 \\
\hline Short-rotation coppice: Erosion areas & -0.527 & -0.366 & -0.058 & -0.400 & -0.259 & 0.010 & -0.528 & -0.366 & -0.058 & -0.400 & -0.260 & 0.010 & -0.529 & -0.368 & -0.059 & -0.401 & -0.261 & 0.009 \\
\hline Solid cattle manure & 0.313 & 0.342 & 0.389 & 0.429 & 0.440 & 0.451 & 0.312 & 0.342 & 0.388 & 0.429 & 0.439 & 0.451 & 0.309 & 0.339 & 0.386 & 0.426 & 0.437 & 0.448 \\
\hline Solid swine manure & 0.386 & 0.499 & 0.698 & 0.500 & 0.595 & 0.759 & 0.385 & 0.498 & 0.697 & 0.499 & 0.594 & 0.758 & 0.381 & 0.494 & 0.693 & 0.495 & 0.590 & 0.754 \\
\hline Solid poultry manure & 0.714 & 0.658 & 0.548 & 0.827 & 0.753 & 0.608 & 0.713 & 0.658 & 0.548 & 0.826 & 0.752 & 0.608 & 0.712 & 0.657 & 0.547 & 0.825 & 0.751 & 0.607 \\
\hline Commercial and industrial waste & 0.701 & 0.703 & 0.696 & 0.826 & 0.807 & 0.762 & 0.701 & 0.702 & 0.695 & 0.825 & 0.806 & 0.761 & 0.699 & 0.700 & 0.693 & 0.823 & 0.804 & 0.759 \\
\hline Organic municipal solid waste & 0.068 & 0.153 & 0.302 & 0.180 & 0.246 & 0.362 & 0.067 & 0.152 & 0.301 & 0.180 & 0.246 & 0.361 & 0.064 & 0.149 & 0.298 & 0.177 & 0.243 & 0.358 \\
\hline
\end{tabular}

Sources: Teichmann (2014a: Table 44).

Notes: Values rounded. DM = dry mass. $\mathrm{t}=$ tonne. GHG emissions are indicated by a negative sign, $\mathrm{C}$ removals or avoided emissions are displayed as positive values. Negative total net avoided GHG emissions are highlighted by grey color. 
Table 44: Total Net Avoided GHG Emissions, 2050, Scenario Max 1

\begin{tabular}{|c|c|c|c|c|c|c|c|c|c|c|c|c|c|c|c|c|c|c|}
\hline \multirow[b]{5}{*}{ Feedstocks } & \multicolumn{6}{|c|}{ Small-scale pyrolysis units } & \multicolumn{6}{|c|}{ Medium-scale pyrolysis units } & \multicolumn{6}{|c|}{ Large-scale pyrolysis units } \\
\hline & \multicolumn{3}{|c|}{ No process heat recovery } & \multicolumn{3}{|c|}{ Process heat recovery } & \multicolumn{3}{|c|}{ No process heat recovery } & \multicolumn{3}{|c|}{ Process heat recovery } & \multicolumn{3}{|c|}{ No process heat recovery } & \multicolumn{3}{|c|}{ Process heat recovery } \\
\hline & Lignite & $\begin{array}{c}\text { Hard } \\
\text { coal }\end{array}$ & $\begin{array}{l}\text { Natu- } \\
\text { ral gas }\end{array}$ & Lignite & $\begin{array}{c}\text { Hard } \\
\text { coal }\end{array}$ & $\begin{array}{l}\text { Natu- } \\
\text { ral gas }\end{array}$ & Lignite & $\begin{array}{c}\text { Hard } \\
\text { coal }\end{array}$ & $\begin{array}{l}\text { Natu- } \\
\text { ral gas }\end{array}$ & Lignite & $\begin{array}{c}\text { Hard } \\
\text { coal }\end{array}$ & $\begin{array}{l}\text { Natu- } \\
\text { ral gas }\end{array}$ & Lignite & $\begin{array}{c}\text { Hard } \\
\text { coal }\end{array}$ & $\begin{array}{l}\text { Natu- } \\
\text { ral gas }\end{array}$ & Lignite & $\begin{array}{c}\text { Hard } \\
\text { coal }\end{array}$ & $\begin{array}{c}\text { Natu- } \\
\text { ral gas }\end{array}$ \\
\hline & \multicolumn{6}{|c|}{$\mathrm{t} \mathrm{CO}{ }_{2} \mathrm{e} / \mathrm{t}_{\mathrm{DM}}$ feedstock } & \multicolumn{6}{|c|}{$\mathrm{t} \mathrm{CO}_{2} \mathrm{e} / \mathrm{t}_{\mathrm{DM}}$ feedstock } & \multicolumn{6}{|c|}{$\mathrm{t} \mathrm{CO}_{2} \mathrm{e} / \mathrm{t}_{\mathrm{DM}}$ feedstock } \\
\hline & (1) & (2) & (3) & (4) & (5) & (6) & (7) & (8) & (9) & (10) & (11) & (12) & (13) & (14) & (15) & (16) & (17) & (18) \\
\hline Cereal straw & 0.879 & 0.801 & 0.649 & 1.002 & 0.905 & 0.715 & 0.879 & 0.801 & 0.648 & 1.002 & 0.904 & 0.714 & 0.878 & 0.800 & 0.648 & 1.001 & 0.903 & 0.713 \\
\hline Forestry residues & 0.952 & 0.863 & 0.688 & 1.080 & 0.970 & 0.756 & 0.952 & 0.863 & 0.688 & 1.079 & 0.969 & 0.756 & 0.951 & 0.862 & 0.687 & 1.078 & 0.968 & 0.755 \\
\hline Open-country biomass residues & 1.257 & 1.180 & 1.029 & 1.382 & 1.285 & 1.096 & 1.257 & 1.180 & 1.029 & 1.382 & 1.285 & 1.095 & 1.256 & 1.179 & 1.028 & 1.381 & 1.284 & 1.095 \\
\hline Industrial wood waste & -0.418 & -0.249 & 0.075 & -0.290 & -0.142 & 0.143 & -0.418 & -0.249 & 0.075 & -0.290 & -0.142 & 0.143 & -0.419 & -0.250 & 0.074 & -0.291 & -0.143 & 0.142 \\
\hline Wood in municipal solid waste & 1.367 & 1.278 & 1.103 & 1.495 & 1.385 & 1.172 & 1.367 & 1.278 & 1.103 & 1.495 & 1.385 & 1.171 & 1.366 & 1.277 & 1.102 & 1.494 & 1.384 & 1.170 \\
\hline Green waste: Compensation areas & 0.774 & 0.705 & 0.569 & 0.898 & 0.808 & 0.635 & 0.774 & 0.705 & 0.569 & 0.898 & 0.808 & 0.635 & 0.773 & 0.704 & 0.568 & 0.897 & 0.807 & 0.634 \\
\hline Biomass: Habitat-connectivity areas & 1.257 & 1.180 & 1.029 & 1.382 & 1.285 & 1.096 & 1.257 & 1.180 & 1.029 & 1.382 & 1.285 & 1.095 & 1.256 & 1.179 & 1.028 & 1.381 & 1.284 & 1.095 \\
\hline Green waste: Extensive grassland & 1.257 & 1.180 & 1.029 & 1.382 & 1.285 & 1.096 & 1.257 & 1.180 & 1.029 & 1.382 & 1.285 & 1.095 & 1.256 & 1.179 & 1.028 & 1.381 & 1.284 & 1.095 \\
\hline Short-rotation coppice: Erosion areas & -0.527 & -0.366 & -0.058 & -0.400 & -0.259 & 0.010 & -0.528 & -0.366 & -0.058 & -0.400 & -0.260 & 0.010 & -0.529 & -0.367 & -0.059 & -0.401 & -0.261 & 0.009 \\
\hline Solid cattle manure & 0.313 & 0.342 & 0.389 & 0.429 & 0.440 & 0.451 & 0.312 & 0.342 & 0.389 & 0.429 & 0.439 & 0.451 & 0.310 & 0.340 & 0.386 & 0.427 & 0.437 & 0.448 \\
\hline Solid swine manure & 0.386 & 0.499 & 0.698 & 0.500 & 0.595 & 0.759 & 0.385 & 0.498 & 0.697 & 0.499 & 0.594 & 0.758 & 0.381 & 0.495 & 0.694 & 0.496 & 0.590 & 0.755 \\
\hline Solid poultry manure & 0.714 & 0.658 & 0.548 & 0.827 & 0.753 & 0.608 & 0.713 & 0.658 & 0.548 & 0.827 & 0.752 & 0.608 & 0.712 & 0.657 & 0.547 & 0.825 & 0.751 & 0.607 \\
\hline Commercial and industrial waste & 0.701 & 0.703 & 0.696 & 0.825 & 0.807 & 0.762 & 0.701 & 0.702 & 0.695 & 0.825 & 0.806 & 0.761 & 0.699 & 0.700 & 0.693 & 0.823 & 0.804 & 0.759 \\
\hline Organic municipal solid waste & 0.068 & 0.152 & 0.302 & 0.180 & 0.246 & 0.362 & 0.067 & 0.152 & 0.301 & 0.180 & 0.246 & 0.361 & 0.065 & 0.149 & 0.299 & 0.177 & 0.243 & 0.358 \\
\hline
\end{tabular}

Sources: Teichmann (2014b: Table A.88).

Notes: Values rounded. DM = dry mass. $\mathrm{t}=$ tonne. $\mathrm{GHG}$ emissions are indicated by a negative sign, $\mathrm{C}$ removals or avoided emissions are displayed as positive values. Negative total net avoided GHG emissions are highlighted by grey color. 
Table 45: Net GHG Mitigation Costs of Biochar per Tonne of CO2e Abated, 2015 - Price Path A, Scenarios Max 1, Min 1*

\begin{tabular}{|c|c|c|c|c|c|c|c|c|c|c|c|c|c|c|c|c|c|c|}
\hline \multirow[b]{5}{*}{ Feedstocks } & \multicolumn{6}{|c|}{ Small-scale pyrolysis units } & \multicolumn{6}{|c|}{ Medium-scale pyrolysis units } & \multicolumn{6}{|c|}{ Large-scale pyrolysis units } \\
\hline & \multicolumn{3}{|c|}{ No process heat recovery } & \multicolumn{3}{|c|}{ Process heat recovery } & \multicolumn{3}{|c|}{ No process heat recovery } & \multicolumn{3}{|c|}{ Process heat recovery } & \multicolumn{3}{|c|}{ No process heat recovery } & \multicolumn{3}{|c|}{ Process heat recovery } \\
\hline & $\begin{array}{l}\text { Lig- } \\
\text { nite }\end{array}$ & $\begin{array}{c}\text { Hard } \\
\text { coal }\end{array}$ & $\begin{array}{l}\text { Natu- } \\
\text { ral gas }\end{array}$ & $\begin{array}{l}\text { Lig- } \\
\text { nite }\end{array}$ & $\begin{array}{c}\text { Hard } \\
\text { coal }\end{array}$ & $\begin{array}{l}\text { Natu- } \\
\text { ral gas }\end{array}$ & $\begin{array}{l}\text { Lig- } \\
\text { nite }\end{array}$ & $\begin{array}{c}\text { Hard } \\
\text { coal }\end{array}$ & $\begin{array}{l}\text { Natu- } \\
\text { ral gas }\end{array}$ & $\begin{array}{l}\text { Lig- } \\
\text { nite }\end{array}$ & $\begin{array}{c}\text { Hard } \\
\text { coal }\end{array}$ & $\begin{array}{l}\text { Natu- } \\
\text { ral gas }\end{array}$ & $\begin{array}{l}\text { Lig- } \\
\text { nite }\end{array}$ & $\begin{array}{c}\text { Hard } \\
\text { coal }\end{array}$ & $\begin{array}{l}\text { Natu- } \\
\text { ral gas }\end{array}$ & $\begin{array}{l}\text { Lig- } \\
\text { nite }\end{array}$ & $\begin{array}{c}\text { Hard } \\
\text { coal }\end{array}$ & $\begin{array}{l}\text { Natu- } \\
\text { ral gas }\end{array}$ \\
\hline & \multicolumn{6}{|c|}{$€_{2012} / \mathrm{tCO}_{2} \mathrm{e}$} & \multicolumn{6}{|c|}{$€_{2012} / \mathrm{tCO}_{2} \mathrm{e}$} & \multicolumn{6}{|c|}{$€_{2012} / \mathrm{tCO}_{2} \mathrm{e}$} \\
\hline & (1) & (2) & (3) & (4) & (5) & (6) & (7) & (8) & (9) & (10) & (11) & (12) & (13) & (14) & (15) & (16) & (17) & (18) \\
\hline Cereal straw & 287 & 294 & 319 & 248 & 252 & 264 & 308 & 317 & 347 & 266 & 272 & 290 & 249 & 252 & 267 & 214 & 214 & 217 \\
\hline Forestry residues & 365 & 381 & 429 & 318 & 330 & 366 & 383 & 401 & 455 & 335 & 348 & 389 & 329 & 342 & 380 & 287 & 295 & 321 \\
\hline Open-country biomass residues & 122 & 116 & 105 & 108 & 100 & 82 & 136 & 131 & 122 & 121 & 114 & 98 & 94 & 87 & 71 & 83 & 73 & 50 \\
\hline Industrial wood waste & - & - & 3,157 & - & - & 1,522 & - & - & 3,418 & - & - & 1,651 & - & - & 2,803 & - & - & 1,304 \\
\hline Wood in municipal solid waste & 122 & 115 & 104 & 109 & 100 & 82 & 135 & 129 & 119 & 121 & 113 & 97 & 97 & 89 & 72 & 86 & 76 & 52 \\
\hline Green waste: Compensation areas & - & - & - & - & - & - & - & - & - & - & - & - & - & - & - & - & - & - \\
\hline Biomass: Habitat-connectivity areas & - & - & - & - & - & - & - & - & - & - & - & - & - & - & - & - & - & - \\
\hline Green waste: Extensive grassland & - & - & - & - & - & - & - & - & - & - & - & - & - & - & - & - & - & - \\
\hline Short-rotation coppice: Erosion areas & - & - & - & - & - & - & - & - & - & - & - & - & - & - & - & - & - & - \\
\hline Solid cattle manure & 719 & 684 & 657 & 516 & 514 & 529 & 805 & 761 & 725 & 578 & 574 & 587 & 704 & 669 & 644 & 502 & 500 & 515 \\
\hline Solid swine manure & 667 & 575 & 503 & 508 & 470 & 440 & 755 & 643 & 551 & 575 & 526 & 484 & 730 & 621 & 534 & 552 & 506 & 468 \\
\hline Solid poultry manure & 264 & 268 & 286 & 224 & 225 & 230 & 291 & 298 & 322 & 248 & 251 & 263 & 220 & 221 & 229 & 186 & 183 & 179 \\
\hline Commercial and industrial waste & 70 & 74 & 89 & 56 & 54 & 57 & 104 & 108 & 123 & 84 & 84 & 88 & 51 & 55 & 69 & 39 & 37 & 40 \\
\hline Organic municipal solid waste & -331 & -3 & 153 & -141 & -32 & 83 & 77 & 179 & 246 & 12 & 80 & 160 & -399 & -11 & 155 & -155 & -38 & 82 \\
\hline
\end{tabular}

Sources: Own calculation, Table $45=$ Table S.86/Table 41.

Notes: Values rounded. $\mathrm{t}=$ tonne. $-=$ not applicable. The net GHG mitigation costs are not shown for cases of negative total net avoided GHG emissions per tonne of dry-matter feedstock (cp. Table 41) and for cases of zero GHG mitigation potentials (cp. Table 2). All tables numbered with the leading 'S.' refer to Teichmann (2015).

* In 2015, the Max 1 and Min 1 scenarios coincide. 
Table 46: Net GHG Mitigation Costs of Biochar per Tonne of $\mathrm{CO}_{2} \mathrm{e}$ Abated, 2015 - Price Path A, Scenarios Max 2, Min 2*

\begin{tabular}{|c|c|c|c|c|c|c|c|c|c|c|c|c|c|c|c|c|c|c|}
\hline \multirow[b]{5}{*}{ Feedstocks } & \multicolumn{6}{|c|}{ Small-scale pyrolysis units } & \multicolumn{6}{|c|}{ Medium-scale pyrolysis units } & \multicolumn{6}{|c|}{ Large-scale pyrolysis units } \\
\hline & \multicolumn{3}{|c|}{ No process heat recovery } & \multicolumn{3}{|c|}{ Process heat recovery } & \multicolumn{3}{|c|}{ No process heat recovery } & \multicolumn{3}{|c|}{ Process heat recovery } & \multicolumn{3}{|c|}{ No process heat recovery } & \multicolumn{3}{|c|}{ Process heat recovery } \\
\hline & $\begin{array}{l}\text { Lig- } \\
\text { nite }\end{array}$ & $\begin{array}{c}\text { Hard } \\
\text { coal }\end{array}$ & $\begin{array}{l}\text { Natu- } \\
\text { ral gas }\end{array}$ & $\begin{array}{l}\text { Lig- } \\
\text { nite }\end{array}$ & $\begin{array}{c}\text { Hard } \\
\text { coal }\end{array}$ & $\begin{array}{l}\text { Natu- } \\
\text { ral gas }\end{array}$ & $\begin{array}{l}\text { Lig- } \\
\text { nite }\end{array}$ & $\begin{array}{c}\text { Hard } \\
\text { coal }\end{array}$ & $\begin{array}{l}\text { Natu- } \\
\text { ral gas }\end{array}$ & $\begin{array}{l}\text { Lig- } \\
\text { nite }\end{array}$ & $\begin{array}{c}\text { Hard } \\
\text { coal }\end{array}$ & $\begin{array}{l}\text { Natu- } \\
\text { ral gas }\end{array}$ & $\begin{array}{l}\text { Lig- } \\
\text { nite }\end{array}$ & $\begin{array}{c}\text { Hard } \\
\text { coal }\end{array}$ & $\begin{array}{l}\text { Natu- } \\
\text { ral gas }\end{array}$ & $\begin{array}{l}\text { Lig- } \\
\text { nite }\end{array}$ & $\begin{array}{c}\text { Hard } \\
\text { coal }\end{array}$ & $\begin{array}{l}\text { Natu- } \\
\text { ral gas }\end{array}$ \\
\hline & \multicolumn{6}{|c|}{$\epsilon_{2012} / \mathrm{CO}_{2} \mathrm{e}$} & \multicolumn{6}{|c|}{$€_{2012} / \mathrm{tCO}_{2} \mathrm{e}$} & \multicolumn{6}{|c|}{$€_{2012} / \mathrm{tCO}_{2} \mathrm{e}$} \\
\hline & (1) & (2) & (3) & (4) & (5) & (6) & (7) & (8) & (9) & (10) & (11) & (12) & (13) & (14) & (15) & (16) & (17) & (18) \\
\hline Cereal straw & 288 & 296 & 321 & 249 & 253 & 266 & 309 & 319 & 349 & 268 & 273 & 292 & 252 & 255 & 271 & 217 & 217 & 221 \\
\hline Forestry residues & 366 & 382 & 430 & 319 & 331 & 367 & 385 & 403 & 457 & 336 & 350 & 391 & 332 & 345 & 384 & 289 & 298 & 324 \\
\hline Open-country biomass residues & 123 & 117 & 106 & 109 & 101 & 83 & 137 & 132 & 124 & 122 & 115 & 100 & 96 & 89 & 74 & 85 & 75 & 53 \\
\hline Industrial wood waste & - & - & 3,172 & - & - & 1,530 & - & - & 3,441 & - & - & 1,661 & - & - & 2,848 & - & - & 1,324 \\
\hline Wood in municipal solid waste & 123 & 116 & 105 & 110 & 101 & 83 & 136 & 130 & 121 & 122 & 114 & 98 & 98 & 91 & 75 & 88 & 77 & 54 \\
\hline Green waste: Compensation areas & - & - & - & - & - & - & - & - & - & - & - & - & - & - & - & - & - & - \\
\hline Biomass: Habitat-connectivity areas & - & - & - & - & - & - & - & - & - & - & - & - & - & - & - & - & - & - \\
\hline Green waste: Extensive grassland & - & - & - & - & - & - & - & - & - & - & - & - & - & - & - & - & - & - \\
\hline Short-rotation coppice: Erosion areas & - & - & - & - & - & - & - & - & - & - & - & - & - & - & - & - & - & - \\
\hline
\end{tabular}

Sources: Own calculation, Table $46=$ Table S.87/Table 42.

Notes: Values rounded. $\mathrm{t}=$ tonne. $-\mathrm{=}$ not applicable. The net GHG mitigation costs are not shown for cases of negative total net avoided GHG emissions per tonne of dry-matter feedstock (cp. Table 42) and for cases of zero GHG mitigation potentials (cp. Table 3). All tables numbered with the leading 'S.' refer to Teichmann (2015).

* In 2015, the Max 2 and Min 2 scenarios coincide. 
Table 47: Net GHG Mitigation Costs of Biochar per Tonne of $\mathrm{CO}_{2} \mathrm{e}$ Abated, 2015 - Price Path B, Scenarios Max 1, Min 1*

\begin{tabular}{|c|c|c|c|c|c|c|c|c|c|c|c|c|c|c|c|c|c|c|}
\hline \multirow[b]{5}{*}{ Feedstocks } & \multicolumn{6}{|c|}{ Small-scale pyrolysis units } & \multicolumn{6}{|c|}{ Medium-scale pyrolysis units } & \multicolumn{6}{|c|}{ Large-scale pyrolysis units } \\
\hline & \multicolumn{3}{|c|}{ No process heat recovery } & \multicolumn{3}{|c|}{ Process heat recovery } & \multicolumn{3}{|c|}{ No process heat recovery } & \multicolumn{3}{|c|}{ Process heat recovery } & \multicolumn{3}{|c|}{ No process heat recovery } & \multicolumn{3}{|c|}{ Process heat recovery } \\
\hline & $\begin{array}{l}\text { Lig- } \\
\text { nite }\end{array}$ & $\begin{array}{c}\text { Hard } \\
\text { coal }\end{array}$ & $\begin{array}{l}\text { Natu- } \\
\text { ral gas }\end{array}$ & $\begin{array}{l}\text { Lig- } \\
\text { nite }\end{array}$ & $\begin{array}{c}\text { Hard } \\
\text { coal }\end{array}$ & $\begin{array}{l}\text { Natu- } \\
\text { ral gas }\end{array}$ & $\begin{array}{l}\text { Lig- } \\
\text { nite }\end{array}$ & $\begin{array}{c}\text { Hard } \\
\text { coal }\end{array}$ & $\begin{array}{l}\text { Natu- } \\
\text { ral gas }\end{array}$ & $\begin{array}{l}\text { Lig- } \\
\text { nite }\end{array}$ & $\begin{array}{c}\text { Hard } \\
\text { coal }\end{array}$ & $\begin{array}{l}\text { Natu- } \\
\text { ral gas }\end{array}$ & $\begin{array}{l}\text { Lig- } \\
\text { nite }\end{array}$ & $\begin{array}{c}\text { Hard } \\
\text { coal }\end{array}$ & $\begin{array}{l}\text { Natu- } \\
\text { ral gas }\end{array}$ & $\begin{array}{l}\text { Lig- } \\
\text { nite }\end{array}$ & $\begin{array}{c}\text { Hard } \\
\text { coal }\end{array}$ & $\begin{array}{l}\text { Natu- } \\
\text { ral gas }\end{array}$ \\
\hline & \multicolumn{6}{|c|}{$€_{2012} / \mathrm{tCO}_{2} \mathrm{e}$} & \multicolumn{6}{|c|}{$€_{2012} / \mathrm{tCO}_{2} \mathrm{e}$} & \multicolumn{6}{|c|}{$€_{2012} / \mathrm{tCO}_{2} \mathrm{e}$} \\
\hline & (1) & (2) & (3) & (4) & (5) & (6) & (7) & (8) & (9) & (10) & (11) & (12) & (13) & (14) & (15) & (16) & (17) & (18) \\
\hline Cereal straw & 287 & 296 & 328 & 248 & 254 & 275 & 308 & 319 & 356 & 266 & 274 & 300 & 249 & 254 & 276 & 214 & 216 & 227 \\
\hline Forestry residues & 365 & 383 & 439 & 318 & 332 & 377 & 383 & 403 & 464 & 335 & 350 & 400 & 329 & 344 & 390 & 287 & 297 & 332 \\
\hline Open-country biomass residues & 122 & 117 & 111 & 108 & 102 & 89 & 136 & 132 & 128 & 121 & 115 & 105 & 94 & 88 & 77 & 83 & 75 & 57 \\
\hline Industrial wood waste & - & - & 2,982 & - & - & 1,443 & - & - & 3,242 & - & - & 1,571 & - & - & 2,621 & - & - & 1,222 \\
\hline Wood in municipal solid waste & 122 & 117 & 110 & 109 & 102 & 89 & 135 & 131 & 126 & 121 & 115 & 104 & 97 & 90 & 78 & 86 & 77 & 59 \\
\hline Green waste: Compensation areas & - & - & - & - & - & - & - & - & - & - & - & - & - & - & - & - & - & - \\
\hline Biomass: Habitat-connectivity areas & - & - & - & - & - & - & - & - & - & - & - & - & - & - & - & - & - & - \\
\hline Green waste: Extensive grassland & - & - & - & - & - & - & - & - & - & - & - & - & - & - & - & - & - & - \\
\hline Short-rotation coppice: Erosion areas & - & - & - & - & - & - & - & - & - & - & - & - & - & - & - & - & - & - \\
\hline Solid cattle manure & 719 & 682 & 651 & 516 & 514 & 527 & 805 & 759 & 719 & 578 & 574 & 585 & 704 & 667 & 637 & 502 & 500 & 513 \\
\hline Solid swine manure & 667 & 570 & 489 & 508 & 466 & 430 & 755 & 638 & 537 & 575 & 522 & 474 & 730 & 617 & 521 & 552 & 503 & 458 \\
\hline Solid poultry manure & 264 & 270 & 293 & 224 & 227 & 240 & 291 & 300 & 329 & 248 & 253 & 272 & 220 & 223 & 237 & 186 & 185 & 188 \\
\hline Commercial and industrial waste & 70 & 74 & 88 & 56 & 55 & 59 & 104 & 108 & 122 & 84 & 84 & 90 & 51 & 55 & 69 & 39 & 38 & 41 \\
\hline Organic municipal solid waste & -331 & -15 & 131 & -141 & -38 & 68 & 77 & 168 & 223 & 12 & 75 & 145 & -399 & -23 & 131 & -155 & -44 & 67 \\
\hline
\end{tabular}

Sources: Own calculation, Table $47=$ Table $37 /$ Table 41.

Notes: Values rounded. $\mathrm{t}=$ tonne. $-=$ not applicable. The net GHG mitigation costs are not shown for cases of negative total net avoided GHG emissions per tonne of dry-matter feedstock (cp. Table 41) and for cases of zero GHG mitigation potentials (cp. Table 2).

* In 2015, the Max 1 and Min 1 scenarios coincide. 
Table 48: Net GHG Mitigation Costs of Biochar per Tonne of $\mathrm{CO}_{2} \mathrm{e}$ Abated, 2015 - Price Path B, Scenarios Max 2, Min 2*

\begin{tabular}{|c|c|c|c|c|c|c|c|c|c|c|c|c|c|c|c|c|c|c|}
\hline \multirow[b]{5}{*}{ Feedstocks } & \multicolumn{6}{|c|}{ Small-scale pyrolysis units } & \multicolumn{6}{|c|}{ Medium-scale pyrolysis units } & \multicolumn{6}{|c|}{ Large-scale pyrolysis units } \\
\hline & \multicolumn{3}{|c|}{ No process heat recovery } & \multicolumn{3}{|c|}{ Process heat recovery } & \multicolumn{3}{|c|}{ No process heat recovery } & \multicolumn{3}{|c|}{ Process heat recovery } & \multicolumn{3}{|c|}{ No process heat recovery } & \multicolumn{3}{|c|}{ Process heat recovery } \\
\hline & $\begin{array}{l}\text { Lig- } \\
\text { nite }\end{array}$ & $\begin{array}{c}\text { Hard } \\
\text { coal }\end{array}$ & $\begin{array}{l}\text { Natu- } \\
\text { ral gas }\end{array}$ & $\begin{array}{l}\text { Lig- } \\
\text { nite }\end{array}$ & $\begin{array}{c}\text { Hard } \\
\text { coal }\end{array}$ & $\begin{array}{l}\text { Natu- } \\
\text { ral gas }\end{array}$ & $\begin{array}{l}\text { Lig- } \\
\text { nite }\end{array}$ & $\begin{array}{c}\text { Hard } \\
\text { coal }\end{array}$ & $\begin{array}{l}\text { Natu- } \\
\text { ral gas }\end{array}$ & $\begin{array}{l}\text { Lig- } \\
\text { nite }\end{array}$ & $\begin{array}{c}\text { Hard } \\
\text { coal }\end{array}$ & $\begin{array}{l}\text { Natu- } \\
\text { ral gas }\end{array}$ & $\begin{array}{l}\text { Lig- } \\
\text { nite }\end{array}$ & $\begin{array}{c}\text { Hard } \\
\text { coal }\end{array}$ & $\begin{array}{l}\text { Natu- } \\
\text { ral gas }\end{array}$ & $\begin{array}{l}\text { Lig- } \\
\text { nite }\end{array}$ & $\begin{array}{c}\text { Hard } \\
\text { coal }\end{array}$ & $\begin{array}{l}\text { Natu- } \\
\text { ral gas }\end{array}$ \\
\hline & \multicolumn{6}{|c|}{$\epsilon_{2012} / \mathrm{CO}_{2} \mathrm{e}$} & \multicolumn{6}{|c|}{$€_{2012} / \mathrm{tCO}_{2} \mathrm{e}$} & \multicolumn{6}{|c|}{$€_{2012} / \mathrm{tCO}_{2} \mathrm{e}$} \\
\hline & (1) & (2) & (3) & (4) & (5) & (6) & (7) & (8) & (9) & (10) & (11) & (12) & (13) & (14) & (15) & (16) & (17) & (18) \\
\hline Cereal straw & 288 & 298 & 330 & 249 & 255 & 276 & 309 & 321 & 358 & 268 & 275 & 302 & 252 & 257 & 280 & 217 & 219 & 231 \\
\hline Forestry residues & 366 & 384 & 440 & 319 & 333 & 378 & 385 & 405 & 467 & 336 & 352 & 402 & 332 & 347 & 394 & 289 & 300 & 336 \\
\hline Open-country biomass residues & 123 & 118 & 112 & 109 & 103 & 90 & 137 & 133 & 129 & 122 & 116 & 106 & 96 & 90 & 79 & 85 & 76 & 59 \\
\hline Industrial wood waste & - & - & 2,998 & - & - & 1,450 & - & - & 3,264 & - & - & 1,581 & - & - & 2,665 & - & - & 1,242 \\
\hline Wood in municipal solid waste & 123 & 118 & 111 & 110 & 103 & 90 & 136 & 132 & 127 & 122 & 116 & 105 & 98 & 92 & 81 & 88 & 79 & 62 \\
\hline Green waste: Compensation areas & - & - & - & - & - & - & - & - & - & - & - & - & - & - & - & - & - & - \\
\hline Biomass: Habitat-connectivity areas & - & - & - & - & - & - & - & - & - & - & - & - & - & - & - & - & - & - \\
\hline Green waste: Extensive grassland & - & - & - & - & - & - & - & - & - & - & - & - & - & - & - & - & - & - \\
\hline Short-rotation coppice: Erosion areas & - & - & - & - & - & - & - & - & - & - & - & - & - & - & - & - & - & - \\
\hline
\end{tabular}

Sources: Own calculation, Table $48=$ Table 38/Table 42.

Notes: Values rounded. $\mathrm{t}=$ tonne. $-\mathrm{=}$ not applicable. The net GHG mitigation costs are not shown for cases of negative total net avoided GHG emissions per tonne of dry-matter feedstock (cp. Table 42 ) and for cases of zero GHG mitigation potentials (cp. Table 3).

* In 2015, the Max 2 and Min 2 scenarios coincide. 
Table 49: Net GHG Mitigation Costs of Biochar per Tonne of $\mathrm{CO}_{2} \mathrm{e}$ Abated, 2015 - Price Path C, Scenarios Max 1, Min 1*

\begin{tabular}{|c|c|c|c|c|c|c|c|c|c|c|c|c|c|c|c|c|c|c|}
\hline \multirow[b]{5}{*}{ Feedstocks } & \multicolumn{6}{|c|}{ Small-scale pyrolysis units } & \multicolumn{6}{|c|}{ Medium-scale pyrolysis units } & \multicolumn{6}{|c|}{ Large-scale pyrolysis units } \\
\hline & \multicolumn{3}{|c|}{ No process heat recovery } & \multicolumn{3}{|c|}{ Process heat recovery } & \multicolumn{3}{|c|}{ No process heat recovery } & \multicolumn{3}{|c|}{ Process heat recovery } & \multicolumn{3}{|c|}{ No process heat recovery } & \multicolumn{3}{|c|}{ Process heat recovery } \\
\hline & $\begin{array}{l}\text { Lig- } \\
\text { nite }\end{array}$ & $\begin{array}{c}\text { Hard } \\
\text { coal }\end{array}$ & $\begin{array}{l}\text { Natu- } \\
\text { ral gas }\end{array}$ & $\begin{array}{l}\text { Lig- } \\
\text { nite }\end{array}$ & $\begin{array}{c}\text { Hard } \\
\text { coal }\end{array}$ & $\begin{array}{l}\text { Natu- } \\
\text { ral gas }\end{array}$ & $\begin{array}{l}\text { Lig- } \\
\text { nite }\end{array}$ & $\begin{array}{c}\text { Hard } \\
\text { coal }\end{array}$ & $\begin{array}{l}\text { Natu- } \\
\text { ral gas }\end{array}$ & $\begin{array}{l}\text { Lig- } \\
\text { nite }\end{array}$ & $\begin{array}{c}\text { Hard } \\
\text { coal }\end{array}$ & $\begin{array}{l}\text { Natu- } \\
\text { ral gas }\end{array}$ & $\begin{array}{l}\text { Lig- } \\
\text { nite }\end{array}$ & $\begin{array}{c}\text { Hard } \\
\text { coal }\end{array}$ & $\begin{array}{l}\text { Natu- } \\
\text { ral gas }\end{array}$ & $\begin{array}{l}\text { Lig- } \\
\text { nite }\end{array}$ & $\begin{array}{c}\text { Hard } \\
\text { coal }\end{array}$ & $\begin{array}{l}\text { Natu- } \\
\text { ral gas }\end{array}$ \\
\hline & \multicolumn{6}{|c|}{$€_{2012} / \mathrm{tCO}_{2} \mathrm{e}$} & \multicolumn{6}{|c|}{$€_{2012} / \mathrm{tCO}_{2} \mathrm{e}$} & \multicolumn{6}{|c|}{$€_{2012} / \mathrm{CO}_{2} \mathrm{e}$} \\
\hline & (1) & (2) & (3) & (4) & (5) & (6) & (7) & (8) & (9) & (10) & (11) & (12) & (13) & (14) & $(15)$ & (16) & (17) & (18) \\
\hline Cereal straw & 287 & 300 & 334 & 248 & 258 & 282 & 308 & 323 & 362 & 266 & 278 & 308 & 249 & 258 & 283 & 214 & 221 & 235 \\
\hline Forestry residues & 365 & 387 & 446 & 318 & 337 & 385 & 383 & 407 & 471 & 335 & 355 & 408 & 329 & 348 & 397 & 287 & 302 & 340 \\
\hline Open-country biomass residues & 122 & 120 & 115 & 108 & 105 & 94 & 136 & 135 & 132 & 121 & 118 & 110 & 94 & 91 & 81 & 83 & 78 & 62 \\
\hline Industrial wood waste & - & - & 2,858 & - & - & 1,386 & - & - & 3,116 & - & - & 1,513 & - & - & 2,491 & - & - & 1,164 \\
\hline Wood in municipal solid waste & 122 & 120 & 114 & 109 & 105 & 94 & 135 & 133 & 130 & 121 & 118 & 109 & 97 & 93 & 83 & 86 & 80 & 65 \\
\hline Green waste: Compensation areas & - & - & - & - & - & - & - & - & - & - & - & - & - & - & - & - & - & - \\
\hline Biomass: Habitat-connectivity areas & - & - & - & - & - & - & - & - & - & - & - & - & - & - & - & - & - & - \\
\hline Green waste: Extensive grassland & - & - & - & - & - & - & - & - & - & - & - & - & - & - & - & - & - & - \\
\hline Short-rotation coppice: Erosion areas & - & - & - & - & - & - & - & - & - & - & - & - & - & - & - & - & - & - \\
\hline Solid cattle manure & 719 & 678 & 646 & 516 & 513 & 525 & 805 & 756 & 714 & 578 & 573 & 583 & 704 & 663 & 632 & 502 & 499 & 511 \\
\hline Solid swine manure & 667 & 561 & 480 & 508 & 460 & 423 & 755 & 629 & 528 & 575 & 516 & 467 & 730 & 607 & 511 & 552 & 496 & 451 \\
\hline Solid poultry manure & 264 & 273 & 299 & 224 & 231 & 246 & 291 & 303 & 335 & 248 & 257 & 279 & 220 & 226 & 242 & 186 & 189 & 195 \\
\hline Commercial and industrial waste & 70 & 74 & 88 & 56 & 56 & 60 & 104 & 108 & 122 & 84 & 85 & 91 & 51 & 55 & 69 & 39 & 39 & 42 \\
\hline Organic municipal solid waste & -331 & -37 & 115 & -141 & -49 & 58 & 77 & 145 & 207 & 12 & 64 & 134 & -399 & -47 & 115 & -155 & -55 & 56 \\
\hline
\end{tabular}

Sources: Own calculation, Table $49=$ Table S.88/Table 41 .

Notes: Values rounded. $\mathrm{t}=$ tonne. $-=$ not applicable. The net GHG mitigation costs are not shown for cases of negative total net avoided GHG emissions per tonne of dry-matter feedstock (cp. Table 41) and for cases of zero GHG mitigation potentials (cp. Table 2). All tables numbered with the leading 'S.' refer to Teichmann (2015).

* In 2015, the Max 1 and Min 1 scenarios coincide. 
Table 50: Net GHG Mitigation Costs of Biochar per Tonne of $\mathrm{CO}_{2} \mathrm{e}$ Abated, 2015 - Price Path C, Scenarios Max 2, Min 2*

\begin{tabular}{|c|c|c|c|c|c|c|c|c|c|c|c|c|c|c|c|c|c|c|}
\hline \multirow[b]{5}{*}{ Feedstocks } & \multicolumn{6}{|c|}{ Small-scale pyrolysis units } & \multicolumn{6}{|c|}{ Medium-scale pyrolysis units } & \multicolumn{6}{|c|}{ Large-scale pyrolysis units } \\
\hline & \multicolumn{3}{|c|}{ No process heat recovery } & \multicolumn{3}{|c|}{ Process heat recovery } & \multicolumn{3}{|c|}{ No process heat recovery } & \multicolumn{3}{|c|}{ Process heat recovery } & \multicolumn{3}{|c|}{ No process heat recovery } & \multicolumn{3}{|c|}{ Process heat recovery } \\
\hline & $\begin{array}{l}\text { Lig- } \\
\text { nite }\end{array}$ & $\begin{array}{c}\text { Hard } \\
\text { coal }\end{array}$ & $\begin{array}{l}\text { Natu- } \\
\text { ral gas }\end{array}$ & $\begin{array}{l}\text { Lig- } \\
\text { nite }\end{array}$ & $\begin{array}{c}\text { Hard } \\
\text { coal }\end{array}$ & $\begin{array}{l}\text { Natu- } \\
\text { ral gas }\end{array}$ & $\begin{array}{l}\text { Lig- } \\
\text { nite }\end{array}$ & $\begin{array}{c}\text { Hard } \\
\text { coal }\end{array}$ & $\begin{array}{l}\text { Natu- } \\
\text { ral gas }\end{array}$ & $\begin{array}{l}\text { Lig- } \\
\text { nite }\end{array}$ & $\begin{array}{c}\text { Hard } \\
\text { coal }\end{array}$ & $\begin{array}{l}\text { Natu- } \\
\text { ral gas }\end{array}$ & $\begin{array}{l}\text { Lig- } \\
\text { nite }\end{array}$ & $\begin{array}{c}\text { Hard } \\
\text { coal }\end{array}$ & $\begin{array}{l}\text { Natu- } \\
\text { ral gas }\end{array}$ & $\begin{array}{l}\text { Lig- } \\
\text { nite }\end{array}$ & $\begin{array}{c}\text { Hard } \\
\text { coal }\end{array}$ & $\begin{array}{l}\text { Natu- } \\
\text { ral gas }\end{array}$ \\
\hline & \multicolumn{6}{|c|}{$\epsilon_{2012} / \mathrm{CO}_{2} \mathrm{e}$} & \multicolumn{6}{|c|}{$€_{2012} / \mathrm{tCO}_{2} \mathrm{e}$} & \multicolumn{6}{|c|}{$€_{2012} / \mathrm{tCO}_{2} \mathrm{e}$} \\
\hline & (1) & (2) & (3) & (4) & (5) & (6) & (7) & (8) & (9) & (10) & (11) & (12) & (13) & (14) & (15) & (16) & (17) & (18) \\
\hline Cereal straw & 288 & 302 & 336 & 249 & 259 & 284 & 309 & 325 & 365 & 268 & 280 & 310 & 252 & 261 & 287 & 217 & 224 & 239 \\
\hline Forestry residues & 366 & 388 & 447 & 319 & 338 & 386 & 385 & 409 & 474 & 336 & 357 & 410 & 332 & 351 & 401 & 289 & 305 & 344 \\
\hline Open-country biomass residues & 123 & 121 & 116 & 109 & 106 & 95 & 137 & 136 & 133 & 122 & 120 & 111 & 96 & 93 & 84 & 85 & 80 & 64 \\
\hline Industrial wood waste & - & - & 2,873 & - & - & 1,393 & - & - & 3,139 & - & - & 1,524 & - & - & 2,534 & - & - & 1,184 \\
\hline Wood in municipal solid waste & 123 & 121 & 115 & 110 & 106 & 95 & 136 & 135 & 131 & 122 & 119 & 110 & 98 & 95 & 85 & 88 & 82 & 67 \\
\hline Green waste: Compensation areas & - & - & - & - & - & - & - & - & - & - & - & - & - & - & - & - & - & - \\
\hline Biomass: Habitat-connectivity areas & - & - & - & - & - & - & - & - & - & - & - & - & - & - & - & - & - & - \\
\hline Green waste: Extensive grassland & - & - & - & - & - & - & - & - & - & - & - & - & - & - & - & - & - & - \\
\hline Short-rotation coppice: Erosion areas & - & - & - & - & - & - & - & - & - & - & - & - & - & - & - & - & - & - \\
\hline
\end{tabular}

Sources: Own calculation, Table $50=$ Table S.89/Table 42 .

Notes: Values rounded. $\mathrm{t}=$ tonne. $-\mathrm{=}$ not applicable. The net GHG mitigation costs are not shown for cases of negative total net avoided GHG emissions per tonne of dry-matter feedstock (cp. Table 42) and for cases of zero GHG mitigation potentials (cp. Table 3). All tables numbered with the leading 'S.' refer to Teichmann (2015).

* In 2015, the Max 2 and Min 2 scenarios coincide. 
Table 51: Net GHG Mitigation Costs of Biochar per Tonne of $\mathrm{CO}_{2} \mathrm{e}$ Abated, 2030 - Price Path A, Scenario Max 1

\begin{tabular}{|c|c|c|c|c|c|c|c|c|c|c|c|c|c|c|c|c|c|c|}
\hline \multirow[b]{5}{*}{ Feedstocks } & \multicolumn{6}{|c|}{ Small-scale pyrolysis units } & \multicolumn{6}{|c|}{ Medium-scale pyrolysis units } & \multicolumn{6}{|c|}{ Large-scale pyrolysis units } \\
\hline & \multicolumn{3}{|c|}{ No process heat recovery } & \multicolumn{3}{|c|}{ Process heat recovery } & \multicolumn{3}{|c|}{ No process heat recovery } & \multicolumn{3}{|c|}{ Process heat recovery } & \multicolumn{3}{|c|}{ No process heat recovery } & \multicolumn{3}{|c|}{ Process heat recovery } \\
\hline & $\begin{array}{l}\text { Lig- } \\
\text { nite }\end{array}$ & $\begin{array}{c}\text { Hard } \\
\text { coal }\end{array}$ & $\begin{array}{l}\text { Natu- } \\
\text { ral gas }\end{array}$ & $\begin{array}{l}\text { Lig- } \\
\text { nite }\end{array}$ & $\begin{array}{c}\text { Hard } \\
\text { coal }\end{array}$ & $\begin{array}{l}\text { Natu- } \\
\text { ral gas }\end{array}$ & $\begin{array}{l}\text { Lig- } \\
\text { nite }\end{array}$ & $\begin{array}{c}\text { Hard } \\
\text { coal }\end{array}$ & $\begin{array}{l}\text { Natu- } \\
\text { ral gas }\end{array}$ & $\begin{array}{l}\text { Lig- } \\
\text { nite }\end{array}$ & $\begin{array}{c}\text { Hard } \\
\text { coal }\end{array}$ & $\begin{array}{l}\text { Natu- } \\
\text { ral gas }\end{array}$ & $\begin{array}{l}\text { Lig- } \\
\text { nite }\end{array}$ & $\begin{array}{c}\text { Hard } \\
\text { coal }\end{array}$ & $\begin{array}{l}\text { Natu- } \\
\text { ral gas }\end{array}$ & $\begin{array}{l}\text { Lig- } \\
\text { nite }\end{array}$ & $\begin{array}{c}\text { Hard } \\
\text { coal }\end{array}$ & $\begin{array}{l}\text { Natu- } \\
\text { ral gas }\end{array}$ \\
\hline & \multicolumn{6}{|c|}{$\epsilon_{2012} / \mathrm{t} \mathrm{CO}_{2} \mathrm{e}$} & \multicolumn{6}{|c|}{$€_{2012} / \mathrm{tCO}_{2} \mathrm{e}$} & \multicolumn{6}{|c|}{$\epsilon_{2012} / \mathrm{tCO}_{2} \mathrm{e}$} \\
\hline & (1) & (2) & (3) & (4) & (5) & (6) & (7) & (8) & (9) & (10) & (11) & (12) & (13) & (14) & $(15)$ & (16) & (17) & (18) \\
\hline Cereal straw & 250 & 239 & 227 & 210 & 194 & 163 & 267 & 258 & 250 & 226 & 211 & 184 & 203 & 188 & 163 & 170 & 149 & 106 \\
\hline Forestry residues & 327 & 324 & 332 & 280 & 271 & 260 & 343 & 341 & 353 & 294 & 286 & 280 & 284 & 276 & 272 & 242 & 229 & 206 \\
\hline Open-country biomass residues & 96 & 79 & 48 & 81 & 60 & 17 & 108 & 92 & 62 & 92 & 71 & 30 & 63 & 44 & 7 & 51 & 27 & -21 \\
\hline Industrial wood waste & - & - & 4,402 & - & - & 2,086 & - & - & 4,613 & - & - & 2,192 & - & - & 3,915 & - & - & 1,811 \\
\hline Wood in municipal solid waste & 95 & 77 & 43 & 81 & 59 & 14 & 106 & 89 & 56 & 91 & 70 & 26 & 65 & 45 & 5 & 54 & 29 & -22 \\
\hline Green waste: Compensation areas & 273 & 265 & 259 & 226 & 211 & 184 & 292 & 286 & 285 & 243 & 229 & 207 & 220 & 206 & 186 & 180 & 160 & 118 \\
\hline Biomass: Habitat-connectivity areas & 96 & 79 & 48 & 81 & 60 & 17 & 108 & 92 & 62 & 92 & 71 & 30 & 63 & 44 & 7 & 51 & 27 & -21 \\
\hline Green waste: Extensive grassland & 96 & 79 & 48 & 81 & 60 & 17 & 108 & 92 & 62 & 92 & 71 & 30 & 63 & 44 & 7 & 51 & 27 & -21 \\
\hline Short-rotation coppice: Erosion areas & - & - & - & - & - & 30,154 & - & - & - & - & - & 32,560 & - & - & - & - & - & 30,397 \\
\hline Solid cattle manure & 673 & 654 & 650 & 472 & 474 & 497 & 738 & 713 & 702 & 519 & 520 & 541 & 591 & 578 & 583 & 410 & 414 & 438 \\
\hline Solid swine manure & 659 & 602 & 559 & 492 & 479 & 476 & 722 & 650 & 593 & 540 & 519 & 508 & 631 & 580 & 543 & 469 & 460 & 461 \\
\hline Solid poultry manure & 225 & 214 & 200 & 185 & 167 & 135 & 248 & 239 & 230 & 204 & 189 & 162 & 170 & 154 & 128 & 137 & 115 & 70 \\
\hline Commercial and industrial waste & 41 & 45 & 61 & 25 & 19 & 16 & 67 & 71 & 88 & 47 & 42 & 40 & -2 & 2 & 18 & -12 & -18 & -23 \\
\hline Organic municipal solid waste & -381 & 53 & 245 & -186 & -27 & 128 & -77 & 190 & 315 & -72 & 58 & 186 & -761 & -100 & 171 & -320 & -122 & 65 \\
\hline
\end{tabular}

Sources: Own calculation, Table $51=$ Table S.90/Table 43.

Notes: Values rounded. $\mathrm{t}=$ tonne. $-=$ not applicable. The net GHG mitigation costs are not shown for cases of negative total net avoided GHG emissions per tonne of dry-matter feedstock (cp. Table 43 ). All tables numbered with the leading 'S.' refer to Teichmann (2015) 
Table 52: Net GHG Mitigation Costs of Biochar per Tonne of $\mathrm{CO}_{2} \mathrm{e}$ Abated, 2030 - Price Path A, Scenario Max 2

\begin{tabular}{|c|c|c|c|c|c|c|c|c|c|c|c|c|c|c|c|c|c|c|}
\hline \multirow[b]{5}{*}{ Feedstocks } & \multicolumn{6}{|c|}{ Small-scale pyrolysis units } & \multicolumn{6}{|c|}{ Medium-scale pyrolysis units } & \multicolumn{6}{|c|}{ Large-scale pyrolysis units } \\
\hline & \multicolumn{3}{|c|}{ No process heat recovery } & \multicolumn{3}{|c|}{ Process heat recovery } & \multicolumn{3}{|c|}{ No process heat recovery } & \multicolumn{3}{|c|}{ Process heat recovery } & \multicolumn{3}{|c|}{ No process heat recovery } & \multicolumn{3}{|c|}{ Process heat recovery } \\
\hline & $\begin{array}{l}\text { Lig- } \\
\text { nite }\end{array}$ & $\begin{array}{c}\text { Hard } \\
\text { coal }\end{array}$ & $\begin{array}{l}\text { Natu- } \\
\text { ral gas }\end{array}$ & $\begin{array}{l}\text { Lig- } \\
\text { nite }\end{array}$ & $\begin{array}{c}\text { Hard } \\
\text { coal }\end{array}$ & $\begin{array}{l}\text { Natu- } \\
\text { ral gas }\end{array}$ & $\begin{array}{l}\text { Lig- } \\
\text { nite }\end{array}$ & $\begin{array}{c}\text { Hard } \\
\text { coal }\end{array}$ & $\begin{array}{l}\text { Natu- } \\
\text { ral gas }\end{array}$ & $\begin{array}{l}\text { Lig- } \\
\text { nite }\end{array}$ & $\begin{array}{c}\text { Hard } \\
\text { coal }\end{array}$ & $\begin{array}{l}\text { Natu- } \\
\text { ral gas }\end{array}$ & $\begin{array}{l}\text { Lig- } \\
\text { nite }\end{array}$ & $\begin{array}{c}\text { Hard } \\
\text { coal }\end{array}$ & $\begin{array}{l}\text { Natu- } \\
\text { ral gas }\end{array}$ & $\begin{array}{l}\text { Lig- } \\
\text { nite }\end{array}$ & $\begin{array}{c}\text { Hard } \\
\text { coal }\end{array}$ & $\begin{array}{l}\text { Natu- } \\
\text { ral gas }\end{array}$ \\
\hline & \multicolumn{6}{|c|}{$\epsilon_{2012} / \mathrm{CO}_{2} \mathrm{e}$} & \multicolumn{6}{|c|}{$€_{2012} / \mathrm{tCO}_{2} \mathrm{e}$} & \multicolumn{6}{|c|}{$€_{2012} / \mathrm{CO}_{2} \mathrm{e}$} \\
\hline & (1) & (2) & (3) & (4) & (5) & (6) & (7) & (8) & (9) & (10) & (11) & (12) & (13) & (14) & (15) & (16) & (17) & (18) \\
\hline Cereal straw & 251 & 241 & 228 & 212 & 195 & 165 & 269 & 260 & 252 & 227 & 212 & 186 & 205 & 191 & 166 & 172 & 151 & 108 \\
\hline Forestry residues & 328 & 325 & 333 & 281 & 272 & 262 & 344 & 343 & 355 & 295 & 288 & 281 & 286 & 279 & 275 & 244 & 231 & 208 \\
\hline Open-country biomass residues & 97 & 80 & 49 & 82 & 61 & 17 & 109 & 93 & 63 & 93 & 72 & 31 & 64 & 45 & 9 & 52 & 29 & -20 \\
\hline Industrial wood waste & - & - & 4,417 & - & - & 2,094 & - & - & 4,634 & - & - & 2,202 & - & - & 3,949 & - & - & 1,827 \\
\hline Wood in municipal solid waste & 96 & 78 & 44 & 82 & 60 & 14 & 107 & 90 & 57 & 92 & 71 & 27 & 67 & 46 & 7 & 55 & 31 & -20 \\
\hline Green waste: Compensation areas & 274 & 267 & 260 & 227 & 212 & 185 & 294 & 288 & 287 & 244 & 231 & 209 & 222 & 209 & 189 & 182 & 162 & 121 \\
\hline Biomass: Habitat-connectivity areas & 97 & 80 & 49 & 82 & 61 & 17 & 109 & 93 & 63 & 93 & 72 & 31 & 64 & 45 & 9 & 52 & 29 & -20 \\
\hline Green waste: Extensive grassland & 97 & 80 & 49 & 82 & 61 & 17 & 109 & 93 & 63 & 93 & 72 & 31 & 64 & 45 & 9 & 52 & 29 & -20 \\
\hline Short-rotation coppice: Erosion areas & - & - & - & - & - & 30,313 & - & - & & - & - & 32,863 & - & - & - & - & - & 31,211 \\
\hline
\end{tabular}

Sources: Own calculation, Table 52 = Table S.92/Table S.113.

Notes: Values rounded. $\mathrm{t}=$ tonne. $-=$ not applicable. The net GHG mitigation costs are not shown for cases of negative total net avoided GHG emissions per tonne of dry-matter feedstock (cp. Table S.113). All tables numbered with the leading 'S.' refer to Teichmann (2015). 
Table 53: Net GHG Mitigation Costs of Biochar per Tonne of $\mathrm{CO}_{2} \mathrm{e}$ Abated, 2030 - Price Path B, Scenario Max 1

\begin{tabular}{|c|c|c|c|c|c|c|c|c|c|c|c|c|c|c|c|c|c|c|}
\hline \multirow[b]{5}{*}{ Feedstocks } & \multicolumn{6}{|c|}{ Small-scale pyrolysis units } & \multicolumn{6}{|c|}{ Medium-scale pyrolysis units } & \multicolumn{6}{|c|}{ Large-scale pyrolysis units } \\
\hline & \multicolumn{3}{|c|}{ No process heat recovery } & \multicolumn{3}{|c|}{ Process heat recovery } & \multicolumn{3}{|c|}{ No process heat recovery } & \multicolumn{3}{|c|}{ Process heat recovery } & \multicolumn{3}{|c|}{ No process heat recovery } & \multicolumn{3}{|c|}{ Process heat recovery } \\
\hline & $\begin{array}{l}\text { Lig- } \\
\text { nite }\end{array}$ & $\begin{array}{c}\text { Hard } \\
\text { coal }\end{array}$ & $\begin{array}{l}\text { Natu- } \\
\text { ral gas }\end{array}$ & $\begin{array}{l}\text { Lig- } \\
\text { nite }\end{array}$ & $\begin{array}{c}\text { Hard } \\
\text { coal }\end{array}$ & $\begin{array}{l}\text { Natu- } \\
\text { ral gas }\end{array}$ & $\begin{array}{l}\text { Lig- } \\
\text { nite }\end{array}$ & $\begin{array}{c}\text { Hard } \\
\text { coal }\end{array}$ & $\begin{array}{l}\text { Natu- } \\
\text { ral gas }\end{array}$ & $\begin{array}{l}\text { Lig- } \\
\text { nite }\end{array}$ & $\begin{array}{c}\text { Hard } \\
\text { coal }\end{array}$ & $\begin{array}{l}\text { Natu- } \\
\text { ral gas }\end{array}$ & $\begin{array}{l}\text { Lig- } \\
\text { nite }\end{array}$ & $\begin{array}{c}\text { Hard } \\
\text { coal }\end{array}$ & $\begin{array}{l}\text { Natu- } \\
\text { ral gas }\end{array}$ & $\begin{array}{l}\text { Lig- } \\
\text { nite }\end{array}$ & $\begin{array}{c}\text { Hard } \\
\text { coal }\end{array}$ & $\begin{array}{l}\text { Natu- } \\
\text { ral gas }\end{array}$ \\
\hline & \multicolumn{6}{|c|}{$€_{2012} / \mathrm{tCO}_{2} \mathrm{e}$} & \multicolumn{6}{|c|}{$€_{2012} / \mathrm{tCO}_{2} \mathrm{e}$} & \multicolumn{6}{|c|}{$€_{2012} / \mathrm{tCO}_{2} \mathrm{e}$} \\
\hline & (1) & (2) & (3) & (4) & (5) & (6) & (7) & (8) & (9) & (10) & (11) & (12) & (13) & (14) & (15) & (16) & (17) & (18) \\
\hline Cereal straw & 256 & 254 & 255 & 217 & 210 & 196 & 273 & 273 & 279 & 232 & 227 & 218 & 209 & 202 & 192 & 176 & 165 & 139 \\
\hline Forestry residues & 333 & 339 & 363 & 287 & 288 & 295 & 349 & 356 & 384 & 301 & 303 & 315 & 290 & 292 & 303 & 249 & 245 & 241 \\
\hline Open-country biomass residues & 100 & 89 & 66 & 86 & 71 & 38 & 112 & 101 & 80 & 96 & 82 & 52 & 67 & 53 & 25 & 56 & 39 & 0 \\
\hline Industrial wood waste & - & - & 3,851 & - & - & 1,834 & - & - & 4,060 & - & - & 1,939 & - & - & 3,352 & - & - & 1,556 \\
\hline Wood in municipal solid waste & 100 & 88 & 62 & 86 & 71 & 36 & 111 & 99 & 76 & 96 & 82 & 49 & 69 & 55 & 25 & 59 & 41 & 1 \\
\hline Green waste: Compensation areas & 279 & 280 & 288 & 233 & 227 & 218 & 298 & 301 & 314 & 249 & 246 & 241 & 226 & 221 & 215 & 186 & 176 & 153 \\
\hline Biomass: Habitat-connectivity areas & 100 & 89 & 66 & 86 & 71 & 38 & 112 & 101 & 80 & 96 & 82 & 52 & 67 & 53 & 25 & 56 & 39 & 0 \\
\hline Green waste: Extensive grassland & 100 & 89 & 66 & 86 & 71 & 38 & 112 & 101 & 80 & 96 & 82 & 52 & 67 & 53 & 25 & 56 & 39 & 0 \\
\hline Short-rotation coppice: Erosion areas & - & - & - & - & - & 26,753 & - & - & - & - & - & 29,051 & - & - & - & - & - & 26,416 \\
\hline Solid cattle manure & 667 & 641 & 629 & 470 & 471 & 490 & 731 & 700 & 681 & 517 & 516 & 534 & 583 & 565 & 562 & 408 & 410 & 431 \\
\hline Solid swine manure & 640 & 568 & 517 & 480 & 456 & 444 & 702 & 616 & 551 & 527 & 496 & 476 & 610 & 545 & 500 & 456 & 436 & 428 \\
\hline Solid poultry manure & 230 & 227 & 224 & 191 & 182 & 164 & 253 & 251 & 254 & 210 & 204 & 191 & 175 & 166 & 152 & 143 & 129 & 99 \\
\hline Commercial and industrial waste & 41 & 45 & 60 & 26 & 23 & 21 & 67 & 71 & 86 & 48 & 45 & 45 & -2 & 2 & 17 & -11 & -15 & -18 \\
\hline Organic municipal solid waste & -463 & -28 & 174 & -210 & -66 & 81 & -161 & 108 & 243 & -96 & 18 & 139 & -852 & -185 & 98 & -347 & -163 & 17 \\
\hline
\end{tabular}

Sources: Own calculation, Table $53=$ Table 39/Table 43 .

Notes: Values rounded. $\mathrm{t}=$ tonne. $-\mathrm{=}$ not applicable. The net GHG mitigation costs are not shown for cases of negative total net avoided GHG emissions per tonne of dry-matter feedstock (cp. Table 43). 
Table 54: Net GHG Mitigation Costs of Biochar per Tonne of $\mathrm{CO}_{2} \mathrm{e}$ Abated, 2030 - Price Path B, Scenario Max 2

\begin{tabular}{|c|c|c|c|c|c|c|c|c|c|c|c|c|c|c|c|c|c|c|}
\hline \multirow[b]{5}{*}{ Feedstocks } & \multicolumn{6}{|c|}{ Small-scale pyrolysis units } & \multicolumn{6}{|c|}{ Medium-scale pyrolysis units } & \multicolumn{6}{|c|}{ Large-scale pyrolysis units } \\
\hline & \multicolumn{3}{|c|}{ No process heat recovery } & \multicolumn{3}{|c|}{ Process heat recovery } & \multicolumn{3}{|c|}{ No process heat recovery } & \multicolumn{3}{|c|}{ Process heat recovery } & \multicolumn{3}{|c|}{ No process heat recovery } & \multicolumn{3}{|c|}{ Process heat recovery } \\
\hline & $\begin{array}{l}\text { Lig- } \\
\text { nite }\end{array}$ & $\begin{array}{c}\text { Hard } \\
\text { coal }\end{array}$ & $\begin{array}{l}\text { Natu- } \\
\text { ral gas }\end{array}$ & $\begin{array}{l}\text { Lig- } \\
\text { nite }\end{array}$ & $\begin{array}{c}\text { Hard } \\
\text { coal }\end{array}$ & $\begin{array}{l}\text { Natu- } \\
\text { ral gas }\end{array}$ & $\begin{array}{l}\text { Lig- } \\
\text { nite }\end{array}$ & $\begin{array}{c}\text { Hard } \\
\text { coal }\end{array}$ & $\begin{array}{l}\text { Natu- } \\
\text { ral gas }\end{array}$ & $\begin{array}{l}\text { Lig- } \\
\text { nite }\end{array}$ & $\begin{array}{c}\text { Hard } \\
\text { coal }\end{array}$ & $\begin{array}{l}\text { Natu- } \\
\text { ral gas }\end{array}$ & $\begin{array}{l}\text { Lig- } \\
\text { nite }\end{array}$ & $\begin{array}{c}\text { Hard } \\
\text { coal }\end{array}$ & $\begin{array}{l}\text { Natu- } \\
\text { ral gas }\end{array}$ & $\begin{array}{l}\text { Lig- } \\
\text { nite }\end{array}$ & $\begin{array}{c}\text { Hard } \\
\text { coal }\end{array}$ & $\begin{array}{l}\text { Natu- } \\
\text { ral gas }\end{array}$ \\
\hline & \multicolumn{6}{|c|}{$\epsilon_{2012} / \mathrm{CO}_{2} \mathrm{e}$} & \multicolumn{6}{|c|}{$€_{2012} / \mathrm{tCO}_{2} \mathrm{e}$} & \multicolumn{6}{|c|}{$€_{2012} / \mathrm{tCO}_{2} \mathrm{e}$} \\
\hline & (1) & (2) & (3) & (4) & (5) & (6) & (7) & (8) & (9) & (10) & (11) & (12) & (13) & (14) & (15) & (16) & (17) & (18) \\
\hline Cereal straw & 257 & 255 & 257 & 218 & 211 & 198 & 274 & 274 & 281 & 233 & 228 & 220 & 211 & 205 & 195 & 178 & 167 & 142 \\
\hline Forestry residues & 334 & 341 & 364 & 288 & 289 & 297 & 350 & 358 & 386 & 302 & 304 & 317 & 292 & 294 & 306 & 251 & 247 & 243 \\
\hline Open-country biomass residues & 101 & 90 & 67 & 87 & 72 & 39 & 113 & 102 & 81 & 97 & 84 & 53 & 68 & 55 & 27 & 57 & 40 & 2 \\
\hline Industrial wood waste & - & - & 3,866 & - & - & 1,842 & - & - & 4,080 & - & - & 1,949 & - & - & 3,385 & - & - & 1,571 \\
\hline Wood in municipal solid waste & 101 & 88 & 63 & 87 & 72 & 37 & 112 & 100 & 77 & 97 & 83 & 50 & 71 & 57 & 26 & 60 & 42 & 3 \\
\hline Green waste: Compensation areas & 280 & 281 & 290 & 234 & 229 & 220 & 300 & 303 & 316 & 251 & 247 & 243 & 228 & 224 & 218 & 189 & 178 & 156 \\
\hline Biomass: Habitat-connectivity areas & 101 & 90 & 67 & 87 & 72 & 39 & 113 & 102 & 81 & 97 & 84 & 53 & 68 & 55 & 27 & 57 & 40 & 2 \\
\hline Green waste: Extensive grassland & 101 & 90 & 67 & 87 & 72 & 39 & 113 & 102 & 81 & 97 & 84 & 53 & 68 & 55 & 27 & 57 & 40 & 2 \\
\hline Short-rotation coppice: Erosion areas & - & - & - & - & - & 26,906 & - & - & & - & - & 29,335 & - & - & - & - & - & 27,153 \\
\hline
\end{tabular}

Sources: Own calculation, Table $54=$ Table S.95/Table S.113.

Notes: Values rounded. $\mathrm{t}=$ tonne. $-=$ not applicable. The net GHG mitigation costs are not shown for cases of negative total net avoided GHG emissions per tonne of dry-matter feedstock (cp. Table S.113). All tables numbered with the leading 'S.' refer to Teichmann (2015). 
Table 55: Net GHG Mitigation Costs of Biochar per Tonne of $\mathrm{CO}_{2} \mathrm{e}$ Abated, 2030 - Price Path C, Scenario Max 1

\begin{tabular}{|c|c|c|c|c|c|c|c|c|c|c|c|c|c|c|c|c|c|c|}
\hline \multirow[b]{5}{*}{ Feedstocks } & \multicolumn{6}{|c|}{ Small-scale pyrolysis units } & \multicolumn{6}{|c|}{ Medium-scale pyrolysis units } & \multicolumn{6}{|c|}{ Large-scale pyrolysis units } \\
\hline & \multicolumn{3}{|c|}{ No process heat recovery } & \multicolumn{3}{|c|}{ Process heat recovery } & \multicolumn{3}{|c|}{ No process heat recovery } & \multicolumn{3}{|c|}{ Process heat recovery } & \multicolumn{3}{|c|}{ No process heat recovery } & \multicolumn{3}{|c|}{ Process heat recovery } \\
\hline & $\begin{array}{l}\text { Lig- } \\
\text { nite }\end{array}$ & $\begin{array}{c}\text { Hard } \\
\text { coal }\end{array}$ & $\begin{array}{l}\text { Natu- } \\
\text { ral gas }\end{array}$ & $\begin{array}{l}\text { Lig- } \\
\text { nite }\end{array}$ & $\begin{array}{c}\text { Hard } \\
\text { coal }\end{array}$ & $\begin{array}{l}\text { Natu- } \\
\text { ral gas }\end{array}$ & $\begin{array}{l}\text { Lig- } \\
\text { nite }\end{array}$ & $\begin{array}{c}\text { Hard } \\
\text { coal }\end{array}$ & $\begin{array}{l}\text { Natu- } \\
\text { ral gas }\end{array}$ & $\begin{array}{l}\text { Lig- } \\
\text { nite }\end{array}$ & $\begin{array}{c}\text { Hard } \\
\text { coal }\end{array}$ & $\begin{array}{l}\text { Natu- } \\
\text { ral gas }\end{array}$ & $\begin{array}{l}\text { Lig- } \\
\text { nite }\end{array}$ & $\begin{array}{c}\text { Hard } \\
\text { coal }\end{array}$ & $\begin{array}{l}\text { Natu- } \\
\text { ral gas }\end{array}$ & $\begin{array}{l}\text { Lig- } \\
\text { nite }\end{array}$ & $\begin{array}{c}\text { Hard } \\
\text { coal }\end{array}$ & $\begin{array}{l}\text { Natu- } \\
\text { ral gas }\end{array}$ \\
\hline & \multicolumn{6}{|c|}{$€_{2012} / \mathrm{tCO}_{2} \mathrm{e}$} & \multicolumn{6}{|c|}{$€_{2012} / \mathrm{tCO}_{2} \mathrm{e}$} & \multicolumn{6}{|c|}{$€_{2012} / \mathrm{CO}_{2} \mathrm{e}$} \\
\hline & (1) & (2) & (3) & (4) & (5) & (6) & (7) & (8) & (9) & (10) & (11) & (12) & (13) & (14) & $(15)$ & (16) & (17) & (18) \\
\hline Cereal straw & 260 & 267 & 281 & 222 & 224 & 225 & 277 & 285 & 304 & 237 & 241 & 247 & 213 & 215 & 217 & 181 & 179 & 168 \\
\hline Forestry residues & 338 & 353 & 390 & 292 & 303 & 326 & 353 & 370 & 411 & 306 & 318 & 346 & 295 & 305 & 330 & 254 & 260 & 272 \\
\hline Open-country biomass residues & 103 & 97 & 81 & 89 & 81 & 57 & 115 & 110 & 96 & 100 & 93 & 70 & 70 & 62 & 41 & 59 & 49 & 19 \\
\hline Industrial wood waste & - & - & 3,371 & - & - & 1,615 & - & - & 3,578 & - & - & 1,719 & - & - & 2,862 & - & - & 1,334 \\
\hline Wood in municipal solid waste & 103 & 97 & 79 & 90 & 82 & 56 & 114 & 108 & 93 & 100 & 92 & 69 & 73 & 64 & 42 & 62 & 52 & 21 \\
\hline Green waste: Compensation areas & 283 & 293 & 313 & 237 & 242 & 248 & 303 & 314 & 339 & 254 & 260 & 271 & 230 & 234 & 240 & 191 & 191 & 182 \\
\hline Biomass: Habitat-connectivity areas & 103 & 97 & 81 & 89 & 81 & 57 & 115 & 110 & 96 & 100 & 93 & 70 & 70 & 62 & 41 & 59 & 49 & 19 \\
\hline Green waste: Extensive grassland & 103 & 97 & 81 & 89 & 81 & 57 & 115 & 110 & 96 & 100 & 93 & 70 & 70 & 62 & 41 & 59 & 49 & 19 \\
\hline Short-rotation coppice: Erosion areas & - & - & - & - & - & 23,792 & - & - & - & - & - & 25,994 & - & - & - & - & - & 22,950 \\
\hline Solid cattle manure & 663 & 630 & 611 & 469 & 468 & 483 & 727 & 688 & 663 & 515 & 513 & 528 & 578 & 552 & 543 & 406 & 406 & 424 \\
\hline Solid swine manure & 625 & 538 & 481 & 471 & 435 & 416 & 687 & 586 & 514 & 518 & 475 & 447 & 595 & 514 & 463 & 446 & 414 & 400 \\
\hline Solid poultry manure & 234 & 238 & 246 & 195 & 195 & 190 & 257 & 263 & 275 & 215 & 217 & 217 & 178 & 177 & 173 & 147 & 142 & 125 \\
\hline Commercial and industrial waste & 41 & 45 & 59 & 27 & 26 & 26 & 67 & 71 & 85 & 49 & 48 & 50 & -3 & 1 & 15 & -10 & -12 & -14 \\
\hline Organic municipal solid waste & -522 & -101 & 112 & -228 & -101 & 41 & -222 & 35 & 181 & -114 & -18 & 98 & -919 & -261 & 34 & -366 & -200 & -25 \\
\hline
\end{tabular}

Sources: Own calculation, Table $55=$ Table S.97/Table 43.

Notes: Values rounded. $\mathrm{t}=$ tonne. $-=$ not applicable. The net GHG mitigation costs are not shown for cases of negative total net avoided GHG emissions per tonne of dry-matter feedstock (cp. Table 43 ). All tables numbered with the leading 'S.' refer to Teichmann (2015). 
Table 56: Net GHG Mitigation Costs of Biochar per Tonne of $\mathrm{CO}_{2} \mathrm{e}$ Abated, 2030 - Price Path C, Scenario Max 2

\begin{tabular}{|c|c|c|c|c|c|c|c|c|c|c|c|c|c|c|c|c|c|c|}
\hline \multirow[b]{5}{*}{ Feedstocks } & \multicolumn{6}{|c|}{ Small-scale pyrolysis units } & \multicolumn{6}{|c|}{ Medium-scale pyrolysis units } & \multicolumn{6}{|c|}{ Large-scale pyrolysis units } \\
\hline & \multicolumn{3}{|c|}{ No process heat recovery } & \multicolumn{3}{|c|}{ Process heat recovery } & \multicolumn{3}{|c|}{ No process heat recovery } & \multicolumn{3}{|c|}{ Process heat recovery } & \multicolumn{3}{|c|}{ No process heat recovery } & \multicolumn{3}{|c|}{ Process heat recovery } \\
\hline & $\begin{array}{l}\text { Lig- } \\
\text { nite }\end{array}$ & $\begin{array}{c}\text { Hard } \\
\text { coal }\end{array}$ & $\begin{array}{l}\text { Natu- } \\
\text { ral gas }\end{array}$ & $\begin{array}{l}\text { Lig- } \\
\text { nite }\end{array}$ & $\begin{array}{c}\text { Hard } \\
\text { coal }\end{array}$ & $\begin{array}{l}\text { Natu- } \\
\text { ral gas }\end{array}$ & $\begin{array}{l}\text { Lig- } \\
\text { nite }\end{array}$ & $\begin{array}{c}\text { Hard } \\
\text { coal }\end{array}$ & $\begin{array}{l}\text { Natu- } \\
\text { ral gas }\end{array}$ & $\begin{array}{l}\text { Lig- } \\
\text { nite }\end{array}$ & $\begin{array}{c}\text { Hard } \\
\text { coal }\end{array}$ & $\begin{array}{l}\text { Natu- } \\
\text { ral gas }\end{array}$ & $\begin{array}{l}\text { Lig- } \\
\text { nite }\end{array}$ & $\begin{array}{c}\text { Hard } \\
\text { coal }\end{array}$ & $\begin{array}{l}\text { Natu- } \\
\text { ral gas }\end{array}$ & $\begin{array}{l}\text { Lig- } \\
\text { nite }\end{array}$ & $\begin{array}{c}\text { Hard } \\
\text { coal }\end{array}$ & $\begin{array}{l}\text { Natu- } \\
\text { ral gas }\end{array}$ \\
\hline & \multicolumn{6}{|c|}{$\epsilon_{2012} / \mathrm{CO}_{2} \mathrm{e}$} & \multicolumn{6}{|c|}{$€_{2012} / \mathrm{tCO}_{2} \mathrm{e}$} & \multicolumn{6}{|c|}{$€_{2012} / \mathrm{tCO}_{2} \mathrm{e}$} \\
\hline & (1) & (2) & (3) & (4) & (5) & (6) & (7) & (8) & (9) & (10) & (11) & (12) & (13) & (14) & (15) & (16) & (17) & (18) \\
\hline Cereal straw & 261 & 268 & 282 & 223 & 226 & 227 & 279 & 287 & 306 & 238 & 243 & 248 & 215 & 218 & 220 & 183 & 181 & 170 \\
\hline Forestry residues & 339 & 354 & 391 & 293 & 304 & 327 & 355 & 372 & 413 & 307 & 319 & 347 & 297 & 308 & 333 & 256 & 262 & 274 \\
\hline Open-country biomass residues & 104 & 98 & 82 & 90 & 82 & 58 & 116 & 111 & 97 & 101 & 94 & 72 & 71 & 64 & 43 & 60 & 50 & 21 \\
\hline Industrial wood waste & - & - & 3,386 & - & - & 1,622 & - & - & 3,598 & - & - & 1,729 & - & - & 2,894 & - & - & 1,349 \\
\hline Wood in municipal solid waste & 104 & 98 & 80 & 91 & 82 & 57 & 115 & 109 & 94 & 101 & 93 & 70 & 74 & 66 & 43 & 63 & 53 & 22 \\
\hline Green waste: Compensation areas & 285 & 294 & 315 & 239 & 243 & 249 & 304 & 316 & 342 & 255 & 262 & 273 & 232 & 236 & 244 & 193 & 193 & 185 \\
\hline Biomass: Habitat-connectivity areas & 104 & 98 & 82 & 90 & 82 & 58 & 116 & 111 & 97 & 101 & 94 & 72 & 71 & 64 & 43 & 60 & 50 & 21 \\
\hline Green waste: Extensive grassland & 104 & 98 & 82 & 90 & 82 & 58 & 116 & 111 & 97 & 101 & 94 & 72 & 71 & 64 & 43 & 60 & 50 & 21 \\
\hline Short-rotation coppice: Erosion areas & - & - & - & - & - & 23,939 & - & - & & - & - & 26,264 & - & - & - & - & - & 23,620 \\
\hline
\end{tabular}

Sources: Own calculation, Table 56 = Table S.99/Table S.113.

Notes: Values rounded. $\mathrm{t}=$ tonne. $-=$ not applicable. The net GHG mitigation costs are not shown for cases of negative total net avoided GHG emissions per tonne of dry-matter feedstock (cp. Table S.113). All tables numbered with the leading 'S.' refer to Teichmann (2015). 
Table 57: Net GHG Mitigation Costs of Biochar per Tonne of $\mathrm{CO}_{2} \mathrm{e}$ Abated, 2050 - Price Path A, Scenario Max 1

\begin{tabular}{|c|c|c|c|c|c|c|c|c|c|c|c|c|c|c|c|c|c|c|}
\hline \multirow[b]{5}{*}{ Feedstocks } & \multicolumn{6}{|c|}{ Small-scale pyrolysis units } & \multicolumn{6}{|c|}{ Medium-scale pyrolysis units } & \multicolumn{6}{|c|}{ Large-scale pyrolysis units } \\
\hline & \multicolumn{3}{|c|}{ No process heat recovery } & \multicolumn{3}{|c|}{ Process heat recovery } & \multicolumn{3}{|c|}{ No process heat recovery } & \multicolumn{3}{|c|}{ Process heat recovery } & \multicolumn{3}{|c|}{ No process heat recovery } & \multicolumn{3}{|c|}{ Process heat recovery } \\
\hline & $\begin{array}{l}\text { Lig- } \\
\text { nite }\end{array}$ & $\begin{array}{c}\text { Hard } \\
\text { coal }\end{array}$ & $\begin{array}{l}\text { Natu- } \\
\text { ral gas }\end{array}$ & $\begin{array}{l}\text { Lig- } \\
\text { nite }\end{array}$ & $\begin{array}{c}\text { Hard } \\
\text { coal }\end{array}$ & $\begin{array}{l}\text { Natu- } \\
\text { ral gas }\end{array}$ & $\begin{array}{l}\text { Lig- } \\
\text { nite }\end{array}$ & $\begin{array}{c}\text { Hard } \\
\text { coal }\end{array}$ & $\begin{array}{l}\text { Natu- } \\
\text { ral gas }\end{array}$ & $\begin{array}{l}\text { Lig- } \\
\text { nite }\end{array}$ & $\begin{array}{c}\text { Hard } \\
\text { coal }\end{array}$ & $\begin{array}{l}\text { Natu- } \\
\text { ral gas }\end{array}$ & $\begin{array}{l}\text { Lig- } \\
\text { nite }\end{array}$ & $\begin{array}{c}\text { Hard } \\
\text { coal }\end{array}$ & $\begin{array}{l}\text { Natu- } \\
\text { ral gas }\end{array}$ & $\begin{array}{l}\text { Lig- } \\
\text { nite }\end{array}$ & $\begin{array}{c}\text { Hard } \\
\text { coal }\end{array}$ & $\begin{array}{l}\text { Natu- } \\
\text { ral gas }\end{array}$ \\
\hline & \multicolumn{6}{|c|}{$€_{2012} / \mathrm{tCO}_{2} \mathrm{e}$} & \multicolumn{6}{|c|}{$€_{2012} / \mathrm{tCO}_{2} \mathrm{e}$} & \multicolumn{6}{|c|}{$€_{2012} / \mathrm{CO}_{2} \mathrm{e}$} \\
\hline & (1) & (2) & (3) & (4) & (5) & (6) & (7) & (8) & (9) & (10) & (11) & (12) & (13) & (14) & $(15)$ & (16) & (17) & (18) \\
\hline Cereal straw & 228 & 191 & 133 & 187 & 141 & 57 & 244 & 209 & 156 & 202 & 157 & 77 & 183 & 141 & 72 & 148 & 97 & 1 \\
\hline Forestry residues & 304 & 273 & 231 & 256 & 215 & 148 & 319 & 289 & 252 & 270 & 230 & 167 & 263 & 227 & 174 & 220 & 175 & 95 \\
\hline Open-country biomass residues & 81 & 46 & -11 & 64 & 22 & -53 & 92 & 58 & 3 & 74 & 33 & -40 & 49 & 12 & -50 & 35 & -9 & -89 \\
\hline Industrial wood waste & - & - & 6,037 & - & - & 2,830 & - & - & 6,245 & - & - & 2,934 & - & - & 5,589 & - & - & 2,571 \\
\hline Wood in municipal solid waste & 79 & 42 & -20 & 64 & 20 & -59 & 90 & 54 & -7 & 74 & 30 & -47 & 50 & 11 & -56 & 37 & -9 & -93 \\
\hline Green waste: Compensation areas & 250 & 215 & 163 & 202 & 156 & 74 & 269 & 236 & 189 & 218 & 174 & 97 & 199 & 159 & 93 & 157 & 107 & 11 \\
\hline Biomass: Habitat-connectivity areas & 81 & 46 & -11 & 64 & 22 & -53 & 92 & 58 & 3 & 74 & 33 & -40 & 49 & 12 & -50 & 35 & -9 & -89 \\
\hline Green waste: Extensive grassland & 81 & 46 & -11 & 64 & 22 & -53 & 92 & 58 & 3 & 74 & 33 & -40 & 49 & 12 & -50 & 35 & -9 & -89 \\
\hline Short-rotation coppice: Erosion areas & - & - & - & - & - & 40,243 & - & - & - & - & - & 42,757 & - & - & - & - & - & 41,481 \\
\hline Solid cattle manure & 681 & 683 & 703 & 468 & 477 & 511 & 744 & 740 & 754 & 514 & 521 & 554 & 603 & 612 & 641 & 410 & 420 & 455 \\
\hline Solid swine manure & 709 & 698 & 680 & 523 & 546 & 569 & 770 & 745 & 714 & 570 & 585 & 600 & 685 & 679 & 667 & 503 & 529 & 556 \\
\hline Solid poultry manure & 204 & 170 & 120 & 162 & 117 & 39 & 226 & 194 & 149 & 181 & 139 & 65 & 151 & 112 & 50 & 116 & 67 & -24 \\
\hline Commercial and industrial waste & 36 & 41 & 61 & 15 & 4 & -5 & 61 & 66 & 87 & 37 & 26 & 19 & -5 & 0 & 20 & -19 & -32 & -42 \\
\hline Organic municipal solid waste & -187 & 282 & 451 & -134 & 80 & 261 & 114 & 417 & 519 & -21 & 163 & 318 & -526 & 145 & 384 & -257 & -6 & 204 \\
\hline
\end{tabular}

Sources: Own calculation, Table $57=$ Table S.101/Table 44.

Notes: Values rounded. $\mathrm{t}=$ tonne. $-=$ not applicable. The net GHG mitigation costs are not shown for cases of negative total net avoided GHG emissions per tonne of dry-matter feedstock (cp. Table 44). All tables numbered with the leading 'S', refer to Teichmann (2015). 
Table 58: Net GHG Mitigation Costs of Biochar per Tonne of $\mathrm{CO}_{2} \mathrm{e}$ Abated, 2050 - Price Path A, Scenario Max 2

\begin{tabular}{|c|c|c|c|c|c|c|c|c|c|c|c|c|c|c|c|c|c|c|}
\hline \multirow[b]{5}{*}{ Feedstocks } & \multicolumn{6}{|c|}{ Small-scale pyrolysis units } & \multicolumn{6}{|c|}{ Medium-scale pyrolysis units } & \multicolumn{6}{|c|}{ Large-scale pyrolysis units } \\
\hline & \multicolumn{3}{|c|}{ No process heat recovery } & \multicolumn{3}{|c|}{ Process heat recovery } & \multicolumn{3}{|c|}{ No process heat recovery } & \multicolumn{3}{|c|}{ Process heat recovery } & \multicolumn{3}{|c|}{ No process heat recovery } & \multicolumn{3}{|c|}{ Process heat recovery } \\
\hline & $\begin{array}{l}\text { Lig- } \\
\text { nite }\end{array}$ & $\begin{array}{c}\text { Hard } \\
\text { coal }\end{array}$ & $\begin{array}{l}\text { Natu- } \\
\text { ral gas }\end{array}$ & $\begin{array}{l}\text { Lig- } \\
\text { nite }\end{array}$ & $\begin{array}{c}\text { Hard } \\
\text { coal }\end{array}$ & $\begin{array}{l}\text { Natu- } \\
\text { ral gas }\end{array}$ & $\begin{array}{l}\text { Lig- } \\
\text { nite }\end{array}$ & $\begin{array}{c}\text { Hard } \\
\text { coal }\end{array}$ & $\begin{array}{l}\text { Natu- } \\
\text { ral gas }\end{array}$ & $\begin{array}{l}\text { Lig- } \\
\text { nite }\end{array}$ & $\begin{array}{c}\text { Hard } \\
\text { coal }\end{array}$ & $\begin{array}{l}\text { Natu- } \\
\text { ral gas }\end{array}$ & $\begin{array}{l}\text { Lig- } \\
\text { nite }\end{array}$ & $\begin{array}{c}\text { Hard } \\
\text { coal }\end{array}$ & $\begin{array}{l}\text { Natu- } \\
\text { ral gas }\end{array}$ & $\begin{array}{l}\text { Lig- } \\
\text { nite }\end{array}$ & $\begin{array}{c}\text { Hard } \\
\text { coal }\end{array}$ & $\begin{array}{l}\text { Natu- } \\
\text { ral gas }\end{array}$ \\
\hline & \multicolumn{6}{|c|}{$\epsilon_{2012} / \mathrm{CO}_{2} \mathrm{e}$} & \multicolumn{6}{|c|}{$€_{2012} / \mathrm{tCO}_{2} \mathrm{e}$} & \multicolumn{6}{|c|}{$€_{2012} / \mathrm{tCO}_{2} \mathrm{e}$} \\
\hline & (1) & (2) & (3) & (4) & (5) & (6) & (7) & (8) & (9) & (10) & (11) & (12) & (13) & (14) & (15) & (16) & (17) & (18) \\
\hline Cereal straw & 229 & 192 & 135 & 188 & 142 & 58 & 246 & 211 & 158 & 203 & 158 & 79 & 185 & 144 & 75 & 150 & 99 & 4 \\
\hline Forestry residues & 305 & 274 & 233 & 257 & 216 & 149 & 321 & 291 & 254 & 271 & 232 & 169 & 265 & 229 & 177 & 222 & 177 & 98 \\
\hline Open-country biomass residues & 81 & 47 & -10 & 65 & 23 & -52 & 93 & 59 & 4 & 75 & 34 & -38 & 50 & 14 & -48 & 37 & -7 & -87 \\
\hline Industrial wood waste & - & - & 6,052 & - & - & 2,838 & - & - & 6,267 & - & - & 2,945 & - & - & 5,626 & - & - & 2,587 \\
\hline Wood in municipal solid waste & 80 & 43 & -19 & 65 & 21 & -58 & 91 & 55 & -5 & 75 & 31 & -46 & 52 & 13 & -54 & 39 & -7 & -91 \\
\hline Green waste: Compensation areas & 252 & 217 & 165 & 203 & 157 & 76 & 271 & 238 & 191 & 219 & 175 & 99 & 202 & 161 & 97 & 160 & 109 & 14 \\
\hline Biomass: Habitat-connectivity areas & 81 & 47 & -10 & 65 & 23 & -52 & 93 & 59 & 4 & 75 & 34 & -38 & 50 & 14 & -48 & 37 & -7 & -87 \\
\hline Green waste: Extensive grassland & 81 & 47 & -10 & 65 & 23 & -52 & 93 & 59 & 4 & 75 & 34 & -38 & 50 & 14 & -48 & 37 & -7 & -87 \\
\hline Short-rotation coppice: Erosion areas & - & - & - & - & - & 40,415 & - & - & - & - & - & 43,089 & - & - & - & - & - & 42,396 \\
\hline
\end{tabular}

Sources: Own calculation, Table $58=$ Table S.103/Table S.116.

Notes: Values rounded. $\mathrm{t}=$ tonne. $-=$ not applicable. The net GHG mitigation costs are not shown for cases of negative total net avoided GHG emissions per tonne of dry-matter feedstock (cp. Table S.116). All tables numbered with the leading 'S.' refer to Teichmann (2015). 
Table 59: Net GHG Mitigation Costs of Biochar per Tonne of $\mathrm{CO}_{2} \mathrm{e}$ Abated, 2050 - Price Path B, Scenario Max 1

\begin{tabular}{|c|c|c|c|c|c|c|c|c|c|c|c|c|c|c|c|c|c|c|}
\hline \multirow[b]{5}{*}{ Feedstocks } & \multicolumn{6}{|c|}{ Small-scale pyrolysis units } & \multicolumn{6}{|c|}{ Medium-scale pyrolysis units } & \multicolumn{6}{|c|}{ Large-scale pyrolysis units } \\
\hline & \multicolumn{3}{|c|}{ No process heat recovery } & \multicolumn{3}{|c|}{ Process heat recovery } & \multicolumn{3}{|c|}{ No process heat recovery } & \multicolumn{3}{|c|}{ Process heat recovery } & \multicolumn{3}{|c|}{ No process heat recovery } & \multicolumn{3}{|c|}{ Process heat recovery } \\
\hline & $\begin{array}{l}\text { Lig- } \\
\text { nite }\end{array}$ & $\begin{array}{c}\text { Hard } \\
\text { coal }\end{array}$ & $\begin{array}{l}\text { Natu- } \\
\text { ral gas }\end{array}$ & $\begin{array}{l}\text { Lig- } \\
\text { nite }\end{array}$ & $\begin{array}{c}\text { Hard } \\
\text { coal }\end{array}$ & $\begin{array}{l}\text { Natu- } \\
\text { ral gas }\end{array}$ & $\begin{array}{l}\text { Lig- } \\
\text { nite }\end{array}$ & $\begin{array}{c}\text { Hard } \\
\text { coal }\end{array}$ & $\begin{array}{l}\text { Natu- } \\
\text { ral gas }\end{array}$ & $\begin{array}{l}\text { Lig- } \\
\text { nite }\end{array}$ & $\begin{array}{c}\text { Hard } \\
\text { coal }\end{array}$ & $\begin{array}{l}\text { Natu- } \\
\text { ral gas }\end{array}$ & $\begin{array}{l}\text { Lig- } \\
\text { nite }\end{array}$ & $\begin{array}{c}\text { Hard } \\
\text { coal }\end{array}$ & $\begin{array}{l}\text { Natu- } \\
\text { ral gas }\end{array}$ & $\begin{array}{l}\text { Lig- } \\
\text { nite }\end{array}$ & $\begin{array}{c}\text { Hard } \\
\text { coal }\end{array}$ & $\begin{array}{l}\text { Natu- } \\
\text { ral gas }\end{array}$ \\
\hline & \multicolumn{6}{|c|}{$€_{2012} / \mathrm{tCO}_{2} \mathrm{e}$} & \multicolumn{6}{|c|}{$€_{2012} / \mathrm{tCO}_{2} \mathrm{e}$} & \multicolumn{6}{|c|}{$€_{2012} / \mathrm{tCO}_{2} \mathrm{e}$} \\
\hline & (1) & (2) & (3) & (4) & (5) & (6) & (7) & (8) & (9) & (10) & (11) & (12) & (13) & (14) & (15) & (16) & (17) & (18) \\
\hline Cereal straw & 237 & 223 & 205 & 198 & 177 & 140 & 254 & 241 & 228 & 212 & 193 & 160 & 192 & 174 & 144 & 158 & 133 & 84 \\
\hline Forestry residues & 315 & 307 & 309 & 267 & 253 & 236 & 330 & 324 & 330 & 281 & 268 & 254 & 273 & 261 & 251 & 231 & 213 & 183 \\
\hline Open-country biomass residues & 87 & 68 & 34 & 72 & 48 & 1 & 99 & 80 & 48 & 82 & 59 & 14 & 56 & 34 & -5 & 43 & 17 & -35 \\
\hline Industrial wood waste & - & - & 4,665 & - & - & 2,203 & - & - & 4,869 & - & - & 2,305 & - & - & 4,194 & - & - & 1,938 \\
\hline Wood in municipal solid waste & 87 & 66 & 29 & 72 & 47 & -2 & 97 & 77 & 42 & 82 & 57 & 10 & 58 & 35 & -7 & 45 & 18 & -36 \\
\hline Green waste: Compensation areas & 260 & 248 & 236 & 213 & 193 & 159 & 279 & 268 & 261 & 229 & 211 & 182 & 209 & 191 & 166 & 168 & 144 & 96 \\
\hline Biomass: Habitat-connectivity areas & 87 & 68 & 34 & 72 & 48 & 1 & 99 & 80 & 48 & 82 & 59 & 14 & 56 & 34 & -5 & 43 & 17 & -35 \\
\hline Green waste: Extensive grassland & 87 & 68 & 34 & 72 & 48 & 1 & 99 & 80 & 48 & 82 & 59 & 14 & 56 & 34 & -5 & 43 & 17 & -35 \\
\hline Short-rotation coppice: Erosion areas & - & - & - & - & - & 31,762 & - & - & - & - & - & 34,042 & - & - & - & - & - & 31,775 \\
\hline Solid cattle manure & 670 & 654 & 652 & 465 & 469 & 493 & 733 & 711 & 702 & 511 & 513 & 536 & 591 & 581 & 588 & 406 & 411 & 437 \\
\hline Solid swine manure & 677 & 622 & 576 & 502 & 492 & 489 & 737 & 668 & 610 & 549 & 531 & 520 & 651 & 601 & 562 & 481 & 474 & 475 \\
\hline Solid poultry manure & 212 & 198 & 180 & 172 & 151 & 112 & 235 & 223 & 209 & 191 & 172 & 138 & 159 & 141 & 111 & 126 & 100 & 50 \\
\hline Commercial and industrial waste & 36 & 40 & 57 & 18 & 12 & 8 & 61 & 65 & 83 & 39 & 34 & 32 & -5 & -1 & 16 & -17 & -24 & -29 \\
\hline Organic municipal solid waste & -321 & 96 & 273 & -173 & -9 & 144 & -24 & 230 & 341 & -61 & 73 & 201 & -674 & -47 & 203 & -299 & -99 & 85 \\
\hline
\end{tabular}

Sources: Own calculation, Table $59=$ Table 40/Table 44 .

Notes: Values rounded. $\mathrm{t}=$ tonne. $-\mathrm{=}$ not applicable. The net GHG mitigation costs are not shown for cases of negative total net avoided GHG emissions per tonne of dry-matter feedstock (cp. Table 44). 
Table 60: Net GHG Mitigation Costs of Biochar per Tonne of $\mathrm{CO}_{2} \mathrm{e}$ Abated, 2050 - Price Path B, Scenario Max 2

\begin{tabular}{|c|c|c|c|c|c|c|c|c|c|c|c|c|c|c|c|c|c|c|}
\hline \multirow[b]{5}{*}{ Feedstocks } & \multicolumn{6}{|c|}{ Small-scale pyrolysis units } & \multicolumn{6}{|c|}{ Medium-scale pyrolysis units } & \multicolumn{6}{|c|}{ Large-scale pyrolysis units } \\
\hline & \multicolumn{3}{|c|}{ No process heat recovery } & \multicolumn{3}{|c|}{ Process heat recovery } & \multicolumn{3}{|c|}{ No process heat recovery } & \multicolumn{3}{|c|}{ Process heat recovery } & \multicolumn{3}{|c|}{ No process heat recovery } & \multicolumn{3}{|c|}{ Process heat recovery } \\
\hline & $\begin{array}{l}\text { Lig- } \\
\text { nite }\end{array}$ & $\begin{array}{c}\text { Hard } \\
\text { coal } \\
\end{array}$ & $\begin{array}{l}\text { Natu- } \\
\text { ral gas }\end{array}$ & $\begin{array}{l}\text { Lig- } \\
\text { nite }\end{array}$ & $\begin{array}{c}\text { Hard } \\
\text { coal }\end{array}$ & $\begin{array}{l}\text { Natu- } \\
\text { ral gas }\end{array}$ & $\begin{array}{l}\text { Lig- } \\
\text { nite }\end{array}$ & $\begin{array}{c}\text { Hard } \\
\text { coal }\end{array}$ & $\begin{array}{l}\text { Natu- } \\
\text { ral gas }\end{array}$ & $\begin{array}{l}\text { Lig- } \\
\text { nite }\end{array}$ & $\begin{array}{c}\text { Hard } \\
\text { coal }\end{array}$ & $\begin{array}{l}\text { Natu- } \\
\text { ral gas }\end{array}$ & $\begin{array}{l}\text { Lig- } \\
\text { nite }\end{array}$ & $\begin{array}{c}\text { Hard } \\
\text { coal }\end{array}$ & $\begin{array}{l}\text { Natu- } \\
\text { ral gas }\end{array}$ & $\begin{array}{l}\text { Lig- } \\
\text { nite }\end{array}$ & $\begin{array}{c}\text { Hard } \\
\text { coal }\end{array}$ & $\begin{array}{l}\text { Natu- } \\
\text { ral gas }\end{array}$ \\
\hline & \multicolumn{6}{|c|}{$€_{2012} / \mathrm{tCO}_{2} \mathrm{e}$} & \multicolumn{6}{|c|}{$€_{2012} / \mathrm{tCO}_{2} \mathrm{e}$} & \multicolumn{6}{|c|}{$€_{2012} / \mathrm{tCO}_{2} \mathrm{e}$} \\
\hline & (1) & (2) & (3) & (4) & (5) & (6) & (7) & (8) & (9) & (10) & (11) & (12) & (13) & (14) & (15) & (16) & (17) & (18) \\
\hline Cereal straw & 239 & 225 & 207 & 199 & 178 & 141 & 256 & 243 & 230 & 214 & 195 & 162 & 195 & 176 & 147 & 160 & 135 & 87 \\
\hline Forestry residues & 316 & 309 & 310 & 268 & 255 & 237 & 331 & 326 & 332 & 282 & 270 & 256 & 275 & 264 & 254 & 233 & 215 & 186 \\
\hline Open-country biomass residues & 88 & 69 & 35 & 73 & 49 & 2 & 100 & 81 & 49 & 83 & 60 & 15 & 57 & 36 & -3 & 44 & 18 & -34 \\
\hline Industrial wood waste & - & - & 4,680 & - & - & 2,211 & - & - & 4,890 & - & - & 2,316 & - & - & 4,227 & - & - & 1,953 \\
\hline Wood in municipal solid waste & 87 & 67 & 30 & 73 & 48 & -1 & 98 & 78 & 43 & 83 & 58 & 11 & 59 & 36 & -6 & 47 & 20 & -35 \\
\hline Green waste: Compensation areas & 262 & 250 & 238 & 214 & 194 & 161 & 281 & 270 & 264 & 230 & 213 & 184 & 211 & 194 & 169 & 170 & 146 & 99 \\
\hline Biomass: Habitat-connectivity areas & 88 & 69 & 35 & 73 & 49 & 2 & 100 & 81 & 49 & 83 & 60 & 15 & 57 & 36 & -3 & 44 & 18 & -34 \\
\hline Green waste: Extensive grassland & 88 & 69 & 35 & 73 & 49 & 2 & 100 & 81 & 49 & 83 & 60 & 15 & 57 & 36 & -3 & 44 & 18 & -34 \\
\hline Short-rotation coppice: Erosion areas & - & - & - & - & - & 31,922 & - & - & - & - & - & 34,336 & - & - & - & - & - & 32,529 \\
\hline
\end{tabular}

Sources: Own calculation, Table $60=$ Table S.106/Table S.116.

Notes: Values rounded. $\mathrm{t}=$ tonne. $-=$ not applicable. The net GHG mitigation costs are not shown for cases of negative total net avoided GHG emissions per tonne of dry-matter feedstock (cp. Table S.116). All tables numbered with the leading 'S.' refer to Teichmann (2015). 
Table 61: Net GHG Mitigation Costs of Biochar per Tonne of $\mathrm{CO}_{2} \mathrm{e}$ Abated, 2050 - Price Path C, Scenario Max 1

\begin{tabular}{|c|c|c|c|c|c|c|c|c|c|c|c|c|c|c|c|c|c|c|}
\hline \multirow[b]{5}{*}{ Feedstocks } & \multicolumn{6}{|c|}{ Small-scale pyrolysis units } & \multicolumn{6}{|c|}{ Medium-scale pyrolysis units } & \multicolumn{6}{|c|}{ Large-scale pyrolysis units } \\
\hline & \multicolumn{3}{|c|}{ No process heat recovery } & \multicolumn{3}{|c|}{ Process heat recovery } & \multicolumn{3}{|c|}{ No process heat recovery } & \multicolumn{3}{|c|}{ Process heat recovery } & \multicolumn{3}{|c|}{ No process heat recovery } & \multicolumn{3}{|c|}{ Process heat recovery } \\
\hline & $\begin{array}{l}\text { Lig- } \\
\text { nite }\end{array}$ & $\begin{array}{c}\text { Hard } \\
\text { coal }\end{array}$ & $\begin{array}{l}\text { Natu- } \\
\text { ral gas }\end{array}$ & $\begin{array}{l}\text { Lig- } \\
\text { nite }\end{array}$ & $\begin{array}{c}\text { Hard } \\
\text { coal }\end{array}$ & $\begin{array}{l}\text { Natu- } \\
\text { ral gas }\end{array}$ & $\begin{array}{l}\text { Lig- } \\
\text { nite }\end{array}$ & $\begin{array}{c}\text { Hard } \\
\text { coal }\end{array}$ & $\begin{array}{l}\text { Natu- } \\
\text { ral gas }\end{array}$ & $\begin{array}{l}\text { Lig- } \\
\text { nite }\end{array}$ & $\begin{array}{c}\text { Hard } \\
\text { coal }\end{array}$ & $\begin{array}{l}\text { Natu- } \\
\text { ral gas }\end{array}$ & $\begin{array}{l}\text { Lig- } \\
\text { nite }\end{array}$ & $\begin{array}{c}\text { Hard } \\
\text { coal }\end{array}$ & $\begin{array}{l}\text { Natu- } \\
\text { ral gas }\end{array}$ & $\begin{array}{l}\text { Lig- } \\
\text { nite }\end{array}$ & $\begin{array}{c}\text { Hard } \\
\text { coal }\end{array}$ & $\begin{array}{l}\text { Natu- } \\
\text { ral gas }\end{array}$ \\
\hline & \multicolumn{6}{|c|}{$€_{2012} / \mathrm{tCO}_{2} \mathrm{e}$} & \multicolumn{6}{|c|}{$€_{2012} / \mathrm{tCO}_{2} \mathrm{e}$} & \multicolumn{6}{|c|}{$€_{2012} / \mathrm{CO}_{2} \mathrm{e}$} \\
\hline & (1) & (2) & (3) & (4) & (5) & (6) & (7) & (8) & (9) & (10) & (11) & (12) & (13) & (14) & $(15)$ & (16) & (17) & (18) \\
\hline Cereal straw & 244 & 244 & 247 & 205 & 200 & 188 & 261 & 262 & 270 & 220 & 216 & 209 & 199 & 194 & 186 & 165 & 156 & 133 \\
\hline Forestry residues & 321 & 329 & 354 & 275 & 278 & 287 & 336 & 346 & 375 & 288 & 292 & 306 & 280 & 283 & 297 & 238 & 237 & 235 \\
\hline Open-country biomass residues & 92 & 82 & 60 & 77 & 64 & 33 & 103 & 94 & 74 & 87 & 75 & 46 & 60 & 48 & 21 & 48 & 33 & -4 \\
\hline Industrial wood waste & - & - & 3,858 & - & - & 1,834 & - & - & 4,059 & - & - & 1,936 & - & - & 3,372 & - & - & 1,565 \\
\hline Wood in municipal solid waste & 92 & 81 & 57 & 78 & 64 & 31 & 102 & 92 & 70 & 87 & 74 & 43 & 62 & 50 & 21 & 51 & 35 & -3 \\
\hline Green waste: Compensation areas & 267 & 269 & 279 & 220 & 217 & 209 & 285 & 289 & 304 & 236 & 234 & 232 & 215 & 212 & 208 & 175 & 167 & 146 \\
\hline Biomass: Habitat-connectivity areas & 92 & 82 & 60 & 77 & 64 & 33 & 103 & 94 & 74 & 87 & 75 & 46 & 60 & 48 & 21 & 48 & 33 & -4 \\
\hline Green waste: Extensive grassland & 92 & 82 & 60 & 77 & 64 & 33 & 103 & 94 & 74 & 87 & 75 & 46 & 60 & 48 & 21 & 48 & 33 & -4 \\
\hline Short-rotation coppice: Erosion areas & - & - & - & - & - & 26,775 & - & - & - & - & - & 28,916 & - & - & - & - & - & 26,060 \\
\hline Solid cattle manure & 663 & 635 & 622 & 464 & 463 & 482 & 726 & 692 & 672 & 509 & 508 & 525 & 583 & 562 & 557 & 404 & 405 & 425 \\
\hline Solid swine manure & 655 & 573 & 515 & 489 & 458 & 442 & 715 & 620 & 548 & 535 & 497 & 473 & 628 & 551 & 499 & 466 & 439 & 427 \\
\hline Solid poultry manure & 218 & 216 & 215 & 178 & 172 & 155 & 240 & 241 & 245 & 198 & 193 & 181 & 165 & 158 & 146 & 132 & 121 & 93 \\
\hline Commercial and industrial waste & 36 & 40 & 55 & 20 & 17 & 16 & 61 & 65 & 80 & 41 & 39 & 39 & -5 & -1 & 13 & -15 & -19 & -22 \\
\hline Organic municipal solid waste & -410 & -22 & 168 & -199 & -66 & 76 & -115 & 111 & 236 & -88 & 15 & 132 & -773 & -170 & 96 & -328 & -158 & 15 \\
\hline
\end{tabular}

Sources: Own calculation, Table $61=$ Table S.108/Table 44

Notes: Values rounded. $\mathrm{t}=$ tonne $-=$ not applicable. The net GHG mitigation costs are not shown for cases of negative total net avoided GHG emissions per tonne of dry-matter feedstock (cp. Table 44 ). All tables numbered with the leading 'S.' refer to Teichmann (2015). 
Table 62: Net GHG Mitigation Costs of Biochar per Tonne of $\mathrm{CO}_{2} \mathrm{e}$ Abated, 2050 - Price Path C, Scenario Max 2

\begin{tabular}{|c|c|c|c|c|c|c|c|c|c|c|c|c|c|c|c|c|c|c|}
\hline \multirow[b]{5}{*}{ Feedstocks } & \multicolumn{6}{|c|}{ Small-scale pyrolysis units } & \multicolumn{6}{|c|}{ Medium-scale pyrolysis units } & \multicolumn{6}{|c|}{ Large-scale pyrolysis units } \\
\hline & \multicolumn{3}{|c|}{ No process heat recovery } & \multicolumn{3}{|c|}{ Process heat recovery } & \multicolumn{3}{|c|}{ No process heat recovery } & \multicolumn{3}{|c|}{ Process heat recovery } & \multicolumn{3}{|c|}{ No process heat recovery } & \multicolumn{3}{|c|}{ Process heat recovery } \\
\hline & $\begin{array}{l}\text { Lig- } \\
\text { nite }\end{array}$ & $\begin{array}{c}\text { Hard } \\
\text { coal }\end{array}$ & $\begin{array}{l}\text { Natu- } \\
\text { ral gas }\end{array}$ & $\begin{array}{l}\text { Lig- } \\
\text { nite }\end{array}$ & $\begin{array}{c}\text { Hard } \\
\text { coal }\end{array}$ & $\begin{array}{l}\text { Natu- } \\
\text { ral gas }\end{array}$ & $\begin{array}{l}\text { Lig- } \\
\text { nite }\end{array}$ & $\begin{array}{c}\text { Hard } \\
\text { coal }\end{array}$ & $\begin{array}{l}\text { Natu- } \\
\text { ral gas }\end{array}$ & $\begin{array}{l}\text { Lig- } \\
\text { nite }\end{array}$ & $\begin{array}{c}\text { Hard } \\
\text { coal }\end{array}$ & $\begin{array}{l}\text { Natu- } \\
\text { ral gas }\end{array}$ & $\begin{array}{l}\text { Lig- } \\
\text { nite }\end{array}$ & $\begin{array}{c}\text { Hard } \\
\text { coal }\end{array}$ & $\begin{array}{l}\text { Natu- } \\
\text { ral gas }\end{array}$ & $\begin{array}{l}\text { Lig- } \\
\text { nite }\end{array}$ & $\begin{array}{c}\text { Hard } \\
\text { coal }\end{array}$ & $\begin{array}{l}\text { Natu- } \\
\text { ral gas }\end{array}$ \\
\hline & \multicolumn{6}{|c|}{$\epsilon_{2012} / \mathrm{tCO}_{2} \mathrm{e}$} & \multicolumn{6}{|c|}{$€_{2012} / \mathrm{tCO}_{2} \mathrm{e}$} & \multicolumn{6}{|c|}{$€_{2012} / \mathrm{tCO}_{2} \mathrm{e}$} \\
\hline & (1) & (2) & (3) & (4) & (5) & (6) & (7) & (8) & (9) & (10) & (11) & (12) & (13) & (14) & (15) & (16) & (17) & (18) \\
\hline Cereal straw & 245 & 245 & 249 & 206 & 201 & 190 & 262 & 264 & 272 & 221 & 218 & 211 & 201 & 197 & 189 & 167 & 158 & 135 \\
\hline Forestry residues & 323 & 331 & 356 & 276 & 279 & 289 & 338 & 348 & 377 & 289 & 294 & 308 & 282 & 286 & 300 & 240 & 239 & 237 \\
\hline Open-country biomass residues & 93 & 83 & 61 & 78 & 65 & 34 & 104 & 95 & 76 & 88 & 76 & 47 & 62 & 50 & 23 & 49 & 34 & -2 \\
\hline Industrial wood waste & - & - & 3,873 & - & - & 1,842 & - & - & 4,079 & - & - & 1,946 & - & - & 3,404 & - & - & 1,580 \\
\hline Wood in municipal solid waste & 92 & 82 & 58 & 78 & 65 & 32 & 103 & 93 & 71 & 88 & 75 & 44 & 64 & 51 & 23 & 52 & 36 & -1 \\
\hline Green waste: Compensation areas & 268 & 271 & 281 & 221 & 218 & 211 & 287 & 291 & 307 & 238 & 236 & 234 & 218 & 215 & 212 & 178 & 170 & 149 \\
\hline Biomass: Habitat-connectivity areas & 93 & 83 & 61 & 78 & 65 & 34 & 104 & 95 & 76 & 88 & 76 & 47 & 62 & 50 & 23 & 49 & 34 & -2 \\
\hline Green waste: Extensive grassland & 93 & 83 & 61 & 78 & 65 & 34 & 104 & 95 & 76 & 88 & 76 & 47 & 62 & 50 & 23 & 49 & 34 & -2 \\
\hline Short-rotation coppice: Erosion areas & - & - & - & - & - & 26,927 & - & - & - & - & - & 29,187 & - & - & - & - & - & 26,718 \\
\hline
\end{tabular}

Sources: Own calculation, Table $62=$ Table S.110/Table S.116.

Notes: Values rounded. $\mathrm{t}=$ tonne. $-=$ not applicable. The net GHG mitigation costs are not shown for cases of negative total net avoided GHG emissions per tonne of dry-matter feedstock (cp. Table S.116). All tables numbered with the leading 'S.' refer to Teichmann (2015). 